\title{
NOVEL APPROACH TO JUNCTIONAL BLEEDING: TOURNIQUET DEVICE PROPOSAL FOR BATTLEFIELD HEMORRHAGE CONTROL
}

\author{
A thesis presented to \\ the Faculty of California Polytechnic State University, \\ San Luis Obispo \\ In Partial Fulfillment of the Requirements for the Degree \\ Master of Science in Biomedical Engineering
}

Kyle Cabaniss

March 2013 
(C) 2013

Kyle Cabaniss

\section{ALL RIGHTS RESERVED}


TITLE:

AUTHOR:

DATE SUBMITTED:

COMMITTEE CHAIR:

COMMITTEE MEMBER:

COMMITTEE MEMBER:
Novel Approach to Junctional Bleeding: Tourniquet Device

Proposal for Battlefield Hemorrhage Control

Kyle Cabaniss

March 2013

Lanny Griffin, Ph.D., Department Chair

Biomedical and General Engineering Department

Cal Poly, San Luis Obispo

John Kragh, M.D. Orthopedic Surgeon

Brooke Army Medical Center

San Antonio, Texas

Lily Liaho, Ph.D., Associate Professor

Biomedical and General Engineering Department

Cal Poly, San Luis Obispo 


\section{ABSTRACT: \\ Novel Approach to Junctional Bleeding: Tourniquet Device Proposal for Battlefield Hemorrhage Control Kyle Cabaniss}

This study investigated possible solutions to the current wartime problem of junctional hemorrhaging, or massive traumatic hemorrhaging in non-tourinquetable areas such as the neck, groin, or armpit. Junctional hemorrhaging has been identified as a major contributor to potentially survivable deaths seen on the battlefield today and therefore is a priority for the U.S. armed and coalition forces (Kragh et al., 2011a; Bozeman, 2011). Common tourniquets today are standard issue and carried by soldiers in the military, but are limited to distal extremity trauma. As the battlefield has changes however, trauma has transformed from commonly seen gunshot wounds to more extreme trauma such as dismounted complex blast injuries which typically includes loss of one or more appendages. These newly found situations render the traditional tourniquet ineffective. Thus, the development of a new tourniquet to control hemorrhaging from regions such as the neck, armpit, and groin has been deemed necessary.

The development of a new tourniquet for hemorrhage control included market research, preliminary testing to determine design restraints, design ideation, finite element analysis, manufacturing a prototype, and prototype testing. Research and comparisons were done of the strengths and weaknesses of tourniquets already approved by the Food and Drug Administration (FDA). Next, design limitations were found using preliminary testing on a blood-flow replicate model developed by Tracey Cheung. The results from this testing provided a framework for designing a new tourniquet. A new approach to control junction hemorrhaging was then designed, built, and tested on the Cheung model. To verify the design, simplified models were analyzed using finite element analysis. The prototype was then tested and compared against the FDA approved tourniquets, listing the advantages and possible shortcomings. 


\section{ACKNOWLEDGEMENTS:}

First I would like to thank my wonderful parents. I simply would not be here without their support, encouragement, and unconditional love. I would also like to thank the rest of my family, Grandma, Carolyn, Sarah, Kevin, Mike, Adam, and Austin for being my support network and their encouragement. And thank you to Mandy Hoskins, for her love and guidance.

I would secondly like to thank Cal Poly and the faculty involved in my educational process. I am so appreciative of the quality of education I received and the experiences I have learned here at Cal Poly. Specifically I would like to thank Dr. Griffin and Dr. Kragh for the opportunity to work with them on such a relevant issue and their continuous support throughout the thesis process. I would also like to thank Dr. Mello for being gracious enough to open his door and his contagious enthusiasm for engineering. I would also like to thank David Laiho and Dr. Lily Liaho for their educational development and continued support with biomedical device design. Thank you to Tracey Cheung for paving the way and to Michael Polka for pushing me to think like an engineer.

Lastly, I would also like to express my appreciation to God. He is my light and inspiration. With God, all things are possible.

"Life is and will ever remain an equation incapable of solution, but it contains certain known factors." - Nikola Tesla

Keywords: tourniquet, hemorrhage, junctional, abdominal aorta, battlefield, emergency, wound, bandages, bleeding, trauma, prototype 


\section{TABLE OF CONTENTS}

LIST OF TABLES: viii

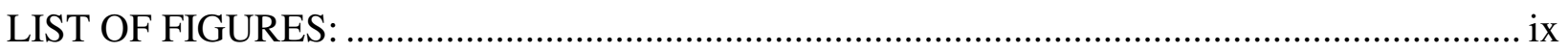

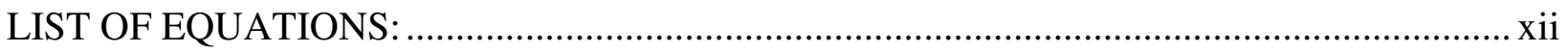

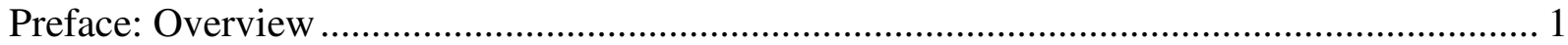

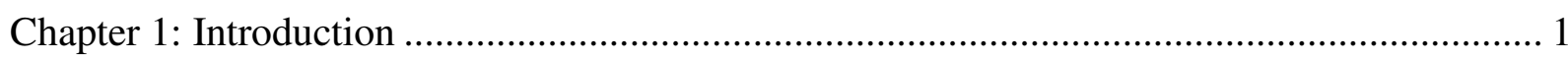

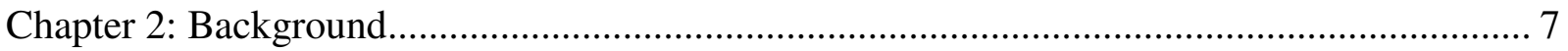

2.1 Historical Context of Tourniquet Use ………....................................................... 7

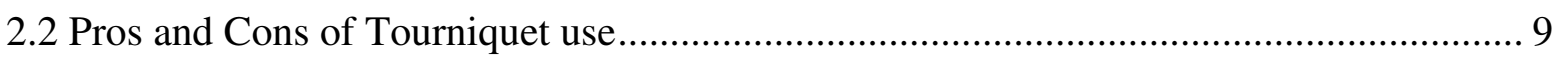

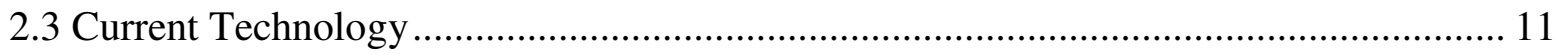

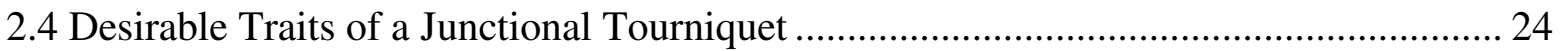

2.5 Critical Buckling Pressure of Tubes .............................................................................. 26

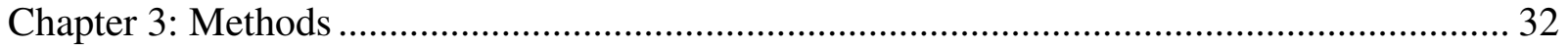

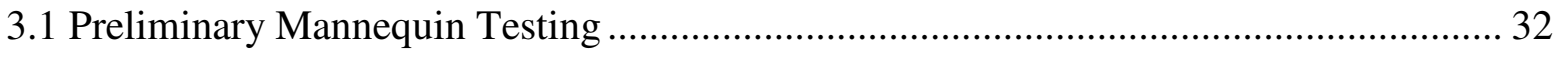

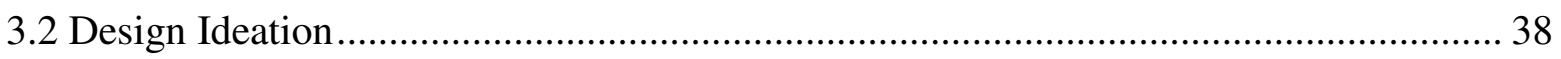

3.3 Final Design Concept …………………………......................................................... 45

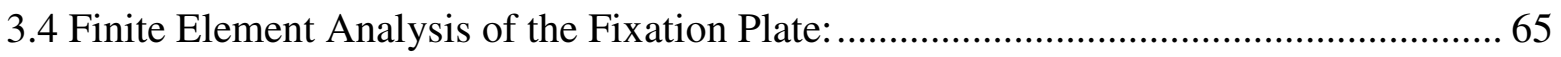

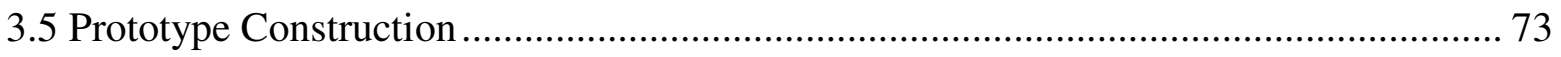

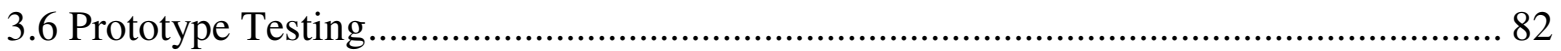

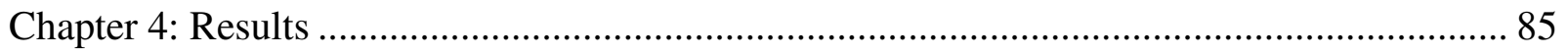

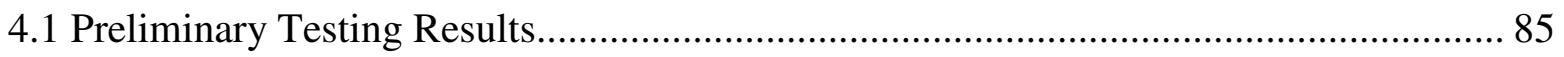

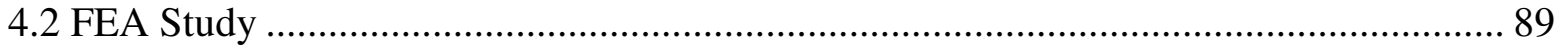

4.3 Prototype Test Results ............................................................................................... 92

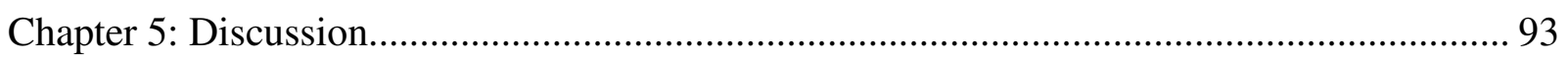

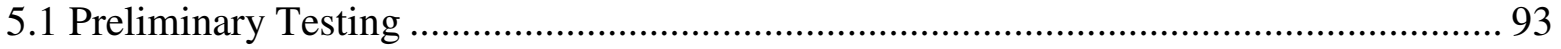

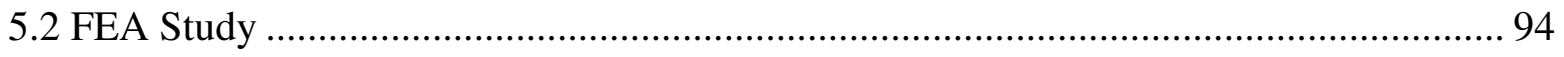

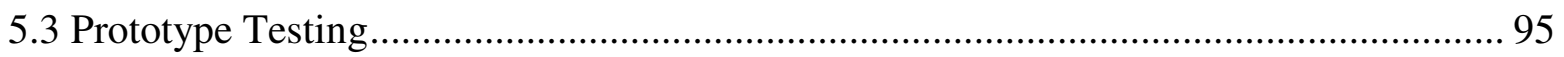

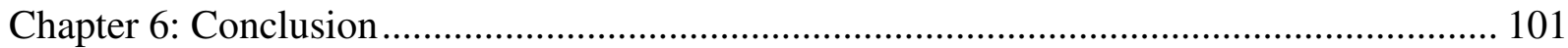

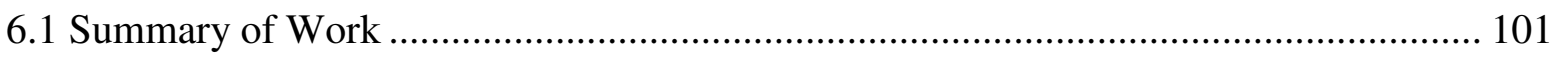

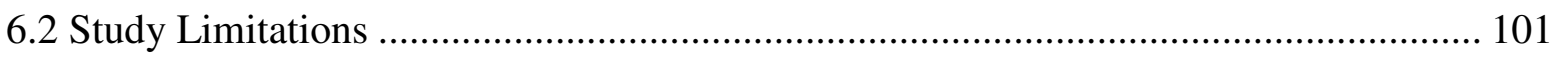


6.3 Future Work ............................................................................................ 103

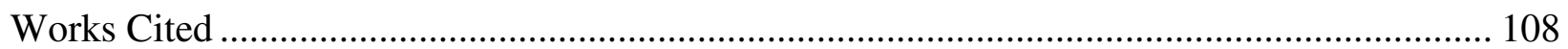

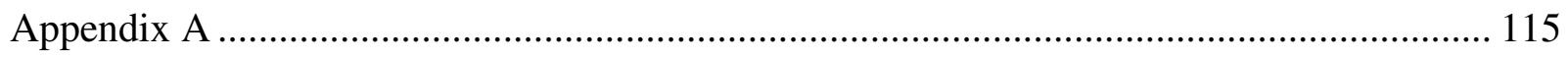

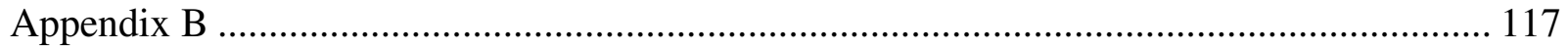

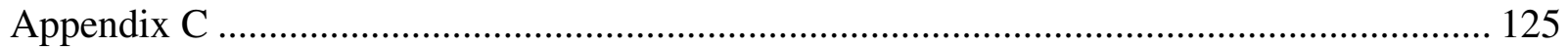

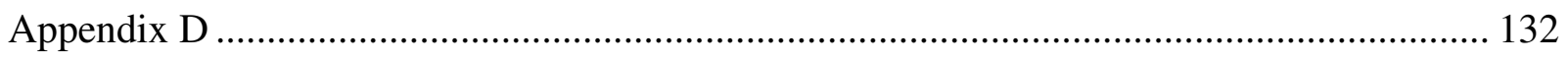

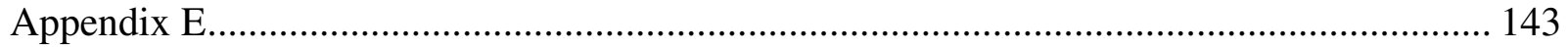

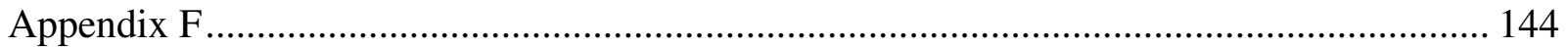

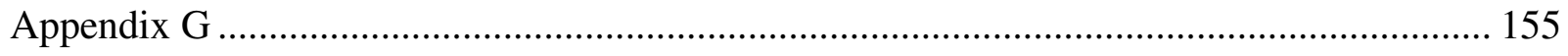




\section{LIST OF TABLES:}

Table 1: Comparison of Three FDA Approved Junctional Tourniquet Devices ....................... 23

Table 2: Ideal Emergency Junctional Tourniquet Traits with Practical Notes ......................... 25

Table 3: Rank of the Ideal Traits of a Junction Tourniquet .................................................. 26

Table 4: Decision Matrix (Pugh Chart) of Junctional Tourniquet Designs ............................. 45

Table 5: Initial Conditions and Known Parameters for Engineering Calculations..................... 46

Table 6: Various Forces, Pressures, and Factors of Safety Used In Online Bore-Size

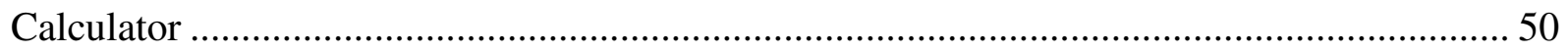

Table 7: Components of Minature Pneumatic Lift with Cost of Raw Material and Cost Per

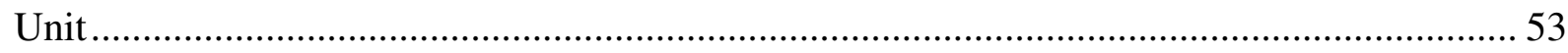

Table 8: Mechanical Properties of Aluminum and Carbon-Fiber Reinforced Composite ........... 58

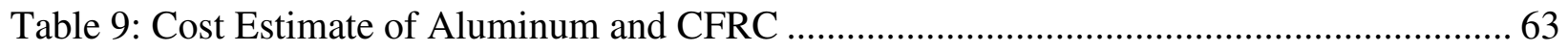

Table 10: Average Deflection and Force Required to Collapse Cheung Model ....................... 85

Table 11: ANOVA Table of Preliminary Testing of Deflection ............................................. 87

Table 12: ANOVA Table of Preliminary Testing of Force .................................................... 88

Table 13: 2D Deflections and Stresses in Three Proposed Materials Using Theoretical and

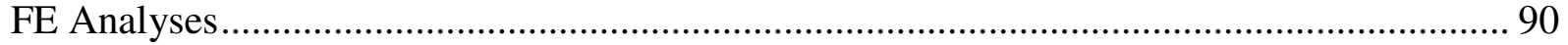

Table 14: 3D Deflections and Stresses in Aluminum Using Theoretical and FE Analyses ......... 90

Table 15: Static Measurements of Junctional Tourniquet Device ........................................... 92

Table 16: Prototype Functionality Test Results ............................................................... 92 


\section{LIST OF FIGURES:}

Figure 1: Abdominal Aorta, Common Iliac Arteries, and Bifurcation ......................................... 3

Figure 2: Lower Abdominal Region Including Labels Extracted From Gray's Anatomy .............. 5

Figure 3: Windlass Tourniquet with Compression Pad ……………………………………..... 8

Figure 4: Combat Application Tourniquet (CAT; Gen 3) ........................................................... 13

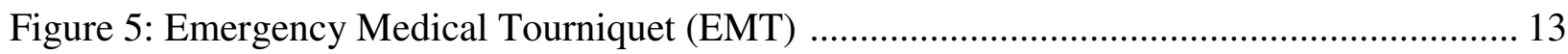

Figure 6: Schematic of a Puematic Antishock Garment …………………………………….... 17

Figure 7: Combat Ready Clamp (CRoC) courtesy of Combat Medical Systems ......................... 18

Figure 8: Abdominal Aortic Tourniquet (AAT) …………………...................................... 20

Figure 9: Example of Abominal Aortic Tourniquet in Use ......................................................... 21

Figure 10: Junctional Emergency Treatement Tool ................................................................... 22

Figure 11: Directions of Abdomen, Abdomen Cross-Section, and Aorta Cross-Section.............. 27

Figure 12: Pressure-Flow Relationship in a Starling Resistor .................................................... 28

Figure 13: Force-Body Diagram of Vessel Under Radial Pressure ………………................. 30

Figure 14: Common Vessel Mechanical Properties taken from Biodynamics Circulation .......... 31

Figure 15: Test Mannequin Courtesy of T. Cheung …………………………….................... 32

Figure 16: DigiFlow 6710M Flow Sensor Showing Flow Rate into Aorta of Mannequin ........... 34

Figure 17: Simplified Diagram of Mannequin Preparation ........................................................... 34

Figure 18: Preliminary Experimental Set Up of Cheung Model .............................................. 35

Figure 19: Preliminary Experimental Set Up of Cheung Model Close Up .................................. 36

Figure 20: Size and Shape Specimens Used in Preliminary Testing ............................................ 36

Figure 21: Examples of Historical Truncal Tourniquets ......................................................... 39

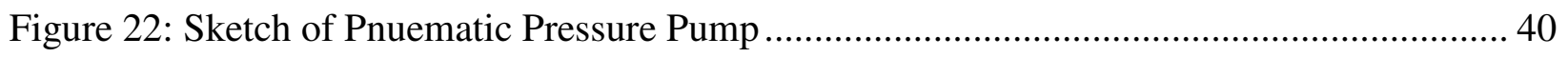

Figure 23: Sketch of Swivel Bow Design................................................................................... 41

Figure 24: Sketch of Strap \& Twist Design .......................................................................... 42

Figure 25: Example of Compass and Sketch of Compass Design ............................................ 42

Figure 26: Example of Hydraulic Lift Table ..................................................................... 43

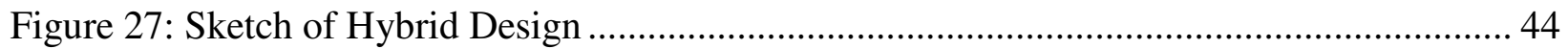

Figure 28: Lezyne Drive Shock Pump …………………...................................................... 49

Figure 29: Solidworks Drawing of Expanded Miniature Pneumatic Lift...................................... 51

Figure 30: Shigley's Textbook, Plate Loaded in Tension by a Pin Through a Hole ..................... 54 


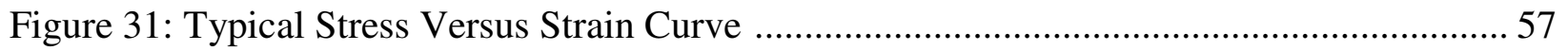

Figure 32: Simplified 2D Representation of the Junctional Tourniquet Device ......................... 59

Figure 33: Approximation of Angle Theta Strap would Apply Force to Fixation Plate ............... 59

Figure 34: Deflection of Aluminum and CFRC at Various Thicknesses ........................................ 61

Figure 35: Weight of Aluminum and CFRC at Various Thicknesses ............................................ 61

Figure 36: Relative Stiffness and Weight of Sandwich Panels Compared to Weight ................... 62

Figure 37: AliMed Universial One Direction Circumferential Strap .......................................... 64

Figure 38: Demonstration of Shear Force on Velcro Strap ………………………….............. 65

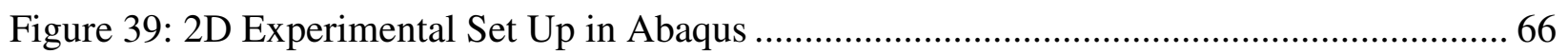

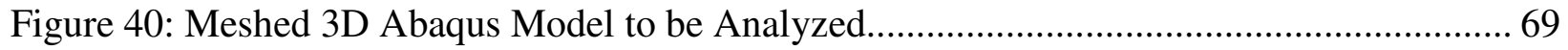

Figure 41: Node of Interest (Node 13) Queried in the 2D Convergence Study ............................ 71

Figure 42: Node of Interest (Node 14903) Queried in the 3D Convergence Study ...................... 71

Figure 43: Mesh Convergence Study of the 2D Model ........................................................... 72

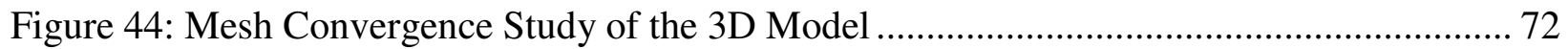

Figure 45: Milling Top Track Slots using 0.1875" End Mill.......................................................... 74

Figure 46: Expanded State of Miniature Pneumatic Lift ......................................................... 76

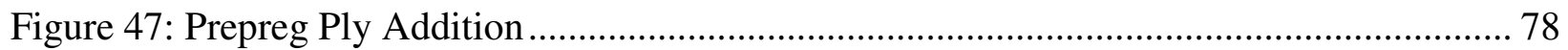

Figure 48: A.) Adhesive Film to Core \& B.) Adhesive Film Balsa Chamfer Pieces ................... 78

Figure 49: Vacuum Bag and Debulking Example .............................................................. 79

Figure 50: Cal Poly Mechanical Engineering Composites Lab Autoclave (192-135) ................. 80

Figure 51: Collapsed and Stored Final Prototype of Junctional Tourniquet Device ..................... 81

Figure 52: Expanded Final Prototype of Junctional Tourniquet Device ..................................... 82

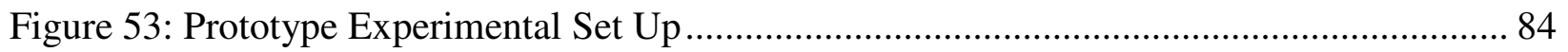

Figure 54: Average Deflection Required to Collapse Chueng Model .......................................... 85

Figure 55: Average Force Required to Collapse Chueng Model................................................. 86

Figure 56: Verification of Independency, Normalcy, and Variance for Deflection ...................... 86

Figure 57: Verification of Independency, Normalcy, and Variance for Force .............................. 87

Figure 58: Main Effect and Interaction Plot of Deflection .......................................................... 88

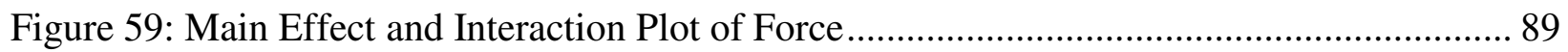

Figure 60: 2D Scaled Deflection in 0.25" Thick Aluminum Fixation Plate.................................. 90

Figure 61: 3D Deflection of Fixation Plate................................................................................. 91 


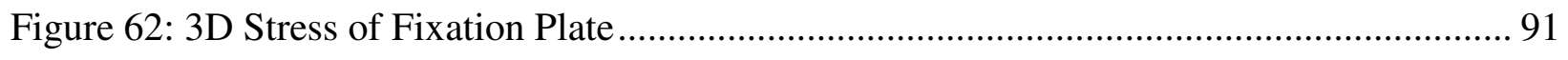

Figure 63: Example of Miniature Linear Rectangular Actuators .......................................... 97

Figure 64: Close up of Instron Demonstrating Large Deformation...................................... 100 


\section{LIST OF EQUATIONS:}

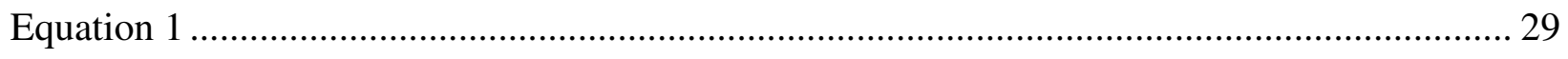

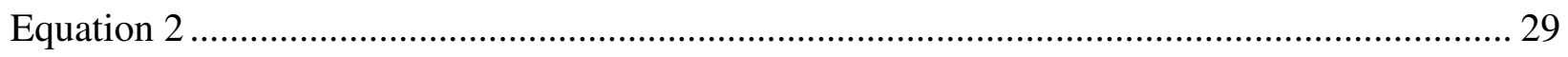

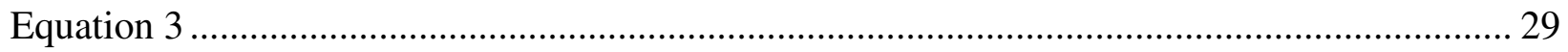

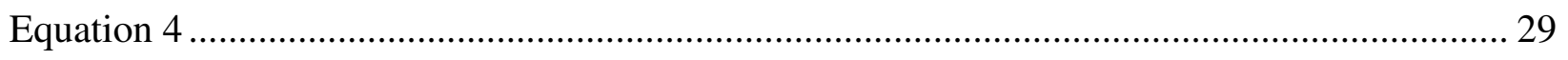

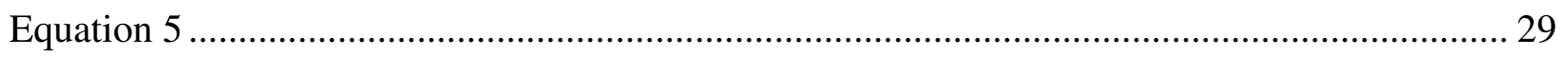

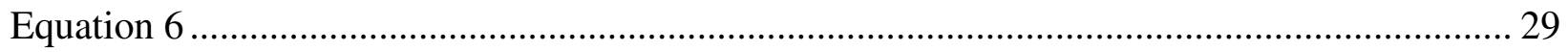

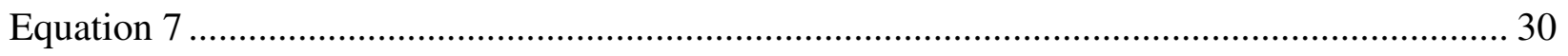

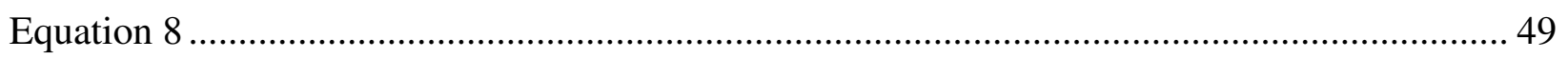

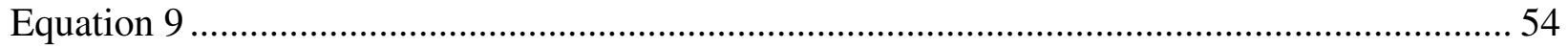

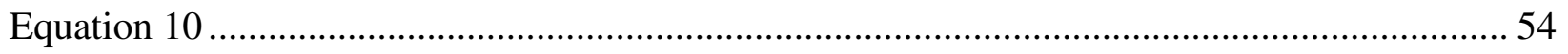

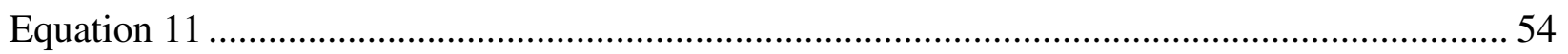

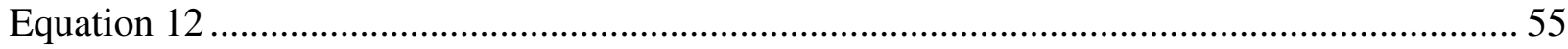

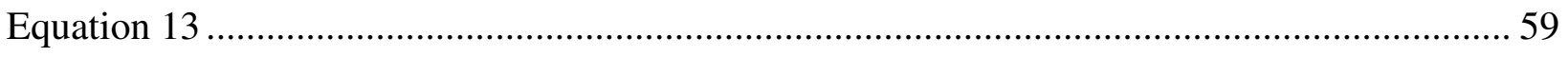

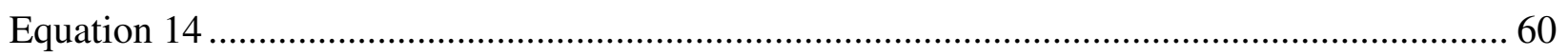

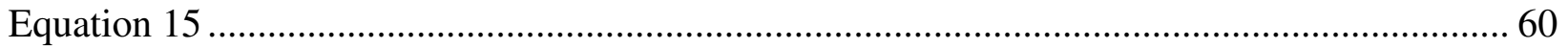




\section{Preface: Overview}

The overall goal of this thesis research was to develop and test a junctional tourniquet prototype for development of junctional hemorrhaging. The main objectives of the device were to be effective, light, safe, durable (combat ready), and easy to use.

\section{Chapter 1: Introduction}

As the battlefield today evolves, the injuries too have evolved. Thus, emergency medical intervention must adapt to the newly evolved battlefield to help keep servicepersons alive. What has been a devastating development in the modern battlefield is the evolution of explosive devices such as rocket propelled grenades (RPGs), improvised explosive devices (IEDs), and other explosive antipersonnel devices transforming the nature of war-time trauma. Trauma has now shifted from gunshot wounds to more dramatic removal of appendages. It has been discovered that a large cause of death on the battlefield today is the inability to stop hemorrhaging in areas such as the armpit, neck, and groin area (Yang et al., 2008). These areas have now taken on the name 'junctional' as the area connecting an appendage to the trunk of the body (Kragh et al., $2011 \&$ Mabry, 2006).

The major goal in junctional hemorrhage control is to stop the bleeding promptly to prevent hemorrhagic shock (Mabry, 2006; Belmont et al., 2010; \& Caravalho, 2011). Hemorrhagic shock is the state of inadequate perfusion that does not sustain the physiologic needs of organ tissues caused by massive blood loss (Bozeman, 2011). Large explosions caused by IEDs or RPGs are more common on the battlefield today and are responsible for major disruption of the body leading to hemorrhagic shock. It is well known that arteries are responsible for transporting blood from the heart. The heart acts as a pump pressurizing the blood to be sent to the body through the arteries and therefore the elevated pressures are typically 
seen in arteries. Veins are the vessels that are responsible for transporting blood back to the heart and typically have pressure closer to atmospheric. Thus, it stands that arteries are responsible for quicker times to expel blood compared to veins. Therefore arteries were used as the target for this study as they are the main contributor to hemorrhagic shock. To locate the ideal artery to occlude, collateral flow must be taken into consideration. Pressure point hemorrhage control has been labeled a "euphemistic misnomer," or a 'replaced fake' by investigators because the blood flow in the presence of collateral arteries is restored momentarily in their study (Bellamy 2000 \& Belmont, 2010). However, if the vessels can be traced back to a location that is relatively free of collateral arteries, it may be possible to effectively control hemorrhaging with no collateral flow (Moore, 1987 \& Swan, 2009). Therefore it is necessary to understand the anatomy and physiology of inguinal region to help better control junctional bleeding.

For the purposes of this study, the abdominal aorta will be the target artery since as it is free of collateral arteries in addition to the groin being the most common type of junctional bleeding (Kragh et al., 2011a; Eastridge et al., 2010; \& Kragh et al., 2008). Anatomically speaking, the abdominal aorta extends from the branches of the renal arteries to the bifurcation to the common iliac arteries seen in Figure 1. The common iliac bifurcation is located $1.1 \mathrm{~cm}$ anteriorly from the fifth lumbar vertebral endplate if the patient is in the supine position (Saladin, 2010). Put more simply, the bifurcation is located under the umbilicus, or the "belly button." This will provide an easy point of reference for application of a junctional bleeding device discussed later. In addition, the common iliac arteries split form the bifurcation on either side of the body and provide opportunity to control hemorrhaging of a one-leg trauma situation. The common iliac arteries are about $7 \mathrm{~cm}$ in length each and run across the first sacral vertebral bone providing the necessary bony structure to compress the artery. Therefore it is possible to 
effectively control hemorrhaging with pressure point application in the pelvic region for the right leg, the left leg, or both simultaneously.

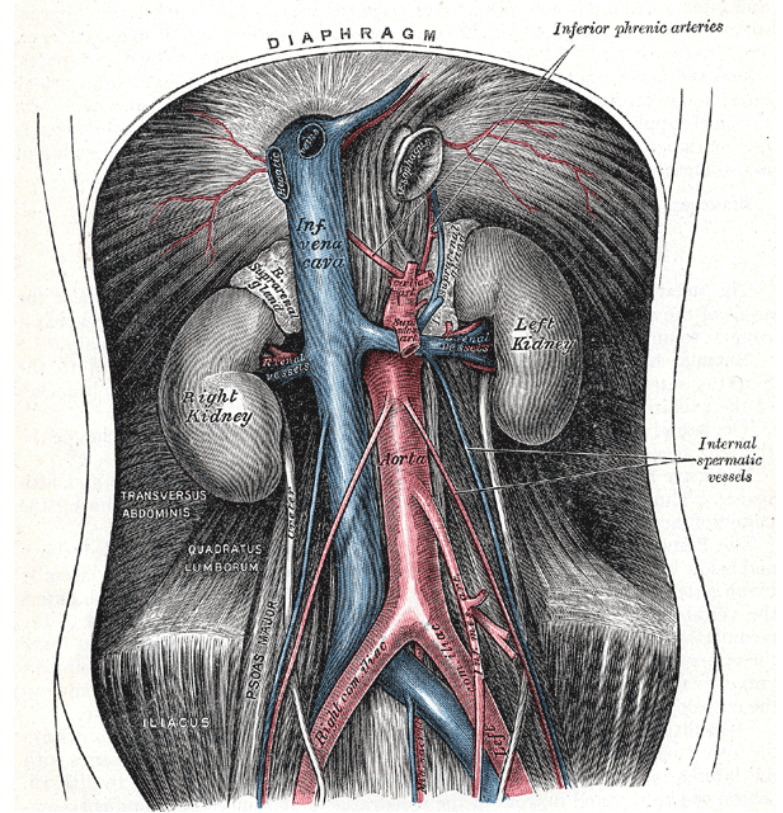

Figure 1: Abdominal Aorta, Common Iliac Arteries, and Bifurcation (Gray, 2000)

It is also necessary to consider the physiology associated with occluding an artery as large as the aorta. In a study conducted by the Medical College of Georgia, 9 male volunteers were used to study hemorrhage control to distal extremities by using ultrasound evaluation (Blaivas et al., 2006). Various weights were used on the volunteers in the supine position until the ultrasound confirmed that the artery was occluded and no blood flow was present. Aortic compression of 80 to 140 pounds led to no flow in the common femoral artery on top of a towel rolled up to the approximate size of an adult knee. The study suggested that compression of the aorta was possible, but that application of upwards of 120 pounds were needed as a target pressure (Blaivas et al., 2006). Furthermore, the study concluded that there were no complications and that compression is safe to use (Blaivas et al., 2006). Therefore, there are 
anatomical and physiological grounds for a well-designed junctional device could plausibly control hemorrhaging (Kragh et al., 2011a).

In 2010, it was reported that explosions account for over $75 \%$ of all combat casualties and have been associated with more complex orthopedic injuries (Belmont, 2010). The increased casualty count seen from explosions has been associated with the distribution of regions not protected by body armor, namely in the legs and groin. It was reported at the Advanced Technology of Combat Casualty Care 2010 Conference that $44 \%$ of pelvic injury related deaths were caused by pelvic arterial injury. In pelvic disruption cases, there is a large possibility of potentially fatal lesions being created and therefore is the focus of uncontrollable junctional hemorrhaging. Junctional lesions on vessels such as the superior gluteal artery, the internal iliac artery, and external iliac artery (Figure 2) can be hard to control in hospital settings much less a pre-hospital setting (Kragh et al., 208). In the emergency room, damage control options include aortic clamping or simple ligation of major vessel injuries which can save lives, but these solutions are not practical in a battlefield situation (Kelly, 2008; Cothren et al., 2007; \& Majno, 1975). The method of direct pelvic packing, or the use of medical gauze or towels to quickly apply pressure to control hemorrhaging, is gaining popularity, but the evidence supporting this technique is preliminary and is hospital-based (Pourmaoghadam et al., 1997; Papadopoulos et al., 2006; Cothren et al., 2007; \& Pinto et al., 2010). Also, emergency angiography has been used as a technique for hemorrhage control, but it is also a hospital-based treatment. In the field, the pelvic girdle is used to help stabilize the pelvis but does not necessarily control bleeding. Therefore there is a need to research a solution to better contain injuries occurring in the battlefield today. 


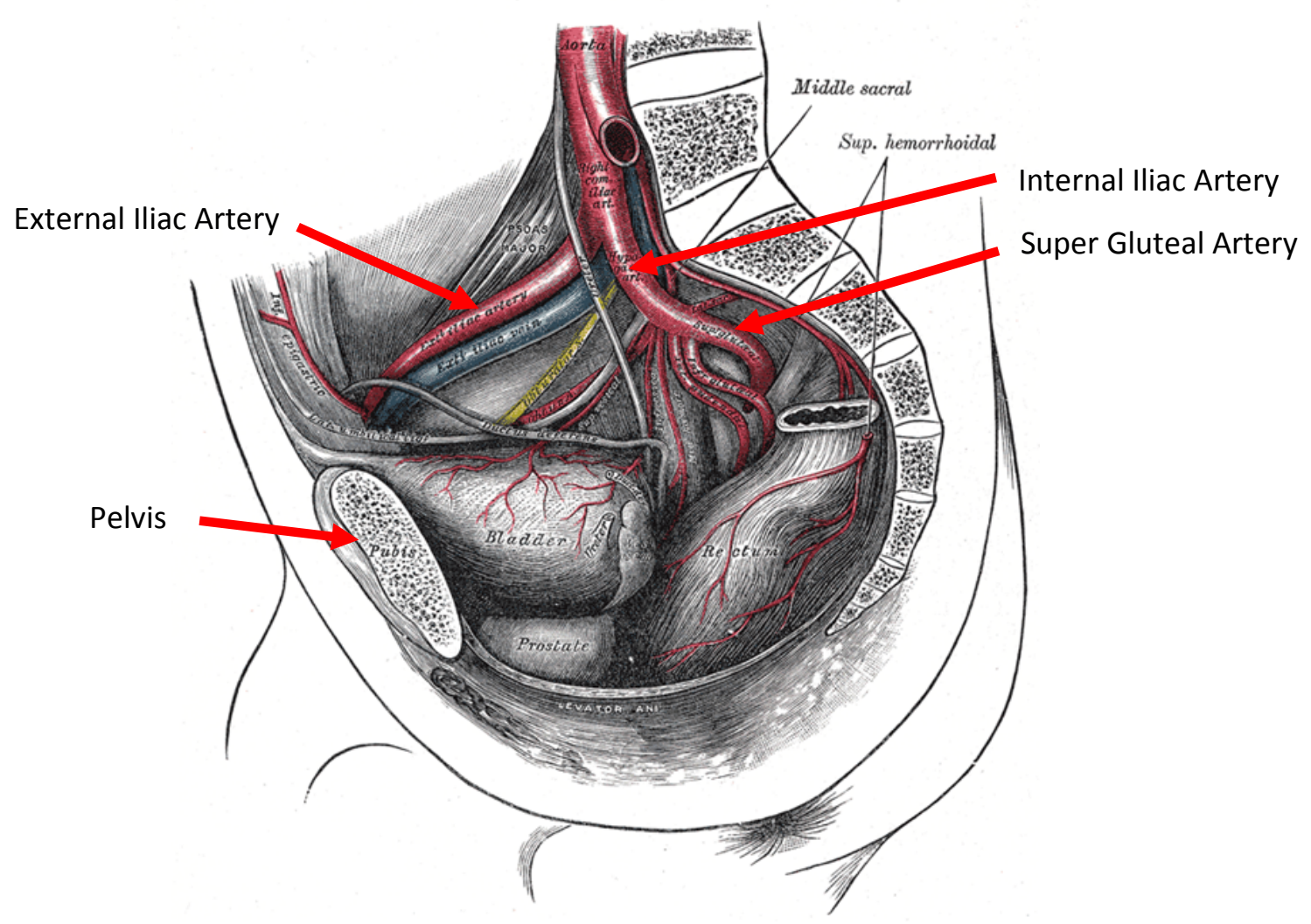

Figure 2: Lower Abdominal Region Including Labels Extracted From Gray's Anatomy (Gray, 2000)

To characterize junctional injuries, the military has labeled such injuries suffered specifically from an explosive device as "Dismounted Complex Blast Injury" (DCBI) (Caravalho, 2011). The Army's Dismounted Complex Blast Injury Task Force defines a DCBI as "an explosion-induced battle injury sustained by a warfighter on foot patrol that produces a specific pattern of wounds including traumatic amputation of at least one leg, a minimum of severe injury to another extremity, and pelvic abdominal, or urogenital wounding" (Caravalho, 2011). Therefore the soldiers that are suffering from DCBIs are typically sustaining more than one major traumatic event within the same region. As mentioned before, 3 out of 4 causalities on the battlefield today are suffered from explosive detonations and therefore treatment of DCBI will be more common. Treatment however can create problems for emergency care as immediate live-saving techniques for the various injuries may interfere with one another. For example, if a 
patient underwent a DCBI, the patient's pelvis may be broken or may be dislocated requiring a pelvic girdle. However, the pelvic girdle may interfere with the implementation of hemorrhage control devices. This is a major consideration in the design and use of junctional hemorrhaging devices.

In the most recent wars in American History, Operation Enduring Freedom (OEF) and Operation Iraqi Freedom (OIF), it was reported that 6450 coalition casualties died from October 1, 2001 to April 30, 2010 (Belmont, 2010; iCasualties, 2009; \& Kelly, 2008). Additionally, it was found that in the given time frame of nearly 9.5 years, an average of about $25 \%$ of deaths were potentially survivable (Kelly, 2008). The authors also reported that of the potentially survivable deaths, an average of $20 \%$ was caused by uncontrollable hemorrhaging from "nontourniquetable" areas (Kragh et al., 2011 \& Kelly, 2008). Therefore, it can be taken that within this given time frame, $5 \%$ of all deaths are potential survivable $(20 \%$ of $25 \%)$ by injury of a junctional region (area describing the neck, armpit, or groin). Extracting the $5 \%$ of deaths being potentially survivable with the ability to control junctional hemorrhaging, approximately 322 deaths could be prevented ( $5 \%$ of 6450 ) over the study's time period. The 322 deaths occurring in the 114 month time span is equivalent to 2.8 deaths per month, or about 3 deaths per month that could have been prevented if the ability to control junction hemorrhaging was available. For this reason, it has been the goal of the U.S. Department of Defense and the U.S. Army Institute of Surgical Research to develop a device that has the capability of effectively controlling junctional bleeding (Kragh et al., 2011a; Kragh et al., 2011b; Majno, 1975; \& von Gersdorff, 1967) 


\section{Chapter 2: Background}

\subsection{Historical Context of Tourniquet Use}

Although the use of tourniquets has been around since $6^{\text {th }}$ century BC, the implementation of them into emergency practice did not follow until much later and until recently, was widely debated for secondary complications. The first recorded use of a tourniquet was in the $6^{\text {th }}$ century $\mathrm{BC}$ to help describe snakebite care, but no hemorrhage control was mentioned (Warren, 1863). Use of tourniquets in emergency care did not come until the $15^{\text {th }}$ century to help describe use in amputation surgery (von Gersdorff, 1967). In 1593, Wilhelm Fabry of Hilden, often called the father of German surgery, described use of a stick to twist a circumferentially constrictive bandage in amputation surgery that was later called a Spanish Windlass (Kragh et al., 2011c). An example of the Windlass can be seen in Figure 3. This simple method of creating a tourniquet with rudimentary tools has be used for centuries and is the basis for the modern standard issue tourniquet for U.S. Armed Services (Macleod, 1858; Lakstein et al., 2003; \& Walters et al., 2005a). In 1674, Étienne J. Morel, a French army surgeon, was credited with the first unambiguous claim of battlefield tourniquet use (Blizard, 1798 \& Macleod, 1858). The word tourniquet stems from the simple method of turning the windlass to create pressure. In 1718, Jean-Louis Petit coined the word tourniquet from the French word 'tourner' based on his newly invented tourniquet device which required turning. Although the use of tourniquet starting gaining popularity, doubts about the effectiveness and safety of the device emerged. 


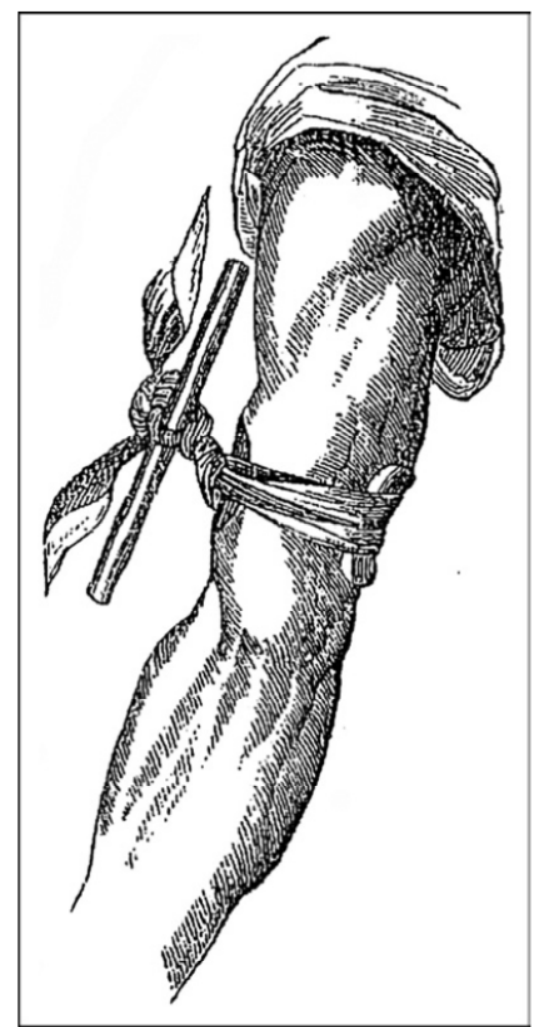

Figure 3: Windlass Tourniquet with Compression Pad (Pilcher, 1899)

As soon as the tourniquet was recommended for use as a life-saving device, it was almost immediately misused and consequently disregarded. It was reported in 1786 by Sir William Blizard, a scholar at the Maritime School in Chelsea, that tourniquets had potential, but may be harmful due to improper use (Blizard ,1798). Blizard surmised that, "The seamen being entirely ignorant of the manner of applying the tourniquet, many instances having occurred of men bleeding to death" (Blizard, 1798). It was ultimately reported by George H.B. Macleod, a British surgeon in a civilian hospital during the Crimean War, "that tourniquets are of little use on the battlefield" (Blizard, 1798 \& Lakstein et al., 2003). All reports from surgeons admitted the fact that hemorrhaging was leading to death on the battlefield, however it was not associated with the poor medical planning, lack of casualty care training of the troops, and the marginal medical 
logistics of the time and almost entirely blamed on the tourniquet device alone (Kragh et al., 2008). It was either determined that training of the soldiers on the proper use of the tourniquet would be ineffective or it was a point of ignorance for the surgeons of this time (Kragh et al., 2008). It was also not fully understood or expressed that there is a connection between a quick response time and hemorrhage control. It was often blamed that tourniquets were ineffective because by the time to application of a tourniquet (by the field surgeon), it was too late (Macleod, 1858). In addition, the application under fire was thought as being too dangerous. This was how the view of tourniquet use stayed until the $20^{\text {th }}$ Century. Not until the late 1980's, after World Wars I \& II, the Korean War, and Vietnam, was the potential of immediate tourniquet application realized.

In 1987, the Israeli Defense Forces adopted a policy encouraging emergency tourniquet use under fire with the rescuer applying the tourniquet before seeking cover (Lakstein et al., 2003). The results from this policy change were promising and showed that no deaths occurred during the time of research and only $5.5 \%$ of nerve palsy was reported from tourniquet use (Lakstein et al., 2003). From this data, tourniquets and tourniquet use was then decided a necessary tool on the battlefield. Army Surgeon General Kevin Kiley decided that a Combat Application Tourniquet (CAT; North American Rescue, Greer, SC) would be a standard issue item to deploying US servicepersons (Walters et al., 2005b). Since that time, data has continued to come out supporting the proper, timely use of tourniquets as a life-saving technique (Kragh et al., 2011b; Kelly et al., 2008, Klenerman, 1983)

\subsection{Pros and Cons of Tourniquet use}

As previously mentioned, the use of traditional tourniquets has been debated for centuries. The tourniquet's life-saving ability is balanced by limitations; nerve paralyses, time 
limitations, and possible morbidity of subjected limb (Graham et al., 1993 \& Willing et al., 2006). In the article, Practical Use of Emergency Tourniquets to Stop Bleeding in Major Limb Trauma, Kragh et al reports on the association of morbidities to tourniquet use in literature (Klenerman, 1983) and within a study group (Kragh et al., 2008). These morbidities included amputation or stump shortening (Coupland, 1993), palsy (Watsons-Jones, 1955 \& Middletown, 1974), (Konrad et al., 2005), myonecrosis (Watsons-Jones, 1955), significant pain (Konrad et al., 2005), clot, fasciotomy (Bohler, 1956), acute renal failure (Watson-Jones, 1948), rigor, abscess (Jolly, 1941), blisters, abrasions, contusions, and pinching (Klenerman, 1983). Kragh et al reports that there were some morbidities possibly associable with tourniquet use. There were several cases of clotting; 1 deep venous thrombosis and 9 thrombectomies. However, these thrombectomies were not associated with tourniquet use by the vascular surgeon (Kragh, 2008). There were also reports of ten verve palsy cases with only four of these cases at the level of the tourniquet (not wound related). All fours cases improved with only one taking longer than the first hour. Kragh et al also reported that 96 fasciotomies were performed in 232 patients and that 87 amputations were performed. Kragh et al goes on to report that tourniquet time was associated with amputation and fasciotomy but no other morbidity. Finally, it was reported that ineffective tourniquet application and use was associated with morbidity and mortality, but only led to a result of 4 deaths (Kragh et al, 2008).

Although it was reported that there was some associations between tourniquet use and morbidities, the main findings of Kragh et al's study presented a low risk of morbidity during tourniquet use (Kragh, 2008). Also, given the ability of tourniquets to save lives, the risk is far out weighted by the reward. Similar finding were reported in two other large comprehensive studies; a study in 1945 with a generalized statement that no morbidity occurred from tourniquet 
use in 200 cases (Wolff \& Adkins, 1945) and the 2003 study of 91 Israeli patients reporting no deaths (Lakstein et al., 2003). In Kragh et al's paper, a vignette was included about a patient's life which was saved due to the use of prehospital and hospital tourniquets. The patient had a proximal femur fracture with femoral artery and vein transection, a near-complete below knee amputation, emergency department thoracotomy, aortic cross clamping, open manual cardiac massage, three cardiac electroconversions, emergency laparotomy, ligature of the common iliac, femoral arteries, and veins as hemorrhage control measures, and an intensive care respite before the tourniquet and amputation could be attended. The patient survived the surgeries and was able to do so by the use of the tourniquet in both the pre-hospital and hospital setting.

\subsection{Current Technology}

To help patients survive from injuries sustained in the field, it is crucial that immediate action be taken to help control hemorrhaging. In some cases, depending on the injury and the location of the injury, a traditional tourniquet has been suggested to help reduce morbidities with low risk (Kragh et al., 2008). If an injury is sustained in which a traditional tourniquet would be most effective, the CAT and EMT have been suggested for use in the battlefield today. However, with a much broader range of injury types seen, traditional tourniquets are not always feasible. If a traditional tourniquet would not suffice (i.e. the injury is located in a non-tourniquetable

location), there are new solutions to help provide a treatment plan that are approved for use by the Food and Drug Administration (FDA). The first method uses blood aggregates to help clot blood on the injury site while providing a large surface area of contact. Three new junctional tourniquets have been developed since 2010: the Combat Ready Clamp in 2010 (CRoC), Abdominal Aorta Tourniquet in 2011 (AAT), and the Junctional Emergency Treatment Tool in 2013 (JETT), are all junctional hemorrhage control devices approved by the FDA for use on 
humans. In the next sections, it will be helpful to examine each device, compare devices, and draw conclusions about each device.

\subsubsection{Traditional Tourniquets}

\subsubsection{Combat Application Tourniquet (CAT)}

As previously mentioned, servicepersons today are issued with the CAT; a traditional windlass tourniquet. The CAT has several components that are prepackaged together (Figure 4). The method of application is simple and can even be performed by the patient themselves. The CAT includes a long self-adhering strap that is $38 \mathrm{~mm}$ wide fitting over the intended extremity. The strap can then be secured in two ways: by simply pulling over the buckle and reattaching it to itself (self-application) or it can be rerouted through the buckle and then strapped back to itself for added security (two-handed method). This second methods adds stabilization to the device as well as security from being accidently undone. Once the strap is secured, the tourniquet can be tightened by twisting the Winlass Rod with the recommended amount of turns is three for effective use (Childers et al., 2011). The twisting motion pulls and gathers the ribbon that runs circumferentially within the device applying pressure. Once the appropriate pressure is applied to the wounded area, the windlass rod can be secured within the Windlass clip with a strap that prevents the rod coming free. This provides a hands-free, constant pressure that controls hemorrhaging on the battlefield. 


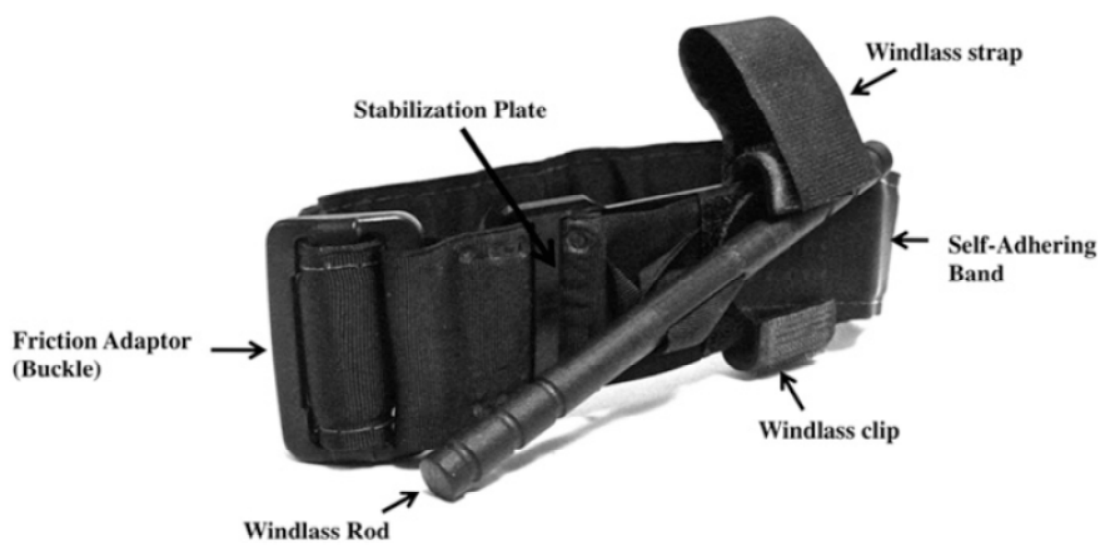

Figure 4: Combat Application Tourniquet (Combat Application Tourniquet, 2012)

\subsubsection{Emergency Medical Tourniquet (EMT)}

The main competitor to the CAT is the Emergency Medical Tourniquet (EMT) (Figure 5). In 2008, the CAT was reported to be the second most efficient tourniquet during a 7 month period observed at the combat support hospital in Baghdad with an efficiency rate of $79 \%$ (166/210) (Kragh et al., 2008 \& Kragh, 2011a). The EMT was reported with an efficiency rating of $92 \%$ (Kragh et al., 2008). The EMT is composed of large bladder that is secured around the extremity much like a blood pressure cuff. The pressure is increase much like a blood pressure

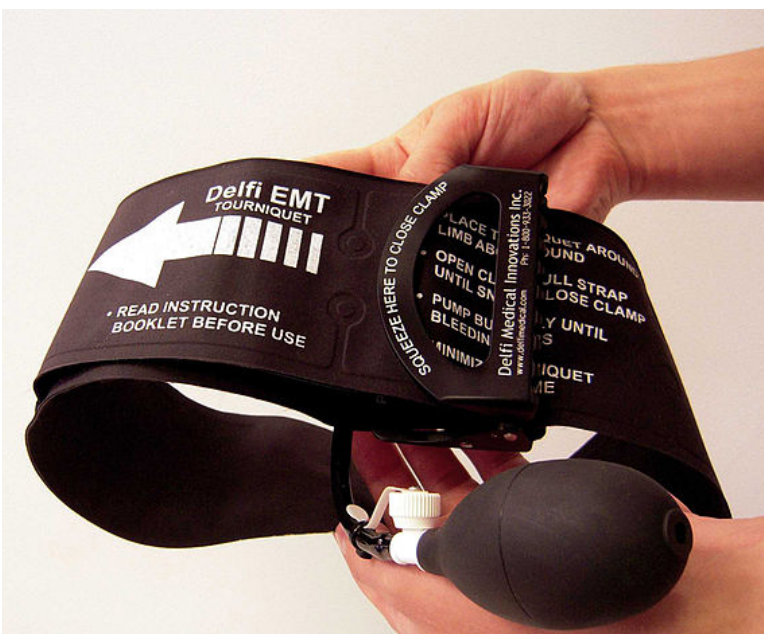

Figure 5: Emergency Medical Tourniquet (EMT) (Defli Medical Innovations Inc. 2011) 
cuff as well with a pneumatic hand pump. It is also well-known that there is a correlation between limb girth, device width, and effectiveness (Kragh et al., 2011a; Kragh et al., n.d.; Kragh et al., 2008; Childers et al., 2011; \& Defli Medical Innovations Inc., 2011). The increased efficiency is due to the larger cross-sectional area that the EMT has to apply the pressure compared to the CAT (Kragh et al., 2011b \& Defli Medical Innovations Inc., 2011). The larger the limb, i.e. the more girth that needs to be pressurized, the more area is needed. Thus the EMT with its $88 \mathrm{~mm}$ wide strap is more capable of applying the necessary pressure versus area compared to the CAT's $38 \mathrm{~mm}$ wide strap (Kragh et al., 2011b).

However, there are several reasons that the CAT was still chosen as standard issue tourniquet. First is that the one of the major drawbacks of the EMT is the exposed bladder. Since it is made of rubber, it is prone to leaks, tears, and punctures from combat. Also, the CAT is worn on the outside of each soldier and therefore is exposed to the elements that the solider is. This would increase the wear and tear of the tourniquet while being stored. Secondly, the EMT is larger and heavier (220 grams (Defli Medical Innovations Inc., 2011)) than the CAT (59 grams (Combat Application Tourniquet, 2012)). With the standard the standard weight of a soldiers 'fighting' equipment being 63.43 lbs, every chance to cut weight is crucial (Dougherty et al., 2003). It was also mentioned that in 2003, when Army Surgeon General Kevin Kiley made the decision after surveying 9 different candidates that "waiting for all information to be in was a recipe for inaction and recommended the Combat Application Tourniquet" (Kragh et al., 2011a). It should also be noted that the EMT are usually used in a hospital setting and therefore place by trained professionals in a more secure location. This may have led to the difference in the efficiency rates recorded between the CAT and the EMT. It was recorded that the CAT was the 
best pre-hospital tourniquet and the EMT was the best emergency department tourniquet (Kragh et al., 2008).

\subsubsection{Other Hemorrhage Control Techniques}

One thing to remember in the discussion of the CAT and the EMT is that both these devices are traditional tourniquets and are not approved for junctional use. The Tactical Combat Casualty Care (TCCC) created a committee to provided guidelines used to train medics by all services in the Department of Defense and by many U.S. coalition forces to provide information on how to deal with injuries that both able to be controlled with a tourniquet (Butler et al., 2010). As of 2011, the TCCC guidelines suggested the use of Combat Gauze. Z-Medica's QuikClot ${ }^{\circledR}$ Combat Gauze is a $50 \%$ rayon and $50 \%$ polyester blended gauze impregnated with mineral kaolin powder (QuikClot Combat Gauze, n.d.). QuikClot ${ }^{\circledR}$ is a granular hemostatic agent cleared by the FDA. Because of the granular nature, QuikClot ${ }^{\circledR}$ can cover a large surface area, but due to the exothermic nature while absorbing water (blood), it has potential to cause tissue damage (Rhee et al., 2008 \& Seamon et al., 2008). Also, one consideration to be made for the junctional hemorrhaging situation is the amount of high blood loss, high blood volume, and high blood pressure, QuikClot® could potentially be "blown-out" or not have the granules remain at the trauma site for a sufficient time (Rhee et al., 2008). Therefore, the QuikClot ${ }^{\circledR}$ was reengineered with the agent kaolin which triggers the body's natural coagulation cascade, resulting in more rapid coagulation (QuikClot Combat Gauze, n.d.). However, even with QuikClot@'s advances in technology and large size availability (4 feet by 4 feet maximum size), there is no way of applying constant pressure without a medic or some device. Even then, the gauze would have to deal with some major blood displacement trauma from a DCBI. Therefore, this project will take into consideration the use of QuikClot ${ }^{\circledR}$ as an additional or supplemental factor and not as a solution (Schwartz, 2011). 


\subsubsection{Junctional Hemorrhage Control}

\subsubsection{Alternative Junctional Hemorrhaging Device Options}

Other devices that have been suggested as possible hemorrhaging controlling devices are extravascular balloon tamponades and pelvic binders. The extravascular balloon catheter inserted into hemorrhaging wounds can control bleeding, but the wound-balloon interface should conform to make for the best tamponade (Lau \& Tee, 2009). This method has been used in hemorrhage control of esophageal or stomach lesions (Kragh et al,. 2011a). However, war wounds are such traumatic injuries such as a DCBI are rarely esophagus-shaped and are not easily distinguishable. Typical injuries seen today are big, open, bleeding wounds from explosions, not the tunnel-like gun-shot wounds once seen in previous wars (Kragh et al., 2011). Also suggested is the use of pelvic binders as a hemorrhage control device. While pelvic binders are good for "open book" pelvic ring fractures, they can over compress and displace fractures into the pelvic cavity doing more harm than good (Krieg et al., 2005). It was also found that pelvic binders don't reduced hemorrhage or mortality which is a big consideration in pre-hospital use (Spanjersberg et al., 2009). Therefore, it still necessary to create a device that is capable of controlling junctional hemorrhaging.

In 2007, the Committee on Tactical Combat Casualty Care (TCCC) recommended military the pneumatic anti-shock garments (PASG) for hemorrhage control around the pelvic region (Butler et al., 2007), but there was contradictory reports on the effectiveness of the trousers (Roberts et al., 1999; Ali \& Duke, 1991a; \& Ali \& Duke, 1991b). PASGs are composed of three large sections that self-adhere around each leg and the waist to be then inflated with a large foot-controlled pneumatic pump (Figure 6). The application process of the PASG is timeconsuming and cumbersome. The manual use of the foot pump is also difficult and not practical in a tactical situation. However, this was the only available recommendation for treatment of 
uncontrollable junctional hemorrhaging. It wasn't until 2009 that the Committee made truncal tourniquets a research priority. Not until 2011 was the first FDA hemorrhage control device was recommended as the update to the PASG (Morse et al., 1986; Dickey \& Jenkins, 2011; \& Honigman et al., 1991).

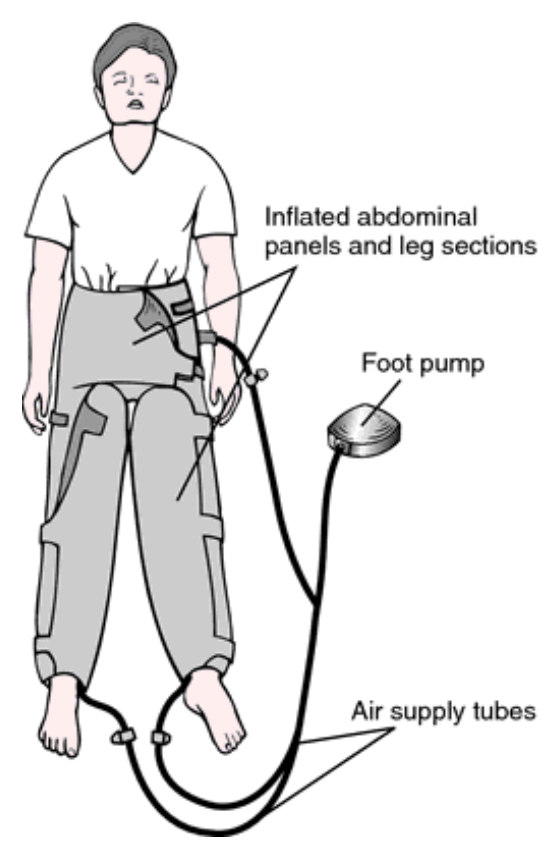

Figure 6: Schematic of a Puematic Antishock Garment (Saunders, 2003)

\subsubsection{The Combat Ready Clamp (CRoC $\left.{ }^{\mathrm{TM}}\right)$}

The first device approved by the FDA to control inguinal hemorrhaging was the Combat Ready Clamp (CRoC) (Kragh et al., 2011 \& Combat Medical Systems, 2009). The CRoC is produced by Combat Medical Systems located in Fayetteville, NC (Figure 7) (Combat Medical Systems, 2009). The CRoC is composed of the base plate for stabilization, vertical and horizontal arms for accessibility and the pressure handle to apply pressure. There are two suggested methods of using the $\mathrm{CRoC}$; direct application and proximal pressure application. In the direct application method, the clamp acts as a pair of hands constantly applying pressure to a small wound such as a gunshot. The second method, the proximal pressure application would be 
in situations where the point of application (the pressure disk) isn't big enough to apply the appropriate amount of pressure. The $\mathrm{CRoC}$ would then be set up to occlude the common iliac artery in the inguinal region. Due to the nature of the product, pre-testing is not possible according to the indicated use, but meets the requirements to collapse the aorta defined by Blaivas et al. et al. and is FDA approved for use (Kragh et al., 2011a; Blaivas et al., 2006; Dickey \& Jenkins, 2011; \& Zukerman, 2010). In addition, the product has been shown to stop arterial flow and pressure through the external iliac artery in multiple cadaver models (Dickey \& Jenkins 2011; Ward et al., 2012; \& Kragh et al., n.d.).

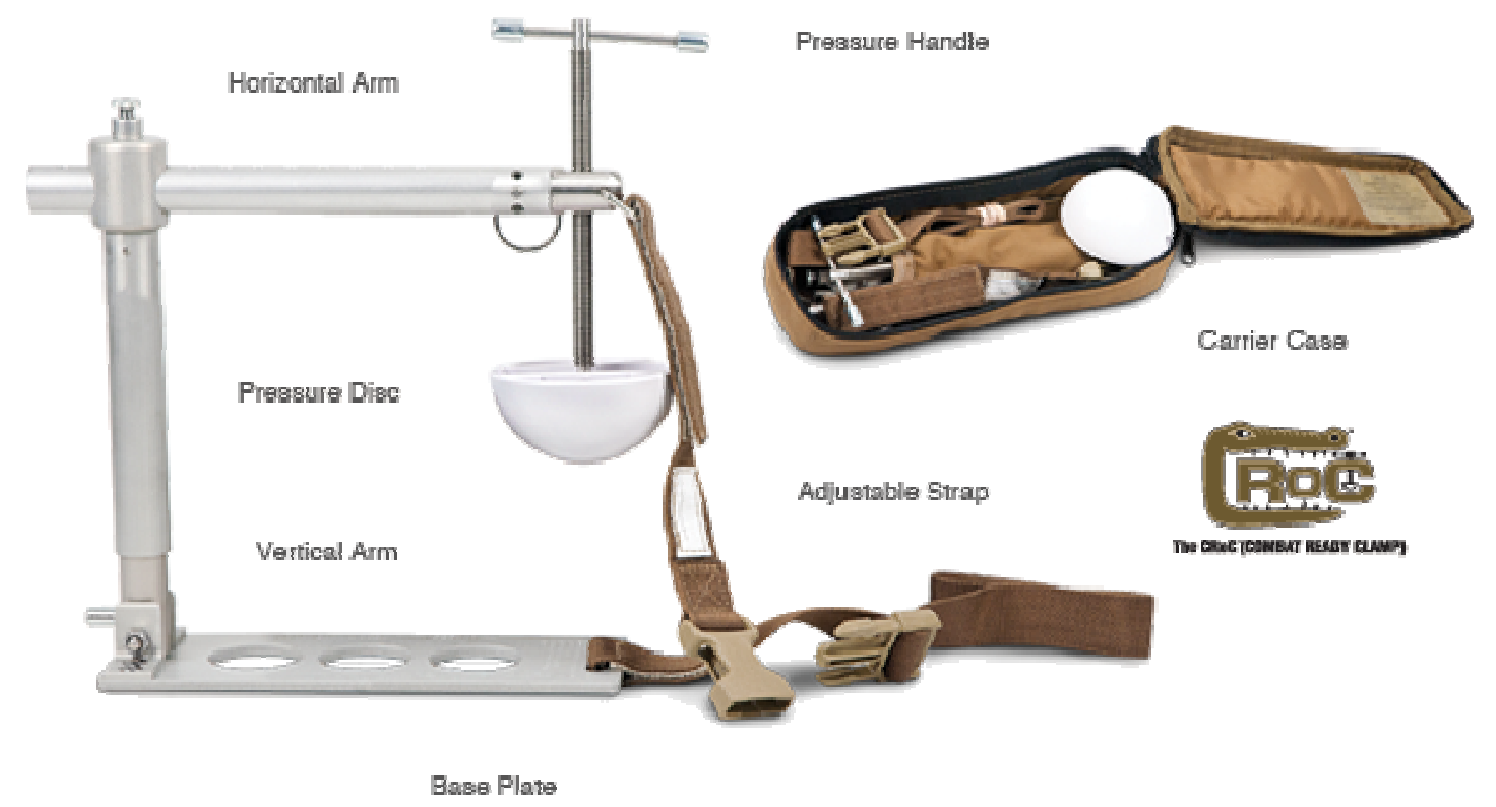

Figure 7: Combat Ready Clamp (CRoC) courtesy of Combat Medical Systems (Combat Medical Systems, 2009)

Since the CRoC has many of the desirable characteristics for combat use, it was chosen as the recommendation for an addition to the TCCC guidelines (Montgomery, 2011; Dickey \& Jenkins, 2011). Therefore this implementation of the CRoC into the TCCC is the first attempt to provide servicepersons with the ability to treat junctional trauma with a device as an attempt to 
replace the previously mentioned pelvic packing. Although the $\mathrm{CRoC}$ was the one of few choices for the recommendation, it still possesses many desirable traits. The $\mathrm{CRoC}$ is a strong recommendation because it is lightweight, collapsible, and has a low stored volume; all of which are important for implementation to the medic's aid bag (Dickey \& Jenkins, 2011). The physical dimensions of the clamp while stored is 3.5 " $\mathrm{x} 11.5$ " x 1.5 " and weighs in at $1.6 \mathrm{lbs}$ (Combat Medical Systems, 2009) and are the specifications that the proposed device in this paper will be compared against.

Although the CRoC has many desirable traits and is the only pressure device of its kind, there are some drawbacks to the design. For instance, the design requires a several step assembly process as well as several adjustments prior to use. This may be confusing and cumbersome in a wartime situation. Also, there was some concern expressed about the stability of the product (Dickey \& Jenkins, 2011). The CRoC does come with a stabilization strap; however it is unknown how well that prevents slippage, movement, or translation during transportation. In addition, the larger protrusion from the abdomen that the device creates during use could be a potential hazard during transportation as well. The device may be prone to being caught on something such as an IV bag or open airway device. Additionally, it is unknown what kind of damage may occur to a preexisting pelvic fracture. It was noted by some members of the Committee on TCCC that the CRoC may serve as a stabilization device, but it is unknown how effective the device would be used concurrently with a pelvic binder (Dickey \& Jenkins, 2011). Finally, as with any tourniquet device, not just the $\mathrm{CRoC}$, it is a concern of when the proper time and place for the use of the device is to be instituted (Dickey \& Jenkins, 2011). It was suggested that proper training may be used to address the concern (Dickey \& Jenkins, 2011). Other issues associated with tourniquets and not just the $\mathrm{CRoC}$ alone include blood accumulation with the 
venous circulation, mortification of limbs if inappropriately used, and persistent paralyses of the nerves within the compressed tissue (Klenerman, 1983; Kragh et al., 2008; Combat Medical Systems, 2009; \& Zuckerman, 2010).

\subsubsection{The Abdominal Aorta Tourniquet (AAT)}

Approved by the FDA in late 2011, the Abdominal Aorta Tourniquet (AAT) was the second device approved for use in junctional hemorrhaging (Figure 8) (Greenfield et al., \& Zuckerman, 2011). This device makes use of a pneumatic bladder that is inflated to locally pressurize the area over the abdominal aorta (AA). The design is composed of a belt, a windlass, and a pneumatic bladder. To apply, the belt is applied and tightened using the windlass. Once secured, the wedged-shaped bladder is inflated and the pressure on the AA occludes the vessel. The device was shown to effective occlude the artery with pressures of $230 \mathrm{mmHg}$, or about 4.5 psi and to be safe for 60 min application periods (Lyon et al., 2012 \& Zukerman, 2011).

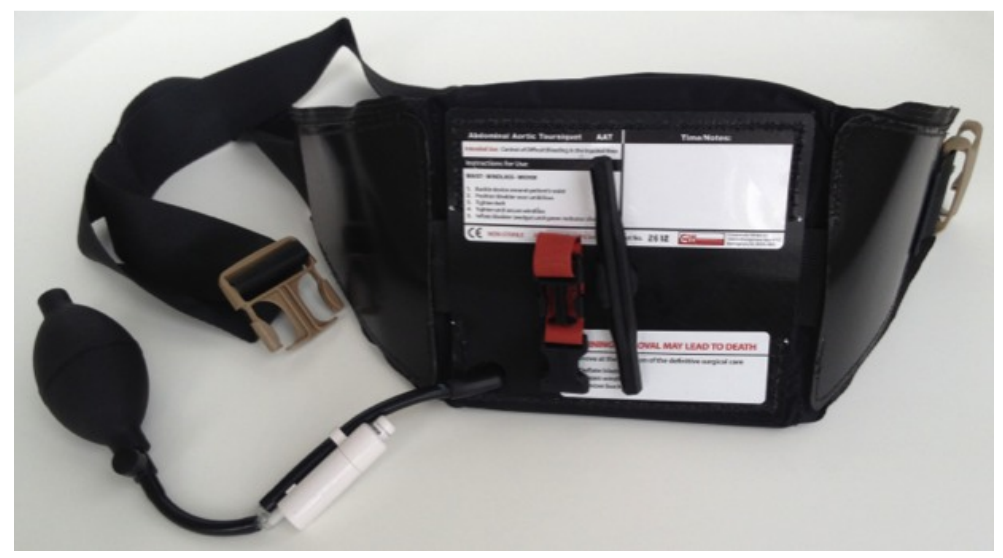

Figure 8: Abdominal Aortic Tourniquet (AAT) (Speer Optech, 2011)

Compared to the CRoC, the AAT has similar positive attributes such as small cube, lightweight, and is collapsible. The design uses a pneumatic bladder to achieve the mechanical pressure on the AA. The design has a smaller profile while in use compared to the CRoC. Figure 9 demonstrates the AAT's similar profile circumferentially to the patient and gear. The AAT also 
makes use of a well-known and familiar inflation mechanism, the bulb inflator from a blood pressure cuff. This would be easy-to-use and familiar for a medic to use. However, the AAT does use a pneumatic bladder which could still be susceptible to leak, puncture, or bursting in wartime environments. Also the need of the windlass to further secure the strap adds an additional step to the inflation procedure. If the strap was not secured using the windlass, it could affect the results of the AAT with a loose strap.

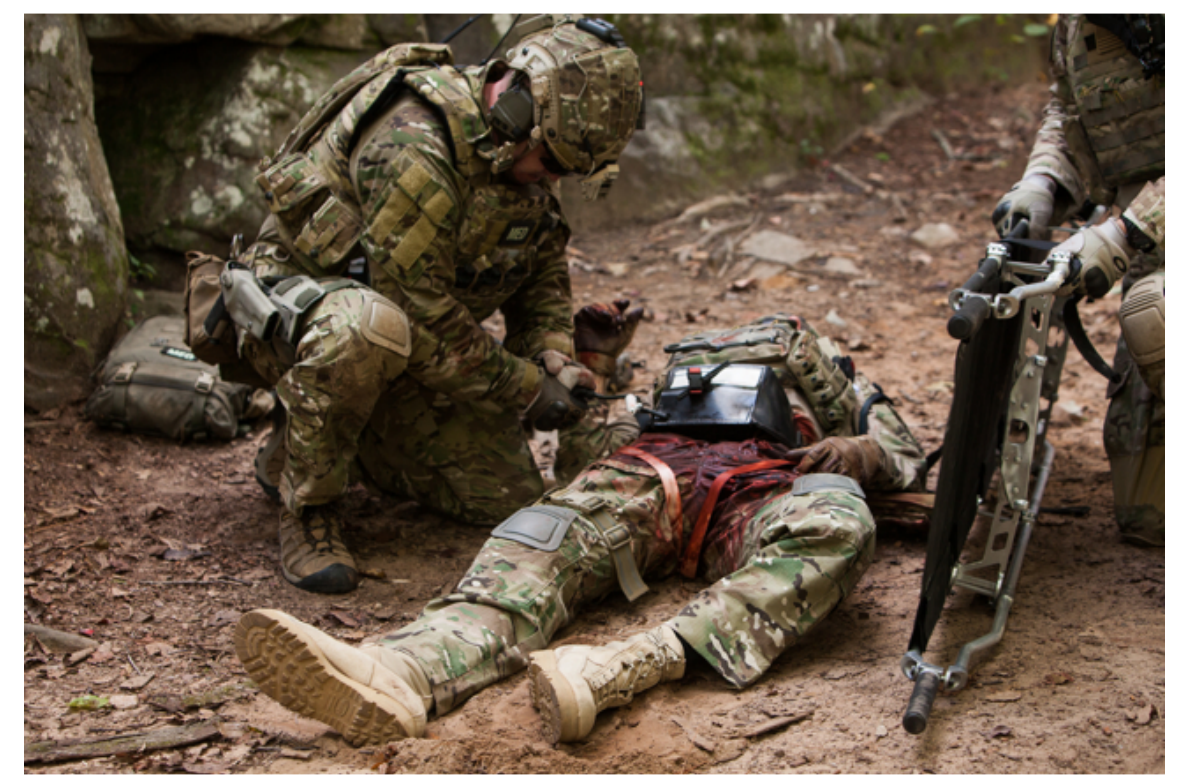

Figure 9: Example of Abominal Aortic Tourniquet in Use (Speer Optech, 2011)

\subsubsection{The Junctional Emergency Treatment Tool (JETT)}

In January of 2013, the FDA approved the third device for junctional hemorrhage control, the Junctional Emergency Treatment Tool (JETT, Figure 10) (Zuckerman, 2013). This design is similar to the $\mathrm{CRoC}$ with the screwing mechanism used for mechanical advantage, but makes use of a circumferential bad to attach the device to the patient. Two pads slide on two straps allowing for quick location adjustments. This design also is able to capture the common iliac arteries at the same time or the abdominal aorta (AA). The JETT also has a smaller, yet similar profile to the CRoC. The screwing mechanism still requires turning of the screw handles to apply pressure 
and the small pads requires anatomic knowledge to apply pressure appropriately. There is a lanyard that acts as a locking mechanism over the two screw handles to prevent depressurization of the pads. Although the locking of the handles is crucial to the sustained functionality of the device, it adds yet another step into the procedure. It is unknown if the locking mechanism would have an effect on the functionality over time, but if the handles were not locked down before transportation, the patient may still be susceptible to continued hemorrhaging. This device has similar volumetric, weight, and pressure application to both the CRoC and the AAT.

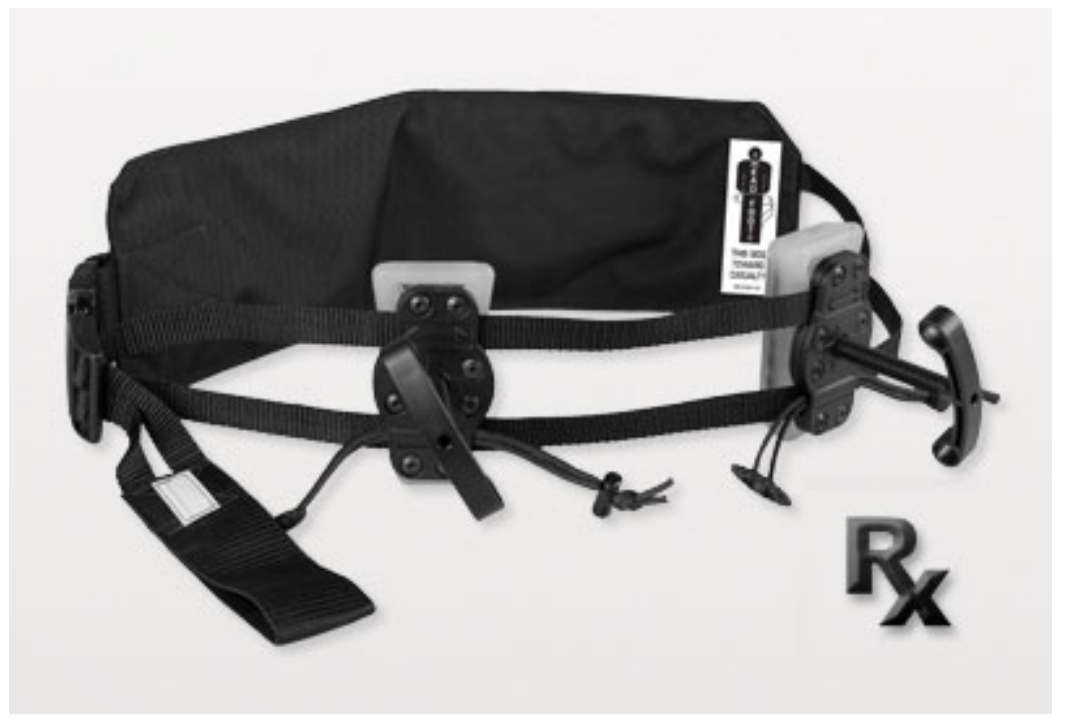

Figure 10: Junctional Emergency Treatement Tool (North American Rescue, 2010)

\subsubsection{Summary of Three Junctional Tourniquet Devices}

In review, there are three devices approved by the FDA to be safe and effective for use to control junctional hemorrhaging. The $\mathrm{CRoC}$ uses a threaded screw with a handle to tighten and a hemispherical end to apply pressure. The design requires assembly to use, and has a tall circumferential profile. The AAT is a pneumatic bladder device using a hand-held inflator to create pressure against the abdomen. The design uses a familiar pressure cuff bulb inflator and has an overall small circumferential profile. The AAT may not be as durable as other designs 
because of the use of the bladder. The third device, the JETT, uses two small pressure pads attached and moved on a strapped belt to locate either the AA or common iliac arteries. The pressure pads are turned to apply pressure, but require anatomic knowledge to ensure effectiveness. Each design has advantages and compromises to the design all attempting to create the most effective, durable, and lightweight device possible. For comparison, Table 1 summarizes the technical specifications of each design.

Table 1: Comparison of Three FDA Approved Junctional Tourniquet Devices

\begin{tabular}{|llll|}
\hline Model: & Weight: & Storage Volume: & Cost: \\
\hline CRoC (Combat Medical Systems, 2009) & $1.6 \mathrm{lbs}$ & $60.4 \mathrm{in}^{3}$ & $\$ 763.24$ \\
\hline AAT (Speer Optech, 2011) & $1.4 \mathrm{lbs}$ & $\sim 80 \mathrm{in}^{3}$ & $\$ 525.00$ \\
\hline JETT (North American Rescue, 2010) & $1.6 \mathrm{lbs}$ & $115.2 \mathrm{in}^{3}$ & $\$ 359.99$ \\
\hline
\end{tabular}




\subsection{Desirable Traits of a Junctional Tourniquet}

The challenge of building a junctional tourniquet goes beyond that of functionality; it must also be feasible for incorporated into the military medic's first aid bag. Implementation into the first aid kit comes with many requirements such as size, weight, and ease-of-use. A list was constructed to encompass the challenge of creating a junctional tourniquet to such limitations and the desired outcome of such a device. Table 2 expands on Kragh et al's list of "Desirable Traits of Candidate Device" in the article New Tourniquet Device Concepts for Battlefield Hemorrhage Control (Kragh et al., 2011a). In addition, not only were the traits where included, but the ideal circumstances of the traits and some practical notes were taken from Kragh et al's The Military Emergency Tourniquet Program's Lessons Learned With Devices and Designs) (Kragh et al., 2011b). 
Table 2: Ideal Emergency Junctional Tourniquet Traits with Practical Notes (Kragh et al., 2011a) (Kragh et al., 2011b)

\begin{tabular}{|c|c|c|}
\hline Trait & Ideal & Practical Notes \\
\hline Effective & Stops distal pulse & $\begin{array}{l}\text { Controls Hemorrhaging from junctional } \\
\text { areas such as the groin, pelvis, buttlock, } \\
\text { shoulder, or neck }\end{array}$ \\
\hline Fit & $\begin{array}{l}\text { Compresses sites where } \\
\text { regular tourniquets cannot } \\
\text { fit }\end{array}$ & Priority to the groin, pelvis, inguinal region \\
\hline Safe & Safety limits & $\begin{array}{l}\text { Pop-off valve, safety breakage point, or } \\
\text { measureable pressure monitor }\end{array}$ \\
\hline Combat ready & $\begin{array}{l}\text { Can be used well in } \\
\text { prehospital setting; tactical } \\
\text { setting }\end{array}$ & $\begin{array}{l}\text { Easy to apply even in tactical setting; } \\
\text { doesn't create noise, shine, or other danger }\end{array}$ \\
\hline Small & Stores densely & $\begin{array}{l}\text { Comes assembled in small storage volume; } \\
\leq 61 \text { cubic inches }\end{array}$ \\
\hline Lightweight & Low carrying weight & Practical, transportable; $\leq 1.5 \mathrm{lbs}$ \\
\hline Low Cost & Inexpensive & Cheaper than competitor; $\leq \$ 450.00$ \\
\hline Easy to Use & $\begin{array}{l}\text { Requires minimal training } \\
\text { or familiarization }\end{array}$ & $\begin{array}{l}\text { Can be familiarized and used in a tactical } \\
\text { setting }\end{array}$ \\
\hline Quickly applied & Don quickly & Fast to don/doff; $\leq 60$ seconds \\
\hline Slippage & $\begin{array}{lr}\text { No movement } & \text { during } \\
\text { application } & \text { or } \\
\text { transportation } & \end{array}$ & Does not slip in tactical situations \\
\hline $\begin{array}{l}\text { Application } \\
\text { Pressure }\end{array}$ & Mechanical advantage & $\begin{array}{l}\text { Can gain effectiveness without huge user } \\
\text { effort }\end{array}$ \\
\hline Release & $\begin{array}{l}\text { Provides easy release of } \\
\text { compression }\end{array}$ & $\begin{array}{l}\text { Can doff in emergency setting, remove with } \\
\text { scissors }\end{array}$ \\
\hline Replacement & Reapplication of device & $\begin{array}{l}\text { Can put back on without excessive time or } \\
\text { trouble }\end{array}$ \\
\hline Shelf Life & $\begin{array}{l}\text { Prolonged life without use; } \\
\text { still effective }\end{array}$ & $\begin{array}{l}\text { Can be used repeatedly and can be easily } \\
\text { cleaned; }>10 \text { years }\end{array}$ \\
\hline
\end{tabular}

With the ideal traits taken from literature, a rank order comparison chart was constructed to determine the importance of each requirement. Table A.1 details each requirement and provides a quantity association with it. Each requirement is directly compared to one another and a value of "1" is associated with the more important of the two. Each row is used as the base requirement of comparison and each column provides the requirement to be held against. If the base requirement is said to be more important to the design, a value of "1" is given. If the 
requirement of comparison is more important, the value associated is " 0 ." Then each row is summed to provide a value for each requirement. Table 3 demonstrates the order that each requirement was ranked, starting with the highest, or most important.

Table 3: Rank of the Ideal Traits of a Junction Tourniquet

\begin{tabular}{|llllll|}
\hline$\#$ & Requirement & Rank & $\#$ & Requirement (con't) & Rank \\
\hline $\mathbf{1}$ & Safe & 13 & $\mathbf{9}$ & Quickly Applied & 5 \\
\hline $\mathbf{2}$ & Effective & 11 & $\mathbf{1 0}$ & Lightweight & 4 \\
\hline $\mathbf{3}$ & Release & 11 & $\mathbf{1 1}$ & Small & 3 \\
\hline $\mathbf{5}$ & Fit & 9 & $\mathbf{1 2}$ & Replacement & 3 \\
\hline $\mathbf{6}$ & Application Pressure & 9 & $\mathbf{1 4}$ & Shelf Life & 0 \\
\hline $\mathbf{7}$ & Combat Ready & 7 & & & \\
\hline $\mathbf{8}$ & Easy to Use & 7 & & & \\
\hline
\end{tabular}

\subsection{Critical Buckling Pressure of Tubes}

\subsubsection{Orientation}

To introduce the collapsible tube theory behind the idea of a junctional tourniquet, it is important to establish a coordinate system. Figure 11 helps to visualize this established coordinate system for both the abdomen and the aorta. Simplifying the cross-section of an abdomen into an ellipse, the radial direction was considered to be the direction normal, and inward to the abdomen. The y-direction was considered the line that would run from the head to the toes, while the $\mathrm{x}$-direction was considered as the line perpendicular to that, crossing the body in the same plane as a cross-section. 


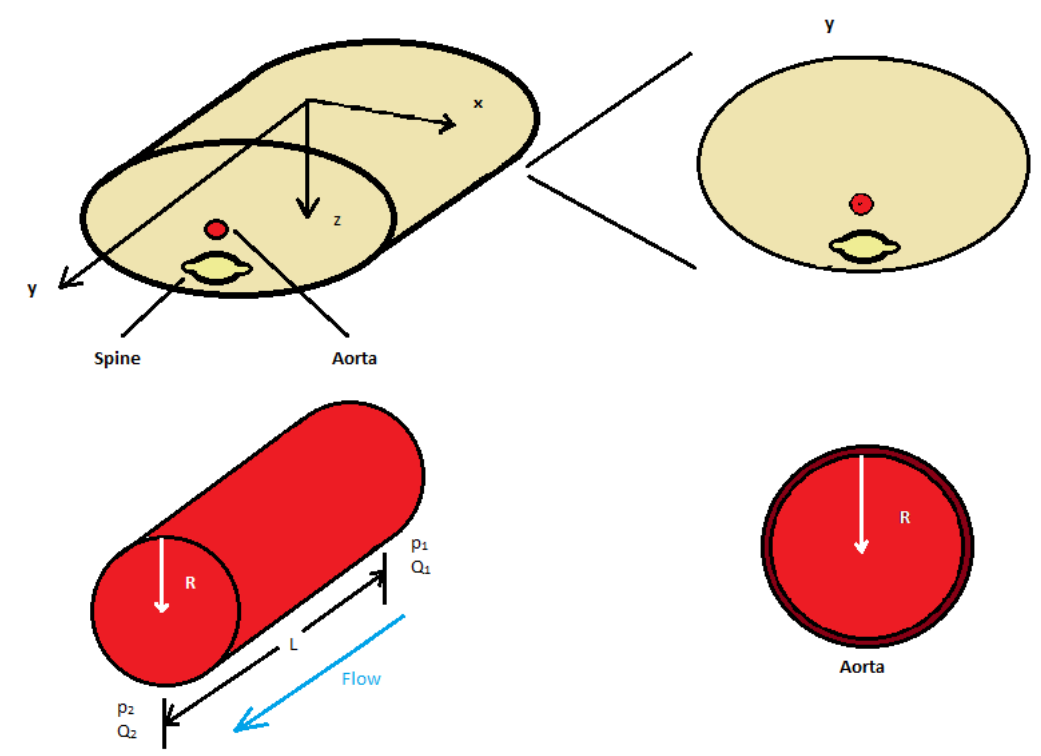

Figure 11: Directions of Abdomen, Abdomen Cross-Section, and Aorta Cross-Section

\subsubsection{The Effect of External Pressure on Collapsible Tubes}

It is of importance to understand the concept of "collapsed tube" in during testing for this application. The tube was considered to be collapsed at $20 \%$ flow, or $80 \%$ diminished flow as indicated by literature. William A. Conrad's study in 1969 entitled "Pressure-Flow Relationship in Collapsible Tubes," the understanding of collapsible tubes under external pressure was best explored. Conrad's study helped to relate the change of pressure through the tube to the flow rate with an external pressure, the exact scenario of junctional hemorrhaging. It was found that as pressure difference between the inlet and the outlet decreases, the external pressure changes the cross-sectional area creating three distinct regions on the effects of flow rate (Conrad, 1969). The pressure at the inlet was taken as $\mathrm{p}_{1}$, the pressure at the outlet was taken to be $\mathrm{p}_{2}$, the external pressure was taken as $\mathrm{p}_{\mathrm{e}}$, and flow rate, or $\mathrm{Q}$, was taken as cross-sectional area times the velocity of the fluid. To help better demonstrate this relationship, Error! Reference source not found.Figure 18 was extracted from Conrad's paper with $P n=p_{1}-p_{2}=\left(p_{1}-p_{e}\right)-\left(p_{2}-p_{e}\right)$. The three distinct regions were labeled I, II, and III in the graph. In region $\mathrm{I}$, both $\left(\mathrm{p}_{1}-\mathrm{p}_{\mathrm{e}}\right)$ and $\left(\mathrm{p}_{2}-\mathrm{p}_{\mathrm{e}}\right)$ are greater 
than zero demonstrating a decrease in pressure with decreased flow rate. Region II shows the increase of pressure with decreasing flow rate because $\left(\mathrm{p}_{1}-\mathrm{p}_{\mathrm{e}}\right)>0$, but $\left(\mathrm{p}_{2}-\mathrm{p}_{\mathrm{e}}\right)<0$. Finally, Region III shows the sharp decrease in flow rate as the tube collapses since both $\left(\mathrm{p}_{1}-\mathrm{p}_{\mathrm{e}}\right)$ and $\left(\mathrm{p}_{2}-\right.$ $p_{e}$ ) are less than zero. It is crucial that the tube be within the last region, or the final collapse phase. At a flow rate of $20 \%$, the tube would be in well-within the collapsed region indicating blood flow control (Figure 12).

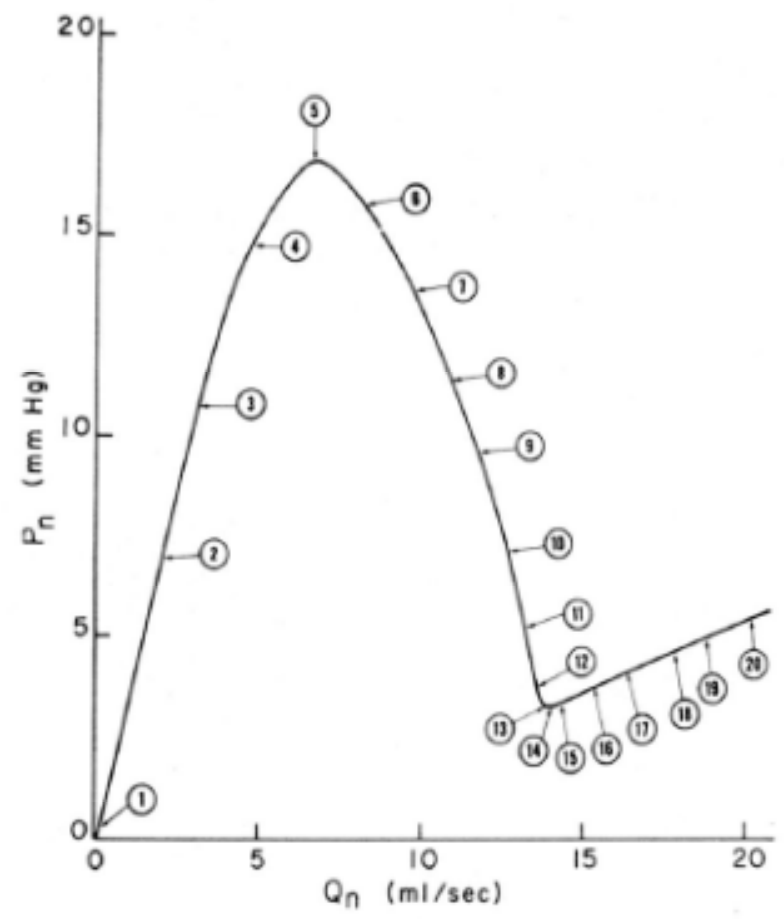

(a)

Figure 12: Pressure-Flow Relationship in a Starling Resistor (Conrad, 1969)

\subsubsection{Finding the Speed Index}

Using Bernoulli's equation for fluid flow along a streamline and assuming that the fluid that is flowing is laminar, elastic, and incompressible, Equation 1 was found with $p_{o}$ the stagnation pressure, $\mathrm{p}$ is the static pressure, $\rho$ as the density, and $\mathrm{v}$ as the velocity of the fluid. Using the definition of flow rate, Equation 2 was found with $\mathrm{Q}$ as the flow rate, $\mathrm{A}$ as the cross- 
sectional area, and $\mathrm{v}$ as the velocity from Equation 1. The derivative is then taken to find the slope of the relationship to find the maximum and the valley for the relationship seen in Error! Reference source not found.Figure 18 (Equation 3). Next, the velocity of propagation of progressive waves (Equation 4) was used to solve Equation 3, relating the wave propagation to velocity in the tube. The change in flow rate compared to the change in pressure $\left(p-p_{e}\right)$ was then simplified and solved for (Equation 5). Therefore, the Speed ratio is v/c (Equation 6), the velocity over the speed of wave propagation. This is the mathematical model of the three observational zones in Error! Reference source not found.Figure 18 and can be used to characterize flow region. If $\mathrm{v}<\mathrm{u}$, the flow is characterized by region $\mathrm{I}$. When $\mathrm{u}=\mathrm{c}$, the flow is limited, or choked. For $\mathrm{u}<\mathrm{c}$, the decrease in pressure $\left(\mathrm{p}-\mathrm{p}_{\mathrm{e}}\right)$ leads to a decrease in flow rate as well.

$$
\begin{gathered}
p+\frac{1}{2} \rho v^{2}=p_{o} \\
Q=A \sqrt{\frac{2}{\rho}\left(p_{o}-p_{e}\right)-\left(p-p_{e}\right)} \\
\left.\frac{d Q}{d\left(p-p_{e}\right)}=-\frac{A}{\rho}\left\{\frac{2}{\rho}\left[p_{o}-p_{e}\right)-\left(p-p_{e}\right)\right]\right\}^{-\frac{1}{2}} \\
\left.+\frac{d A}{d\left(p-p_{e}\right)}\left\{\frac{2}{\rho}\left[p_{o}-p_{e}\right)-\left(p-p_{e}\right)\right]\right\}^{\frac{1}{2}} \\
\frac{d Q}{d\left(p-p_{e}\right)}=\frac{A}{\rho v}\left(\frac{v^{2}}{c^{2}}-1\right)
\end{gathered}
$$




$$
S=\frac{v}{c}
$$

Having better understood the flow properties of the tube, the collapsibility of the tube was then examined. Modeled as a beam in compression, similarities can be drawn. There is some point in which the pressure being applied will cause the vessel (beam) to buckle. Outlined in Y.C. Fung's Biodynamics Circulation, Chapter 4.3 "Instability of a Circular Cylindrical Tube Subjected to External Pressure" describes methods used to find this critical pressure (Fung, 1984). Using a Force body diagram of the small circular sample of the cross-section provided a solution to buckling of the tube (Figure 13). Using the mechanical properties such as modulus of the vessel and the area, the buckling equation was found (Equation 7) where E is young's modulus of the vessel, $h$ is the thickness of the vessel wall, and $v$ is Poissons' ratio. Using Table 3.1:1 from Fung's book, the critical pressure was found to be 0.040 psi for the abdominal aorta noting the data provided is for a canine specimen (Figure 14) and assuming a Poisson's ratio is 0.3 .

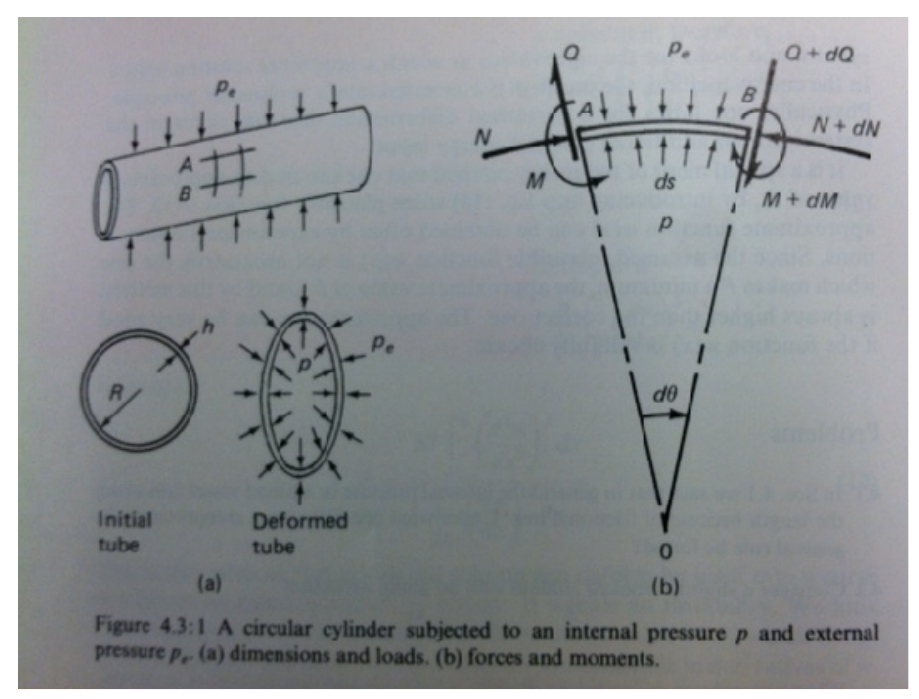

Figure 13: Force-Body Diagram of Vessel Under Radial Pressure (Fung, 1984) 


$$
\left(p_{e}-p\right)_{c r}=\frac{3 E I}{R^{3}}=\frac{E h^{3}}{4\left(1-v^{2}\right) R^{3}}
$$

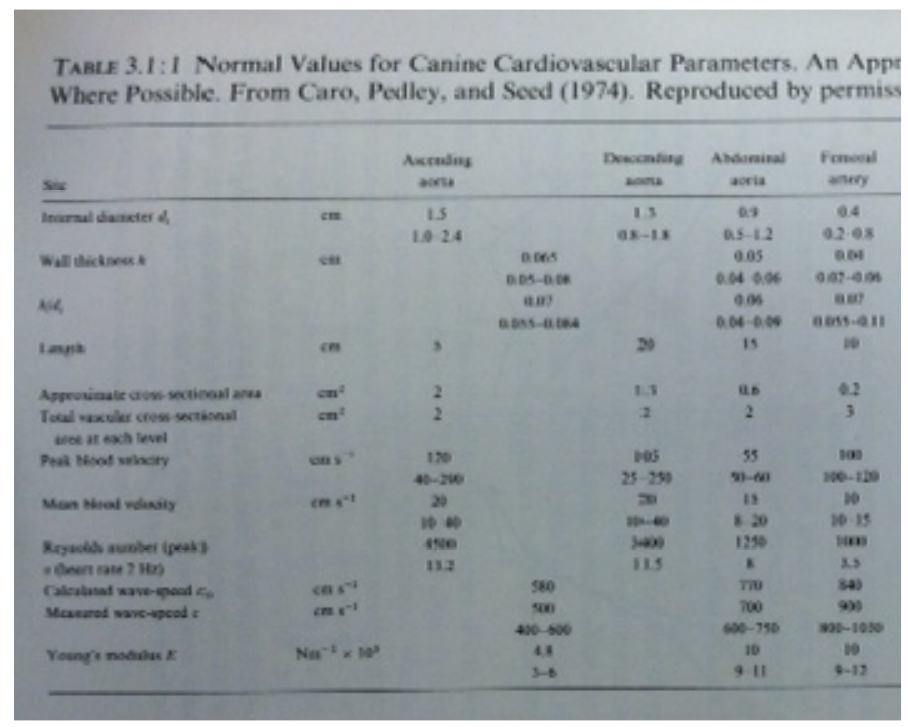

Figure 14: Common Vessel Mechanical Properties taken from

Biodynamics Circulation (Fung, 1984) 


\section{Chapter 3: Methods}

\subsection{Preliminary Mannequin Testing}

To help validate a final prototype once constructed, a preliminary work was done from September 2011 to June 2012 by Tracey Cheung to create a model replicating junctional blood flow (Cheung, 2012). Cheung created a mannequin for testing for a junctional tourniquet device using anatomical mimetic materials specifically design for modeling physiological properties. The lower torso of the human anatomy was replicated with the model to include a spine, pelvis, an aorta mimetic, a synthetic junction for the common iliac arties, flesh-substitute foam, and a skin replicate covering. The aortic mimetic was purchased from Sani-Tech West and has acceptable mechanical properties compared to native tissue (Sani-Tech West Sanitary Silicone Tubing Specifications Sheet, 2008). Testing was performed in a compressive Instron machine to compare the $120 \mathrm{lbs}$ of force reported needed to collapse the AA (Blaivas et al., 2006) to the Cheung model as an accuracy measurement for validating a junctional bleeding tourniquet. The Cheung model can be seen in Figure 15.

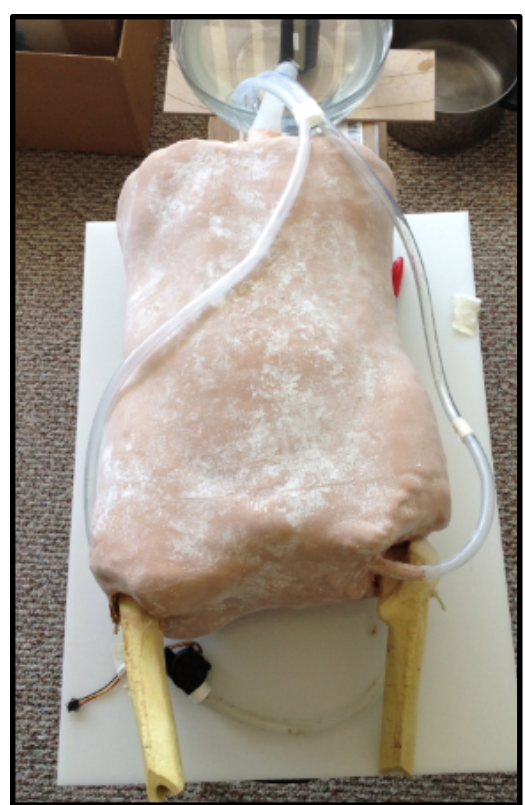

Figure 15: Test Mannequin Courtesy of T. Cheung (Cheung, 2012) 


\subsubsection{Preparation of the Testing Mannequin}

To replicate blood flow, water was used as a first-order approximation. Although it is well-known that blood exhibits non-Newtonian fluid properties (Fung, 1984; Fung, 1993; \& Pilcher, 1899), for this application using water (Newtonian Fluid) was acceptable to simplify the study. To replicate blood flow, a water pump was used to flow water through the connecting tubes, through the mannequin and the aorta replicate, and out the common iliac artery replicates into a reservoir. Again, a large simplification was made with a constant flow pump when compared to the pulsatile flow of the heart. The pump used in this system was a Supreme Classic General Purpose Utility Pump, an off-the-shelf pump rated to 250 gallons per hour (GPH). The flow rate needed to replicate blood flow is only $80 \mathrm{GPH}(5.0 \mathrm{~L} / \mathrm{min})$, but to overcome the head losses due to the tube connections and resistance of the tube, a higher flow pump was used. A flow restrictor was placed downstream from the pump to help dial-in the flow at the inlet of the aorta. To ensure that the appropriate flow rate at the aorta entrance, a Digiflow 6710M flow sensor was used (Figure 16). The water was pumped from a 5-gallon bucket used as a reservoir, through the mannequin, and back into the bucket to create a self-contained, open system (Figure 17). 


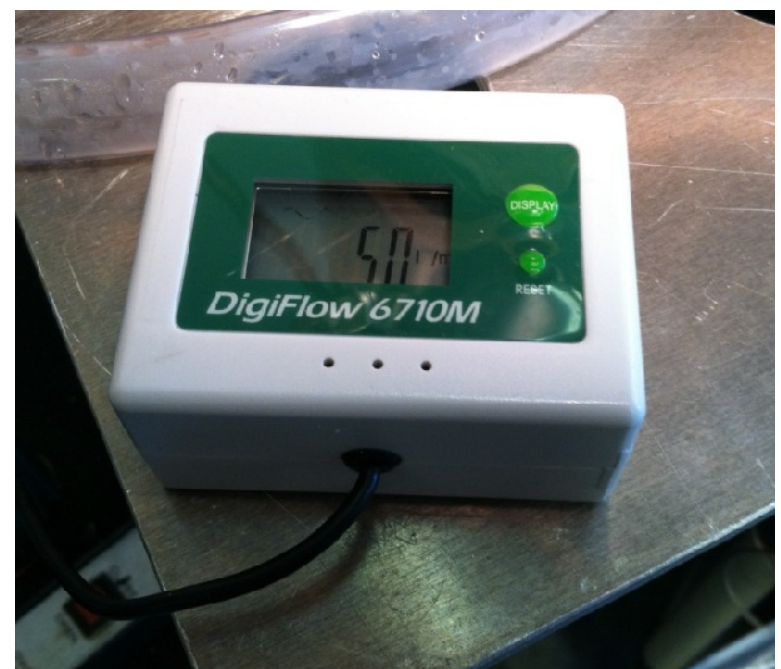

Figure 16: DigiFlow 6710M Flow Sensor Showing Flow Rate into Aorta of Mannequin

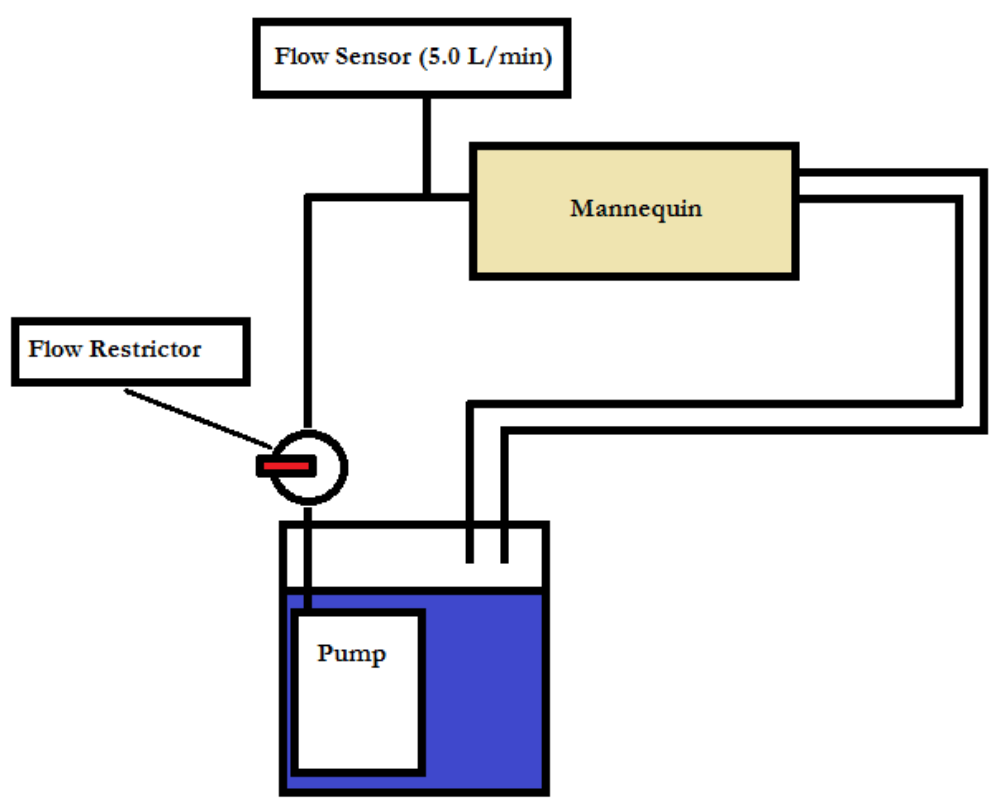

Figure 17: Simplified Diagram of Mannequin Preparation

\subsubsection{Measuring Force and Deflection}

To help track the force required and the necessary deflection to decrease the flow, compressive testing was conducted in an Instron machine. The Cheung model (Figure 17) that models blood flow through the mannequin previously mentioned was set up in an Instron machine with a large aluminum plate used as a flat surface for the mannequin to rest upon to 
replicate the ground. To understand the effect of shape and size the depression head would have on the force required to collapse the aorta, various heads sizes and shapes were used during testing. Two sizes, 3 and 4 inches, and two shapes, flat and hemispherical, were used to test the model. The experiment was set up as a two level, two factor, full factorial test with 5 replicates for a total of 20 runs. The run order was randomized to help eliminate any nuisance factors from skewing the data. The experimental was set up (Figure $18 \&$ Figure 19) and conducted with the four depression treatments (Figure 20).

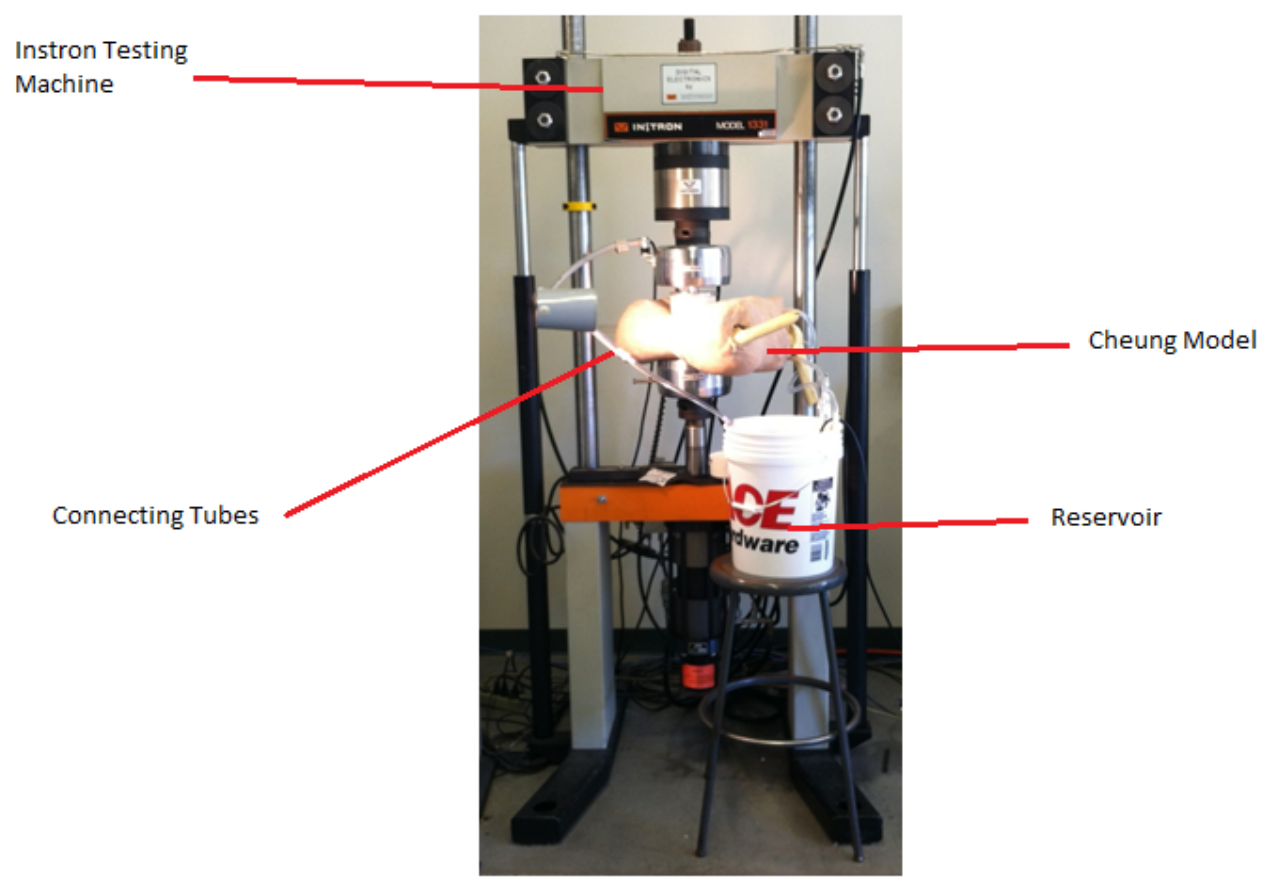

Figure 18: Preliminary Experimental Set Up of Cheung Model 


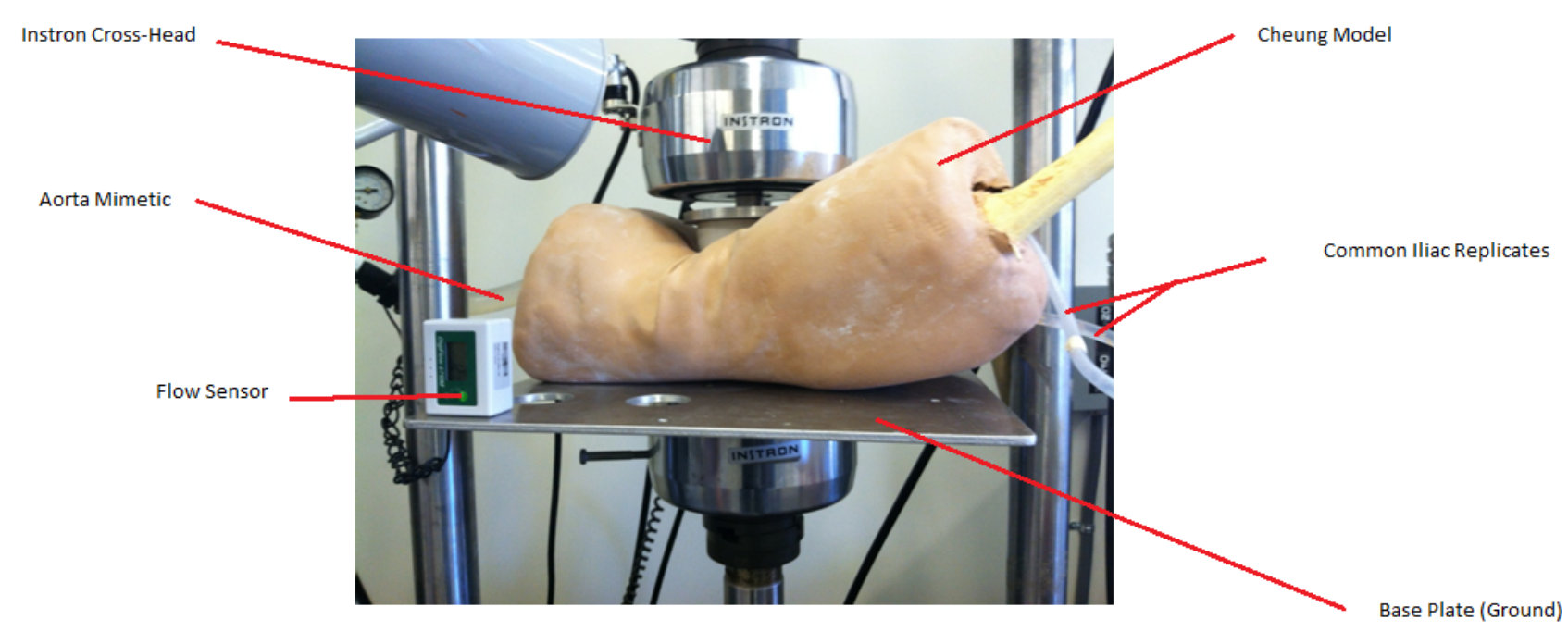

Figure 19: Preliminary Experimental Set Up of Cheung Model Close Up

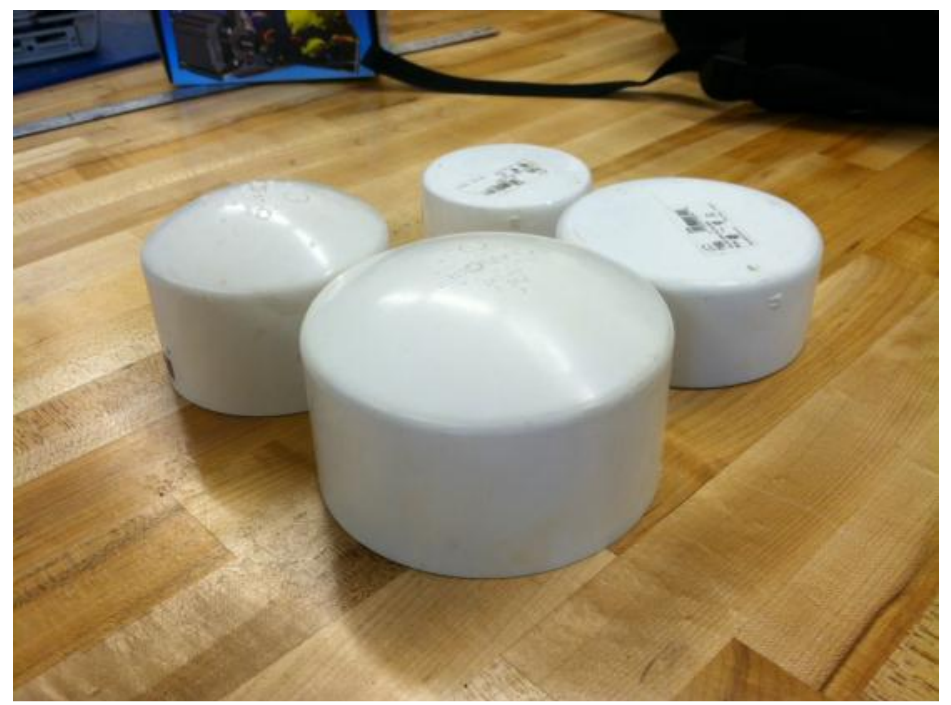

Figure 20: Size and Shape Specimens Used in Preliminary Testing

Once the Cheung model was set up (Figure 17), the testing was conducted in the Instron machine. The flow sensor was checked before each run to make sure that the flow rate was 5.0 L/min. 5.0 L/min is considered to be physiologically relevant (Fung, 1993 \& Pilcher 1899). The appropriate size and shaped pressure applicator was placed on top of the mannequin following the run order seen in Appendix E. Initial cross-head and preload conditions were recorded from the Instron. The Instron cross-head was then moved down at a speed of $0.0025 \mathrm{~m} / \mathrm{s}$ until the flow 
meter read $20 \%$ of initial reading or $1 \mathrm{~L} /$ min according to justification in Chapter 2.5. The crosshead was then stopped when the reading was stable at $1 \mathrm{~L} / \mathrm{min}$. The total difference deflection and force were taken from the Instron and recorded.

\subsubsection{Statistical Analysis}

Both the deflection and the force data was placed into the statistical software Minitab and analyzed as a full factorial design. It is important to note that running a full factorial design requires assumptions to be made about the data. The assumptions are that the data is normally distributed, independent of run order, and appropriately variant. The residuals, or the difference a specific point is away from the overall mean, are analyzed to verify these assumptions. To check the data for normalcy, the residuals are graphed against a normal line. Deviance from this line is indication that the data is not normally distributed. Independency is verified by plotting the residuals against the run order. If there is any overall trend, such as and increase or decrease, the data is considered to be not independent. Variance is verified by plotting the residuals against fitted values. Again, if there is any overall trend, the data is considered not to vary. Minitab provides these plots and they were used to verify the data in this experiment.

Once the assumptions were checked, the data was analyzed. Full factorial design tests the main effect of each factor, i.e. the effect that size and the effect that shape has on the response. Also checked with the factorial design is the interaction that the two factors have together on the response. This analysis was done for both deflection and force as the responses. The results are then reported in an analysis of variance (ANOVA) table. The table provides key information about the data such as the degrees of freedom, the error, and the p-value, or a standardization of confidence interval. The p-value is typically tested a 95\% confidence for Type I error, or incorrect rejection of the null hypothesis. For this experiment, a type I error would happen if it is 
assumed that size or shape has an effect on the response when in fact it does not. The p-value relates by the percent of confidence the experiment has. A 95\% confidence interval would therefore have a threshold p-value of 0.05 . If the p-value is greater than 0.05 , the null hypothesis cannot be rejected and we cannot say if size, shape, or interaction of the two has an effect on either response. However, if the p-value is less than 0.05 , then the null hypothesis is rejected, and the effect or interaction with the significant p-value is said to have an effect on the response indicated with a 95\% confidence. Therefore, the ANOVA table and p-value will be used to determine effects of the factors. A graphical representation of this p-value may help to aid in visualization of significance and is called a "normal plot of standardized effects." In summary, to determine the effect that each factor (size, shape) has on the responses (deflection, force), ANOVA, p-values, and standardized plots were used.

\subsection{Design Ideation}

To begin the ideation process, both previous designs and the requirements were examined to determine the best approach for solving this complex problem. First examined were historical truncal tourniquet examples (Figure 21). These designs include a screw type mechanism seen in Pancoast's aortic tourniquet and spring set tourniquets like Esmarch's aortic tourniquet. Using these tourniquets as a basis, five designs were created. 


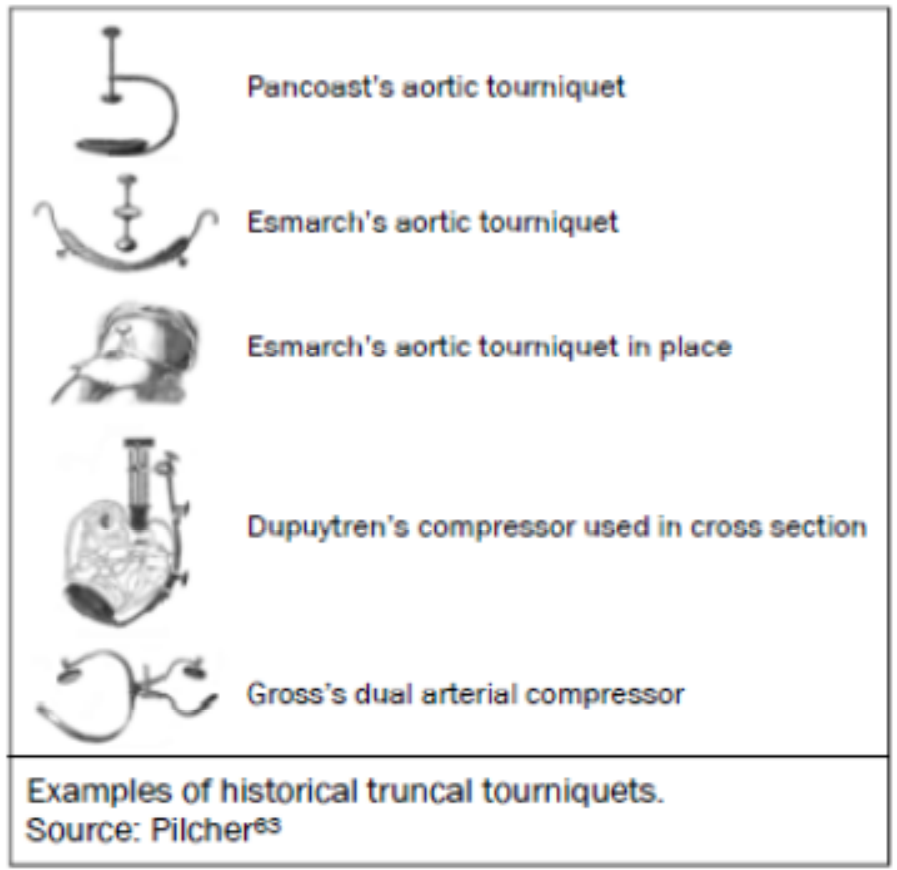

Figure 21: Examples of Historical Truncal Tourniquets (Kragh et al., 2011a \& Pilcher, 1899)

\subsubsection{Pneumatic Pressure Pump Design}

The first design uses pneumatic pressure for mechanical advantage, much like a bicycle pump. A hydraulic piston would actuate outward applying a downward pressure on the patient. A small band would connect to each side of the actuator and provide stabilization. Connected to the actuating piston would be small hand pump, either like a compact bicycle pump or a pressure cuff inflator. This would transmit the pressure down a flexible tube allowing for supine application for both the patient and the medical personnel. The advantages to this design include the large mechanical advantage of a pneumatic pump to create the force necessary. However, the application method of using small straps around the body creates concern for stabilization and fixation during massive hemorrhaging. The pneumatic design (Figure 22). 


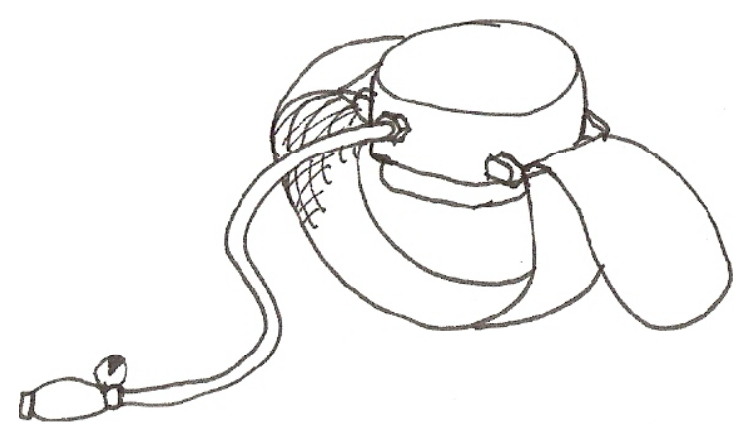

Figure 22: Sketch of Pnuematic Pressure Pump

\subsubsection{Swivel Bow Design}

For the second design, an improved Esmarch's aortic tourniquet was proposed. This device would have two curved members formed in the shape of the back, looking similar to a hunting bow. The device would be outfitted with a centralized pin at the apex of the bow allowing the bow to collapse in half for storage. When deployed, the device would easy open swiveling around the pin and slide under the back of the patient. Elastic straps would connect across the abdomen and be connected to a screw device. This screw device would then be held tight across the abdomen and be opened to apply pressure to the patient. This design has potential for being small and lightweight, however may sacrifice stability during application (Figure 23). 


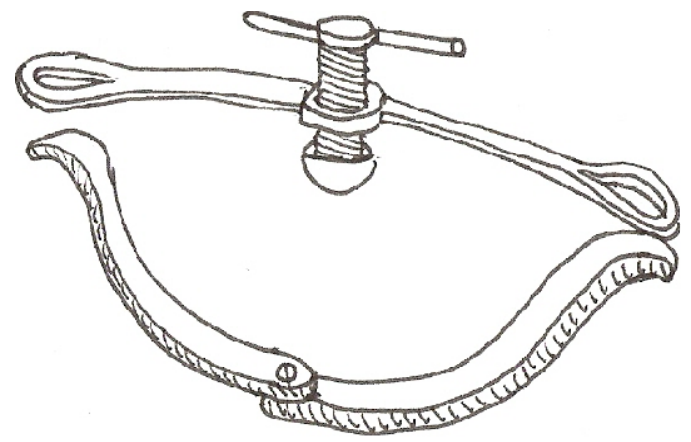

Figure 23: Sketch of Swivel Bow Design

\subsubsection{The Strap and Twist Design}

The third design is made of a centralized plate place over the abdomen and connecting straps connecting under the patient's back. This design would be modular with the pressure applicator being inserted into the plate and the plate being fixed with the connecting straps. The plate would be strapped tightly across the body. The screwing mechanism would then be inserted and twisted to fix into the plate. Once locked, the device would then apply pressure by a screwing motion using the resistance against the fixation plate. This design provides excellent stabilization, but still relies on the archaic method of turning a screw to create force. Due to the twisting motion of the locking mechanism and the screwing motion, this design was called the "strap and twist" (Figure 24). 


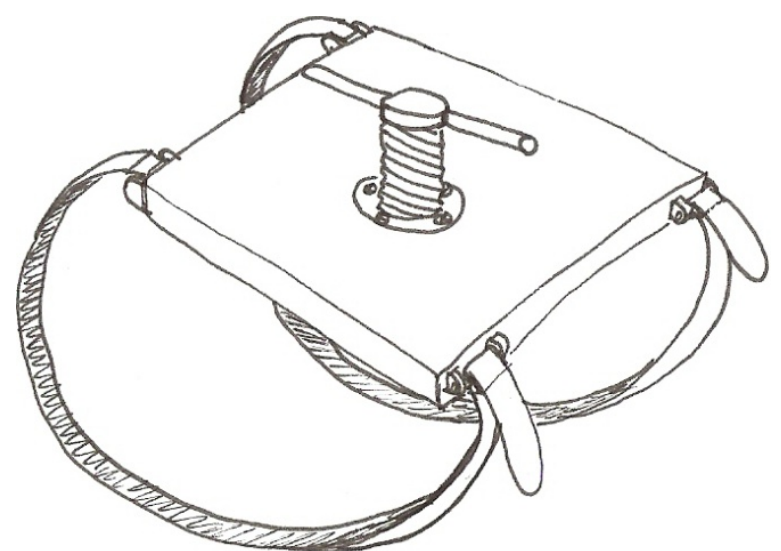

Figure 24: Sketch of Strap \& Twist Design

\subsubsection{The Compass Design}

Modeled after a drafting compass (Figure 25), the fourth design has some interesting potential. Two extending arms would be place over the abdomen and the other side of the arms would be connected to a screwing mechanism. There would be a fixed length connecting member to provide lever action for the two arms. As the screw is turned, the arms would be pressed together, pressing on the abdomen to the correct pressure. The compass design has potential for providing a sleek profile and small storage volume.
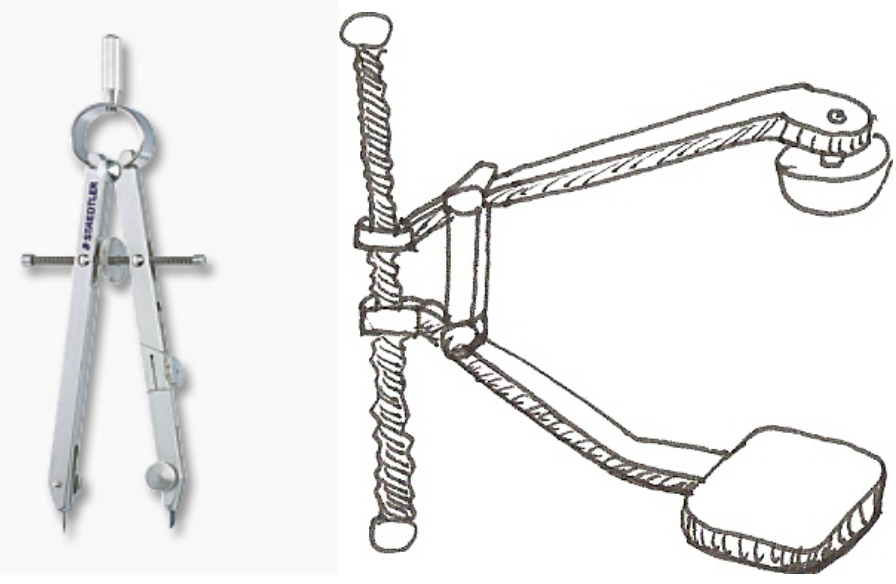

Figure 25: Example of Compass and Sketch of Compass Design (Staedtler Technical Drawing Equipment, 2011) 


\subsubsection{The Hybrid Design}

To capture the mechanical advantage of the pneumatic pump and the stabilization plate of the twist and turn design, a hybrid design was created. This design would consist of one large fixation plate to be place on the abdomen, a pneumatic actuator used for force application, and a large strap to fix device to the body. To create a large deflection with a small storage cube, the design was modeled after a hydraulic table lift (Figure 26). A pneumatic actuator would be attached to the fixation plate horizontally and move a scissor lift upwards. This design incorporates the advantages of both the pneumatic and strap and twist designs such as stability and small storage while eliminating some of the disadvantages such as large radial (to abdomen) height or instability (Figure 27).

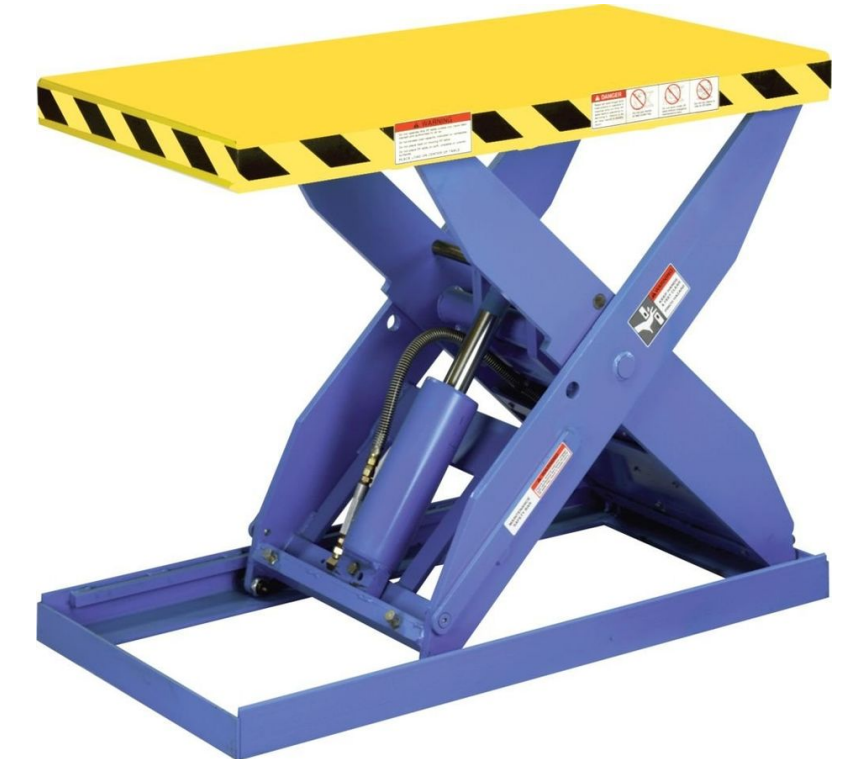

Figure 26: Example of Hydraulic Lift Table (Direct Industry, 2013) 


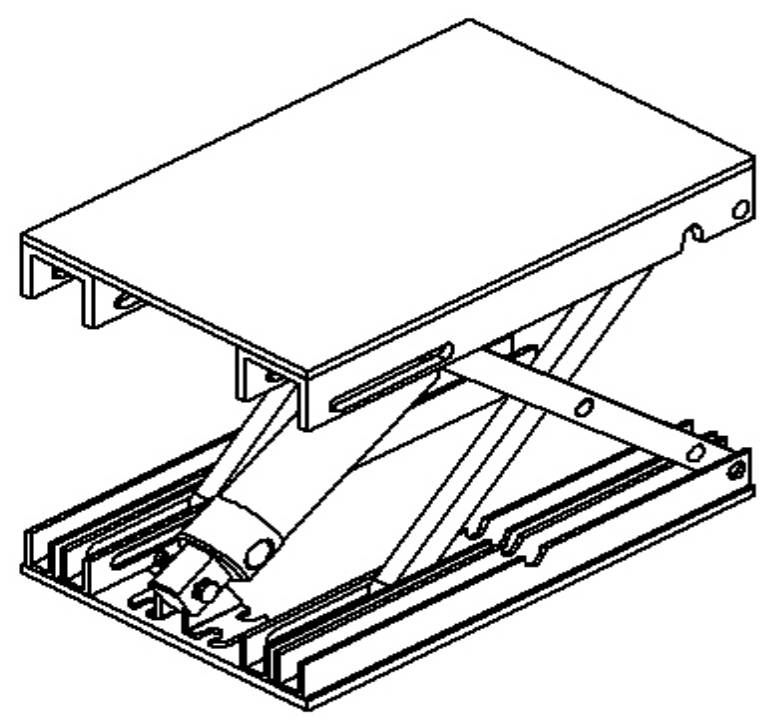

Figure 27: Sketch of Hybrid Design

Each design was then compared directly to each requirement using the $\mathrm{CRoC}$ as a datum for comparison. The decision (Pugh) chart displaying the five designs was then created (Table 4). 
Table 4: Decision Matrix (Pugh Chart) of Junctional Tourniquet Designs

\begin{tabular}{|c|c|c|c|c|c|c|c|}
\hline $\begin{array}{l}\text { Requiremen } \\
t\end{array}$ & Rank & $\begin{array}{l}\text { CRo } \\
\text { C }\end{array}$ & $\begin{array}{l}\text { Pneumati } \\
\text { c Pump }\end{array}$ & $\begin{array}{l}\text { Bow and } \\
\text { Screw }\end{array}$ & $\begin{array}{l}\text { Twist } \\
\text { and Turn }\end{array}$ & $\begin{array}{l}\text { Compas } \\
\mathbf{s}\end{array}$ & $\begin{array}{l}\text { Hybri } \\
\text { d }\end{array}$ \\
\hline Safe & 13 & $\begin{array}{l}\text { Datu } \\
\mathrm{m}\end{array}$ & + & - & $\mathrm{S}$ & - & + \\
\hline Effective & 11 & $\begin{array}{l}\text { Datu } \\
\text { m }\end{array}$ & + & + & $\mathrm{S}$ & $\mathrm{S}$ & + \\
\hline Release & 11 & $\begin{array}{l}\text { Datu } \\
\mathrm{m}\end{array}$ & + & S & - & - & + \\
\hline Fit & 9 & $\begin{array}{l}\text { Datu } \\
\mathrm{m}\end{array}$ & $S$ & $\mathrm{~S}$ & + & - & + \\
\hline Slippage & 9 & $\begin{array}{l}\text { Datu } \\
\mathrm{m}\end{array}$ & - & $\mathrm{S}$ & + & - & + \\
\hline $\begin{array}{l}\text { Application } \\
\text { Pressure }\end{array}$ & 9 & $\begin{array}{l}\text { Datu } \\
\mathrm{m}\end{array}$ & + & $\mathrm{S}$ & $\mathrm{S}$ & - & + \\
\hline $\begin{array}{l}\text { Combat } \\
\text { ready }\end{array}$ & 7 & $\begin{array}{l}\text { Datu } \\
\mathrm{m}\end{array}$ & - & $\mathrm{S}$ & $\mathrm{S}$ & $\mathrm{S}$ & $\mathrm{S}$ \\
\hline Easy to Use & 7 & $\begin{array}{l}\text { Datu } \\
\mathrm{m}\end{array}$ & + & + & + & $\mathrm{S}$ & + \\
\hline $\begin{array}{l}\text { Quickly } \\
\text { applied }\end{array}$ & 5 & $\begin{array}{l}\text { Datu } \\
\mathrm{m}\end{array}$ & + & + & + & - & + \\
\hline Lightweight & 4 & $\begin{array}{l}\text { Datu } \\
\mathrm{m}\end{array}$ & $S$ & $\mathrm{~S}$ & $\mathrm{~S}$ & + & S \\
\hline Small & 3 & $\begin{array}{l}\text { Datu } \\
\mathrm{m}\end{array}$ & $\mathrm{S}$ & + & $\mathrm{S}$ & + & $\mathrm{S}$ \\
\hline $\begin{array}{l}\text { Replacemen } \\
t\end{array}$ & 3 & $\begin{array}{l}\text { Datu } \\
\mathrm{m}\end{array}$ & + & S & $\mathrm{S}$ & $\mathrm{S}$ & + \\
\hline Low Cost & 1 & $\begin{array}{l}\text { Datu } \\
\mathrm{m}\end{array}$ & $\mathrm{S}$ & - & $\mathrm{S}$ & $\mathrm{S}$ & $\mathrm{S}$ \\
\hline Shelf Life & 0 & $\begin{array}{l}\text { Datu } \\
\mathrm{m}\end{array}$ & S & S & S & $\mathrm{S}$ & S \\
\hline TOTAL: & -- & -- & 5 & 2 & 3 & -4 & 9 \\
\hline
\end{tabular}

\subsection{Final Design Concept}

From the decision chart, the hybrid concept was chosen as the final design. This design provides the more advantages over the currently available CRoC. The pneumatic actuator will severely decrease the time to pressurization while still remaining comparable in storage size. The final design will be comprised of three main components: the miniature pneumatic lift (MPL), the fixation plate, and the strap. The MPL was designed to appropriately apply pressure to the abdomen while still remaining as small volumetrically as possible in the radial direction. The 
fixation plate was also designed with size and weight as a consideration. The plate will have two connection edges providing easy application of the strap. The strap will be fixed on one end and looped through on the other. The strap itself will be simple in construction and made out of a highly durable nylon fabric using Velcro as the fixture mechanism. With the final design chosen, the necessary dimensions, size constraints, and materials were found through engineering calculations using necessary simplifying assumptions and standard size of material availability.

For initial design validation, simple hand calculations were performed. Some initial conditions that were known or found through preliminary testing (Chapter 4.1) were used to solve the engineering problems and are listed in Table 5. Since the design consists of three components (MPL, fixation plate, and strap), the analysis was too was split into three simplified versions corresponding to each component.

Table 5: Initial Conditions and Known Parameters for Engineering Calculations

\begin{tabular}{|lll|}
\hline Known Parameter & Value & Unit \\
\hline Force needed to collapse abdominal aorta (Blaivas et al., 2006) & 120 & $\mathrm{lb}$ \\
\hline Force need to collapse Cheung Model & $52.12-134 * *$ & $\mathrm{lb}$ \\
\hline Bore size of pneumatic actuator (Bore Size Calculator, 2013) & 0.75 & Inch \\
\hline Angle between horizontal and strap (Figure 33: Approximation & 47.5 & degrees \\
of Angle Theta Strap would Apply Force to Fixation Plate & & \\
\hline Force applied in x-direction at strap (Figure F. 1) & 55 & lbs \\
\hline Force applied in y-direction at strap (Figure F. 1) & -60 & lbs \\
\hline
\end{tabular}

** Data from the initial testing procedure. 


\subsubsection{Miniature Pneumatic Lift (MPL)}

The design consists of a base plate, a top platform, two sets of scissoring supports for a total of 4 legs, and an actuator (Figure 27). The basic idea is to miniaturize these components into a compact lift for a useable, practical solution. The goal was to design the miniature lift to meet the requirements listed in Table 2 as best as possible while still functioning appropriately.

\subsubsection{Design of Actuator}

The first step in the design of the MPL, was the actuator, or a mechanical device using pressure to in a closed system to move objects in a linear motion. The actuator was responsible for applying the force through the series of levers in the lift. There are two basic actuator designs, hydraulic and pneumatic. Hydraulic uses a noncompressible fluid to apply pressure to the linear motion mechanism. This design does require an external reservoir to fill the housing with. The second type is a pneumatic actuator, or an actuator that uses air as the closed system fluid. The design is similar, but does not require a reservoir as atmospheric pressure can be used as the reservoir. Hydraulic systems have much more mechanical advantage because the fluid used, typically oil, is noncompressible. These actuators are capable of generating orders of magnitude greater force than pneumatic. However, hydraulic systems require more design, components, and structure compared to pneumatic. Pnuematic systems may be easier to work with and lighter, but used air, a compressible fluid, as the pressure mechanism. This causes problems when force is applied on the fluid. The fluid will compress, or become more pressurized, rather than providing an equal and opposite reaction force. Even though it was known that these systems are susceptibility to collapsibility, a pneumatic actuator was chosen because it is compatible with pneumatic hook-ups and the actuator could be purchased off-theshelf. 
To begin the calculations for the actuator itself, an online source was used to help determine the appropriately sized actuator. Clippard, a company specializing in the production of stainless steel pneumatic actuators, provides an online calculator to appropriately size the actuator. The size calculations are based on the bore, or the diameter of the tube in the axial direction, and the stroke length, or the deflection needed. To size the actuator in Clippard's online calculator, two input variables were needed: the maximum pressure that can be provided to the actuator and the force ultimately needed to lift the payload.

To pressurize the actuator, a hand-held bicycle pump will be used. There are two categories of hand bike pumps; manual operation and $\mathrm{CO}_{2}$ compressed air cartridges that rapidly fill the bike tube. Both standard bike and $\mathrm{CO}_{2}$ pumps can pressurize up to 120 psi and are designed specifically for small volumetric storage. However, $\mathrm{CO}_{2}$ cartridges are quite different that standard bike pumps. $\mathrm{CO}_{2}$ pumps rapidly fill the tube with no pressure modulations (can't dial in pressure to specified amount), often have no pressure gauge, and introduces the ability of running out of cartridges. Therefore, having a bike pump that is manually pressurized with a gauge for accuracy is desired. In this application, the ability to pressurize beyond 120 psi will be advantageous in addition to being able to modulate the pressure. Also used in the bicycle community, the hand-held shock pump is used to highly pressurize small volumes. For this design, the Lezyne "Drive" Shock Pump was chosen to provide this pressure (Figure 28). This is a pump designed for pressurizing pneumatic pumps on mountain bike and can provide up to 300 psi. The ability to pressurize the actuator higher will decrease the bore size. Being able to buy a pre-made, off-the-shelf pump will save time and money for this project, but could be redesigned in the future to incorporate a specific pump for the tourniquet. 


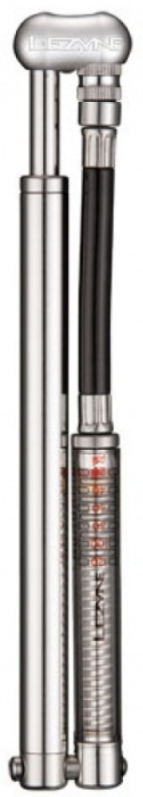

Figure 28: Lezyne Drive Shock Pump (Lezyne, 2013)

With the maximum pressure found, the force needed by the actuator to lift the payload was found next. Using statics in the most expanded state of the device, the forces within the structure were found. Using variables for all the known values, unknown values, and the suggested maximum force of $120 \mathrm{lbs}$ on the abdomen (Blaivas et al., 2006) as the payload being "lifted"(W), the force needed by the actuator was found in relation to the angle between the base plate and the scissoring support member $(\Phi)$. This relationship can be seen in (Equation 8).

$$
F=\frac{\frac{1}{2} W}{(\sin \varphi)}, \text { where } \mathrm{W} \text { is weight "lifted," }
$$

\section{Equation 8}

Using Equation 8, the force needed to lift the payload could now be found using geometry to solve for $\Phi$. With a range of forces being reported as functional, accurately obtaining high pressures with a shock pump and various factors of safety built into Clippard's online bore-size calculator, a merit of combinations of factors and levels were calculated (Table 6). It should also be mentioned that Clippard's maximum operation pressure for their air cylinders is $250 \mathrm{psi}$, and therefore would not allow for calculations above that pressure. 
Table 6: Various Forces, Pressures, and Factors of Safety Used In Online Bore-Size Calculator

\begin{tabular}{|lllll|}
$\begin{array}{l}\text { Force } \\
\text { (lbs) }\end{array}$ & $\begin{array}{l}\text { Applied } \\
\text { (lbs) }\end{array}$ & $\begin{array}{l}\text { Force } \\
\text { (psi) }\end{array}$ & $\begin{array}{l}\text { Seeded } \\
\text { Pressure }\end{array}$ & $\begin{array}{l}\text { Safety Factor } \\
\text { (in) }\end{array}$ \\
\hline $\mathbf{1 2 0}$ & 103.8 & 250 & $20 \%$ & 0.75 \\
\hline $\mathbf{1 2 0}$ & 103.8 & 120 & $20 \%$ & 1.0625 \\
\hline $\mathbf{1 2 0}$ & 103.8 & 250 & $50 \%$ & 0.875 \\
\hline $\mathbf{6 0}$ & 103.8 & 120 & $50 \%$ & 1.25 \\
\hline $\mathbf{6 0}$ & 51.9 & 250 & $20 \%$ & 0.5 \\
\hline $\mathbf{6 0}$ & 51.9 & 120 & $20 \%$ & 0.75 \\
\hline $\mathbf{6 0}$ & 51.9 & 250 & $50 \%$ & 0.625 \\
\hline
\end{tabular}

Under the assumption that a $20 \%$ factor of safety is acceptable and the pressure would not need to exceed, the bore-size was chosen to be 0.75 ". This allows the actuator to be as small as possible while still remaining structurally sound in this application. This size is safe with a $20 \%$ factor of safety when the load is at $120 \mathrm{lbs}$, and the factor of safety become greater than $50 \%$ when the pressure is decreased to $60 \mathrm{lbs}$. Using this actuator, the force was projected to be sufficient to collapse the AA.

\subsubsection{Component Design}

With the actuator accurately sized, the rest of the components of the MPL could be designed. The design was first sketched out to approximate the lengths, widths, and thickness of components needed for the lift. As mentioned, the design consisted of support members, a base plate, a top platform, and support sliding rails for both the top and bottom. The design was first 
visualized in Solidworks, a three-dimensional (3D) computer aided drafting (CAD) program (Figure 29). Initially, the components were made in 3D space only regarding other components to ensure proper fit. But once the design was assembled, components were resized and modified to allow for the less amount of machining. The modification process involved research and sizing of each component on the internet. All the parts, except for the actuator, were found at McMaster Carr, an online provider of over 510,000 hardware parts and raw materials. This website allows for 3D CAD drawings to even be downloaded and used in Solidworks to ensure appropriate fitting. This was done for each component to ensure an off-the-shelf part would be used if possible, and allow for the least amount of machining possible to save time and money.

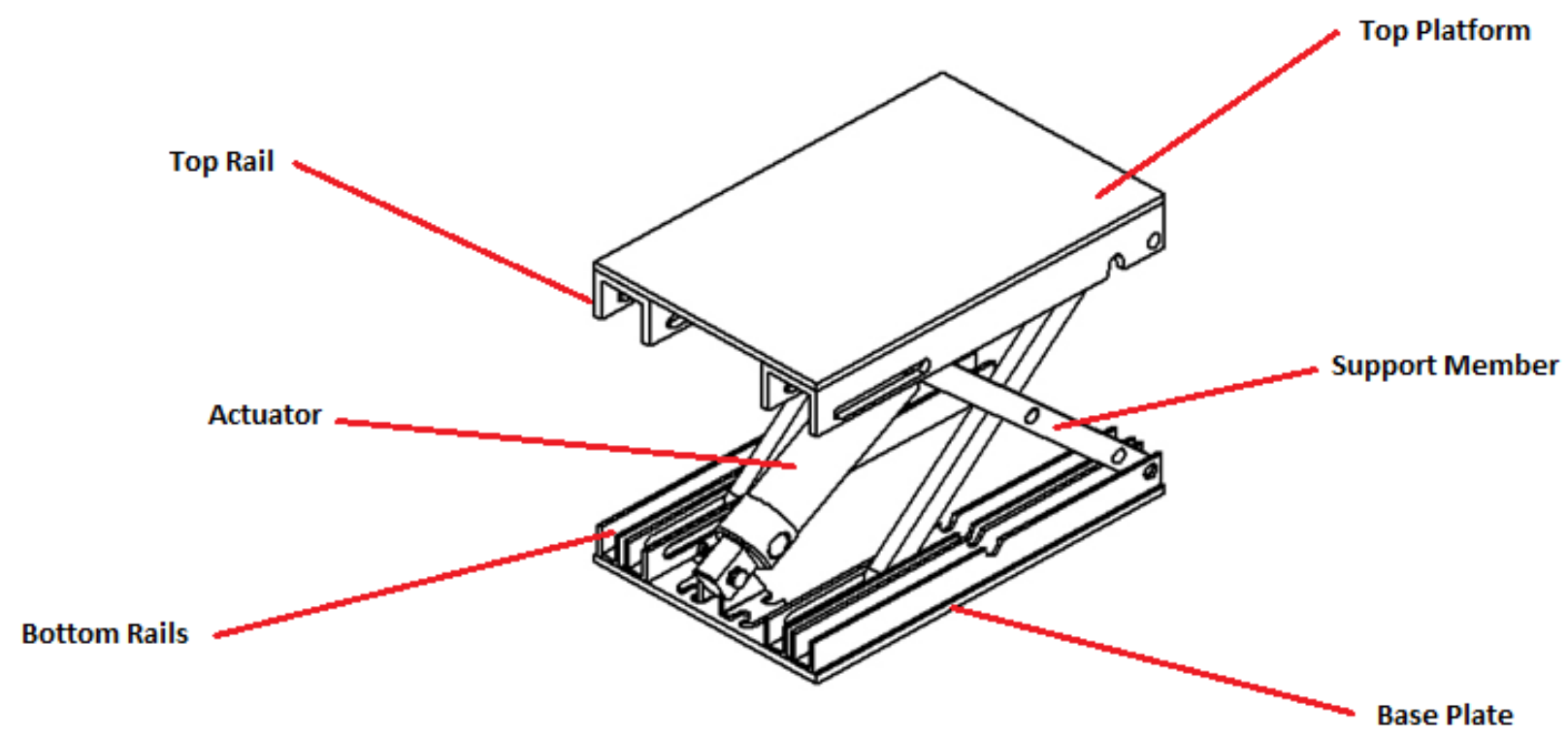

Figure 29: Solidworks Drawing of Expanded Miniature Pneumatic Lift

Each component was designed to provide the necessary lift, provide the structural rigidity necessary, and interact without interference. Two fasteners were used in the design; a threaded aluminum post and rivets. The threaded posts come in various sizes in $1 / 8$ inch increments. The various sizes and low profile bolt made these binding posts perfect for binding the support members to each other and the support members to the top and bottom rails. To attach the rails to 
the top and bottom plates, rivets were used to provide a stable, but low profile joint. To attach the actuator there were two types of clevis used. At the bottom, or the fixed clevis, a pin connecting through the actuator to two brackets was used. This was purchased off the shelf from Clippard, the actuator company. At the other end, a rotating clevis was used. A threaded member attaches the stroking member of the actuator to a cross member (binding post) of the MPL and was order from McMaster Carr. The support member was basic in design being only a rectangular bar with holes was therefore a raw bar of aluminum was ordered and machined to the specified dimensions seen in Figure B. 2. The top and bottom rails were ordered as an extruded aluminum $\mathrm{U}$ channel. The bottom rails consisted of two U-channels to allow the interaction of the scissoring mechanism without interference. The top rail was larger, encompassing both support members and allowing for fixation. They were then milled to create holes and slots for the sliding action. As the lift is forced upward by the actuator, the support members need to slide to accommodate the change in dimension. This was accomplished with slots for the connections to slide within for both the top and bottom rails. Detailed drawings were created in the Solidworks software (Figure B. 5-7). The top platform and bottom plate were also basic in design with only holes drilled into appropriately sized sheet metal (Figure B. 8). With all the components designed, the parts were ordered and assembled. Table 7 breaks down the cost of each component. 
Table 7: Components of Miniature Pneumatic Lift with Cost of Raw Material / Per Unit

\begin{tabular}{|c|c|c|c|c|c|c|}
\hline Item & $\mathbf{P} / \mathbf{N}$ & Description & Cost & Qty. & Neded & Cost/Unit \\
\hline 1 & USR-12-1 1/2 & Pneumatic Air Cylinder Actuator & $\$ 17.48$ & 1 & 1 & $\$ 17.48$ \\
\hline 2 & 6498K562 & Pivot Bracket (5/8") & $\$ 3.27$ & 1 & 1 & $\$ 3.27$ \\
\hline 3 & $8123 \mathrm{~A} 43$ & 3' x 17/64" Aluminum U-Channel & $\$ 10.58$ & 5 & 4 & $\$ 8.46$ \\
\hline 4 & $8123 \mathrm{~A} 48$ & 3' x 3/4" Aluminum U-Channel & $\$ 20.33$ & 5 & 4 & $\$ 16.26$ \\
\hline 5 & $2447 \mathrm{~K} 13$ & Clevis Rod End & $\$ 7.21$ & 1 & 1 & $\$ 7.21$ \\
\hline 6 & 8975 K713 & Aluminum Alloy (1/4"x2"x3') & $\$ 14.57$ & 24 & 4 & $\$ 2.43$ \\
\hline 7 & 94887A153 & Light Weight Binding Post (3/4") & $\$ 7.24$ & 5 & 4 & $\$ 5.79$ \\
\hline 8 & 94887A136 & Light Weight Binding Post (3/8") & $\$ 6.54$ & 10 & 2 & $\$ 1.31$ \\
\hline 9 & 94887A211 & Light Weight Binding Post (2.75") & $\$ 9.74$ & 5 & 1 & $\$ 1.95$ \\
\hline 10 & 94887A162 & Light Weight Binding Post (1") & $\$ 8.37$ & 10 & 2 & $\$ 1.67$ \\
\hline 11 & $97525 \mathrm{~A} 670$ & Rivets (1/8") & $\$ 14.22$ & 100 & 20 & $\$ 2.84$ \\
\hline 12 & $7237 \mathrm{~K} 18$ & $\begin{array}{l}\text { Aluminum Alloy Tube Spacer (.25" } \\
\text { OD) }\end{array}$ & $\$ 11.42$ & 10 & 2 & $\$ 2.28$ \\
\hline 13 & $8975 \mathrm{~K} 419$ & Aluminum Alloy Sheet (1/8"x4"x3') & $\$ 17.57$ & 5 & 2 & $\$ 7.03$ \\
\hline 14 & $5340 \mathrm{~K} 31$ & 90 Elbow $1 / 8 "$ to $1 / 8 "$ swivel pipe & $\$ 2.38$ & 1 & 1 & $\$ 2.38$ \\
\hline 15 & 8063 K33 & Schrader Value to $1 / 8^{\prime \prime}$ & $\$ 5.23$ & 1 & 1 & $\$ 5.23$ \\
\hline 16 & 786526 & Leyzne Drive Shock Pump & $\$ 45.00$ & 1 & 1 & $\$ 45.00$ \\
\hline \multicolumn{6}{|c|}{ Total Cost of Materials: } & $\$ 201.15$ \\
\hline \multicolumn{6}{|c|}{ TOTAL COST PER UNIT: } & $\$ 130.60$ \\
\hline
\end{tabular}

\subsubsection{Preliminary Engineering Analysis}

With the design finalized, each force-bearing component was then verified for material yielding and deflection. The support member was the first component considered for stress analysis calculating throughout the thickness of the member. The cross section had an area of $0.09375 \mathrm{in}^{2}$ with a maximum force of $120 \mathrm{lbs}$ the stress was found to be 1,280 psi. With the strength of aluminum before yielding $\left(S_{y}\right)$ of 40,000 psi, the part was well within the mechanical limits of the material. However, with a small amount of material between the hole and each end, the stress concentration was of concern. Using Shigley's Mechanical Engineering Design, $9^{\text {th }}$ Edition, the maximum stress was found for the end of each member. First, the area minimum area of the part was found using Equation 9. The nominal stress was then found using Equation 
10. With this information, Chart A-15-12 (Figure 30) was used to find the stress concentration factor, $\mathrm{K}$, in the support member. The stress concentration factor was found to be 1.6 with $\mathrm{d} / \mathrm{w}=$ .587 and $\mathrm{h} / \mathrm{w}=1$. Equation 11 was used to find the maximum stress with $\mathrm{K}=1.6$.

$$
\begin{array}{cc}
\boldsymbol{A}=(\boldsymbol{w}-\boldsymbol{d}) \boldsymbol{t}=(\mathbf{0 . 3 7 5}-.22) .25 & \text { Equation } 9 \\
=\mathbf{0 . 0 3 8 7 5} \boldsymbol{~ i n}^{2} & \\
\boldsymbol{\sigma}_{\mathbf{0}}=\frac{\boldsymbol{F}}{\boldsymbol{A}}=\frac{\mathbf{1 0 3 . 8} \boldsymbol{l b}}{\mathbf{0 . 0 3 8 7 5} \boldsymbol{~ i n}^{2}}=\mathbf{2 , 6 7 8 . 7} \mathbf{p s i} & \text { Equation } 10
\end{array}
$$
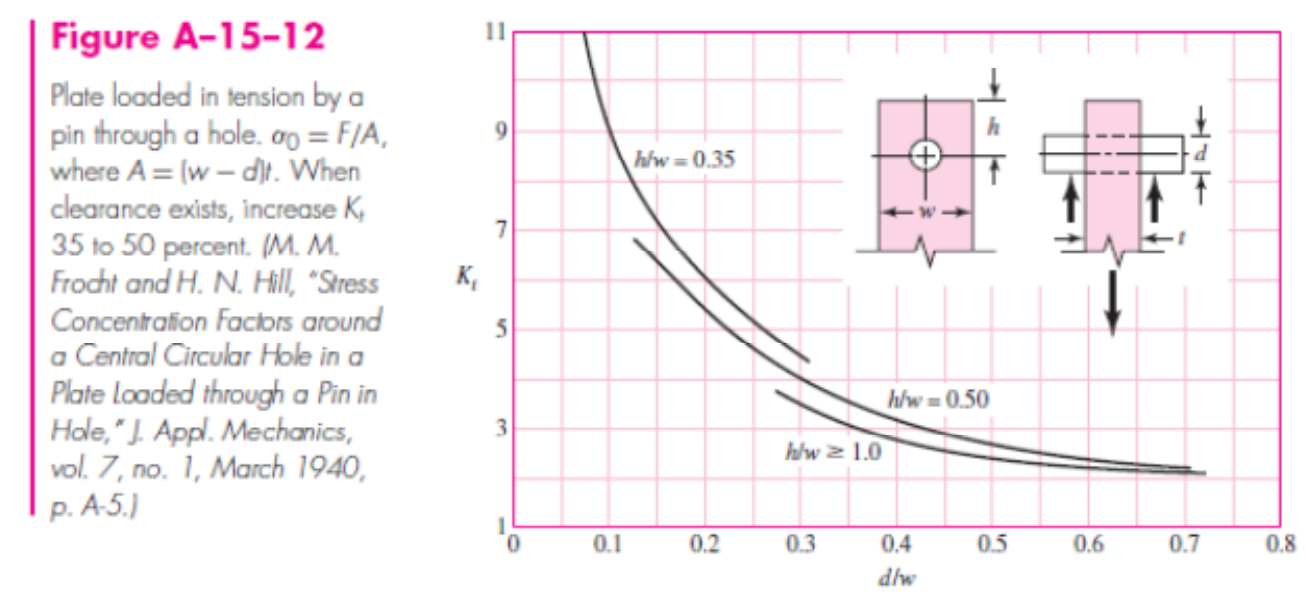

Figure 30: Shigley's Textbook, Plate Loaded in Tension by a Pin Through a Hole (Budynas, 2010)

$$
\begin{aligned}
& \sigma_{\max }=K * \sigma_{0}=1.6 * 2,678.7 p s i \quad \text { Equation } 11 \\
& =4,285.9 \mathrm{psi}
\end{aligned}
$$

Since 4,285.9, or the maximum force that the end of the rod would experience due to this stress concentration, the part was considered to be very safe (Factor of Safety $\sim 9$ ).

With the support member verified for safety, the next area of concern was the clevis attaching the actuator to the base plate. The clevis bracket was made of steel ( $\mathrm{S}_{\mathrm{y}}$ of $\left.65000 \mathrm{psi}\right)$. Based on the geometry of $\mathrm{d}=0.25, \mathrm{w}=0.65, \mathrm{~h}=0.125$ and $\mathrm{t}=0.0625$, the stress concentration around the mounting hole was verified to be well within the yielding limits. Using Equations 2, 
$3, \& 4$, the stress concentration factor was found to be 2.9 with a factor of safety of 5.5 . This means that the clevis was also safe to use.

Using Equations 2, 3, \& 4 again, the top and bottom brackets were tested next. The brackets had holes and a slots being loaded in the same manner (Figure 30). With the geometry of $\mathrm{d}=0.22, \mathrm{w}=0.5, \mathrm{t}=0.0625$ and $\mathrm{h}=0.125$ the stress concentration was found to be 3.05 and the factor of safety to be 2.32 . Because this part is made from aluminum, it will yield sooner than the steel clevis, hence the lower factor of safety.

The last component under direct force load is the cross member that attaches the actuator to the support members. This component was loaded in classic three-point bending at modeled as such. The part was made from 18-8 stainless steel having a $S_{y}$ of 75,000 psi. The maximum stress in three-point bending scenario can be found using Equation 12.

$$
\sigma=\frac{P L}{\pi R^{3}}
$$

The geometry used in Equation 12 were $\mathrm{L}=2$ ", $\mathrm{P}=103.8 \mathrm{lbs}$, and $\mathrm{R}=0.11$ providing stress to be 63,300 psi for a factor of safety of 1.57 . This low safety factor is not desirably high, but sufficient. To help combat the possibility of yielding, the span (L) could be shortened to lower the stress experience by the beam.

With all the components designed, the actuator appropriately sized, and the components verified for safety, the initial prototype of the miniature pneumatic lift was ready to be built.

\subsubsection{Fixation Plate}

The second major component of the design is the fixation plate (FP). The function of the FP is to provide a large, stable platform for the MPL to press against to provide the necessary resistance. The FP needed to be lightweight, durable, and extremely rigid. The plate needs to be 
extremely rigid because every tenth of an inch could be crucial loss in the overall deflection needed to collapse the aorta. For these reasons, the materials were narrowed down to two: aluminum sheet metal or a carbon-fiber reinforced composite structure (CFRC). Aluminum has advantages such as being much cheaper for a price per unit and much easier to work with, but it lacks the tailorability and weight to strength ratio that composite have. Composites on the other hand, have great tailorability and strength properties, but are very expensive and can be hard to work with. To determine the appropriate material to use, a series of comparisons were made such as mechanical property, deflection calculations, and cost analysis.

\subsubsection{Mechanical Properties}

To compare the mechanical properties of both materials, some basic background on both materials is needed. Mechanical properties of materials are often given in relation to stress and strain values. Stress relates to the force and the amount of the material there. Strain relates the change in the length of the material due to the force applied. Also related to strain is Possion's ratio or the ratio of decreased cross-sectional area compared to the elongation. A typical stress versus strain curve of a linear elastic material is shown to aid in visualization of material properties (Figure 31). As the force increases, so does the stress. As a result, the material elongates creating strain and moves along the $\mathrm{x}$-axis. The linear region of the graph is called the elastic region as the material can return to its original shape once the force is removed. The slop of the line is taken to provide the Young's Modulus, a very important mechanical property. Once the yielding point is reached, the material moves into the plastic region, or the region where the material is permanently deformed. The material undergoes structural reorganization on a microscopic level called strain hardening. This hardening is done until the ultimate strength is reached. After that point the material weakens until fracture, or breaking. The important 
mechanical properties of any material are therefore yield strength $\left(\mathrm{S}_{\mathrm{y}}\right)$, ultimate strength $\left(\mathrm{S}_{\mathrm{U}}\right)$, Young's Modulus (E), and Possion's Ratio (v).

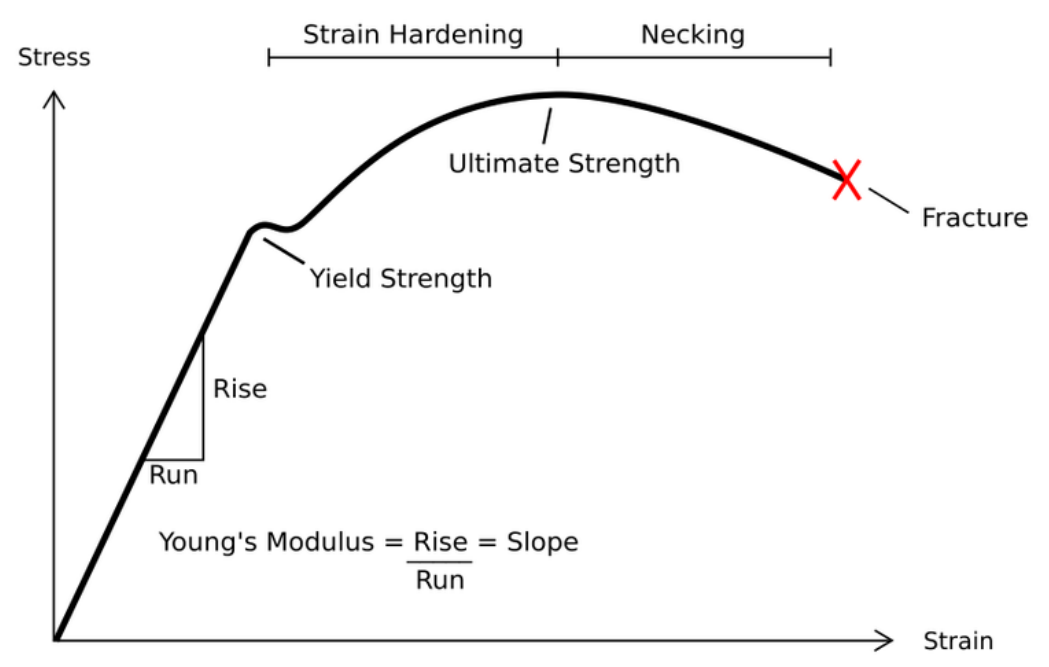

Figure 31: Typical Stress Versus Strain Curve (AutoDesk, 2011)

How these materials differ on a basic level is the composition. Aluminum is considered to be isotropic, or assumed to have the same properties in all directions. Although any material cannot be completely isotropic due to imperfections such as impurities or dislocations, it is safe to assume aluminum is isotropic compared to carbon fiber. CFRC is said to be the opposite or anisotropic, not the same in all directions. This directional variance is caused by the fiber alignment when compared to the perpendicular plan. Carbon is extremely strong and therefore exhibits excellent strength in the direction of the fiber. However, the fibers are usually held together by an epoxy matrix which exhibits much lower mechanical properties. Therefore, since the strength is dependent on the direction force is applied, CFRC are anisotropic. To help better demonstrate this, Table 8 shows the mechanical properties of both aluminum and CFRC. 
Table 8: Mechanical Properties of Aluminum and Carbon-Fiber Reinforced Composite

\begin{tabular}{|c|c|c|}
\hline Mechanical Property & Aluminum* & CFRC *** \\
\hline $\begin{array}{l}\text { Ultimate Longitudinal Tensile Strength ( } \text { S }_{\text {UTS }} \\
\text { 1) }\end{array}$ & $45 \mathrm{ksi}$ & $280 \mathrm{ksi}$ \\
\hline Ultimate Transverse Tensile Strength $\left(\mathbf{S}_{\mathrm{UTS} 2}\right)$ & $45 \mathrm{ksi}$ & $8.3 \mathrm{ksi}$ \\
\hline Longitudinal Modulus $\left(\mathrm{E}_{1}\right)$ & 10 Msi & $20 \quad$ Msi \\
\hline Transverse Modulus $\left(\mathbf{E}_{2}\right)$ & 10 Msi & 1.4 Msi \\
\hline Major Possion's Ratio ( $\mathbf{v}_{12}$ ) & 0.334 & 0.30 \\
\hline Minor Possion's Ratio $\left(\mathbf{v}_{21}\right)$ & 0.334 & 0.021 \\
\hline Density & $0.097 \mathrm{lb} / \mathrm{in}^{3}$ & $0.057 \mathrm{lb} / \mathrm{in}^{3}$ \\
\hline
\end{tabular}

*Material Properties taken from Shigley's Mechanical Engineering Design, $9^{\text {th }}$ Edition (Budynas, 2010)

**Material Properties take from Dr. Joseph Mello’s Lecture (Mello, 2011a)

\subsubsection{Deflection}

With a better understanding of the mechanical properties of both aluminum and CFRCs, the difference in deflection will be of great value to determining an appropriate material. Simplifications will be made to the geometry and beam theory will be used to determine the deflections. Using beam theory, a series of assumptions must be made. For example, the strap pressure acting on the both attached edges with a constant force was considered a consistent direction, one side of attached sides was assumed to be pinned while the other side was assumed to be on a roller, and the force acting on the device from the MPL was represented as a point force (Figure 32). Using these simplifications, it was possible to calculate the static loading forces. The know force "F" from literature (Blaivas et al., 2006) was taken as point load of 120 lbs acting at the midpoint of the beam. By symmetry, it is known that both reaction forces $\mathrm{F}_{\mathrm{y}}$ are equivalent and equal to $60 \mathrm{lbs}$. Next, using the Chueng model, it was found the angle that the strap would be pulling on the FP to be $\theta=47.5^{\circ}$ (Figure 32). Using basic trigonometry, $F_{x}$ and $F_{s}$ were found to be $55 \mathrm{lbs}$ and $81.4 \mathrm{lbs}$ respectively. Then, Equation 13 was used to find the maximum deflection at the center for both aluminum and CFRC. 


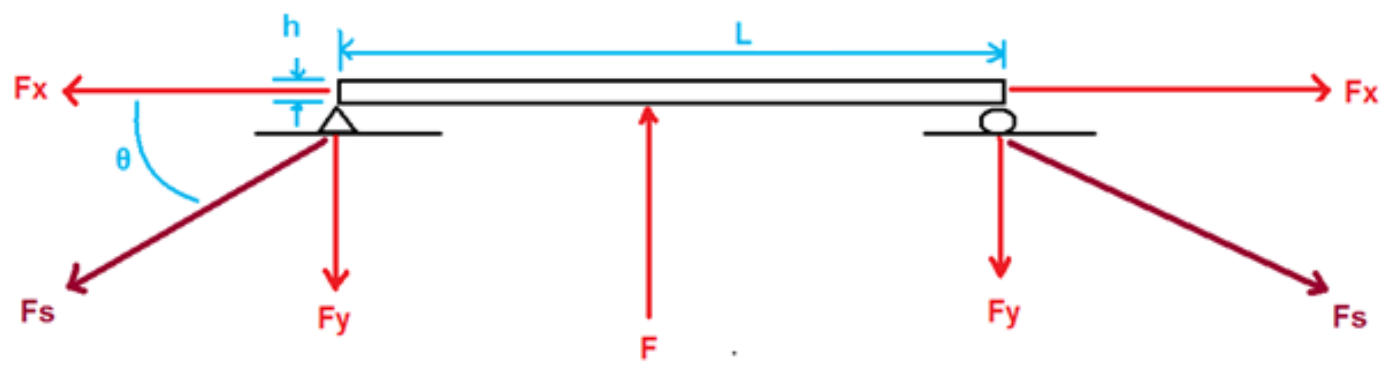

Figure 32: Simplified 2D Representation of the Junctional Tourniquet Device

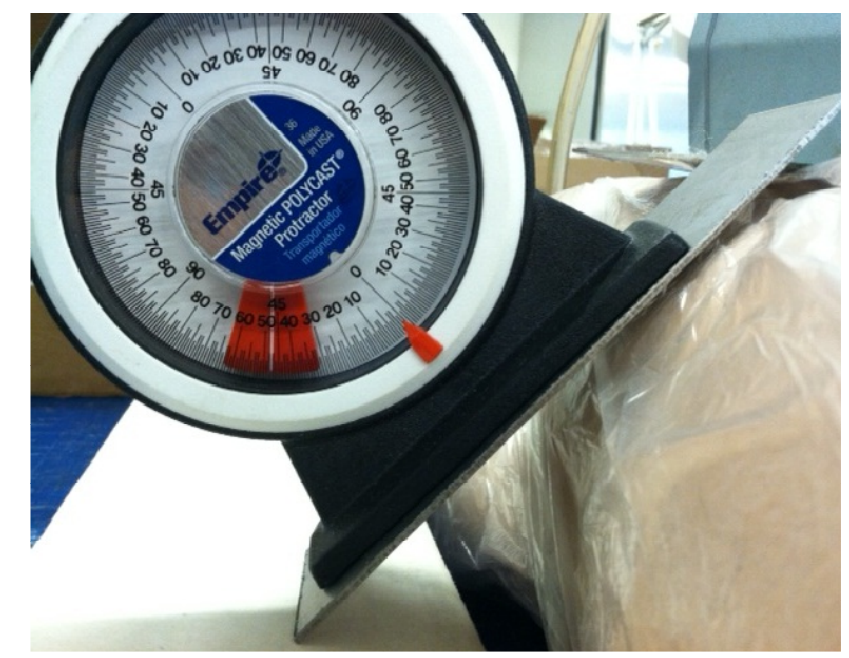

Figure 33: Approximation of Angle Theta Strap would Apply Force to Fixation Plate

$$
y_{\max }=\frac{F L^{3}}{48 E I}
$$

Using geometry, known values, and mechanical properties, the deflections were found for the simplified fixation plate model. It can be seen in Equation 13 that the mechanical properties are a contributing role to the deflections. The force used in the deflection calculation was 120 as it is the $\mathrm{F}$ in Equation 13 is for the force in the middle of the beam. The length, L, was taken from the geometry as 8 inches. The moduli are known and taken from Table 8 with $\mathrm{E}_{1}$ used for CFRC since the load will be in the fiber direction. The term "I" is a geometric factor called the moment of inertia and is calculated by Equation 14. "I" incorporates the thickness of the material 
being deflected and becomes important to understand when minimizing the weight. In Equation 14 , " $\mathrm{b}$ " is defined as the width of the cross-section (6.25 inches) and $\mathrm{h}$ is defined by the thickness. Using Equation 13 and Equation 14, the moment of inertia was calculated to find the deflection for both materials at various thicknesses using classic beam theory. To further evaluate the deflection of carbon fiber, plate theory was used assuming that the plate is wide, fixed on one end, and on a roller on the other. Plate theory relates moments and forces to line loads, line moments to relate stress to curvature. To aid in the calculations, the calculation software, MATLAB, was used to input initial conditions such as number of plies (thickness), line load from the strap in the $\mathrm{x}$-direction $\left(\mathrm{N}_{\mathrm{x}}\right)$, and the line moment created around the connections $\left(\mathrm{M}_{\mathrm{x}}\right)$ to find the deflections. The deflections were then analyzed with the MATLAB code being labeled as "Advanced Modeling" (Figure 34). The MATLAB code was extracted from Dr. Joseph Mello's lectures in the Spring of 2011 and the code can be seen in Appendix C. A trend can be seen displaying that as thickness decreases (Figure 34), the deflections increases. To provide a comparison to the deflection, the weight of the material was also included using Equation 15 (Figure 35).

$$
\begin{gathered}
I=\frac{1}{12} b h^{3} \\
\text { Weight }=\text { Density } * \text { Volume }
\end{gathered}
$$

\section{Equation 14}

Equation 15 


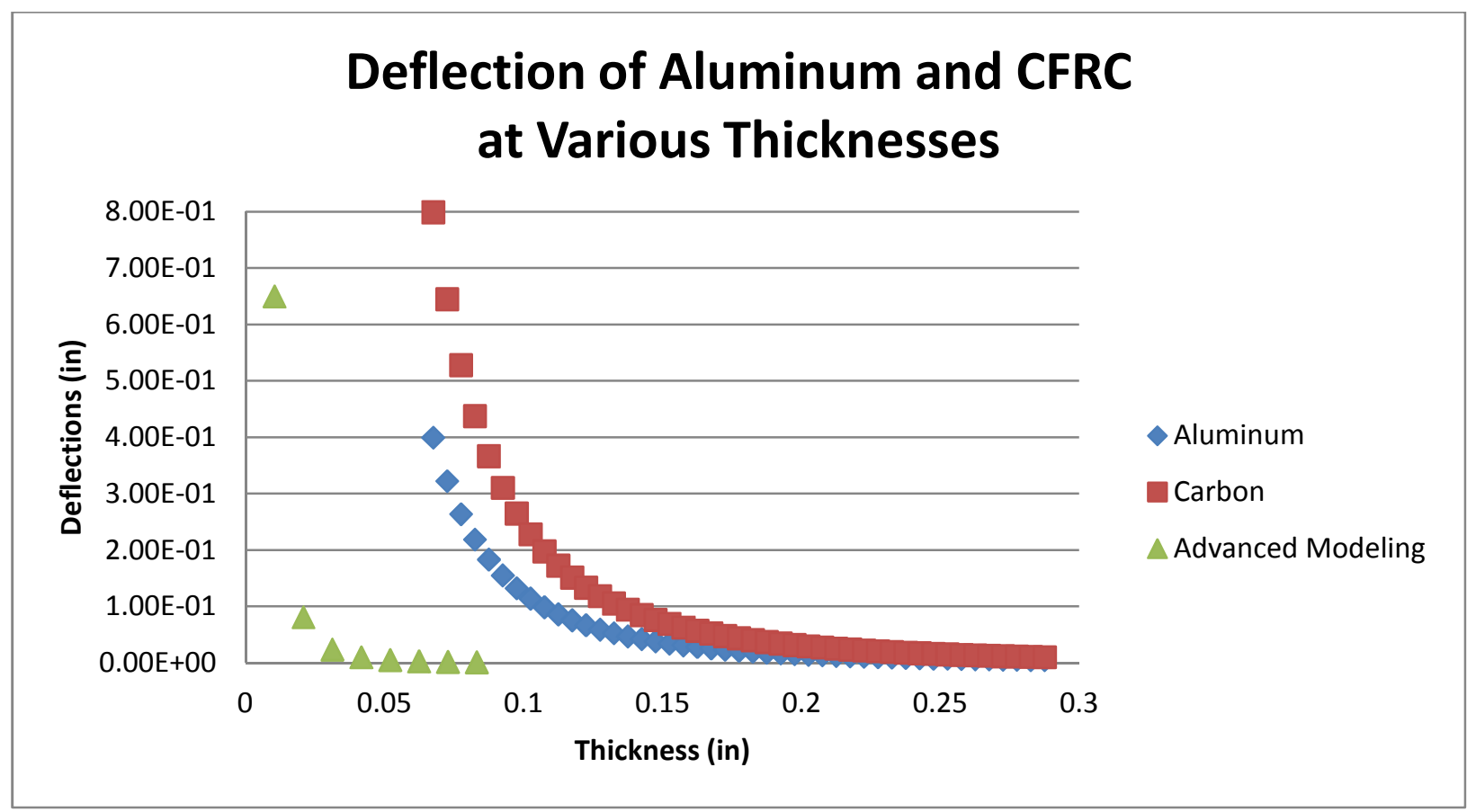

Figure 34: Deflection of Aluminum and CFRC at Various Thicknesses

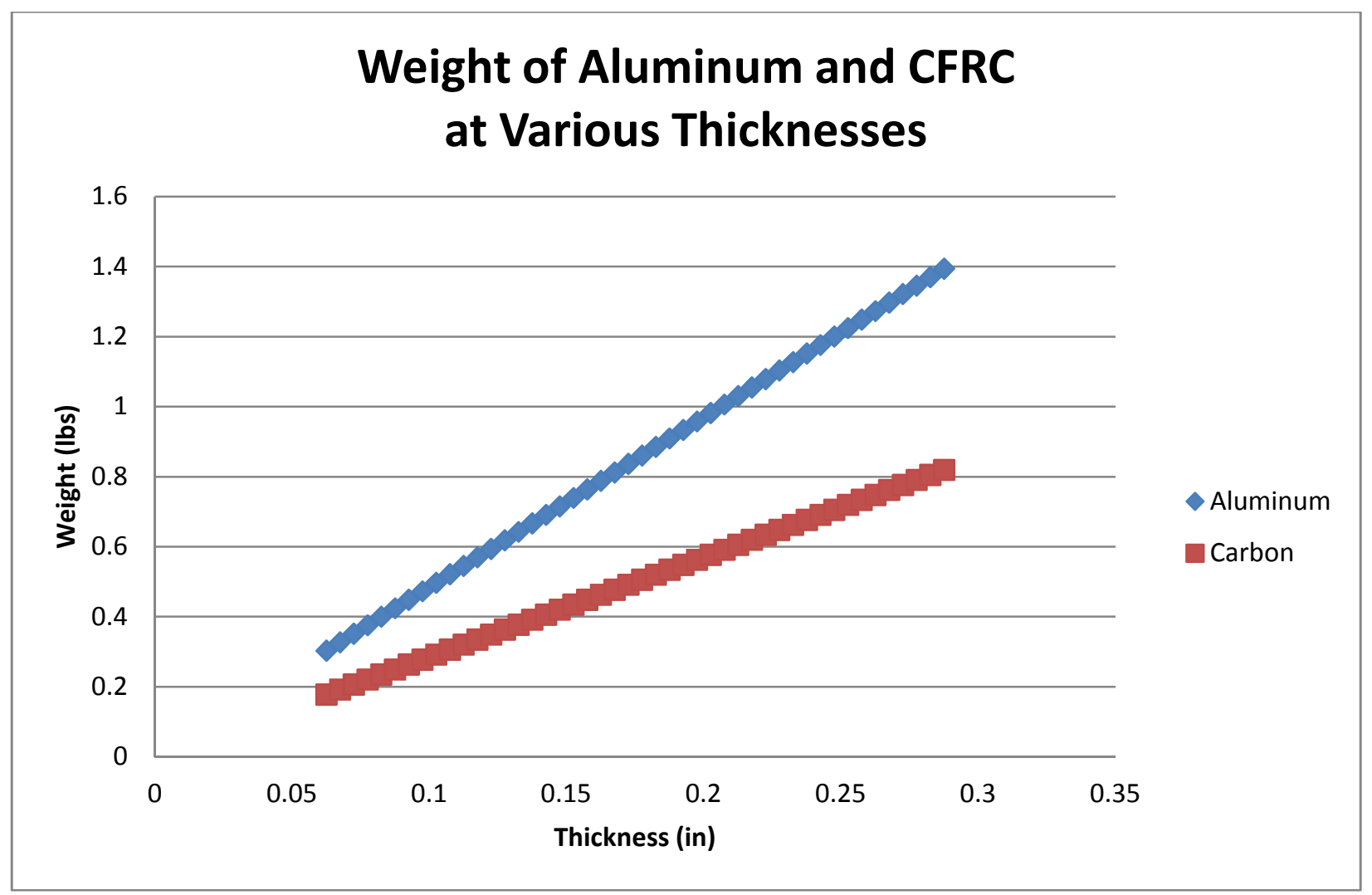

Figure 35: Weight of Aluminum and CFRC at Various Thicknesses 
Due to the fact that unidirectional carbon fiber composites are so thin, using a Nomex honeycomb core was considered to help increase the thickness and benefit the stiffness versus weight ratio. Use of core in the CFRC provides structure rigidity by increasing thickness, $h$, and therefore greatly increases "I." This increase in thickness provides an exponential increase in rigidity correlating to an exponential decrease in deflection (Figure 36). The addition of the core would not add much weight, but greatly increase the structural rigidity. As previously mentioned the rigidity is crucial to the overall functionality of the device and was considered a worth-while investment.

\begin{tabular}{|c|c|c|c|}
\hline & $\begin{array}{l}\text { Solid Material } \\
\text { L }\end{array}$ & 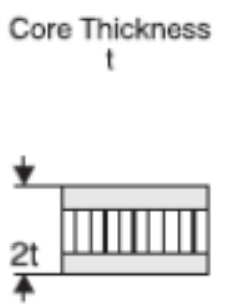 & $\begin{array}{l}\text { Core Thickness } \\
+ \\
+\end{array}$ \\
\hline Stiffness & 1.0 & 7.0 & 37.0 \\
\hline $\begin{array}{l}\text { Flexural } \\
\text { Strength }\end{array}$ & 1.0 & 3.5 & 9.2 \\
\hline Weight & 1.0 & 1.03 & 1.06 \\
\hline
\end{tabular}

Figure 36: Relative Stiffness and Weight of Sandwich Panels Compared to Weight (HexWeb Honeycomb Sandwich Design Technology, 2000)

\subsubsection{Cost Analysis}

Finally, the last comparison of the two materials was performed. The cost of each was considered by finding the price on the same website that parts were ordered from for the MPL, McMaster Carr. Table 9 provides a price comparison for both aluminum, carbon-fiber reinforced composite, and CFRC with Nomex honeycomb core with price per unit estimated. It can be seen that the price for aluminum is about 3.5 times cheaper than that of carbon fiber and about 5 times 
cheaper than the carbon fiber with the core. However, the use of the pre-made carbon fiber composite would save time and money compared to the cost of fabrication using raw carbon fiber and epoxy matrix. If the device was to be made in production, investing in the appropriate materials and tools would be necessary to produce carbon fiber, which too would increase overall cost of the device.

Table 9: Cost Estimate of Aluminum and CFRC

\begin{tabular}{|llll|}
\hline Material: & Dimensions: & Total Price*: & Price per in ${ }^{3}$ \\
\hline Aluminum & 1/4"X6"x6" & $\$ 72.83$ & $\$ 0.67$ \\
\hline CFRC & 1/16"x12"12" & $\$ 57.43$ & $\$ 6.38$ \\
\hline Nomex Core CFRC & 1/4"x6"x24" & $\$ 130.50$ & $\$ 3.63$ \\
\hline
\end{tabular}

* Price Quoted from McMaster Carr website (McMaster Carr, 2013)

After considering the importance of the mechanical properties, the deflection on the functionality of the device, and the potential differences in the cost per unit, it was decided that the Nomex honeycomb core carbon-fiber reinforced composite structure would be used for the prototype. Rigidity is the main function of the fixation plate and outweighs the cost increase. To help compensate for the potential limiting factor the price would cause, two different devices could be made. If the tourniquet made it to mass production, two models could be made, a composite and an aluminum device at various prices to reflect overall weight. With the material selected for the FP, the prototype was produced.

\subsubsection{Strap}

\subsubsection{Self-Adherent Strap}

To connect the two ends of the fixation plate around the patient and apply initial pressure, a premade self-adhering strap was purchased. The Universal One-Piece Circumferential Strap is made by AliMed is a 6" x76" Velcro strap that is self-adherent. The AliMed strap comes with two sections, the "hook" and "loop" sections. The two sections are color coated with the hook 
section colored red for contrast against the remainder of the blue, "looped" strap. The red hooked area can be attached anywhere or on either side of the blue looped section. The AliMed strap with both the red hook and blue loop sections are easily distinguishable and would be clear to the user (Figure 37). These large dimensions of the strap will allow it to appropriately fit within the fixation plate width and fit around a large male with extra material to double back onto itself to secure the apparatus with. The bright color contrast will make it easy for anybody to distinguish the difference the attachment site. It addition to the premade strap, a white cloth strip was added to the outside section of the strap. The purpose of this white strip is to provide the medic with a location to write a time of application and was modeled after the CAT (Belmont et al., 2010) (Figure 7).

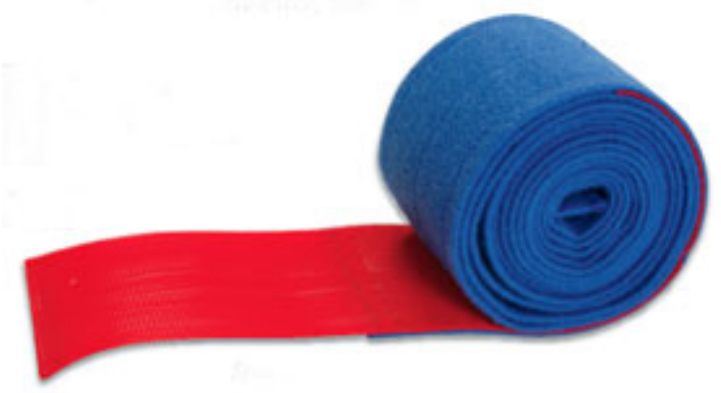

Figure 37: AliMed Universial One Direction Circumferential Strap (AliMed, 2013)

\subsubsection{Analysis of Strap}

To analyze the strap, the forces calculated in Appendix F were used with the tensile force on the strap being $81.4 \mathrm{lbs}$. The force was assumed to work in a tension for the simplified calculations but would be in fact working as a shear forced compared to the attachment mechanism of the self-adherent strap (Figure 38). Therefore, the shear strength of 14.0 psi was used taken from the Velcro specification sheet (Velcro, 2010). The strap was assumed to be in contact with at least 4 inches of itself providing an area of shear application of $24 \mathrm{in}^{2}$ resulting in a 3.4 psi stress across the strap. This stress is well below that of the rated strength of the material 
(Velcro, 2010), and has a factor of safety of about 4 . The minimum amount of area that the hook section needs to be in contact with the looped section to provide a 1.5 factor of safety is about 1.5 inches longitudinally. Therefore it is safe to use the strap as long as 1.5 inches of the red hook section is self-adhered.

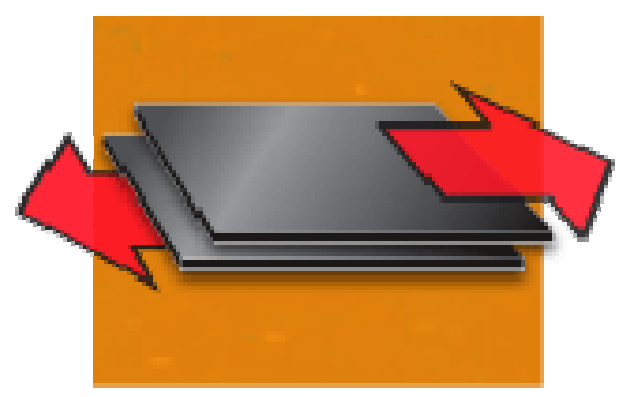

Figure 38: Demonstration of Shear Force on Velcro Strap (Velcro, 2010)

\subsection{Finite Element Analysis of the Fixation Plate:}

To more accurately measure the forces and stress to be seen in the fixation plate, a model was created in Abaqus, a finite element analysis (FEA) software. Since the device has complex geometry that would be difficult to model in the FEA software, the geometry was simplified into a $2 \mathrm{D}$ approximation and then extended to a 3D model. Due to this complex 3D geometry, the drawing was imported into Abaqus from the part designed in Solidworks (Figure B. 3). In this study, only the fixation plate was examined. Boundary conditions and forces used from the calculations in (Figure F. 1) will be applied to the edges to replicate the strap restraint. Also, the maximum pressure exerted by MPL will be modeled on the plate. To simplify the model, forces on the fixation plate were considered to be concentration loads.

\subsubsection{FEA for Fixation Plate Material selection}

First examined was the 2D beam representation to find deflections from various thicknesses and materials. Forces from Table 5: Initial Conditions and Known Parameters for Engineering 
CalculationsTable 5 were used to find the exact solution. The 2D representation was then created in Abaqus for help with material selection. The beam was modeled as a $2 \mathrm{D}$, deformable beam model. The side profile was designed to match that of the device geometry with varying thicknesses and modeled as the same the beam theory profile (Figure 32). Using the beam elements in Abaqus, 2D Shell elements were used with no thickness to provide approximate solutions. Next, the materials and sections were created and assigned to the geometry. A variety of materials, PET, PEEK, aluminum, and a carbon-fiber reinforced composite were included in the $2 \mathrm{D}$ model to help determine an appropriate material for the device. The modulus of each material was found using CES software taking the average of the range provided. Next the part was instanced, and a load application step was created in Abaqus. Then the part was meshed. Next, the loading and boundary conditions were assigned to the model. A point load at the center of the model was included to represent the piston acting of the fixation plate (

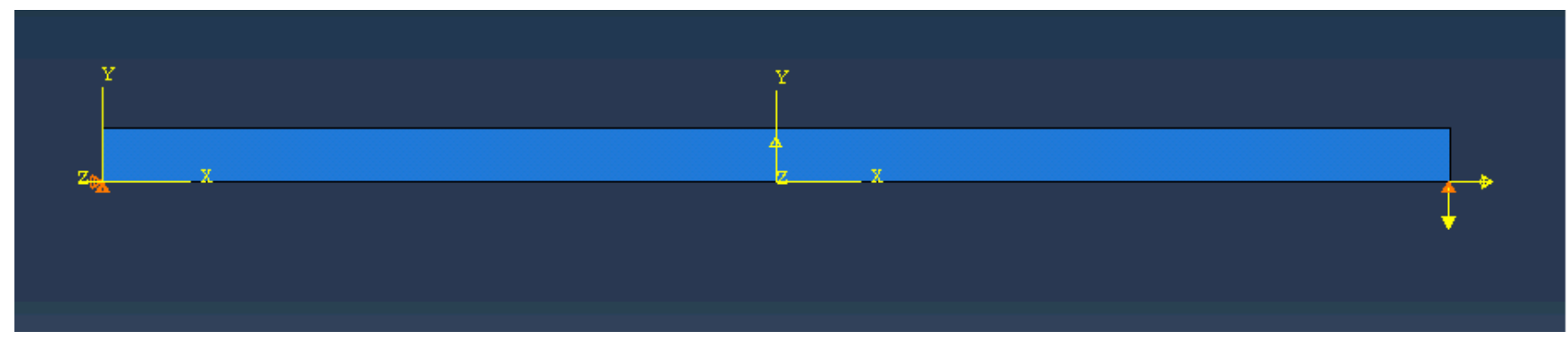

Figure 39). Also, the forces in the $\mathrm{x}$ and $\mathrm{y}$ direction were included at the bottom corners of the right and left sides of the fixation plate. The boundary conditions were also included at each bottom corner. The left side was modeled as a pinned connection, with the $\mathrm{x}$ and $\mathrm{y}$ displacements fixed but rotation was left open. The right was modeled as a roller with the $y$ direction constrained, but the $\mathrm{x}$ direction and rotation remaining free (Figure 39: 2D Experimental Set Up in Abaqus. Finally, a job was created and the model was run. with the different materials. 


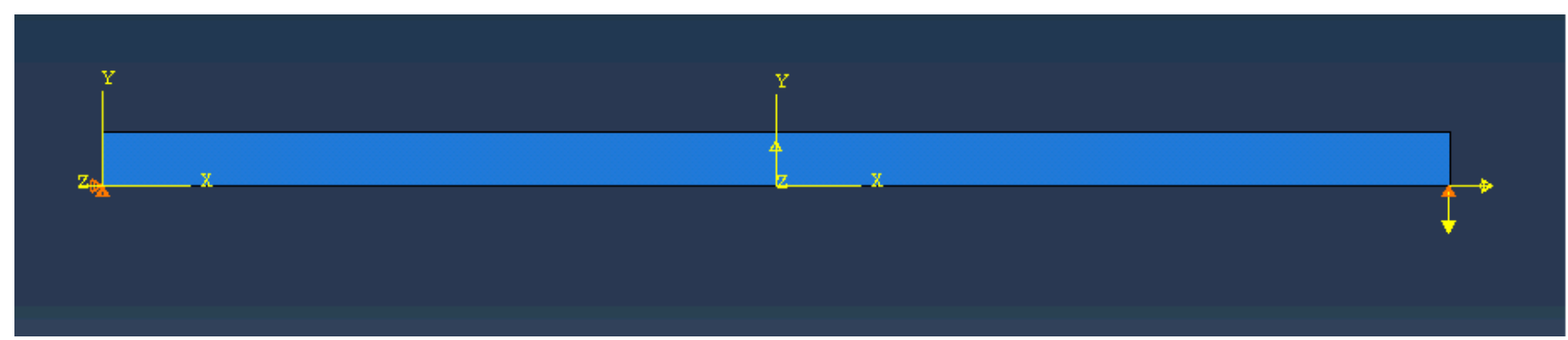

Figure 39: 2D Experimental Set Up in Abaqus

With the 2D model completed, the model was then put into $3 \mathrm{D}$ space. The process was similar to the $2 \mathrm{D}$ by creating a part (import from Solidworks), a material, a section, assigning the material, step creation, meshing, applying forces, and applying boundary conditions. However there were some differences in the construction of the model. In this model, only aluminum and a carbon fiber composite with core were used to provide the necessary stiffness. To create the carbon-fiber lay-up, the composite tool was used in Abaqus. A series of partitions were used to replicated the fiber and core dimensions. Also, the mesh needed to be altered greatly and is discussed further in section 3.4.2, "Mesh Development." The strap force was added to the model along outer edge of the the slotted hole using $F_{x}=55$ lbs. and $F_{y}=60 \mathrm{lbs}$ with the $x$-direction being tension application and 60 being reaction moments to the 120 force against abdomen (Figure F. 1). It was shown that applying loads acting in the same direction as the fixed boundary condition did not affect the results of the model. Therefore, only a force in x-direction was included as both sides were constrained in the y-direction. To replicate the force of the MPL, a partition area matching the dimensions of the top was created. Then a pressure equivalent to the force $(120 \mathrm{lbs})$ over the area of the area of the MPL lift plate $\left(24 \mathrm{in}^{2}\right)$. The part was then run and deflection was found for both the aluminum and carbon-fiber 3D parts. 


\subsubsection{Mesh Development}

After the mesh convergence study, discussed later, it was found that a seed side of 0.25 was appropriate to provide accurate data in the $2 \mathrm{D}$ model. The model was meshed with standard CPS8 elements, or an 8-node biquadratic plane stress quadrilateral element which help to better understand the deflection of the beam. The $2 \mathrm{D}$ approximation can be easily modeled using the quadrailateral elements to represent the shape. Using the quadratic based elements allows for more accurate measurements and since the geometry is so simple, this does not add much computational time. The model easily remained within the defined maximum and minimum angles of the software. The model was run using this element type and a seed size of 0.25 inches to provide the deflection and stresses in the plate. This simulation provided 266. degrees of freedom with only the CPS8 element being used.

To develop the 3D model, more complex meshing methods were used. First, to create the part in Abaqus, the part was imported from Solidworks. Then the part was partitioned to help define the mesh. The part was partioned to incorporate the composite lay-up, and was left the same for the aluminum for consistency. The part was then meshed using a biasing operation with a seed size of 0.5 inches as it was deemed an appropriate convergence point. The element type used for this analysis was the C3D8R, or the 8-node, reduced integration, hourglass control linear brick. This element provides a linear and quadrilateral mesh and is beneficial for more accurate results as previously discussed. The final model finished with 100206 degrees of 


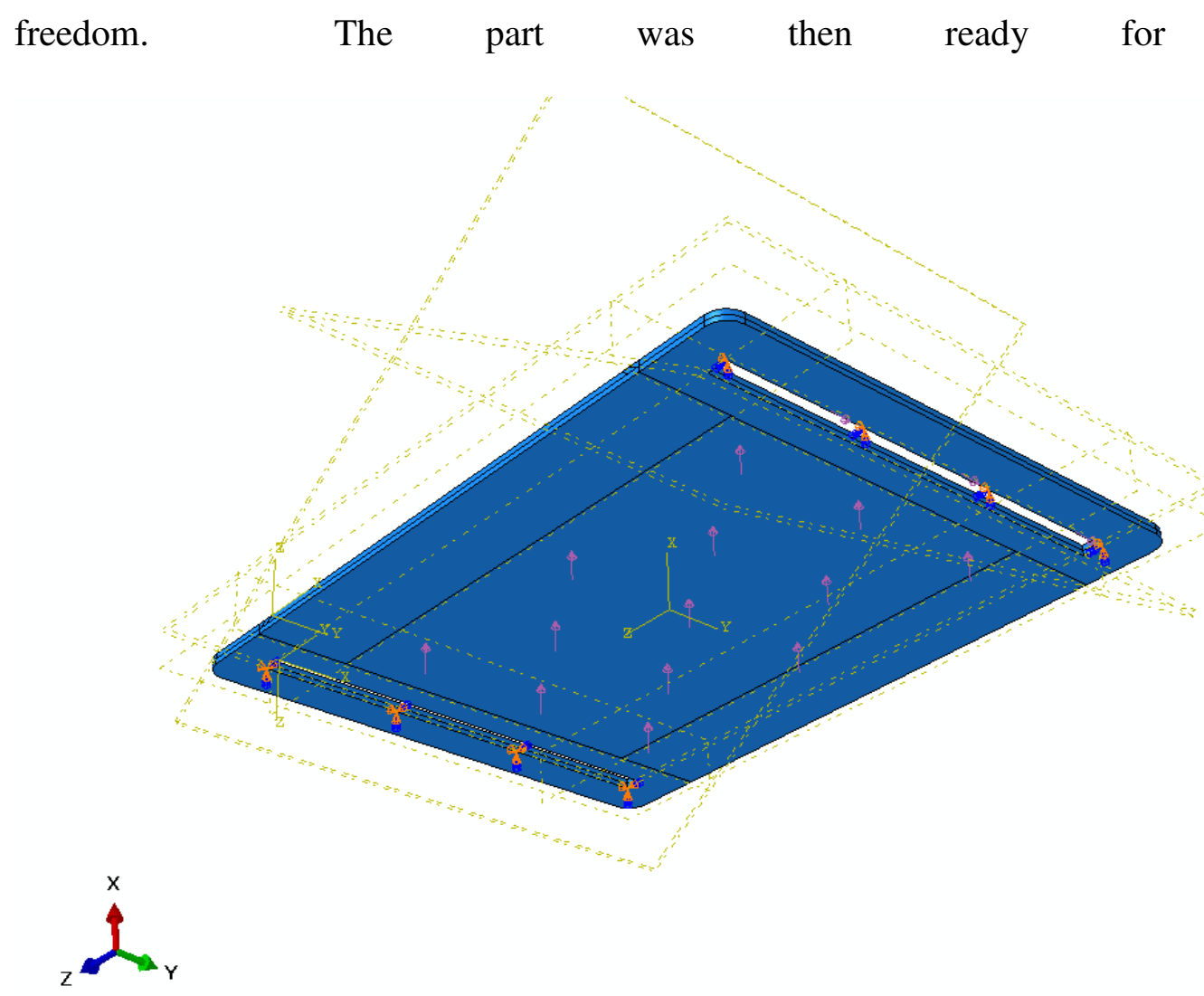

Figure 40). 


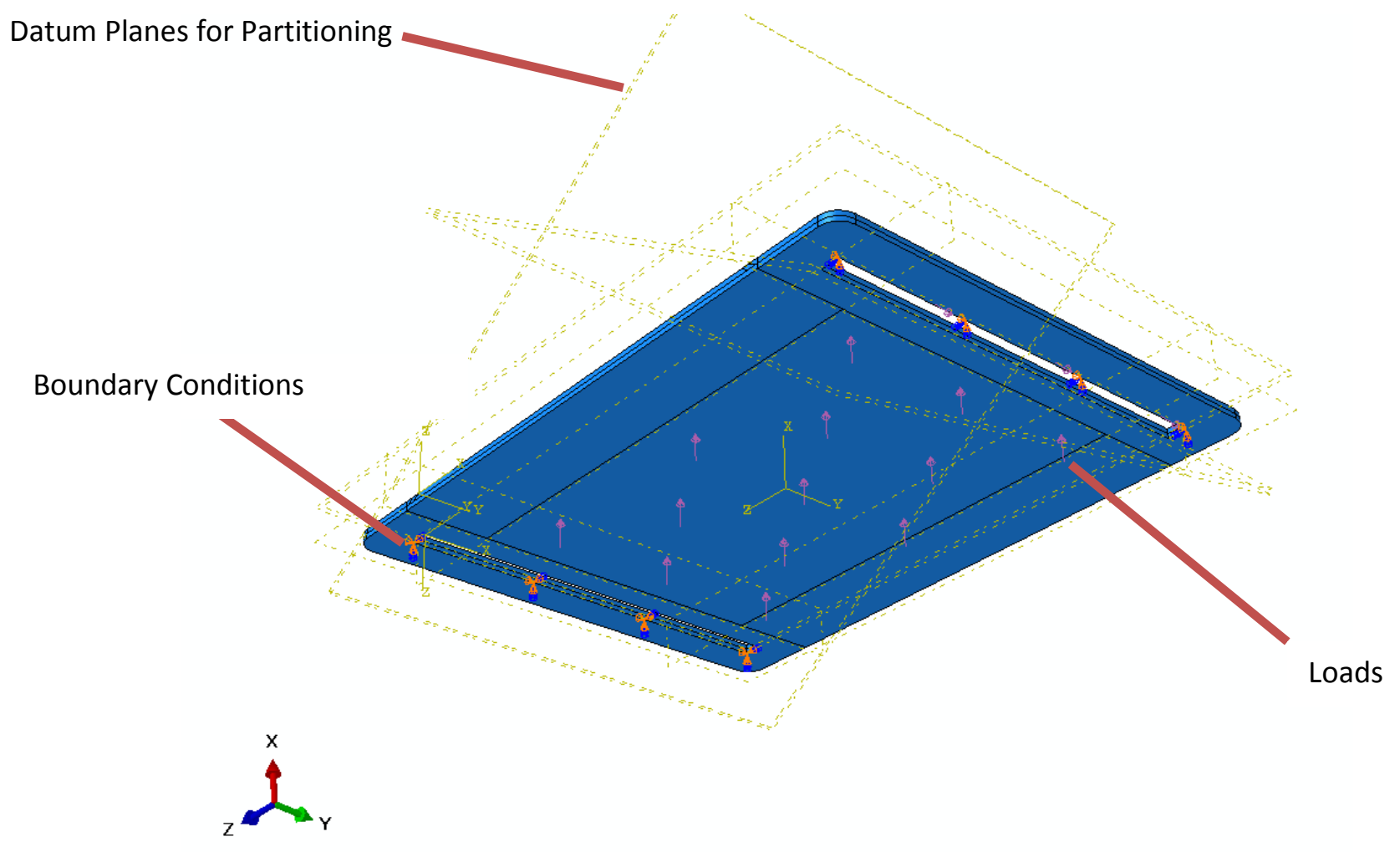

Figure 40: Meshed 3D Abaqus Model to be Analyzed.

\subsubsection{Analysis of the FEA Models}

As previously discussed, both two-dimensional and three-dimensional models where analyzed. With respect to the 2D case, the loading/boundary conditions were determined. First modeled was the fixation plate with no boundary conditions to take into account forces acting both in the $\mathrm{x}$ - and $\mathrm{y}$ - directions. However, the results were undesirable and heavily skewed. Secondly, the fixation plate was modeled to have only one side pinned while the other was loaded with the forces, however this job would not run as it would abort due to non-convergence (boundary condition problem). Third, the MPL force was considered as a "fixed" position and the forces were placed on both edges. But due to the calculation method of Abaqus, one side deflected more than the other. This model also would run through completion, but provided unrealistic results. Finally, with both sides fixed and the forces applied in the $y$ - and x-direction, the model completed providing results within an order of magnitude of the validation 
calculations. In three-dimensions, the same method of fixation and loading were used to find converging, reasonable results.

\subsubsection{Mesh Convergence}

To determine the appropriate seed size for the mesh, a mesh convergence study was conducted on both the $2 \mathrm{D}$ and $3 \mathrm{D}$ models. To determine convergence, the model was meshed using decreasing seed sizes and one element was checked for displacement for each mesh size. This displacement was then compared to the degrees of freedom found in the data file output by the Abaqus software. As the seed size decreases, and thus the element size, the degrees of freedom increases (more nodes) resulting in a changing, more accurate model representation. This change in final result due to a higher mesh quality is said to be converging to a final solution. However, to save computation time, the mesh should be small as possible while still be considered accurate.

For this study, this method of convergence was used in both the $2 \mathrm{D}$ and $3 \mathrm{D}$ case starting with a seed size of 1.5 inches. The model was meshed with this size, run, and monitored. The midpoint of the fixation plate was chosen as the point of interest. For the $2 \mathrm{D}$ case, the midpoint between the two fixed edges was chosen and the node selected was 1 (Figure 41). In the 3D case, the midpoint of both the $\mathrm{x}$ and $\mathrm{y}$ direction (z-axis being normal to the thickness) was chosen being node 14903 (Figure 42). The seed size of 1.5 inches was chosen because it is important to have the initial seed size larger enough to provide a point well outside of the point of convergence to demonstrate convergence. Then the element size was then reduced to 1 inch for both models, meshed, re-run, and the displacement was found at the same node as before in both cases. Again the seed size was reduced further to $1,0.75,0.5,0.5$, and 0.1875 inches and the deformation was found. The number of degrees of freedom were found for all seed sizes. The convergence studies 
were then graphed for both the 2D and 3D models respectively (Figure $43 \&$ Figure 44) from the raw data (Appendix B).

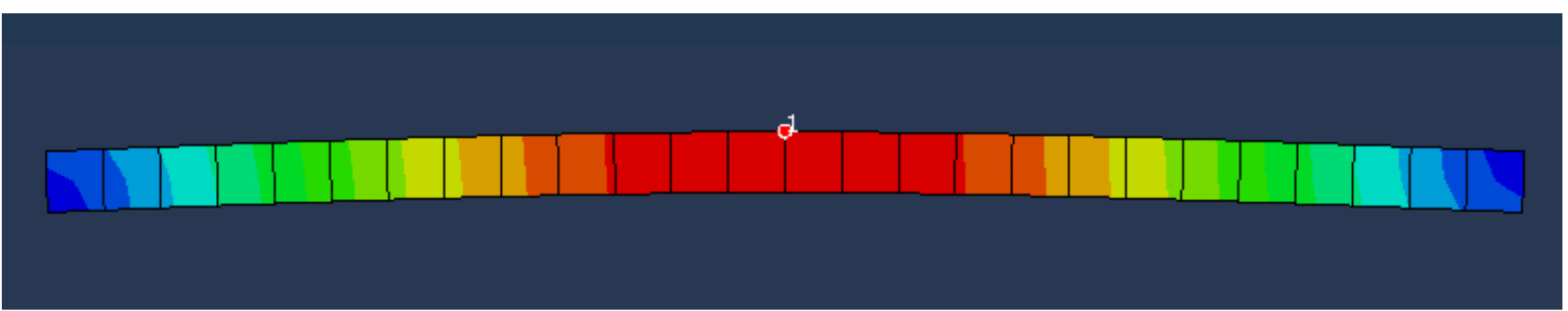

Figure 41: Node of Interest (Node 13) Queried in the 2D Convergence Study

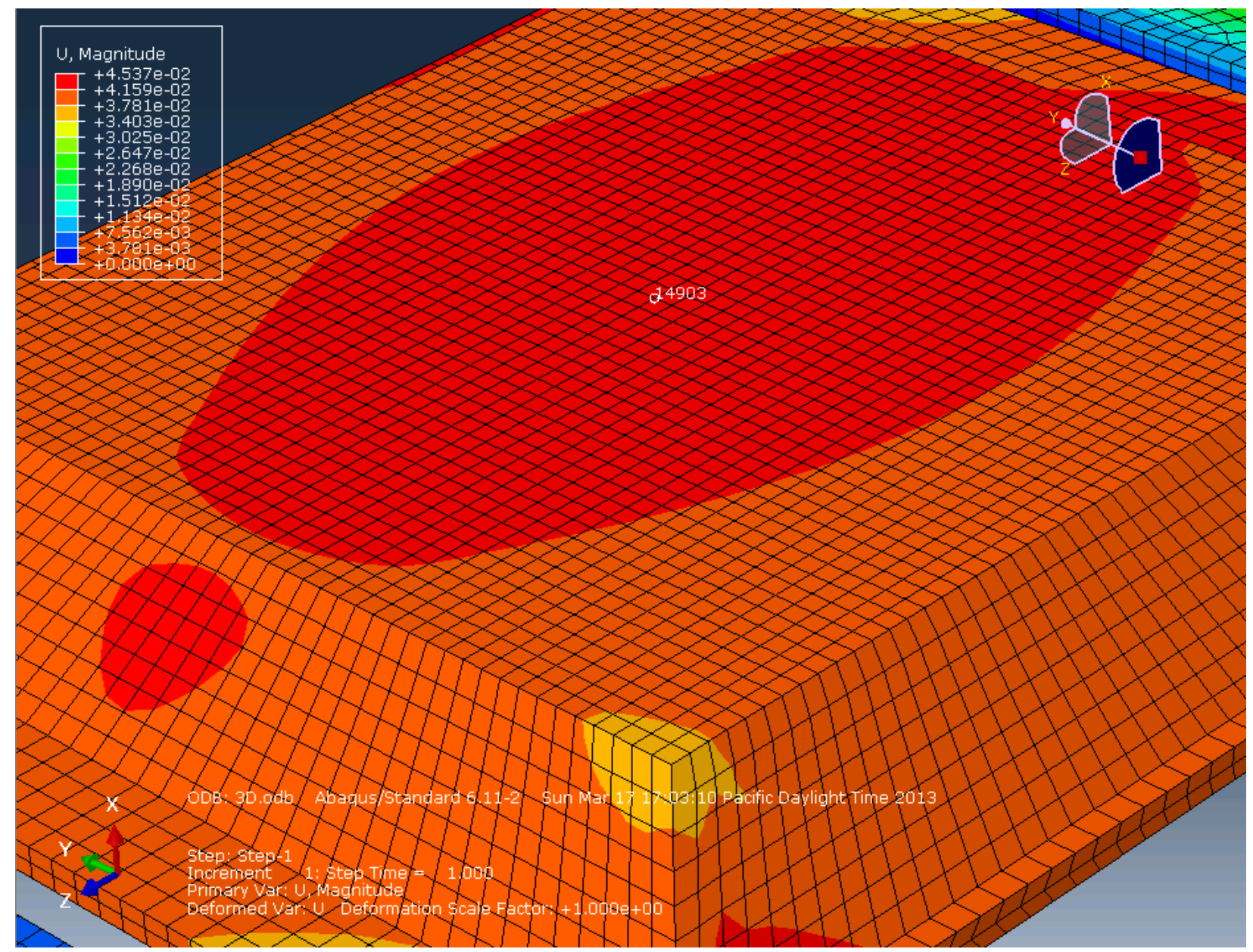

Figure 42: Node of Interest (Node 14903) Queried in the 3D Convergence Study 


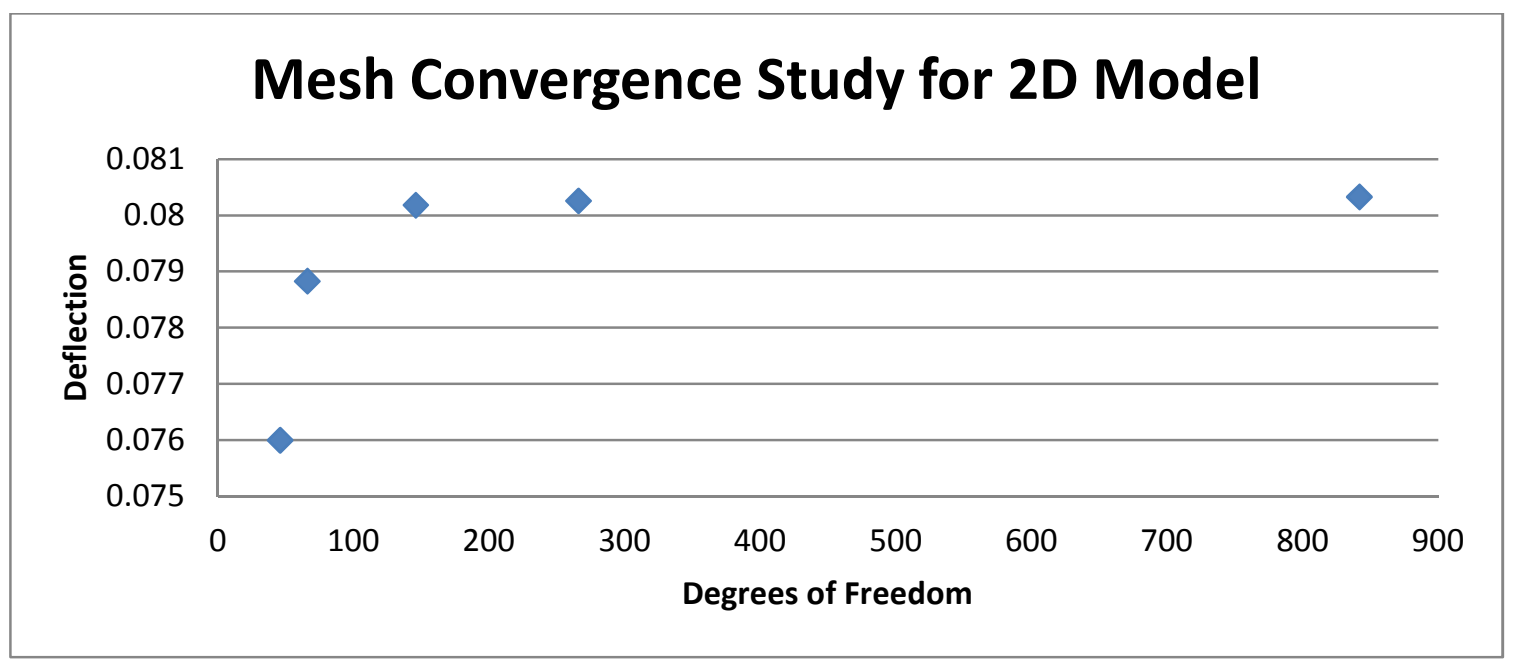

Figure 43: Mesh Convergence Study of the 2D Model

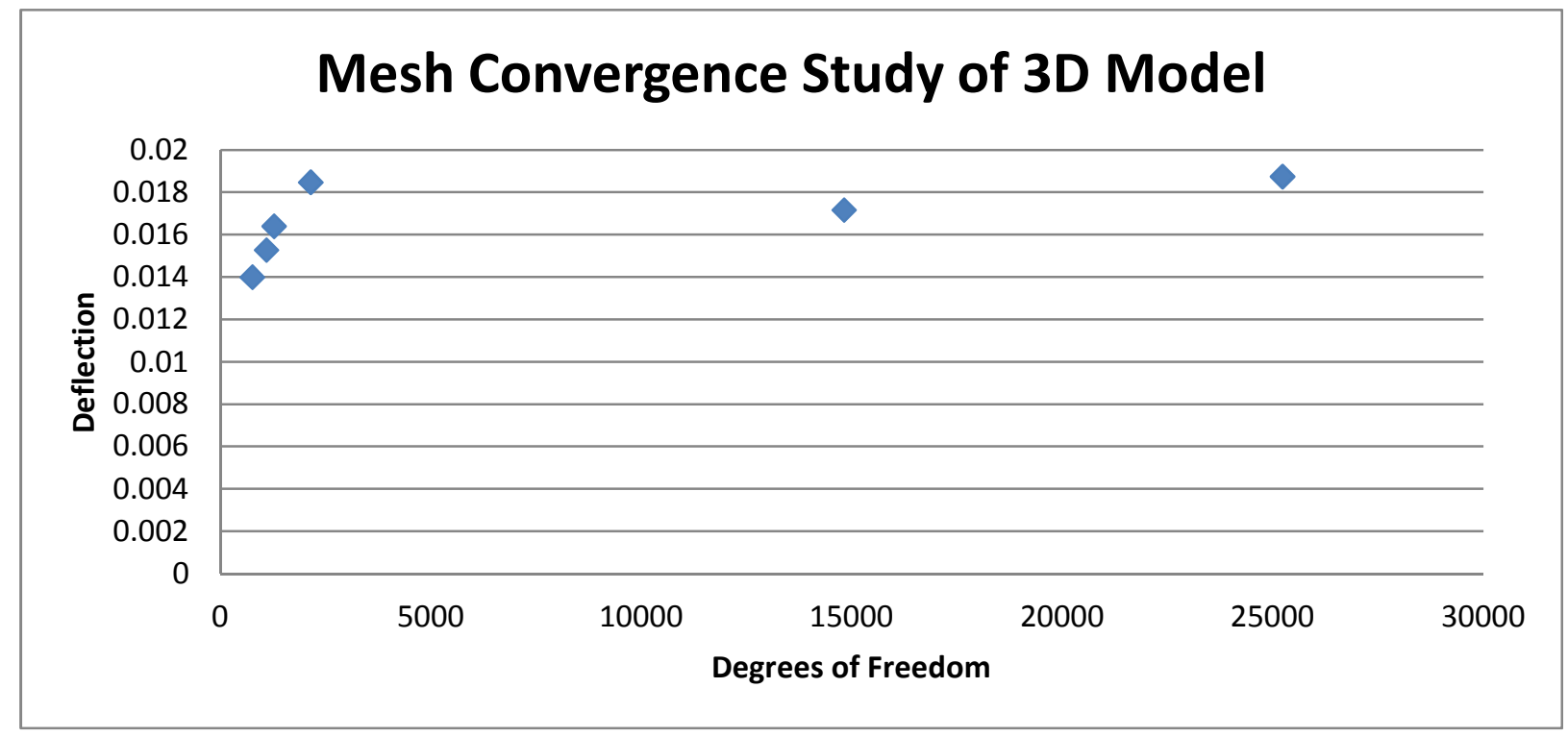

Figure 44: Mesh Convergence Study of the 3D Model

With the mesh convergence study complete, it was found that the $2 \mathrm{D}$ model converged at 0.25 inches and the $3 \mathrm{D}$ model converged quicker at 0.375 inches. These seed size used were then used to find the final displacements and stresses within the fixation plate. With the mesh size determined, there still remain limitations to the convergence study. Choosing a bigger mesh size may provide results that are not exact. To combat this issue, a more robust element type can be 
chosen. However this too adds to the computational time. Modeling requires compromise to create the most accurate analysis possible. Also, in the 3D model, the addition of a circular partition creates complex element shapes. All elements remained within the minimum and maximum angle constraints, but may have altered the overall solution. Therefore, the smaller seed size of 0.25 inches was used around this partition to help create a more accurate model using a single biasing mesh.

\subsection{Prototype Construction}

\subsubsection{Manufacturing of the Miniature Pneumatic Lift}

With the design for the MPL finalized, the parts were ordered and fabrication begun. The components needing to be machined were the support members, top and bottom tracks, and the top and bottom plates. To manufacture the components to the specific design, the mill, the drill press, the vertical band saw, the horizontal band saw, and an assortment of hand tools were used. Using the Solidworks drawings seen in Appendix B, the components were machined to a thousandth of an inch to ensure easy assembly. Other parts not needing to be machined, were bought off-the-shelf from McMaster Carr such as binding posts, clevis brackets, the end rod clevis, elbow connector, Schrader valve, and the rivets.

Four support members were created from 0.25 " thick aluminum bar that was 2 inches wide. The aluminum bar was cut to a length of 6 " on the vertical band saw. Then four 0.375 " thick pieces were cut on the vertical band saw providing four aluminum bars with dimensions 0.25 " 0.375 " 6 ". The bars were then milled to provide holes for the connections to other components to be made. The bars were milled using a 3/16, rounded, two-flute end mill. Each hole was milled to drawing specifications. The corners of the bars were then sanded to follow the contour of the hole using a large, metal circular sander. The parts were then ready assembly. 
Both tracks were fabricated next. The u-channels were cut to length using the horizontal band saw. The bottom tracks were milled using the same end mill as the support members. Holes were created first, with the slots being created second. Once the hole and slot were created on the corresponding track, the support members were fitted to map point of intersection during collapse. These areas of interference were marked and milled out using a 0.1875 " round, two flute end mill. The parts were re-fitted for accuracy and milled again as necessary. Once the parts binding posts fit through the tracks, the parts were joined creating a subassembly. Next, the large U-channels were milled for the top tracks. The process was the same as before for the bottom tracks, ensuring accurate passes were being taken (Figure 45). As before the part was preassembled, marked, re-milled, and fitted finally for the subassembly. Next, the bottom tracks were drilled for 4 rivets each (16 total) on the bottom surface for attachment to the base plate using the 0.125 " drill on the drill press. The top plate was also drilled with 6 holes each (12 total) for a grand total of 28 rivets and holes between the six tracks.

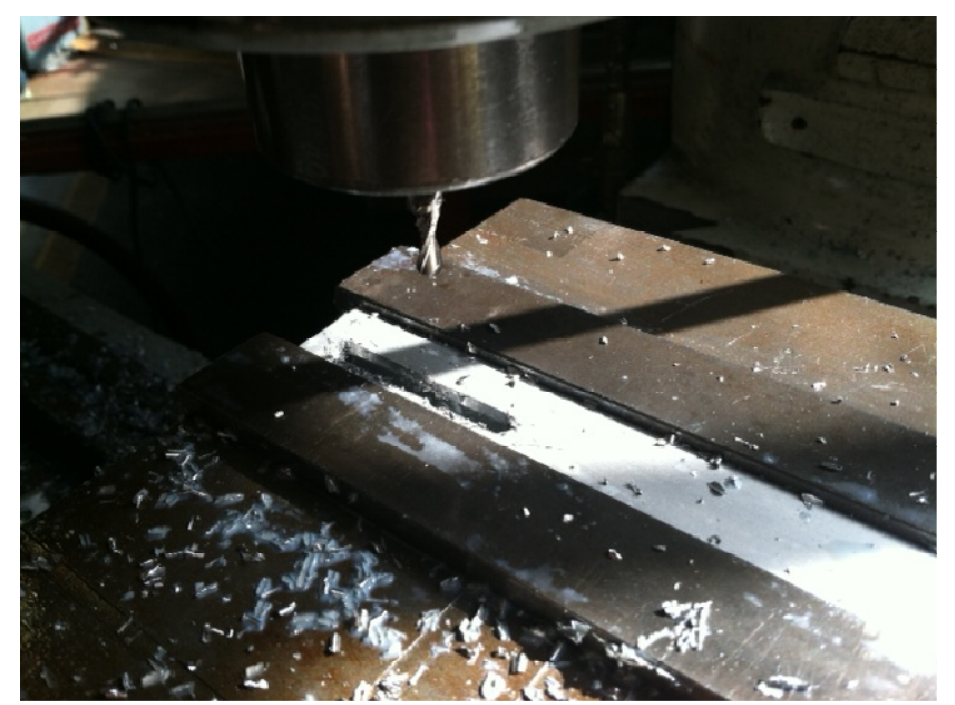

Figure 45: Milling Top Track Slots using 0.1875" End Mill

The top and bottom plates were machined next. Both the top plate and the base plate were cut to length using the horizontal band saw. The corners were then rounded for safety of the 
patient. Holes were drilled through the U-channels and through the top and base plates for rivets using the $0.125 "$ drill bit as before. The tracks and plates were drilled together to ensure alignment of the rivet holes. To attach the plates to the channels, 3/32 rivets were deployed through specified holes for each track providing a secure, stable platform for lifting. Next the holes for the clevis were drilled also using the 0.125 " drill bit. The holes on the backside, or the side not with the tracks attached, were countersunk for the rivets to be recessed in.

To finalize the assembly, the last premade components were added to the subassembly. The binding posts, bolts, washers, retaining rings, and clevis brackets were tightened, fixing these components to the base plate. The actuator was then attached to the clevis. The rod-end clevis was threaded onto the end of the actuator and the binding post connecting the two support members was run through the 0.25 " opening attaching the actuator to the moving assembly of the MPL. The remaining pressurizing components were added to the actuator such as the $90^{\circ}$ elbow, 0.25 " connector and the 0.25 " to Schrader valve stem. The threaded components to the actuator were wrapped in silicone tape to ensure an air-tight fit. With the actuator checked for proper pressurization, the miniature pneumatic lift assembly was complete (Figure 46). 


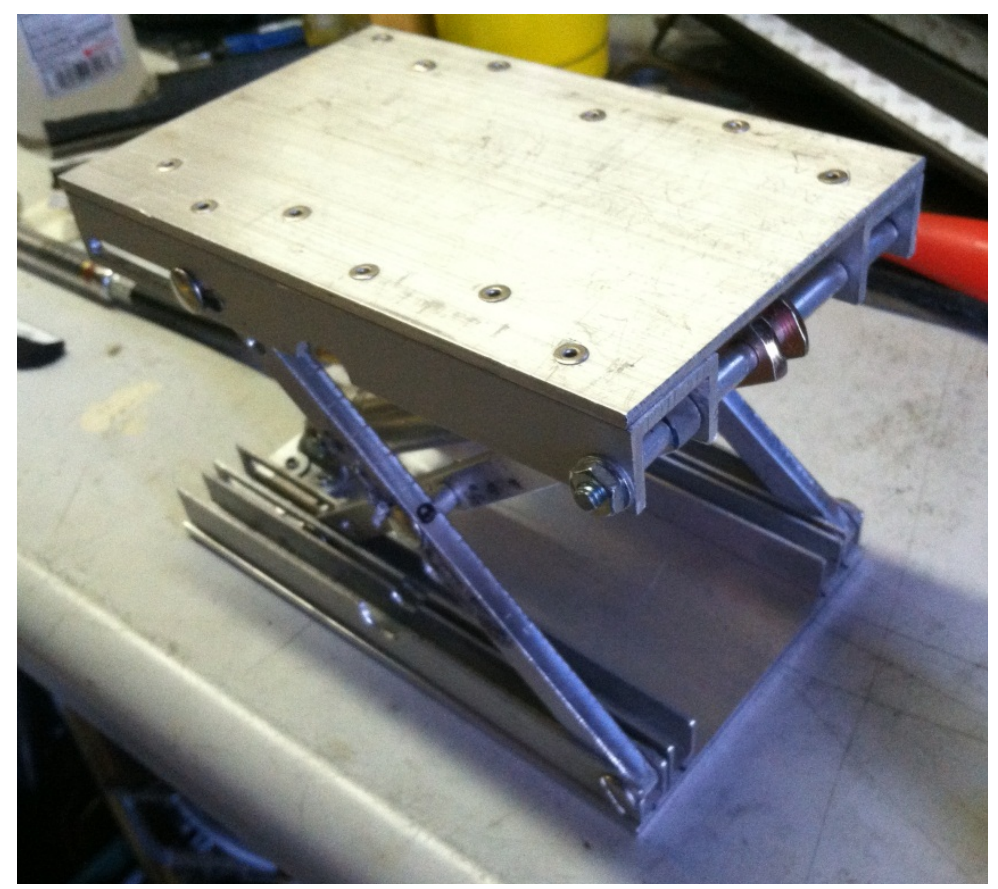

Figure 46: Expanded State of Miniature Pneumatic Lift

\subsubsection{Manufacturing of the Fixation Plate}

To begin manufacturing of the fixation plate the appropriate size was chosen. Using the geometry from the MPL and anatomic geometry, the overall dimensions of the FP were chosen to be 0.25 " $\mathrm{x} 6.25 " \mathrm{x} 8$ " as (Figure B. 3). This geometry allowed for a thin radial profile, with an appropriately sized fixation plate for stability. The width of 6.25 inches was chosen to be a maximum length while remaining safely within the constraints of the anatomy such as the pelvis and rib cage. The length of 8 inches was chosen as an accommodating dimension covering the length of the MPL and providing extra room for the attachment of the strap. With the geometry chosen, the part was produced.

The process of composite lay-up is composed of many layers and steps. The lay-up procedure used for the FP was the same as the procedure outlined in Laboratory Project 2, Appendix A by Dr. Mello (Mello, 2011b). To begin, the appropriately sizes of carbon fiber prepreg was cut from donated rolls in the composites lab in Building 192, room 135 (192-135). 
Prepreg, or pre-impregnated carbon fiber sheets are sheet in which the epoxy has been impregnated into the sheet. Heat and pressure allow the epoxy to flow, fill the voids, and cure creating a CFRC. This is the easiest and cheapest way to create CFRC. The prepreg used in this part was a RS-42X unidirectional prepreg from YLA, Inc. With the prepreg cut to size, the plies were added together as (Figure 47). Stacks of 5 plies then underwent the process called "debulking," or drawing a vacuum on the sheet to help remove any air bubble between plies. Each stack was debulked for 3-5 minutes using a premade debulking set up in 192-135. Then two stacks of 5 were added together creating a stack of 10 and debulked. Next, an adhesive film, 3M Structural Adhesive Film BMS 8-193 G Type I was placed on the carbon fiber layup to attached the core and balsa wood chamfer pieces to the bottom layer (Figure 48). Balsa wood was used as a chamfer between the base and the thickness of the core as it is extremely lightweight and easy to work with. It is important to mention that the unidirectional direction was made parallel to the length of the part to follow the force flow through the part. Another adhesive film was layer over the top to attach the top layers to the core and balsa. The top layers were then added to part. A custom caul plate, or plate that applies uniform pressure to the part while being drawn on a vacuum, was manufactured specifically for this part. A 0.0625 inch steel sheet was notched and bent to the same chamfered shape as the core-balsa complex. The custom caul plate was then placed on top of the part and drawn to debulk the material (Figure 49). 


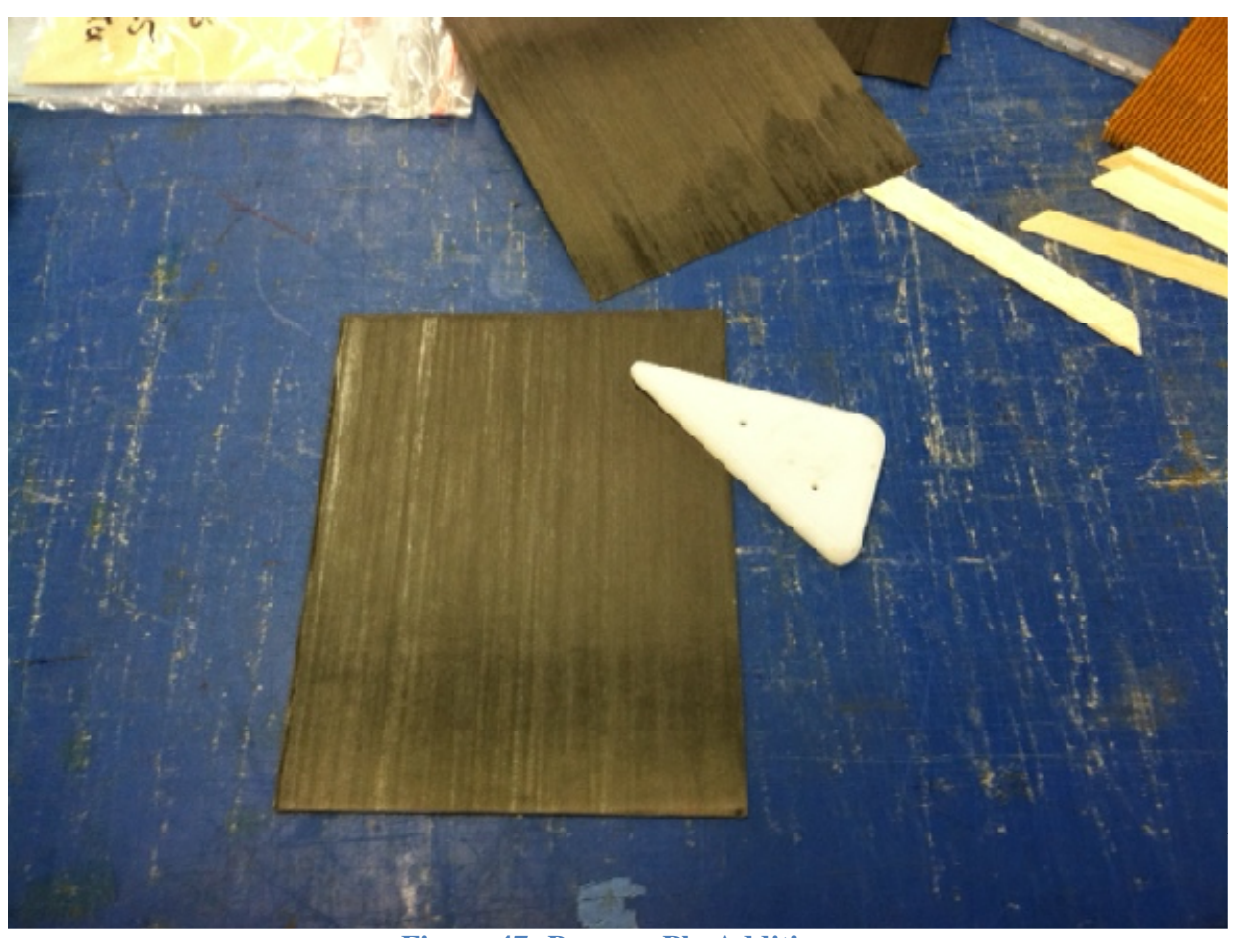

Figure 47: Prepreg Ply Addition

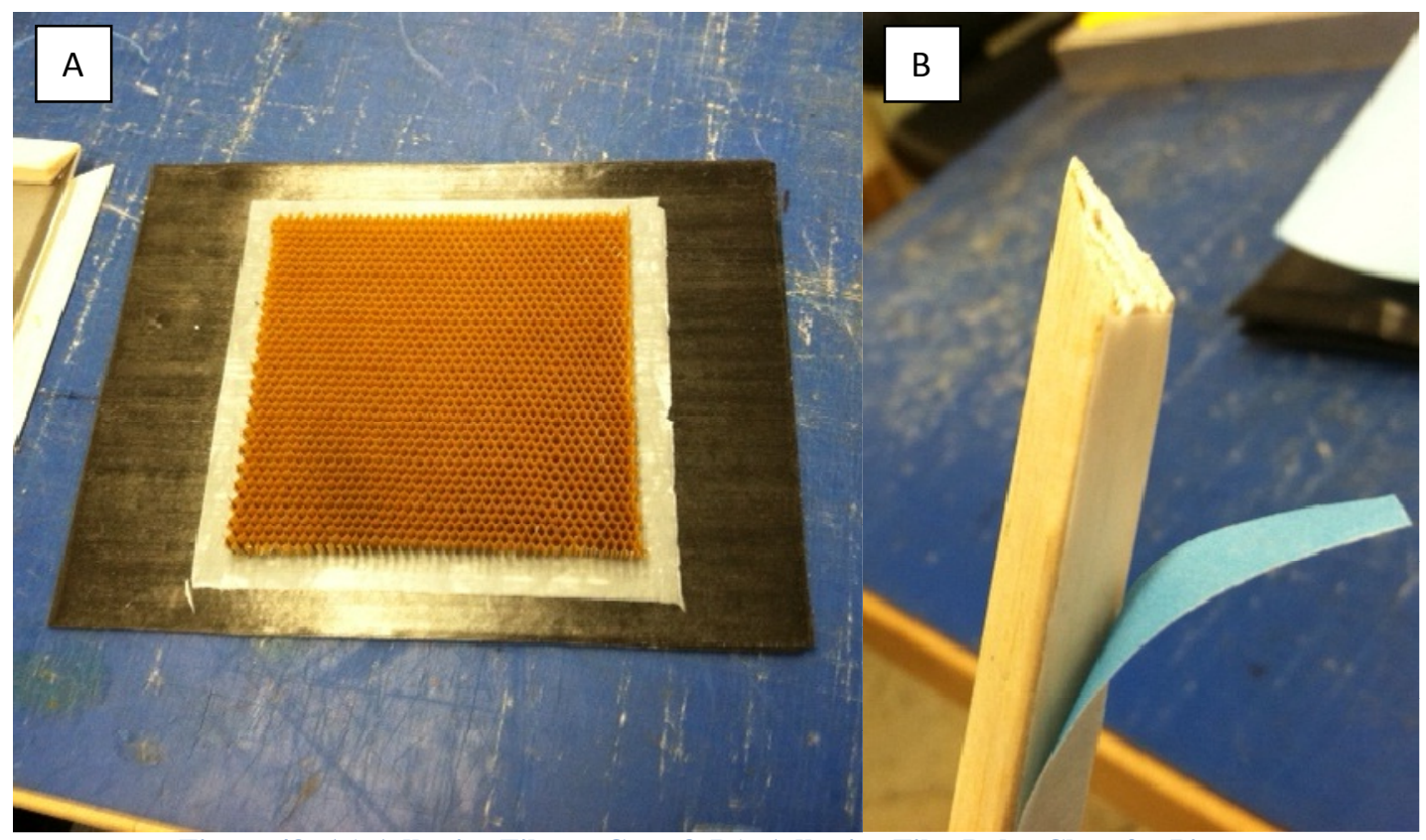

Figure 48: A.) Adhesive Film to Core \& B.) Adhesive Film Balsa Chamfer Pieces 


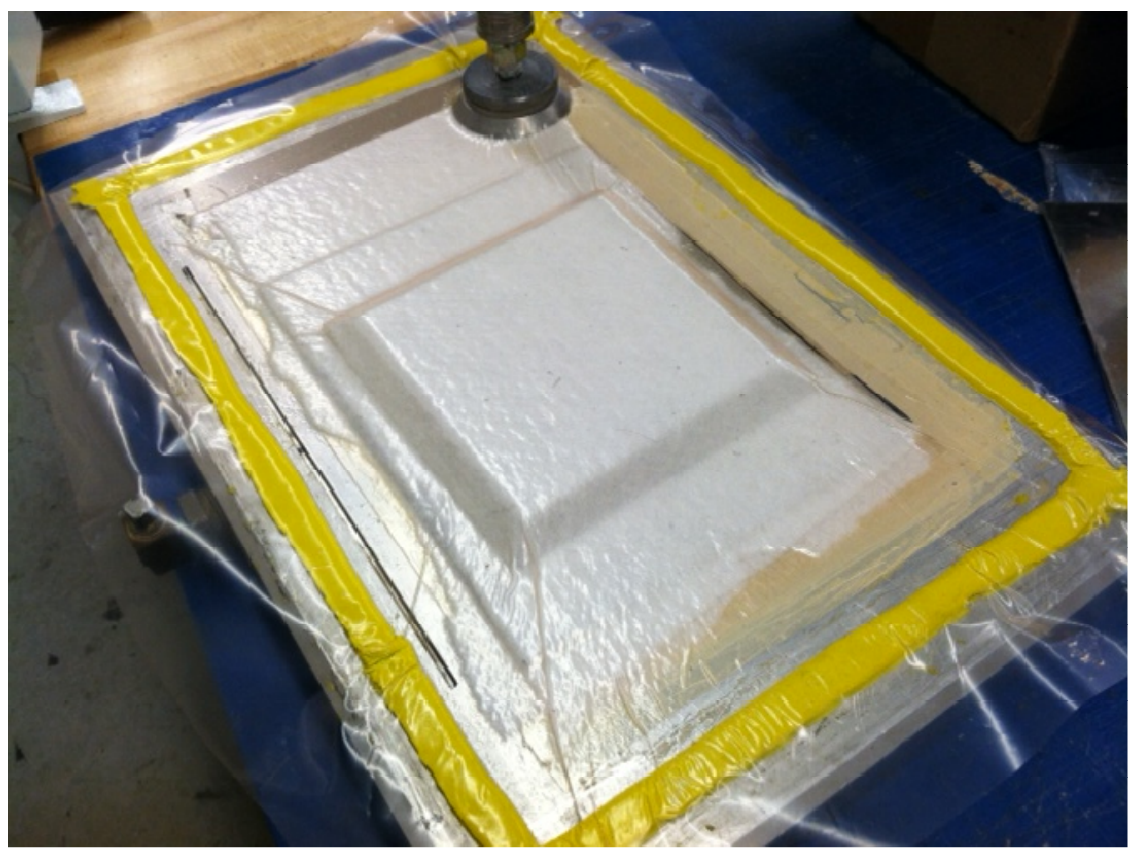

Figure 49: Vacuum Bag and Debulking Example

The next step in the manufacturing of the composite part was the vacuum bagging procedure. Once again the vacuum bag was created following Dr. Mello's Laboratory Procedure (Mello, 2011b). A large, 0.125" aluminum sheet was used as a base plate for the composite vacuum bag. Next, a release cloth was cut to the same size as the part and taped to the base plate. The part was then placed on top of the release cloth and a resin dam was built around the profile of the part. An additional release cloth was placed on top and taped to the resin dam. Next, the part was surrounded by vacuum bag tape to ensure a good seal on the bag. The custom caul plate was then placed on top of the part and release cloth. Breather cloth was laid on top of the caul plate to help protection the part. A vacuum value was inserted onto a vacuum bag allowing for vacuum hook up. Then vacuum bag/valve was then secured to the vacuum tape and drawn to ensure a full seal was created.

With the vacuum bag prepared, the part could then be cured in the autoclave. The autoclave used was ASC autoclave (Figure 49). The part was hooked up to the vacuum within the 
autoclave and cure according to the cure recipe. The curing process involves ramp up, curing, and cool-down phases and take about 3 hours from start to finish. After the autoclave, the carbon-fiber and the matrix are cured and the composite part was considered to be done as seen in Figure 50.

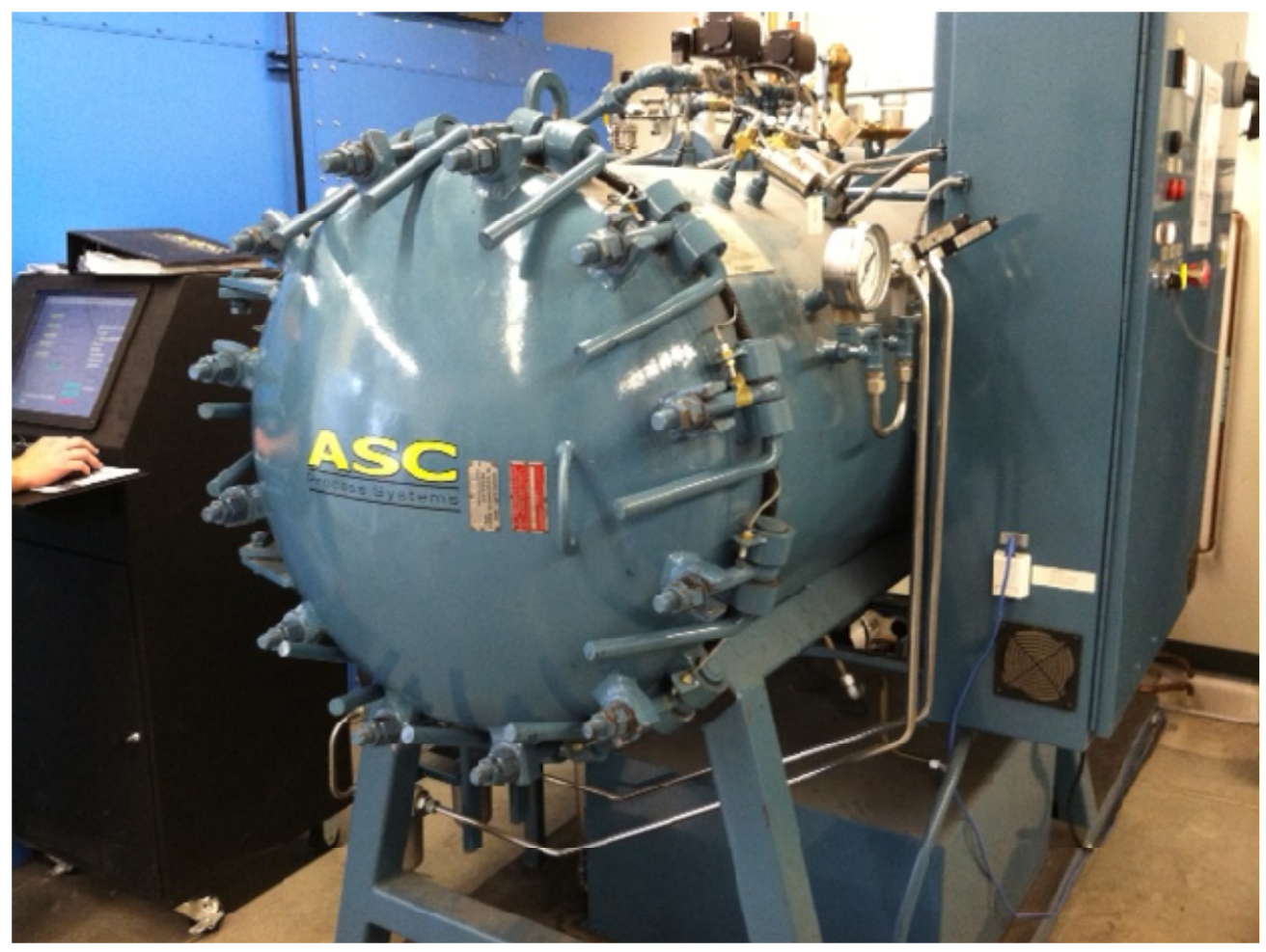

Figure 50: Cal Poly Mechanical Engineering Composites Lab Autoclave (192-135)

\subsubsection{Final Assembly}

Once all the components were purchased, manufactured and subassembled, the final prototype was build. The strap was looped through one of the slots in the fixation plate pulled through to an appropriate length. Due to the fact that the strap is so long compared to a human torso, the strap can be doublebacked on itself and secured circumferentially with any length possible under 70 inches. The strap was sewn to one end of the fixation to permanently secure them together. The strap was stretched over the top side of the fixation plate, and pulled through 
the other slotted hole, entering from the top. The strap could then just be slide under the patient and pulled tight back onto itself with no other attachments needed. This provides an extremely quick, but strong attachment method for the tourniquet. Then MPL was then attached to the fixation plate using an adhesive. Since the two components will be in compression, the strength of the adhesive was not a critical parameter to the functionality of the prototype. Because the MPL has sharp corners, protective foam was applied to the top lengths of the MPL. Baby protection foam was bought, cut to length, and secured onto the top plate using the adhesive provided with the baby protective foam. The device was then completed and ready for testing (Figure 51 \& Figure 52).

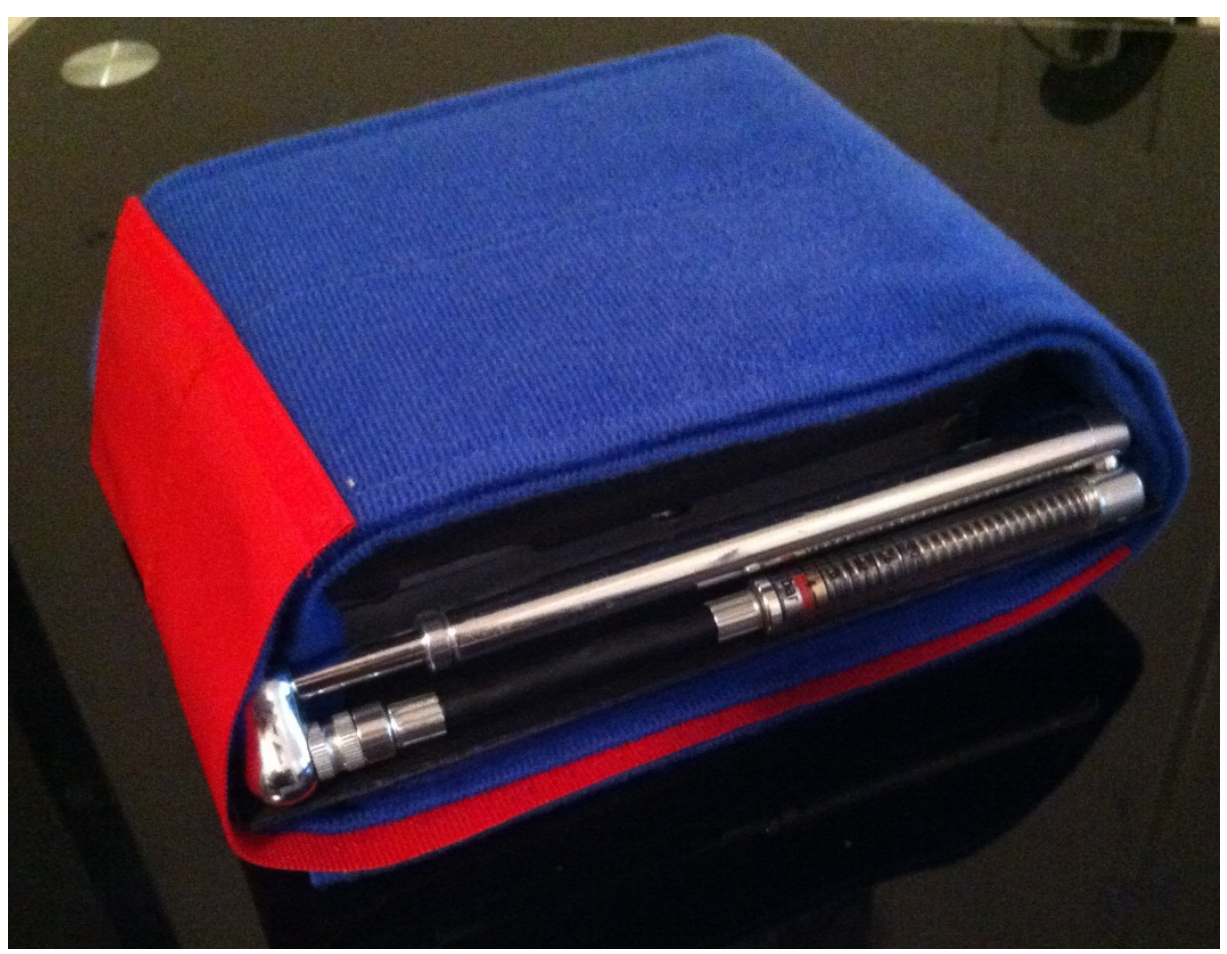

Figure 51: Collapsed and Stored Final Prototype of Junctional Tourniquet Device 


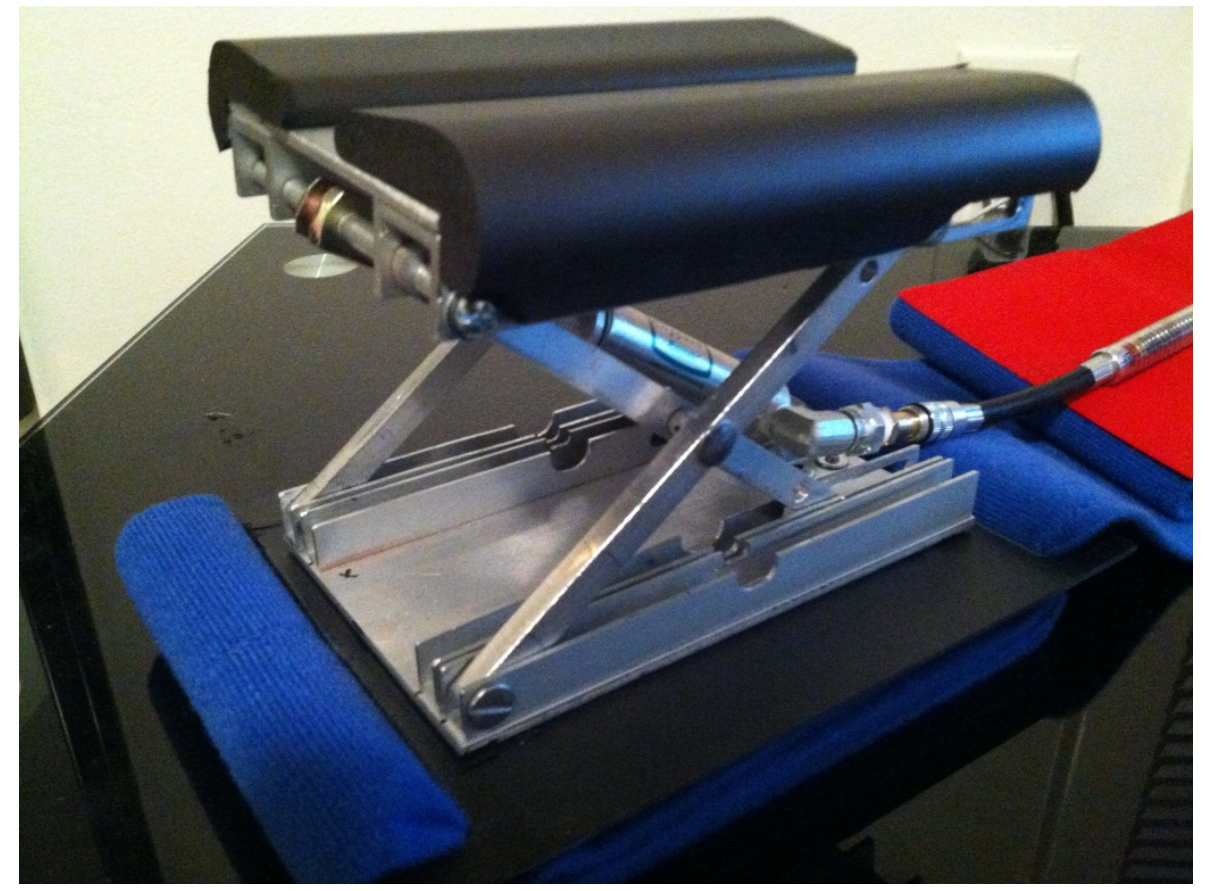

Figure 52: Expanded Final Prototype of Junctional Tourniquet Device

\subsection{Prototype Testing}

With the prototype finalized, the functionality of the device was found next. To validate the prototype, two methods were used. First static, weight-bearing measurements were taken to determine the maximum force that the tourniquet could support. The second method used the Cheung model to replicate a junctional hemorrhage patient and device deployment was measured. The time to don the tourniquet was recorded and pressure at occluded flow was measured. The dynamic test was repeated 8 times with time to don, if occlusion occurred, and inflation pressure recorded each test.

\subsection{1: Prototype Measurements}

Once the prototype fabrication was complete, measurements were taken. Static measurements were taken using calibers and a MODEL XX scale. These measurements included weight, expanded height, maximum deflection, and storage dimensions. 


\subsubsection{Static Loading Experiment}

As the first validation test, the tourniquet was loaded in compression with various weights to determine maximum weight-bearing capabilities. The device was pressurized with under no load, and weight was gradually added to the top surface (abdominal/padded side) until the structure was compromise and returned to the collapsed status. The maximum weight was recorded and the force was found.

\subsection{3: Dynamic Loading Using Mannequin}

\subsubsection{Mannequin Experimental Set Up}

The Cheung Model was set up as before with additional sensor equipment. Figure 53 shows the set up with additional equipment. Water was again used as the first-order blood replicate. The mannequin itself was set on the floor, with the reservoir of water located 30 inches above the mannequin to provide a more physiologically relevant pressure. The flow was ensured to be flowing at $5.0 \mathrm{~L} / \mathrm{min}$ at the inlet and recorded on the outlet to determine percent occlusion. Once the water flow was equalized in the open system, the mannequin was ready for testing. 


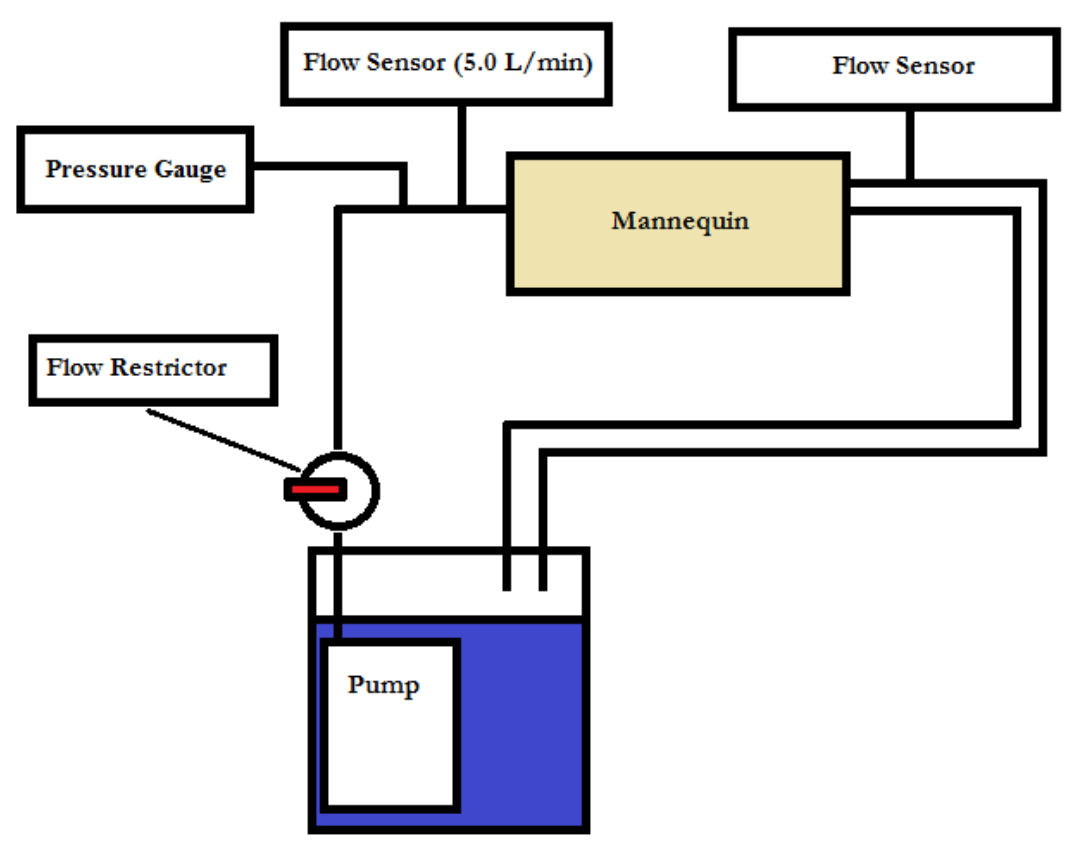

Figure 53: Prototype Experimental Set Up

\subsubsection{2: Device Donning Procedure}

To measure the functionality of the device, the tourniquet was placed on the mannequin and pressurized until $80 \%$ occlusion was reached. To pressurize the tourniquet, the following steps were taken: The open end of the strap was slid underneath the mannequin, looped through the slotted section on the fixation plate, and securely strapped back onto itself ensuring the device was very firmly pressed to the mannequin and appropriately situated. The shock pump was used to pressurize the MPL and collapse the AA was attempted. Pressure reached was recorded, the time-to-don was recorded, and if the device could be self-applied was indicated. 


\section{Chapter 4: Results}

\subsection{Preliminary Testing Results}

The two sizes and two shapes were tested on the Cheung Model to demonstrate accuracy of the model. Results of the average, calibrated values were recorded (Table 10). The assumptions of running a full factorial design were checked using Minitab (Figure 56 \& Figure 57). With the assumptions checked, the ANOVA was conducted (Table $11 \&$ Table 12). The normal plot of the standardized effects were plotted to check for any significance (Figure 58 \& Figure 59).

Table 10: Average Deflection and Force Required to Collapse Cheung Model

\begin{tabular}{|llllll|} 
& Average & & \multicolumn{2}{l|}{ Standard Deviation } & Average \\
& Deflection (in) & $\begin{array}{l}\text { Force } \\
\text { (lb) }\end{array}$ & Deflection (in) & Force (lb) & $\begin{array}{l}\text { Pressure } \\
\text { (psi) }\end{array}$ \\
\hline 3 Flat & 2.96 & 52.3 & 0.073 & 6.8 & 7.4 \\
\hline 4 Flat & 3.02 & 66.6 & 0.346 & 25.8 & 9.4 \\
\hline 3 Hemispherical & 3.16 & 117.6 & 0.131 & 14.7 & 9.3 \\
\hline 4 Hemispherical & 3.21 & 134.7 & 0.372 & 13.7 & 10.7 \\
\hline
\end{tabular}

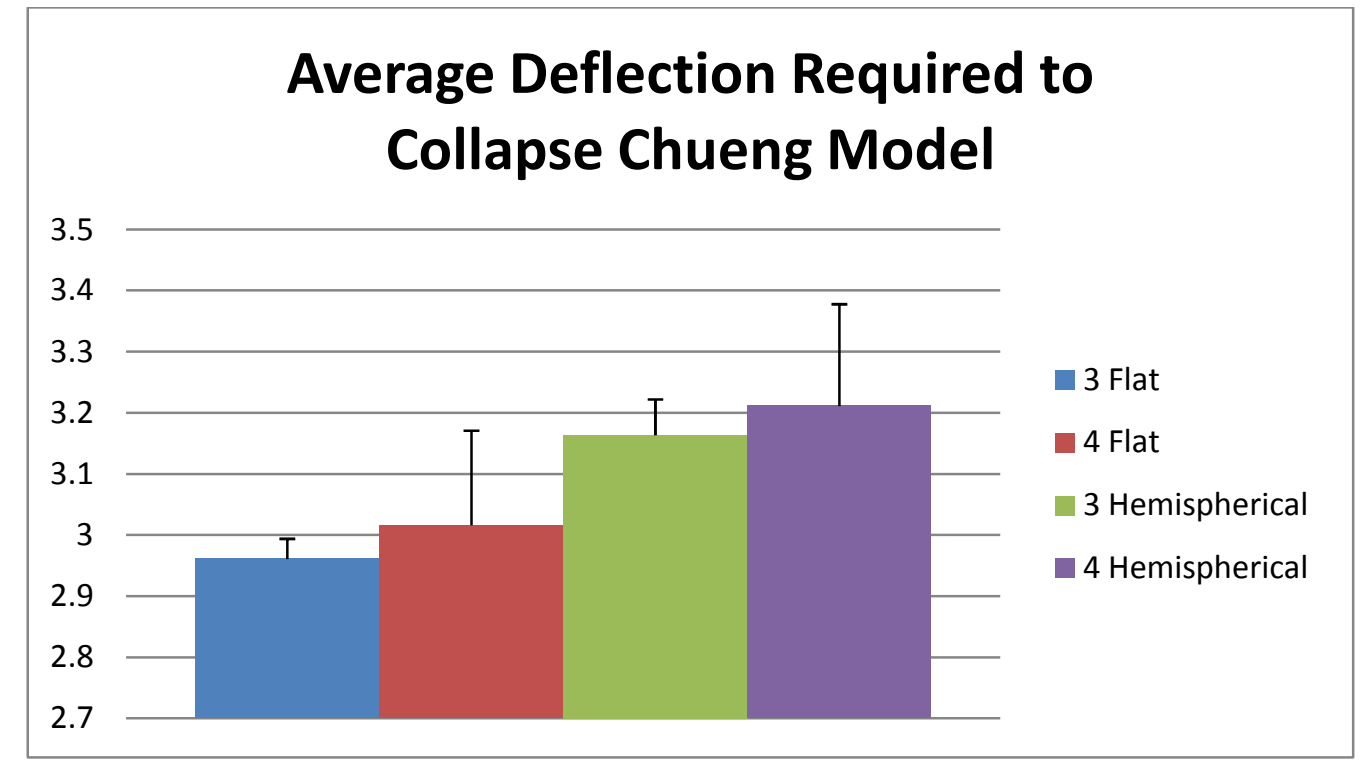

Figure 54: Average Deflection Required to Collapse Chueng Model 


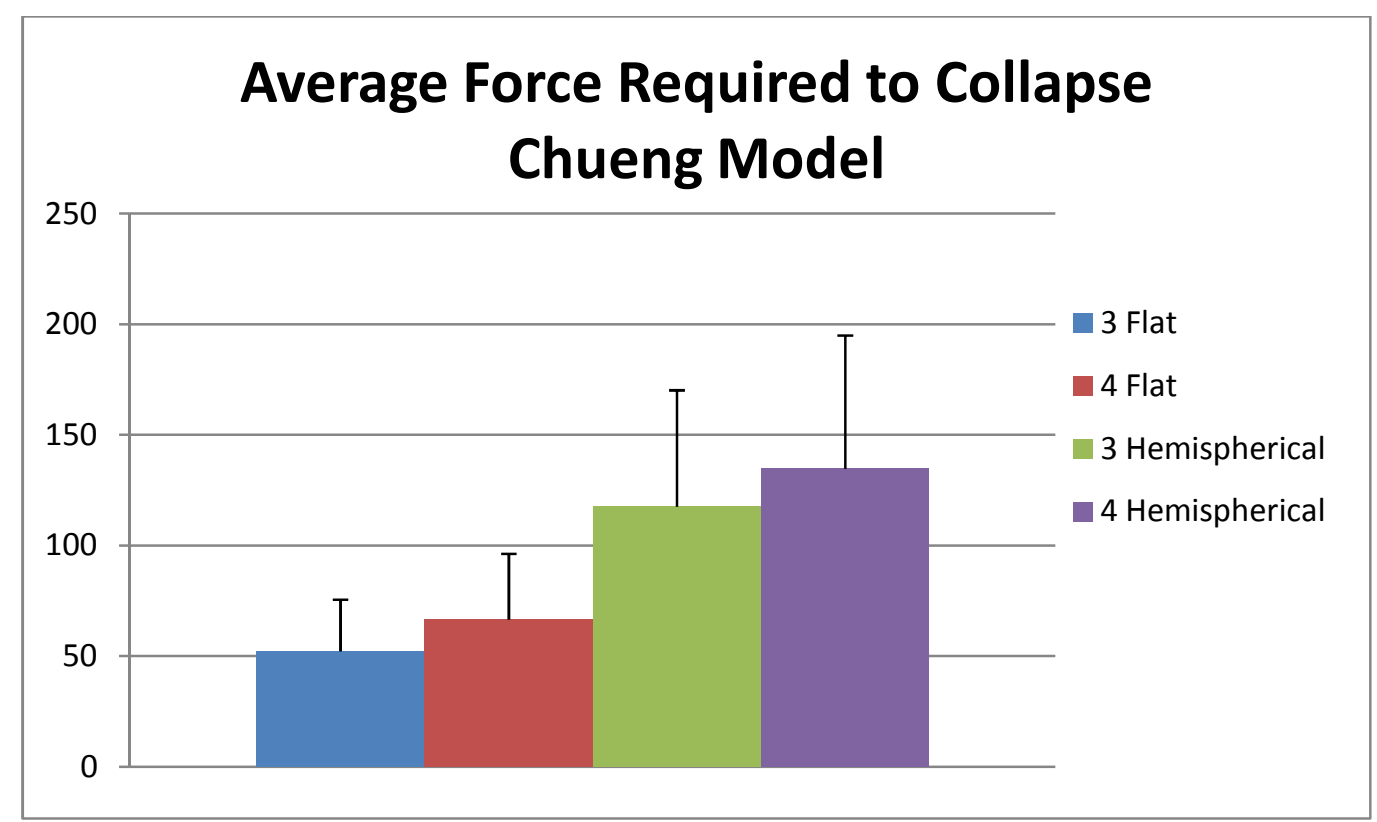

Figure 55: Average Force Required to Collapse Chueng Model

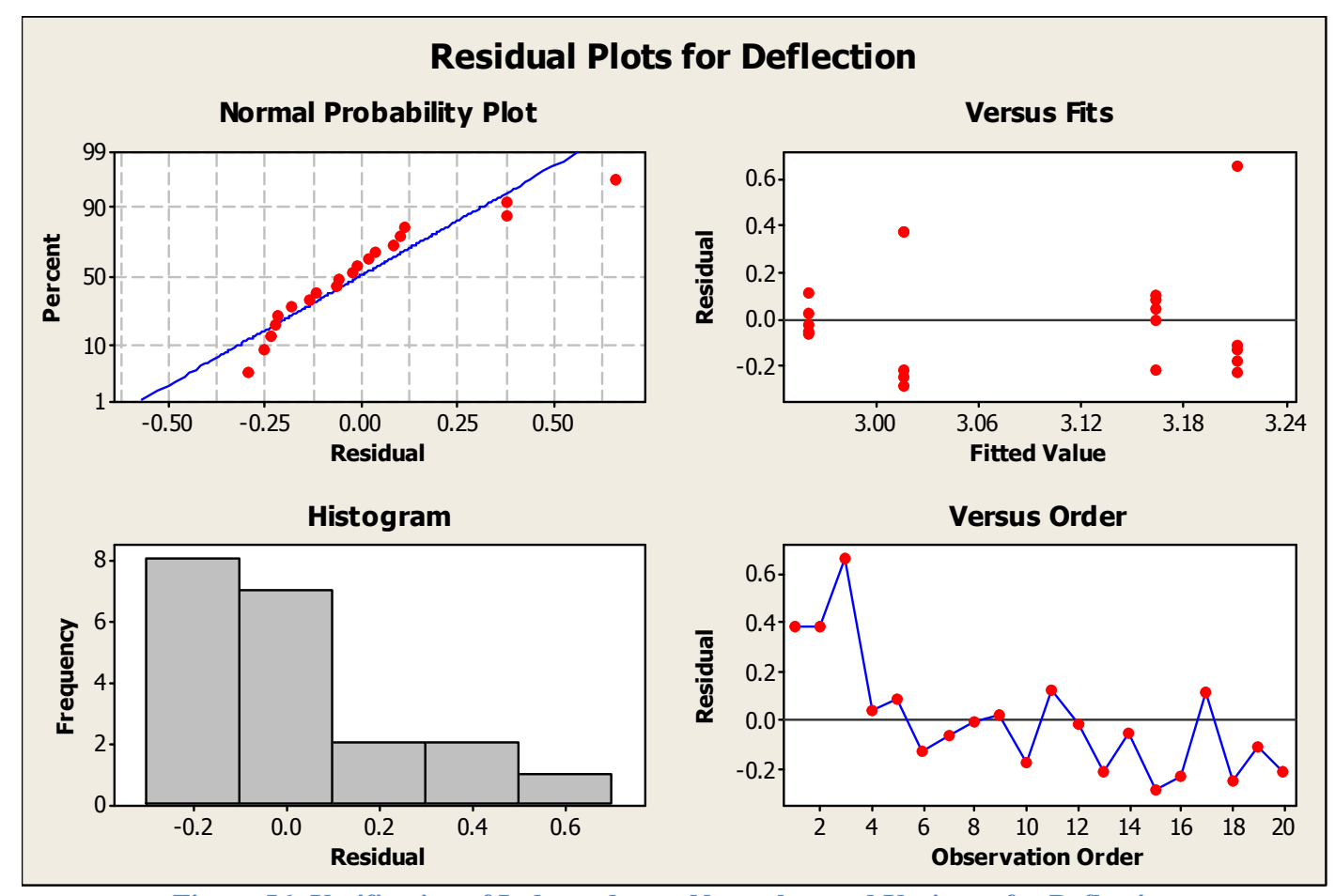

Figure 56: Verification of Independency, Normalcy, and Variance for Deflection 


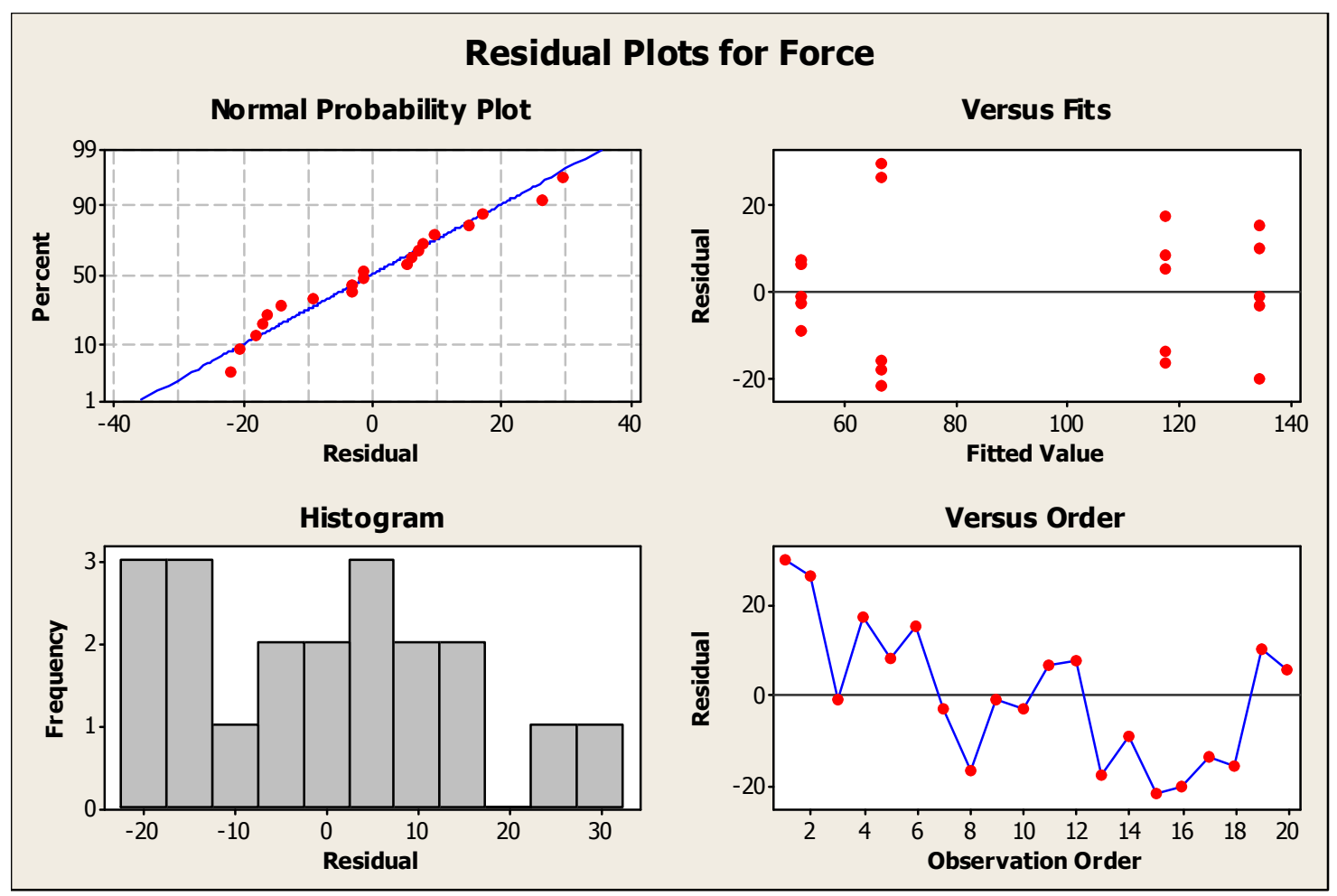

Figure 57: Verification of Independency, Normalcy, and Variance for Force

Table 11: ANOVA Table of Preliminary Testing of Deflection

\begin{tabular}{|lllllll|}
\hline Source & DF & SS & Adj SS & Adj MS & F Test & p-value \\
\hline Size & 1 & 0.01314 & 0.01314 & 0.01314 & 1.5 & $\mathbf{0 . 2 5 2}$ \\
\hline Shape & 1 & 0.19771 & 0.19771 & 0.19771 & 0.19 & $\mathbf{0 . 6 7 1}$ \\
\hline Size*Shape & 1 & 0.00006 & 0.00006 & 0.00006 & 0.00 & $\mathbf{0 . 9 7 6}$ \\
\hline Error & 16 & 1.1223 & 1.1223 & 0.070144 & & \\
\hline Total & 19 & 1.333 & & & & \\
\hline
\end{tabular}


Table 12: ANOVA Table of Preliminary Testing of Force

\begin{tabular}{|lllllll|} 
Source & DF & SS & Adj SS & Adj MS & F Test & p-value \\
\hline Size & 1 & 1234.2 & 1234.2 & 1234.2 & 4.42 & $\mathbf{0 . 0 5 2}$ \\
\hline Shape & 1 & 22274.5 & 22274.5 & 22274.5 & 79.8 & $\mathbf{0 . 0 0 0}$ \\
\hline Size*Shape & 1 & 10 & 10 & 10 & 0.04 & $\mathbf{0 . 8 5 3}$ \\
\hline Error & 16 & 4465.9 & 4465.9 & 279.1 & & \\
\hline Total & 19 & 27984.5 & & & & \\
\hline
\end{tabular}

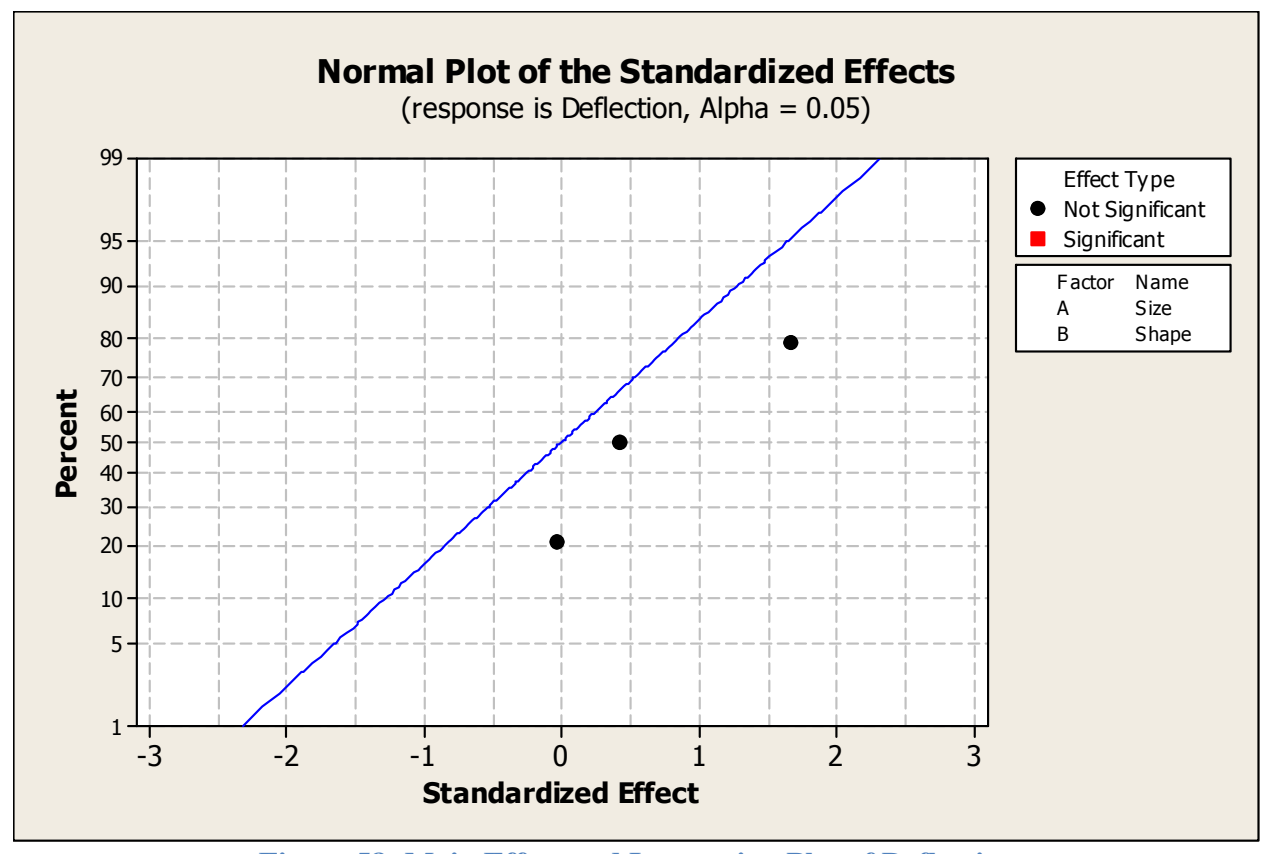

Figure 58: Main Effect and Interaction Plot of Deflection 


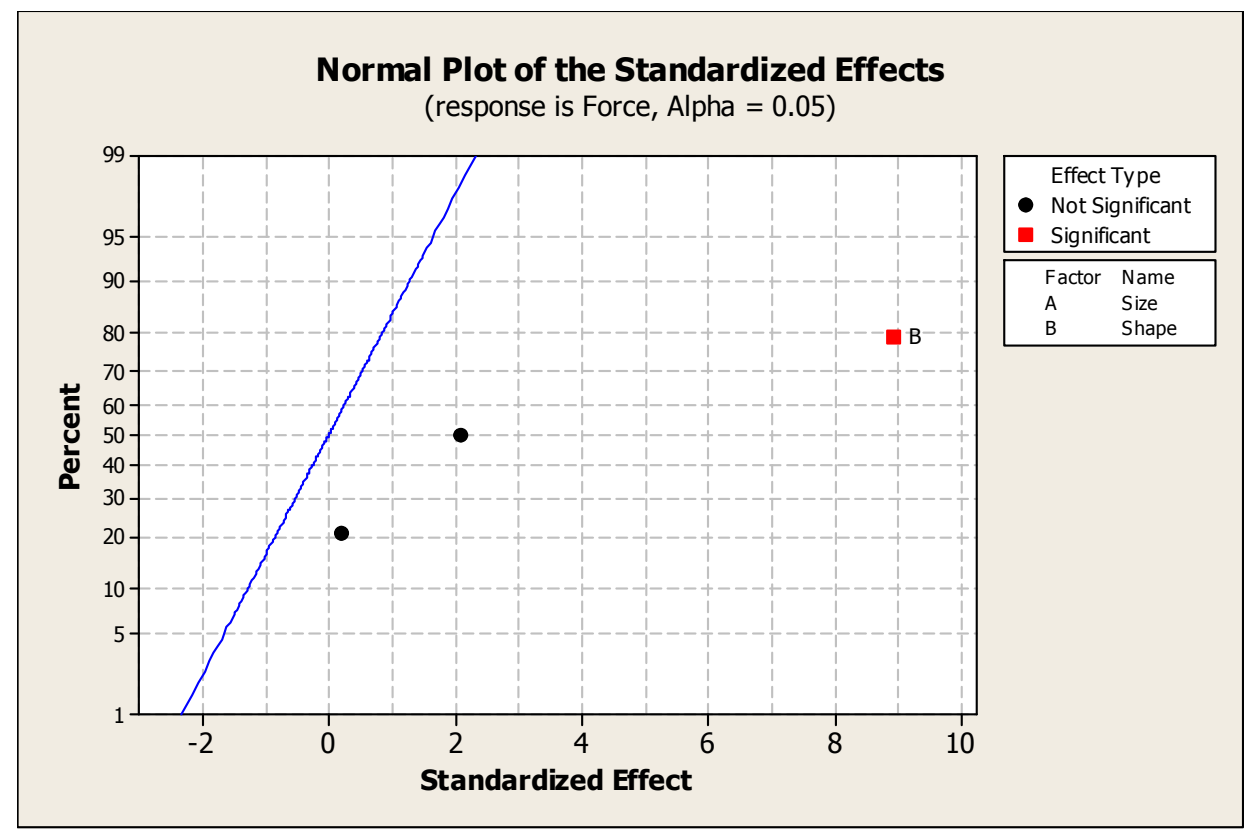

Figure 59: Main Effect and Interaction Plot of Force

\subsection{FEA Study}

The $2 \mathrm{D}$ case proved to be off from the validation results, however within an order of magnitude for deflection. The deflections and the stress at the center of the $2 \mathrm{D}$ element are compared to the theoretical (Figure F. 4) in Table 13. Additionally, a goal of this study was to determine a suitable material to use for the fixation plate and therefore the deflections and stresses of each material are included in Table 13. Deflections were then found in the 2D beam (Figure 60: 2D Scaled Deflection in 0.25" Thick Aluminum Fixation PlateFigure 60). Table 14 lists the deflections and stresses associated with the 3D model. A before, the deflection and stress in the fixation plate were modeled (Figure $61 \&$ Figure 62). The deflection calculation was extremely close to matching, however, the stress calculation still remained higher in the FEA model. 
Table 13: 2D Deflections and Stresses in 3 Materials Using Theoretical and FE Analyses

\begin{tabular}{llllll}
\hline Material: & Thickness & Modulus & I & $\begin{array}{l}\text { Theoretical } \\
\text { Deflection }\end{array}$ & $\begin{array}{l}\text { Abaqus } \\
\text { Deflection }\end{array}$ \\
\hline \multirow{3}{*}{ Al } & 0.5 & $1.00 \mathrm{E}+07$ & $4.17 \mathrm{E}-02$ & $1.46 \mathrm{E}-03$ & $9.62 \mathrm{E}-03$ \\
& 0.375 & $1.00 \mathrm{E}+07$ & $1.76 \mathrm{E}-02$ & $3.47 \mathrm{E}-03$ & $2.33 \mathrm{E}-02$ \\
& 0.25 & $1.00 \mathrm{E}+07$ & $5.21 \mathrm{E}-03$ & $1.17 \mathrm{E}-02$ & $8.02 \mathrm{E}-02$ \\
\multirow{3}{*}{ PET } & 0.5 & $5.50 \mathrm{E}+05$ & $4.17 \mathrm{E}-02$ & $2.66 \mathrm{E}-02$ & $1.09 \mathrm{E}-01$ \\
& 0.375 & $5.50 \mathrm{E}+05$ & $1.76 \mathrm{E}-02$ & $6.31 \mathrm{E}-02$ & $2.65 \mathrm{E}-01$ \\
& 0.25 & $5.50 \mathrm{E}+05$ & $5.21 \mathrm{E}-03$ & $2.13 \mathrm{E}-01$ & $9.12 \mathrm{E}-01$ \\
& 0.5 & $3.19 \mathrm{E}+05$ & $4.17 \mathrm{E}-02$ & $4.59 \mathrm{E}-02$ & $1.89 \mathrm{E}-01$ \\
PC & 0.375 & $3.19 \mathrm{E}+05$ & $1.76 \mathrm{E}-02$ & $1.09 \mathrm{E}-01$ & $4.56 \mathrm{E}-01$ \\
& 0.25 & $3.19 \mathrm{E}+05$ & $5.21 \mathrm{E}-03$ & $3.67 \mathrm{E}-01$ & $1.57 \mathrm{E}+00$ \\
\hline
\end{tabular}

Table 14: 3D Deflections and Stresses in Aluminum Using Theoretical and FE Analyses

\begin{tabular}{|c|c|c|c|c|c|}
\hline Material & $\begin{array}{l}\text { Modulus } \\
\text { (psi) }\end{array}$ & $\begin{array}{l}\text { Theoretical } \\
\text { Deflection (in) }\end{array}$ & $\begin{array}{l}\text { Abaqus } \\
\text { Deflection } \\
\text { (in) }\end{array}$ & $\begin{array}{l}\text { Theoretical } \\
\text { Stress (psi) }\end{array}$ & $\begin{array}{l}\text { Abaqus } \\
\text { Stress } \\
\text { (psi) }\end{array}$ \\
\hline $\begin{array}{l}\text { Aluminum } \\
\left(0.25^{\prime \prime}\right)\end{array}$ & $10 \mathrm{e} 6$ & $1.17 \mathrm{E}-02$ & $9.20 \mathrm{E}-01$ & $4.50 \mathrm{E}+03$ & $2.60 \mathrm{E}+03$ \\
\hline $\begin{array}{l}\text { Aluminum } \\
(\mathbf{0 . 1 2 5})\end{array}$ & $10 \mathrm{e} 6$ & 9.38E-02 & $6.76 \mathrm{E}+00$ & $1.80 \mathrm{E}+04$ & $9.00 \mathrm{E}+03$ \\
\hline Carbon Fiber & $20 \mathrm{e} 6$ & 7.32E-04 & $4.54 \mathrm{E}-02$ & $1.13 \mathrm{FE}+03$ & $1.37 \mathrm{E}+04$ \\
\hline
\end{tabular}
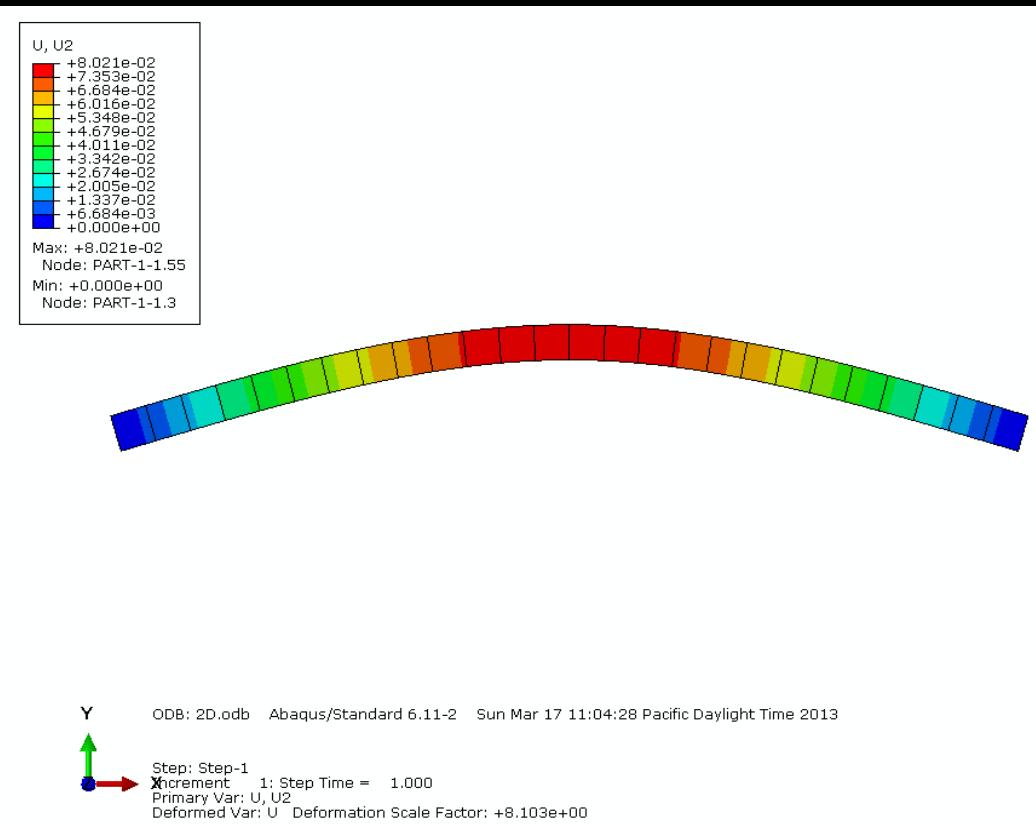

Figure 60: 2D Scaled Deflection in 0.25" Thick Aluminum Fixation Plate 


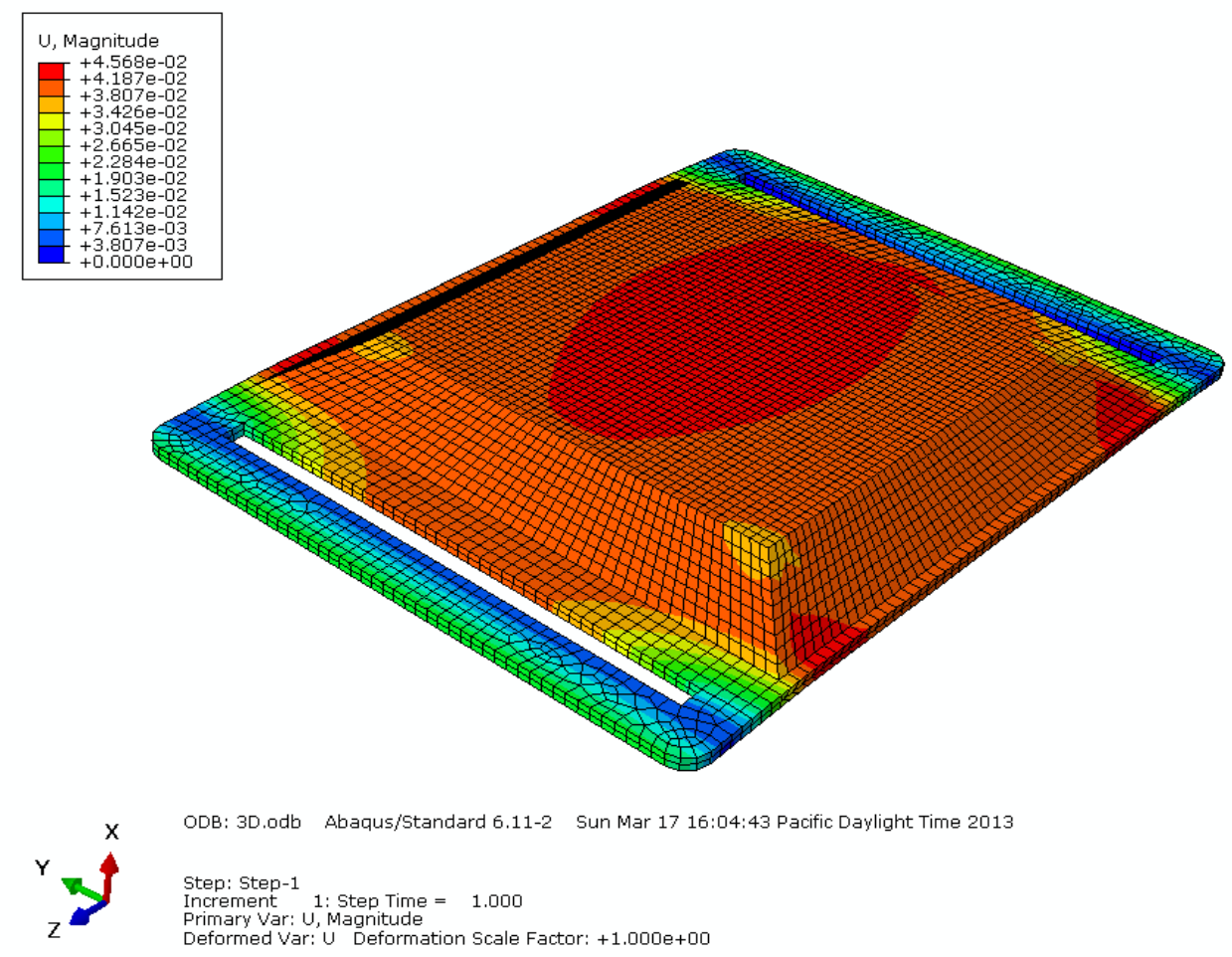

Figure 61: 3D Deflection of Fixation Plate

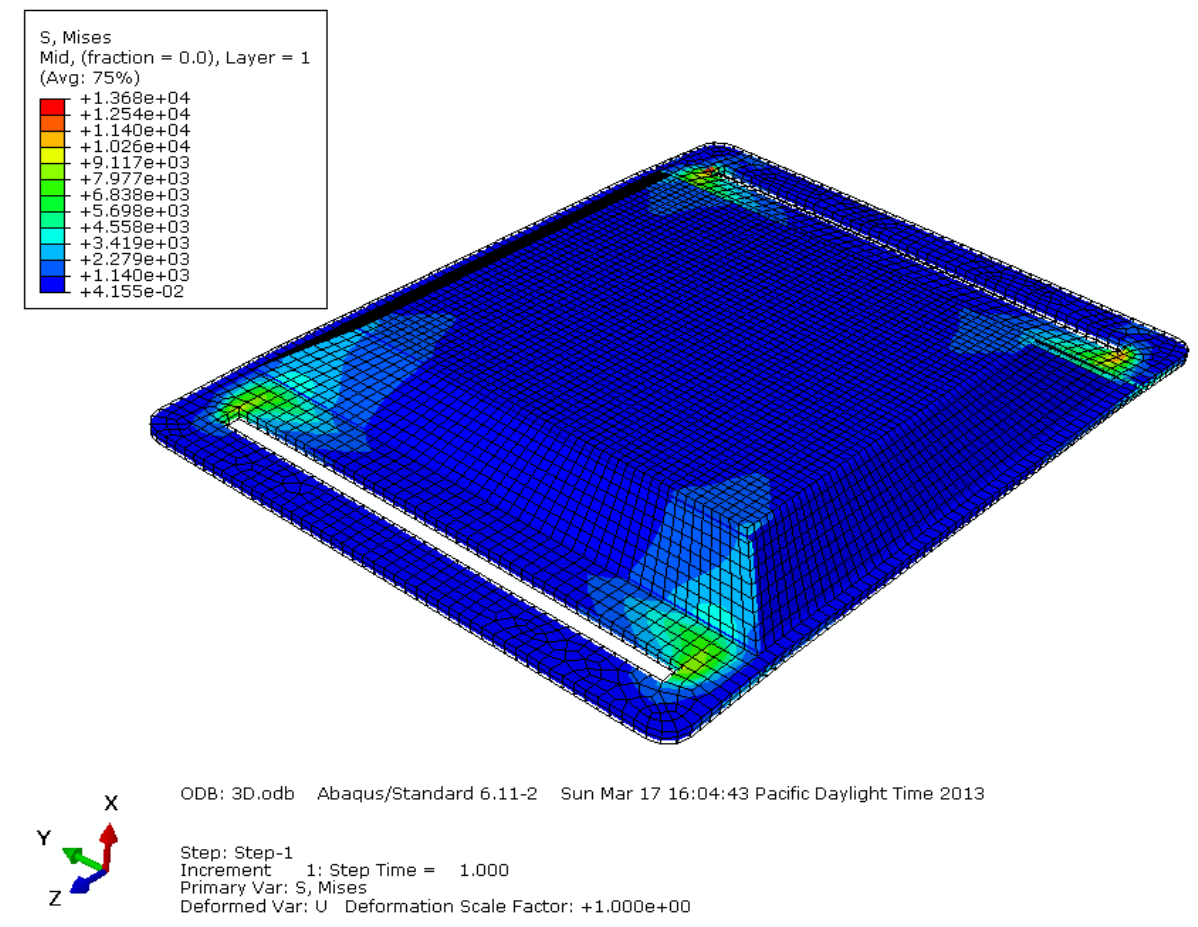

Figure 62: 3D Stress of Fixation Plate 


\subsection{Prototype Test Results}

Static and Dynamic prototype specifications were measured using the Cheung model to test dynamic prototype functionality. Table 15 lists the static measurements taken with calipers. Table 16 lists the time-to-don, status of complete occlusion, and pressure at occlusion of the eight samples taken.

Table 15: Static Measurements of Junctional Tourniquet Device

\begin{tabular}{|lll|}
\hline Observation: & Measurement: & Unit: \\
\hline Weight & 2.82 & lbs \\
\hline Height (collapsed) & 2.125 & in \\
\hline Height (expanded) & 5.25 & in \\
\hline Height (stored) & 3.5 & in \\
\hline Length (stored) & 9 & in \\
\hline Width (stored) & 6.5 & in \\
\hline Maximum Deflection & 3.125 & in \\
\hline Maximum Force & 67.5 & lbs \\
\hline Application Area & 25 & in \\
\hline Volume & 204.75 & in $^{3}$ \\
\hline
\end{tabular}

Table 16: Prototype Functionality Test Results

\begin{tabular}{|lll|}
\hline $\begin{array}{l}\text { Item Achieved? } \\
\text { Occlusion }\end{array}$ & Response & Units \\
(Y/N) & A & -- \\
\hline Maximum Pressure & 275 & lbs/in ${ }^{2}$ \\
\hline Inlet Flow Rate & 1.3 & gallons/min \\
\hline Outlet Flow Rate & 1.2 & gallons/min \\
\hline Don Time & 34 & seonds \\
\hline Self-Donning? & $\mathrm{Y}$ & -- \\
\hline
\end{tabular}




\section{Chapter 5: Discussion}

\subsection{Preliminary Testing}

From Table 10 and Figure 54, it can be observed that the deflection needed to occlude the AA is between 2.94 and 3.2 inches regardless of size or shape. Therefore as a general approximation, a deflection target was over 3 inches. More specifically, looking at the data it can be seen that there is a trend between size and force or deflection needed to collapse the AA. The larger the diameter of the depressor, the more force and therefore the more deflection was needed. This is relationship is understandable with respect to the definition of pressure. If the area increases, the force required to maintain the same pressure would also have to increase. The data reflects this well. The apparent trend in difference between the shapes could be caused by the same relationship. The hemispherical shape would engage less of the tube in the longitudinal direction because of the shape. Therefore it can be seen that there is a trend between total area and the length of AA being engaged during deflected.

Next, deeper examination of the statistical significant of both the deflection and force responses was done. Due to the large variation in the deflection of foam on the Cheung model, none of the factors were found to be significant. This is demonstrated by the p-values larger than 0.05 in Table 11 and lack of significant factors (Figure 58). The large variation was seen in the force data as well, but there was significance. The p-values of 0.00 in Table 12 and red indication that shape has a significant influence on the force needed to collapse the AA (Figure 59). It can be seen that a flat shape lead to a lower force and deflection requirement. The shape is nearly significant indicated that the trend observed for the force is of some merit. One possible cause that force was found to be significant while deflection was not could be to the magnitude of the measured observations. Since the force measurements were larger in value than the deflection 
measurements, the data could be more robust comparatively. Therefore, the conclusions drawn from these experiments are the approximation deflection needed from the tourniquet is over 3 inches and using the flat shape would decrease the required force.

It is also important to note that the assumptions of the ANOVA in Table 11 and Table 12 were not verified to be true. There is an apparent trend when plotting the residual values compared to the run order displayed in the lower right-sided graph of Figure 56 and Figure 57. There is an apparent decrease in deflection and force with run order. The trend is hypothesized to be a cause from the stress-relaxation of the prosthetic foam used in the Cheung model. As the model was repeated tested, the foam became permanently depressed, decreasing the required force and deflection needed to occlude the AA. The other assumptions are verified to be variant and normally distributed for both deflection and force responses.

\subsection{FEA Study}

In almost all cases, the values found by FEA were higher than that of the theoretical calculations. There could be several reasons for this. In the $2 \mathrm{D}$ loading case, the discrepancies between the theoretical calculations and the values that Abaqus provided could be due to the plane stress assumption of the element type. The CPS8 element has plane stress built in as a stated assumption. It does seem like a reasonable assumption, however needs to be further investigated. Also in the 3D case, the point of interest was right above the surface pressure. There could be locating deformations and stresses caused by this pressure that were not included in the simulations. One major concern in both the 2D and 3D scenarios is the boundary conditions. After several attempts to incorporate edge loading, a rather large assumption was made stating that both edges could be constrained in the y-direction (parallel to the force application). This was done to allow the script to run but could be the cause of some of the error. 
The results in this work provided two things: first providing a justification for material selection, and secondly a first order attempt at understanding this complex problem. These results should be used to help design the junctional tourniquet device by providing stress patterns of the fixation plate. Further work could help provide stress concentrations for the design in other components and help justify feasibility of the overall device.

\subsection{Prototype Testing}

With the completion of testing, it can be seen that the prototype can withstand forces up to XX lbs and was shown to collapse the aorta on the Cheung model. It is the first time a device using this mechanism has shown to occlude the aorta and effectively control hemorrhaging. Using this design, it is possible to move forward with further redesign and development of the device. In order for this design to compete with other devices already on the market, some design consideration must be made.

\subsubsection{Effectiveness}

Ranked as the second most important attribute of the device in the rank order chart (Table 3), the device needed to be effective. The device was required to reduce blood flow by $80 \%$ to consider the tube to be effectively occluded, but was unfortunately unable to do so. Demonstrating that the tourniquet could not provide the necessary pressure to occlude the artery, further design iteration will be necessary to accomplish effectiveness.

It is therefore important to understand the mechanism in which causes the device to not occlude the artery. Because air is said to be compressible, the actuator does not provide necessary force required to move the lift upwards. Compressibility is a measure of relative volume change of a fluid as a response to a pressure. So initially, as the pressure increases the 
volume increases until the entirety of the actuator is taken up. Then the volume is held constant, and the pressure is increased in the actuator until the max pressure is reached. But the tourniquet in this study cannot create enough pressure to change the volume without exceeding the limitations of the actuator. The pressure back onto the tourniquet from the body is too great and overcomes the pressure within the actuator, causing a pressure increase within the chamber, rather than a volume change. Because of the fluid compression of the actuator, the device failed to successfully collapse the AA.

\subsubsection{Size}

With the overall dimensions of 3.5"x6.25"x9" for a volume of $204.75 \mathrm{in}^{3}$ makes this prototype larger than the all other devices. However, as this design is a prototype, there is much room for improvement. The overall size is dependent very heavily on the size of the actuator within the MPL. The minimum collapsed height of the device is based on the size of the bore to appropriately house the actuator. One possible solution is to use a rectangular shaped actuator to provide same force in a slimmer profile (Figure 63). Another solution is to use a mechanical actuator, using a worm gear to actuate the lift upwards. This would overcome the drawbacks seen by the pneumatic actuator. Finally, to reduce size, each dimension of the prototype could be reduced to help reduced the volume. Further research to determine the minimum area or corresponding dimensions to provide a functional device could be incorporated into making these dimensions smaller. 


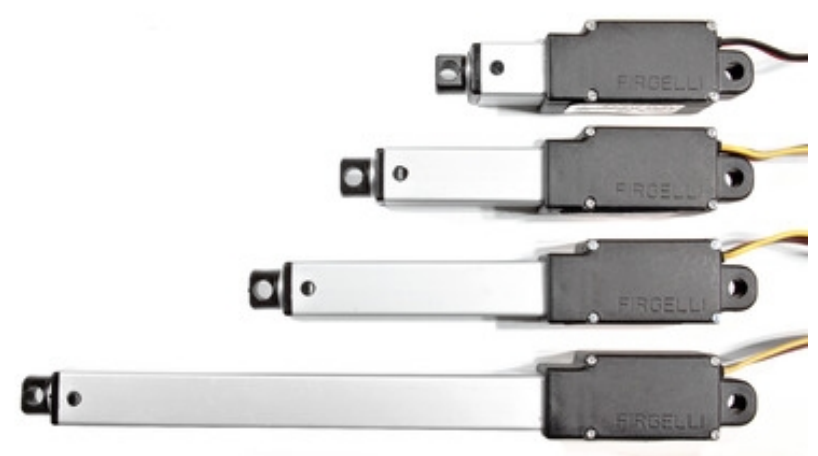

Figure 63: Example of Miniature Linear Rectangular Actuators

\subsubsection{Weight}

One major concern for the design is weight. The device weighs too much to be incorporated into medic gear much less standard gear equipment. Larger and heavier devices can be accepted into use by being located at a hospital or forward operating medical center, but not on the battlefield where the tourniquet is most needed.

The weight of the prototype with all of the components (MPL, fixation plate, strap, and shock pump) is 2.83 , or 1.30 over the average weight of competitors. Largely contributing to the weight is the metal components, the fasteners, and the extremely conservative, but bulky design. Reducing the number of parts and fasteners would be an easy way to shave off weight. Also optimizing each component of the device to be safe, yet still remain light as possible could help reduce weight. Standardizing the length of the strap could also help to remove any excess material and weight.

As with most medical equipment, the more intuitive and easy the device is to use, the more accepted it will become. This is a large advantage that the tourniquet has over others; the operation of this device is extremely easy and intuitive. With the bright red color contrasted with 
the blue strap and the familiarity of Velcro, it is clear that the strap must be used to secure the device around the body. Next located the proper location for the MPL to be placed over the aorta is easy with the anatomical landmark of the umbilicus. Visual aids could be incorporated to better demonstrate this. Lastly, using a familiar tool, the bike pump, it is clear that the device needs to be pumped up. These steps would be intuitive and familiar to the operator, making for quick response to the emergency, even for non- medically trained personnel.

Another advantage to the design is the ability to apply the tourniquet to one's self. No other junctional tourniquet hemorrhage is able to do this. The ability to apply the tourniquet to yourself increases the number of people who can use it. If a solider is caught in a situation in which medical attention is available, this attribute to the design could mean the difference between the life and death.

\subsubsection{Durability}

It is important to consider durability with the design of any military device. It can be assumed that the device will have to survive the harsh conditions that military service personnel undergo. Dirt and dust will be a large environmental factor seen by the device. The tourniquet must be able to operate under any conditions, from subzero temperatures, to hot desert days, while still functioning in the dust, dirt, water, and blood. The device will also undergo a lot of wear and tear if located on a solider. Dropping, bumming, and shaking are daily occurrences seen by military gear. After all of this abuse, the device must be able to work after a long time of infrequent use.

The design being built out of tough material such as metal, CFRC, and Nylon, it is believed that the tourniquet will survive the harsh environment. The device will be able to withstand this abuse and still function because while the device is in the stored position, the strap wrapped around the 
MPL and fixation plate acts as padding for the device (Figure 51). This storage technique, along with the side walls of the tracks, would keep out any dust or dirt from interfering with the mechanisms. However, a possible redesign could incorporate a dust guard, or having the top and bottom interlock in the collapsed position to lock and seal the internal mechanisms. One area of concern with the mechanism is the blood-material interaction. As the tourniquet is in use, it will most like come in contact with blood. Further investigation to whether this interaction could affect functionality should be considered.

\subsubsection{Safety}

Ranked as the most important attribute, the tourniquet must be safe to use. The tourniquet accomplished safety with an extremely strap and the fixation plate. These two features use together decrease the likelihood of slippage or inappropriate pressure on other organ not in the target area. Using the wide strap, the force is distributed over a large area decreasing the comorbidity likelihood. It has been shown that traditional tourniquets are safe, but no investigation onto whether collapse of the aorta has any associated comorbidities.

The application of force on the body also has to be examined. Although using this tourniquet could potentially save lives, the associated pain caused by the device could be of concern. During preliminary testing, it was noticed that 3 inch deflection into abdomen appeared very painful (Figure 64). To combat the pressure, an increase in area was used. However, increasing the depression site caused the fit within the abdomen cavity to concerning. When the device is in location, the rib cage is located immediately superior. Depending on the person, the rib cage could be captured under the depression head. This would cause much larger complications to the patient and is avoided. As mentioned previously, decreasing the size to help reduce weight would also benefit by alleviating this complication possibility. 


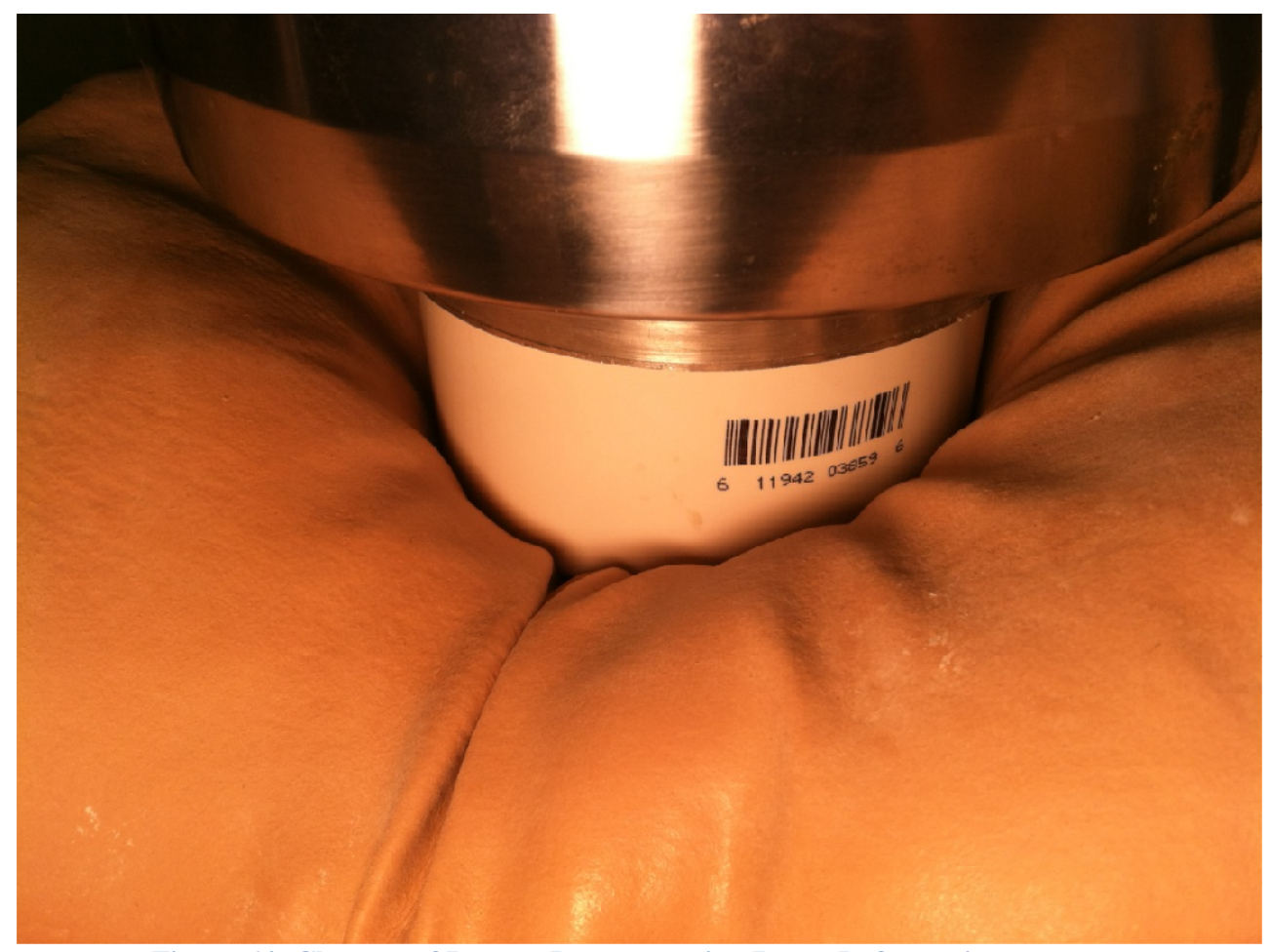

Figure 64: Close up of Instron Demonstrating Large Deformation 


\section{Chapter 6: Conclusion}

\subsection{Summary of Work}

The overall goal of project was to develop and test a junctional tourniquet prototype for development of junctional hemorrhaging. The device needed to be effective, light, safe, durable (combat ready), and easy to use. Since the focus of this project was to build a prototype, there were many areas for improvement before a final device could be produced. But the design and creation of the prototype demonstrated the feasibility of a novel approach to junctional hemorrhaging and the direction forward.

\subsection{Study Limitations}

Throughout the development of the junctional tourniquet device, limitations were encountered. Some limitations encountered were simplifications of analysis to help provide an exact solution. Other limitations were based on geometry, availability, or were beyond the scope of this project.

\subsubsection{Preliminary Testing}

Some of the major limitations of the preliminary testing were caused by the mannequin. All tests were conducted on one model and therefore the results are only valid for that one model. Extrapolation to other models or human use could only be hypothesis and any unknown sources of variances caused by the model would not be apparent. As previously mentioned, the stress-relaxation properties of the prosthetic foam caused permanent deformation throughout the testing. This deformation in the Cheung model caused extremely large variation in the response data and affected the validation of independency for the ANOVA. The large variance is to be expected when measuring a soft tissue, but ideally would be minimized. Also, due to the geometry of the Instron test, the water entering the mannequin was not pressurized as it would be 
physiologically. The water was not pressurized due to head losses occurring into the mannequin during Instron testing. The collapsible tube theory seen in Chapter 2.5, the transmural pressure becomes quite important to the buckling modes tubes and therefore, the lack of measured pressure is a limitation to this experiment.

\subsubsection{FEA}

The limitations in the finite element analysis were based on the simplifying assumptions made. Due to the manner in which the program runs, unexpected deformations and displacements occur when parts are not fixed. Therefore, to model the tourniquet, it was assumed that the strap connection was a pin or a hinge while the other was on a roller. It was difficult to accurately model the deflection and the force because as body is deflected, the tourniquet also deflects. This leaves no datum to which the pinned assumption would be accurate. Also modeling the force as a concentrated point load was a large assumption. The software attempts to calculate the localized stress and deflections caused by this concentrated load. For this reason, the data could be skewed. Revising the FEA model with more appropriate boundary and loading conditions would increase the accuracy the model and would be advisable.

\subsubsection{Design and Construction}

Due to the time and resources, the prototype was much heavier, bulker, and bigger than the potential competitors. The materials used were based on the available stock sizes and were designed to require the least about of manufacturing possible. For this reason, main components were over-designed and could be refined. Aluminum was used because it was easy to work with (compared to steel or CFRC) and available in a large range of sizes and shapes. But if the tourniquet were to be produced, many of the parts could be combined. Similarly, if the device was produced using carbon-fiber reinforce composite structures, more components could be incorporated into one to further lighten the overall device. Advised component combination 
would include the base plate and bottom tracks, the clevis mount to the base plate, and the top tracks and the top platform. Unifying these parts, using a CFRC structure or extruded aluminum, could reduce the weight considerably. Further revision would to redesign the pneumatic actuator into a hand-operated mechanical actuator. Also, fasteners used were off the shelf and based on availability. It would be advisable to redesign fasteners tailored to the design such as the binding posts.

\subsubsection{Prototype Testing}

As before, only using one model for all the tests could have hidden sources of variance. Also, using the mannequin after permanent deformation caused by the preliminary testing could have greatly affected the results. Also the initial strap pressure applied could have be a source of variance. Individuals applying the device would strap the device with varying initial pressures. Incorporation of the varying into the design with the ability to overcome "light" strapping would be helpful.

\subsection{Future Work}

With the development of the first prototype completed, many considerations could be made for possible redesigning or improvement. Many of the limitations experienced during the study could be improved in future work to help ensure accuracy of testing. Finally, looking forward at the possibility of manufacturing the device for production brought up additional areas of improvement.

\subsubsection{Preliminary Testing}

There are many improvements that could be made to help reduce noise and nuisance factor in the preliminary testing. To help improve the test results, a fixture for the mannequin could be made. Testing of the mannequin involved several feet of tubing, the pump having to overcome head, and no mechanism to secure the model. Using a large fixture for the mannequin 
to rest in, with a fixed input and outputs for the tubing to connect to, the pump being able to pressurize the water to help replicate physiological conditions, and better security of the model for repeatability could greatly improve test results by reducing the noise, or variance seen in the data.

Another major concern for the preliminary testing was the lack of independency seen in the data. As it was mentioned, the cause of this dependency could be related to the mechanical properties of the prosthetic foam. If the foam does not fully recover from repeated testing, it would merit further investigation. Simple screen testing could be used to record the mechanical behavior of the foam under continuous testing, measuring deflection trends and time to full recovery of the foam. With a better understanding of the foam properties, the testing could be re-run and better data could be obtained.

\subsubsection{FEA}

It would be advisable in future work to further research the constraint issue, research other material options, and further develop the model to match than more closely to the device. Understanding the boundary conditions in this problem is essential as the force is being applied nearly perpendicular to the constraining mechanisms. A better understanding of the Abaqus software, and how to properly address the loading conditions could improve the approximations seen. Also, due to the abstract boundary conditions being simplified, further investigation on how to over simplification of the boundary conditions affect model accuracy should be investigated.. Finally, this model's geometry was greatly simplified to provide results. Further work would include iterations of the device, contact of the MPL using explicit analysis or dynamic loading could increase the results. 


\subsubsection{Prototype and Testing}

Once the prototype was developed, it was testing using the same mannequin as before. There were some areas of concern for using the same model. The Cheung model was permanently deformed after preliminary testing; this permanent deformation could have had adverse effects on the prototype results. If the prosthetic foam was deformed, and not providing the proper mechanical properties, the results could be severely limited. It would be advisable to calibrate the mannequin before each test to record deformation by recording the circumference of the model at the mid-plane of device application.

In addition to the mannequin, there are many areas in which the prototype could be improved as well. Because the design uses a pneumatic actuator, the device is limited by the compressibility of the air. Initially, the pneumatic actuator was chosen for compactness and compatibility with bike air accessories. However, a mechanical actuator might provide a better platform for lifting and remaining constant under pressure. Modification to the design to allow for hand operated could be done with a worm gear, a mounted sleeve connected to the gear and to the top of the lift, and a "U" joint transmitting the rotation of the gear as it was lifted.

The overall prototype could be improved by precisely manufacturing all components, ensuring exact fit to help reduce tendency of part binding. Also, working with the dimensions to the component to reduce volume would be make the device more competitive compared to the other junctional tourniquet devices would be advantageous as previously mentioned.

\subsubsection{Manufacturing and Marketing of the Junctional Tourniquet}

Looking forward to production manufacturing of the device, the prototype could be significantly changed to help minimize volume and weight, while increasing the force and deflection capabilities. If the prototype were brought into mass manufacturing, many of the 
components could be combined creating less parts for easier assembly. The base plate and top plate could be made from a solid extrusion, with slots and holes milled after. By properly designing the thicknesses, the overall weight could be greatly reduced with the extrusion pieces. The extrusion pieces would also removed the need for rivets which would increase overall rigidity. In addition to the extrusion pieces, a specifically tailored actuator could be developed. Developing an actuator could help in maximizing the overall length while reducing the weight. Also investigation to the weight versus functionality could compare hydraulic, mechanical, and pneumatic actuators. Since pneumatic actuators make use of the air, a compressible fluid, it is possible for the device to collapse given enough weight. But hydraulic systems weigh more because of the fluid weight and require more components such as flow control and a reservoir. A mechanical actuator could be used and still remain simple with few components. However, transfer of motion and turning of the worm gear would be required and would take more time to apply the tourniqet. Finally, all components could be further investigated and redesigned to minimize weight while still providing the necessary strength.

With consideration of mass production, the appropriate materials should be chosen. It would be possible to greatly decrease weight by creating all possible components from CFRC and composite-core structures. It would be possible to combine the fixation plate, the base plate, and the bottom tracks into one piece. The top platform and top tracks could also be combined reducing number of parts. However, with using CFRC, the cost of production would greatly increase. It would be advisable then to create two available tourniquet devices; an expensive, lightweight composite tourniquet designed for special operation personnel, and a durable metal tourniquet designed for medical personnel. The two design options would be reflected in price, and expand consumer base. Also, considering marketing availability, a tourniquet could be 
designed for the private sector. A low-cost driven design could be made to make the tourniquet available to private consumers or first-responders.

\subsubsection{Final Remarks}

The goal of this study was to present a new junctional tourniquet device, provide justification for the design, and validate the results through testing on the Cheung model. Although this approach to hemorrhage control was not shown to occlude blood flow on the Cheung model with the prototype, the design is novel with large potential to compete with the three FDA approved junctional tourniquet devices upon revision of the design. 


\section{Works Cited}

Ali, J., Duke, K. "Pneumatic Anitshock Garment Decrease Hemorrhage and Mortality From Splenic Injury." Canadian Journal of Surgery 34, no. 5 (1991a): 496-501.

Ali, J., Duke, K. "Timing and Interpretation of the Hemodynamic Effects of the Pneumatic Antishock Garment." Annals of Emergency Medicine 20, no. 11 (1991b): 1183-87.

AliMed. AliMed Universial Strap. 2013. http://www.alimed.com/alimed-universal-straps-onepiece-circumferential.html (accessed March 11, 2013).

AutoDesk. Sustainability Workship. 2011. http://sustainabilityworkshop.autodesk.com/products/metrics-and-basics-mechanics (accessed March 3, 2013).

Bellamy, R.F. "Why is Marine Combat Mortality Less than that of the Army?" Military Medicine 165 (2000): 362-367.

Belmont, P.J., Schoenfeld, A.J., Goodman, G. "Epidemiology of Combat Wounds in Operation Iraqi Freedom and Operation Enduring Freedom: Orthopaedic Burden of Disease." Journal of Surgical Orthopaedic Advances 130, no. 2 (2010): 251-256.

Blaivas, M., Shiver, S., Lyon, M., Adhikari, S. "Control of Hemorrhage in Critical Femoral or Inguinal Penetrating Wounds - An Ultrasound Evaluation." Prehospital and Disaster Medicine 21, no. 6 (2006): 379-382.

Blizard, W. "A lecture on the situation of the large blood-vessels of the extremites; and the methods of making effectual pressure on the arteries." In Cases of Dangerous Effusions of Blood From Wounds. London: Dilly, 1798.

Bohler, L. The Treatment of Fractures. New York: Grune \& Stratton, 1956.

Bore Size Calculator. Cippard. 2013. http://www.clippard.com/calculators/bore-size (accessed March 7, 2013).

Bozeman, W.P. Hemorrhagic Shock in Emergency Medicine. Medscape. March 18, 2011. http://emedicine.medscape.com/article/827930-overview (accessed August 15, 2012).

Budynas, R.G., Nisbett, J.K. Shigley's Mechanical Engineering, 9th Eidition. New York, New York: McGraw Hill, 2010.

Butler, F.K., Giebner S.D., McSwain N., et al. Prehospital Trauma Life Support Manual: Military Verison. 7th Edition. St. Louis: Mosby, 2010. 
Butler, F.K., Holcomb, J.B., Giebner, S.D., et al. "Tactical Combat Casualty Care 2007: Evolving Concepts and Battlefield Experience." Military Medicine 172, no. 11 (2007): 119.

Caravalho, J. Report of the Army Dismounted Complex Blast Injury Task Force. Fort Sam Houston: Dismounted Complex Blast Injury Task Force, 2011.

Cheung, T. "Design and Implementation of a Closed-Loop Blood-Flow Torso Model For Future Tourniquet Device Testing." 2012: 1-55.

Childers, R., Tolentino, J.C., Leasiolagi, J., Wiley, N., Liehardt, D., Barbabella, S., Kragh, J.K. "Tourniquets Exposed to the Afghanistan Combat Environment Have Decreased Efficacy and Increased Breakage Compared to Unexposed Tourniquets." Military Medicine 176, no. 12 (2011): 1400-3.

Clippard. Bore Size Calculator. 2012. http://www.clippard.com/calculators/bore-size (accessed 3 $8,2013)$.

Combat Application Tourniquet. C-A-T. 2012. http://combattourniquet.com/ (accessed July 27, 2012).

Combat Medical Systems. CRoC Combat Ready Clamp. 2009.

www.combatmedicalsystems.com/CRoC_p/31-200.htm (accessed July 30, 2012).

Conrad, W.A. "Pressure-Flow Realtionship in Collapsible Tubes." IEEE 4, no. BME-16 (1969): 284-295.

Cothren, C.C., Osborn, P.M., Moore, E.E., Morgan, S.J., Johnson, J.L., Smith, W.R. "Preperitonal Pelvic Packing for Hemodynamically Unstable Pelvic Fractures: A Paradigm Shift." The Journal of Trauma 62, no. 4 (2007): 834-842.

Coupland, R.M. War Wounds of Limbs, Surgical Management. Oxford: Butterworth-Heinemann 1993.

Defli Medical Innovations Inc. Emergency Medical Tourniquet . 2011. http://www.delfimedical.com/pts-ii/emt/ (accessed July 27, 2012).

Dickey, N.W., Jenkins, D. "Letter of Recommendation: Combat Ready Clamp Addition to the Tactical Combat Casualty Care Guidelines 2011-07." September 23, 2011. http://www.health.mil/Libraries/110808_TCCC_Course_Materials/0762-DHB-Memo110923-Combat-Ready-Clamp.pdf (accessed July 30, 2012).

Direct Industry. Lift Products. 2013. http://www.directindustry.com/prod/lift-products/hydrauliclift-tables-35420-358509.html (accessed 3 7, 2013). 
Dougherty, Glenn, Donaldson, Dean, Sanchez, Covert, DuPont. "THe Modern Warrior's Combat Load." U.S. Army Center for Army Lessons Learned, 2003: 1-115.

E., Warren. An Epitome of Practical Surgery for Field and Hospital. Richmond, VA: West \& Johnson, 1863.

Eastridge, B., Hardin, M. "Died of Wounds: Cause of Death After Battlefield Injury." Paper presented at: Advanced Technology for the Advancement of Combat Casualty Care 2010 Conference, 2010: St. Pete Beach, FL.

Fung, Y.C. Biodynamics Circulation. New York: Springer-Verlag, 1984.

Fung, Y.C. Biomechanics: Mecahanical Properties of Living Tissues. New York: SpringerVerlag, 1993.

Graham, B., Breault, M.J., McEwen, J.A., McGraw, R.W. "Occlusion of Aterial Flow in the Extremities at Subsystolic Pressures Through the Use of Wide Tourniquet Cuffs." Clinical Orthopedics Relations and Related Research 286 (1993): 257-61.

Gray, Henry. Gray's Anatomy of the Human Body. Philadelphia: Lea \& Febiger; Bartleby, 1918, 20th Ed. (2000).

Greenfield, E.M., McManus, J., Cooke, W.H., Pittman, D., Shiver, S.A, Beatty, J., Croushorn, J., Schwartz, R. Safety and Efficacy of a Novel Abdominal Aortic Tourniquet Device for the Control of Pelvic and Lower Extremity Hemorrhage . Augusta: Department of Emergency Medicine, Medical College of Georgia , 2012.

HexWeb Honeycomb Sandwich Design Technology. Duxford: Hexcel Composites, 2000.

Honigman, b., Lowenstein, S.R., Moore, E.E., Roweder, K., Pons, P. "the Role of the Pneumatic antishock Garment in Penetrating Cardiac Wounds." The Journal of the American Medical Association 266, no. 17 (1991): 2398-2401.

iCasualties. 2009. (accessed July 24, 2012).

Jolly, D.W. Field Surgery in Total War. New York: Hoeber, 1941.

Kelly, J.F., Ritenour, A.E., McLaughlin, D.F., Bagg, K.A., Apodaca, A.N., Mallak, C.T., Pearse, L., Lawnick, M.M., Champion, H.R., Wade, C.E., Holcomb, J.B. "Injury Severity and Causes of Death From Operation Iraqi Freedom and Operation Enduring Freedom: 20032004 Versus 2006." Th Journal of Trauma, 2008: S21-S27.

Klenerman, L. The Tourniquet Manual. London: Springer, 2003.

Klenerman, L. "Tourniquet Paralysis." Journal of Bone \& Joint Surgery, Brtish Volume 65 (1983): 374-375. 
Konrad, G., Markmiller, M., Lenich, A., Mayr, E., Ruter, A. "Tourniquets May Increase Postoperative Swelling, and Pain After Internal Fixation of Ankle Fractures." Clinical Othropaedic and Related Research 433 (2005): 189-194.

Kragh J.F., Murphy, C., Dubick, M.A., Baer, D.G., Johnson, J., Blackbourne, L.H. "New Tourniquet Device Concepts for Battlefield Hemorrhage Control." U.S. Army Medical Department Journal, 2011(a): 38-48.

Kragh, J.F., Murphy, C., Steinbaugh, J., et al. "Emergency Inguinal Clamp Controls Prehospital Hemorrhage in Cadaver Model." Unpublished manuscript, n.d.

Kragh, J.F., O'Neill, M.L., Walters, T.J., Dubick, M.A., Baer, D.G., Wade, C.E., Holcomb, J.B., Blackbourne, L.H. "The Military Emergency Tourniquet Program's Lessons Learned With Devices and Designs." Military Medicine 176, no. 10 (2011(b)): 1144-52.

Kragh, J.F., Swan, Kenneth G., Mabry, Robert L., Blackbourne, Lorne H. "Historical Review of emergency tourniquet use to stop bleeding." The American Journal of Surgery, 2011(c): $1-11$.

Kragh, J.F., Walters, T.J., Baer, D.G., et al. "Practical Use of Emergency Tourniquet to Stop Bleeding in Major Limb Trauma ." The Journal of Trauma 64 (2008): S38-50.

Krieg, J.C., Mohr, M., Ellis, T.J., Simpson, T.S., Madey, S.M., Bottlang, M. "Emergent Stablization of Pelvic Ring Injuries by Controlled Circumgerential Compression: A Clinical Trial." Journal of Trauma 59, no. 3 (2005): 659-664.

Lakstein, D., Blumenfeld, A., Sokolov, T. et al. "Tourniquet for Hemorrhage Control on the Battlefield: A 4-Year Accumulated Experience." Journal Trauma 54 (2003): S221-225.

Lau, M.S., Tee, J.C.,. "Use of a large Rusch Hydrostatic Catheter Balloon to Control Postpartum Hemorrhage Resulting From a Low Placental Implantation." Sinapore Medical Journal 50, no. 9 (2009): e321-e323.

Lezyne. Lezyne. 2013. http://www.lezyne.com/en/shock-drive (accessed March 10, 2013).

Lyon, M., Shiver, S.A., Greenfield, E.M., Reynolds, B.Z., Lerner, E.B., Wedmore, I.S., Schwartz, R.B. "Use of Novel Adominal Aortic Tourniquet to Reduce or Eliminate Flow in the Common Femoral Artery in Human Subjects." The Journal of Trauma and Acute Care Surgery 73, no. Supplemental 2 ( 2012): S103-105.

Mabry, R.L. "Tourniquet Use on the Battlefield ." Military Medicine 171 (2006): 352-356.

Macleod, Geroge H.B. Notes on the Surgery of the War in Crimea, With Remarks on the Treatment of Gunshot Wounds. London: John Churchill, 1858. 
Majno, G. "The Healing Hand: Man and Wound in the Ancient World." Harvard University Press, 1975: 278-9; 403-5.

McMaster Carr. 2013. www.mcmastercarr.com (accessed March 7, 2013).

Mello, J. "AS4/3501-6 Unidirectional Tape Specification Sheet." 2011a.

Mello, J. Laboratory Project 02, Appendix A. San Luis Obsipo: Mechanical Engineering Department - Cal Poly SLO, 2011b.

Middletown, R.W., Varian, J.P. "Tourniquet Paralysis." Australian \& New Zealand Journal of Surgery 44 (1974): 124-128.

Montgomery, Harold. "Presentation: Junctional Tourniquet, to the COMmittee on Tactical Combat Casualty Care." August 2,2011.

Moore, M.R., Garfin, S.R., Hargens, A.R>. "Wide Tourniquets Eliminate Blood flow at low inflation pressuress." Journal of Hand Surgery 12, no. 6 (1987): 1006-11.

Morse, S.S., Strauss, E.B., Sumpio, B.E. "Apparent Arterial Occlusion Due to Pneumatic Antishock Garment: Pitfall in Trauma Angiography (Case Report)." American Journal of Roentgenol 147, no. 2 (1986): 391-392.

North American Rescue. JETT Jucntional Emergency Treatement Tool. 2010. http://www.narescue.com/portal.aspx?CN=73330B0D4AFF (accessed March 11, 2013).

Papadopoulos, I.N., Kanakaris, N., Bonovas, S., et al. "Auditing 655 Fatalities with Pelvic Fractures by Autopsy as a basis to Evaluate Trauma Care." Journal of the American College of Surgeons 203, no. 1 (2006): 30-43.

Pilcher, L.S. Treatment of Wounds: Its Principles and Practice, General and Special, 2nd Ed. New York City: William Wood, 1899.

Pinto, A. Niola, R., Tortora, G., et al. "Role of Multidetector-Row CT in assessing the Source of Arterial Haemorrhage in Patients with Pelvic Vascular Trauma. Comparison with Angiography." Radiology Medical (Torino) 115, no. 4 (2010): 648-667.

Pourmoghadam, K.K., Fogler, R.J., Shaftan, G.W. "Ligation: An Alternative for Control of Exsanguination in Major Vascular Injuries." Journal of Trauma 43, no. 1 (1997): 126130.

QuikClot Combat Gauze. Z-Medica. n.d. http://z-medica.com/healthcare/Products/QuikClotCombat-Gauze.aspx (accessed August 15, 2012).

Rhee, P., Brown, C., Martin, M., Salim, A., Plurad, D., Green, D., Chambers, L., Demetriades, D., Velmahos, G., Alam, H. "QuikClot Use in Truama for Hemorrhage Control: Case 
Series of 103 Documented Uses." Journal of Trauma, Injury, Infection, and Critical Care 64 (2008): 1093-1099.

Roberts, I., Blackhall, K., Dickinson, K.J.,. "No evidence that medical anti-shock trousers improve survival for people with trauma, and some suggestion they may worsen outcomes, but more trials are needed." The Cochrane Library 4 (1999).

Saladin, K.S. Anatomy and Physiology. New York: McGraw Hill, 2010.

"Sani-Tech West Sanitary Silicone Tubing Specifications Sheet." 2008. http://www.sanitechwest.com/Literature/STHT-C.pdf (accessed 3 3/6/13, 2013).

Saunders, J. Medical Dictionary:The Free Dictionary. thefreedictionary.com. 2003. http://medical-dictionary.thefreedictionary.com/garmenting (accessed 8 5, 2012).

Schwartz, R.B., Reynolds, B.Z., Shiver, S.A., Lerner, E.B., Greenfield, E.M., Solis, R.A., Kimpel, N.A., Coule, P.L., McManus, J.G. "Comparison of Two Packable Hemostatic Guaze Dressings in a Procine Hemorrhage Model ." Perhospital Emergency Care 15 (2011): 477-482.

Seamon, M.J., Pathak, A.S., Bradley, K.M., et al. "Emergency Department Thoracotomy: Still Useful After Abdominal Exsanguination?" Journal of Trauma 64, no. 1 (2008): 1-8.

Spanjersberg, W.R., Knops, S.P., Schep, N.W., van Lieshout E.M., Patka, P., Schipper, I.B. "Effectiveness and Complications of Pelvic Circumferential Compression Devices in Patients with Unstable Pelvic Fractures: A Systematic Review of Literature." Injury 40, no. 10 (2009): 1031-1035.

Speer Optech. Speer Operational Technologies . 2011. http://www.speeroptech.com/aat/index.html (accessed March 11, 2013).

Staedtler Technical Drawing Equipment. Staedtler . 2011. http://www.staedtler.ca/comfort_compasses_ca (accessed 3 7, 2013).

Swan, K.G., Wright, D.S., Barbagiovanni, S.S., Swan, B.C, Swan, K.G. "Tourniquets Revisited." Journal of Trauma 66, no. 3 (2009): 672-675.

Velcro Brand: Woven Hook and Loop . Manchester: VELCRO, Inc., 2010.

von Gersdorff, H. Historical Anatomies on the Web. 1967. www.nlm.nih.gov/exhibition.historicalanatomies.gersdorff_bio.html (accessed July 26, 2012).

Walters T.J., Mabry, R.L.,. "Issues Related to the Use of Tourniquets on the Battlefield." Military Medicine 170 (2005a): 770-775. 
Walters, T.J., Wenke, J.C., Kauvar, D.S. et al. "Effectiveness of Self-Applied Tourniquets in Human Volunteers." Prehospital Emergency Care 9 (2005b): 416-22.

Ward, J.A., Husaini, S.H., Abplanalp, A.L., McCall, S., De Lorenzo, R.A. "Developing a Perfused Cadaver Training Model for Invasive Lifesaving Procedures: Uncontrolled Hemorrhage." Brooke Army Medical Center, Fort Sam Houston TX, 2012.

Watson-Jones, R. "Traumatic Uraemia." Journal of Bone \& Joint Surgery, British Volume 30 (1948): 233.

Watsons-Jones, R. Fractures and Joint Injuries, 4th Ed. London: E. \& S. Livingston, 1955.

Willing, D.R., Burris, D.G., Hutton, J.E., Minken, S.L. Rich, N.M.,. "A Balnced Approach to Tourniquet Use: Lessons Learned and Relearned." Journal of American College of Surgeons 203 (2006): 106-115.

Wolff, L.H., Adkins, T.F. "Tourniquet Problems in War Injuries." Bulletin US Army, Medical Department 59 (1945): 77-84.

Yang, J, Gao, J.M., Hu, P., Li, C.H., Zhao, S.H., Lin, X. "Application of Damge Control Orthopedic in 41 Patients with Severe Multiple Injuries." Chinese Journal of Traumatol 11, no. 3 (2008): 157-160.

Zuckerman, B.D. 510(k) Summary: Summary for the Combat Ready Clamp. Silver Spring: Center of Devices and Radiolocial Health, Division of Cardiovascular Devices, 2010.

Zukerman, B.D. K112384: 510(K) Letter of Approval for Abdominal Aortic Tourniquet. Silver Spring: Food and Drug Adminstration, 2011.

Zuckerman, B.D. K123194: Juctional Emergency Treatment Tool. Silver Springs: Food and Drug Adminstration, 2013. 
Appendix A

Table A. 1: Rank Order Comparison Chart of Requirements for the JTD

\begin{tabular}{|c|c|c|c|c|c|c|c|c|c|c|c|c|c|c|c|}
\hline $\begin{array}{l}\text { Requirem } \\
\text { ents }\end{array}$ & $\begin{array}{l}\text { Effect } \\
\text { ive }\end{array}$ & Fit & $\begin{array}{l}\text { Sa } \\
\text { fe }\end{array}$ & $\begin{array}{l}\text { Com } \\
\text { bat } \\
\text { Read } \\
\text { y }\end{array}$ & $\begin{array}{l}\text { Sm } \\
\text { all }\end{array}$ & $\begin{array}{l}\text { Lightwei } \\
\text { ght }\end{array}$ & $\begin{array}{l}\text { Lo } \\
\text { w } \\
\text { Co } \\
\text { st }\end{array}$ & $\begin{array}{l}\text { Ea } \\
\text { sy } \\
\text { to } \\
\text { Us } \\
\text { e } \\
\end{array}$ & $\begin{array}{l}\text { Quic } \\
\text { kly } \\
\text { Appli } \\
\text { ed }\end{array}$ & $\begin{array}{l}\text { Slippa } \\
\text { ge }\end{array}$ & $\begin{array}{l}\text { Applicat } \\
\text { ion } \\
\text { Pressur } \\
\text { e }\end{array}$ & $\begin{array}{l}\text { Relea } \\
\text { se }\end{array}$ & $\begin{array}{l}\text { Replace } \\
\text { ment }\end{array}$ & $\begin{array}{l}\text { She } \\
\text { lf } \\
\text { Lif } \\
\text { e }\end{array}$ & $\begin{array}{l}\text { Tot } \\
\text { al: }\end{array}$ \\
\hline Effective & N/A & 1 & 0 & 1 & 1 & 1 & 1 & 1 & 1 & 1 & 1 & 0 & 1 & 1 & 11 \\
\hline Fit & 0 & $\begin{array}{l}\mathrm{N} / \\
\mathrm{A}\end{array}$ & 0 & 1 & 1 & 1 & 1 & 1 & 1 & 0 & 1 & 1 & 0 & 1 & 9 \\
\hline Safe & 1 & 1 & $\begin{array}{l}\mathrm{N} / \\
\mathrm{A}\end{array}$ & 1 & 1 & 1 & 1 & 1 & 1 & 1 & 1 & 1 & 1 & 1 & 13 \\
\hline $\begin{array}{l}\text { Combat } \\
\text { ready }\end{array}$ & 0 & 0 & 0 & N/A & 1 & 1 & 1 & 0 & 1 & 0 & 1 & 0 & 1 & 1 & 7 \\
\hline Small & 0 & 0 & 0 & 0 & N/A & 0 & 1 & 0 & 0 & 0 & 0 & 0 & 1 & 1 & 3 \\
\hline $\begin{array}{l}\text { Lightweig } \\
\text { ht }\end{array}$ & 0 & 0 & 0 & 0 & 1 & N/A & 1 & 0 & 0 & 0 & 0 & 0 & 1 & 1 & 4 \\
\hline Low Cost & 0 & 0 & 0 & 0 & 0 & 0 & $\begin{array}{l}\mathrm{N} / \\
\mathrm{A}\end{array}$ & 0 & 0 & 0 & 0 & 0 & 0 & 1 & 1 \\
\hline $\begin{array}{ll}\text { Easy } & \text { to } \\
\text { Use } & \\
\end{array}$ & 0 & 0 & 0 & 1 & 1 & 1 & 1 & $\begin{array}{l}\mathrm{N} / \\
\mathrm{A}\end{array}$ & 1 & 0 & 0 & 0 & 1 & 1 & 7 \\
\hline $\begin{array}{l}\text { Quickly } \\
\text { applied }\end{array}$ & 0 & 0 & 0 & 0 & 1 & 1 & 1 & 0 & N/A & 0 & 0 & 0 & 1 & 1 & 5 \\
\hline Slippage & 0 & 1 & 0 & 1 & 1 & 1 & 1 & 1 & 1 & N/A & 0 & 0 & 1 & 1 & 9 \\
\hline $\begin{array}{l}\text { Applicatio } \\
\text { n } \\
\text { Pressure }\end{array}$ & 0 & 0 & 0 & 0 & 1 & 1 & 1 & 1 & 1 & 1 & N/A & 1 & 1 & 1 & 9 \\
\hline Release & 1 & 0 & 0 & 1 & 1 & 1 & 1 & 1 & 1 & 1 & 1 & N/A & 1 & 1 & 11 \\
\hline $\begin{array}{l}\text { Replacem } \\
\text { ent }\end{array}$ & 0 & 1 & 0 & 0 & 0 & 0 & 1 & 0 & 0 & 0 & 0 & 0 & N/A & 1 & 3 \\
\hline Shelf Life & 0 & 0 & 0 & 0 & 0 & 0 & 0 & 0 & 0 & 0 & 0 & 0 & 0 & $\begin{array}{l}\mathrm{N} / \\
\mathrm{A}\end{array}$ & 0 \\
\hline
\end{tabular}


Appendix B

Figure B. 1

\begin{tabular}{|c|c|}
\hline Component & Number \\
\hline Miniature Pnuematic Actuator & 1 \\
\hline Fixation Plate & 2 \\
\hline
\end{tabular}

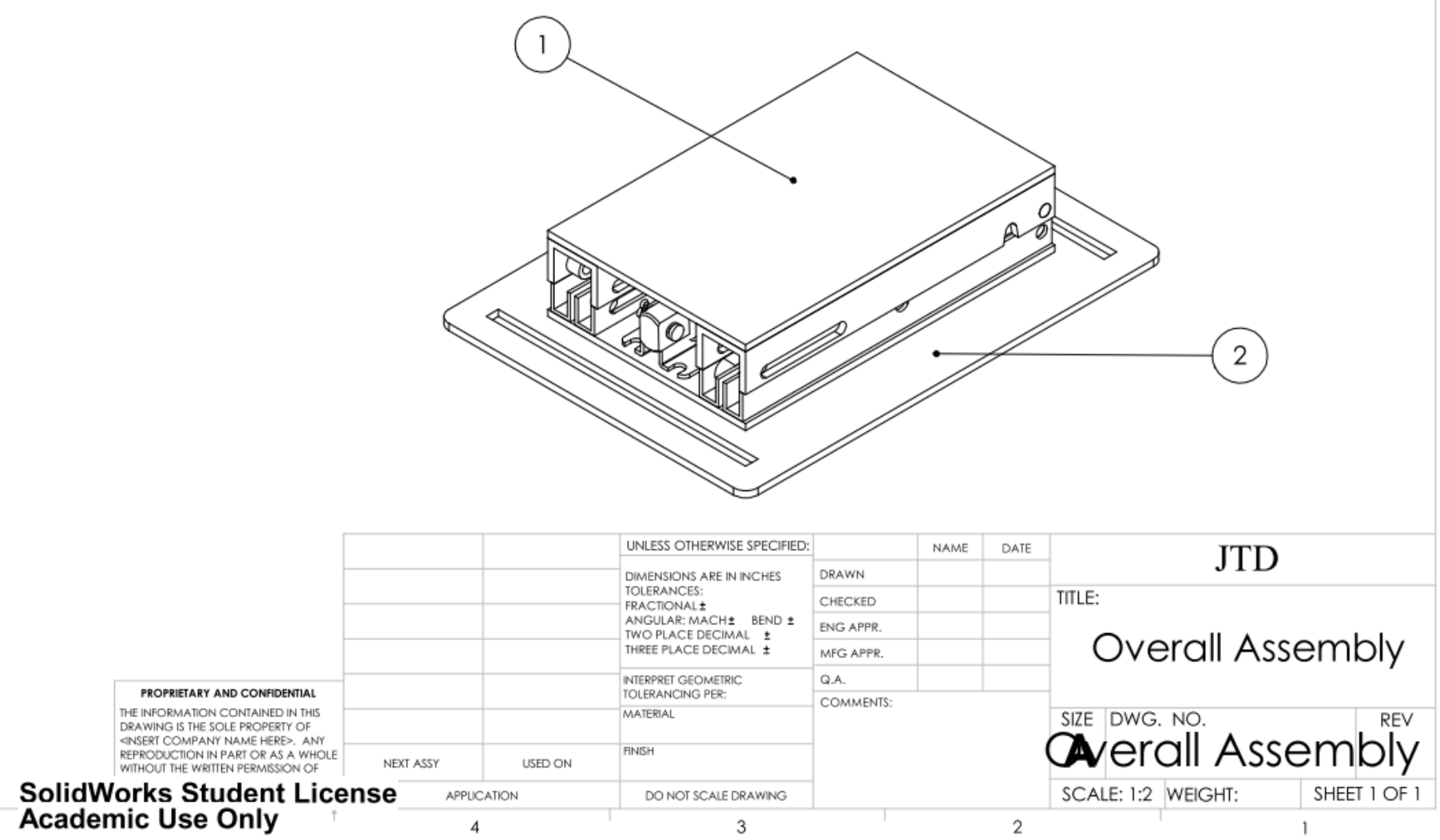


Figure B. 2

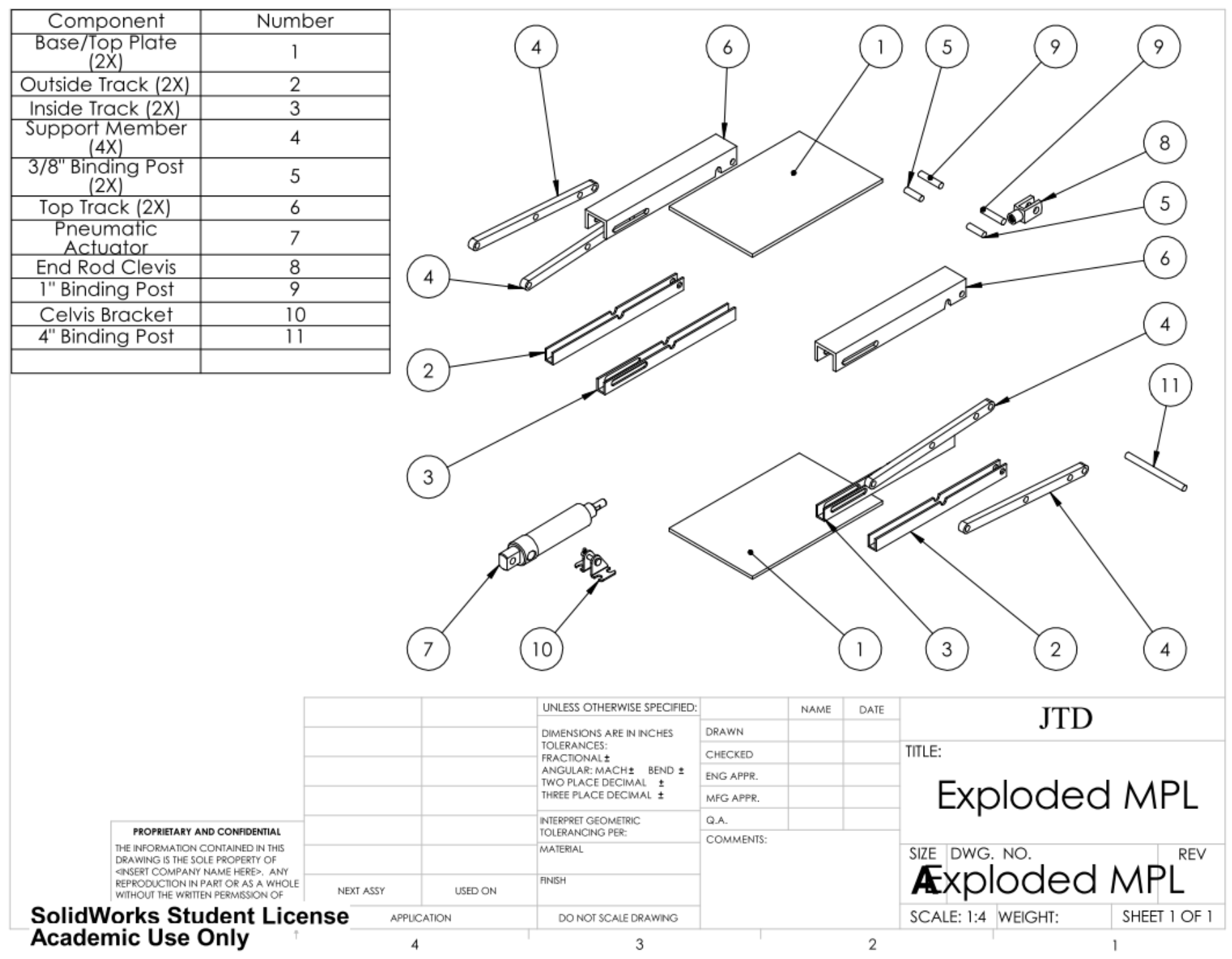


Figure B. 3

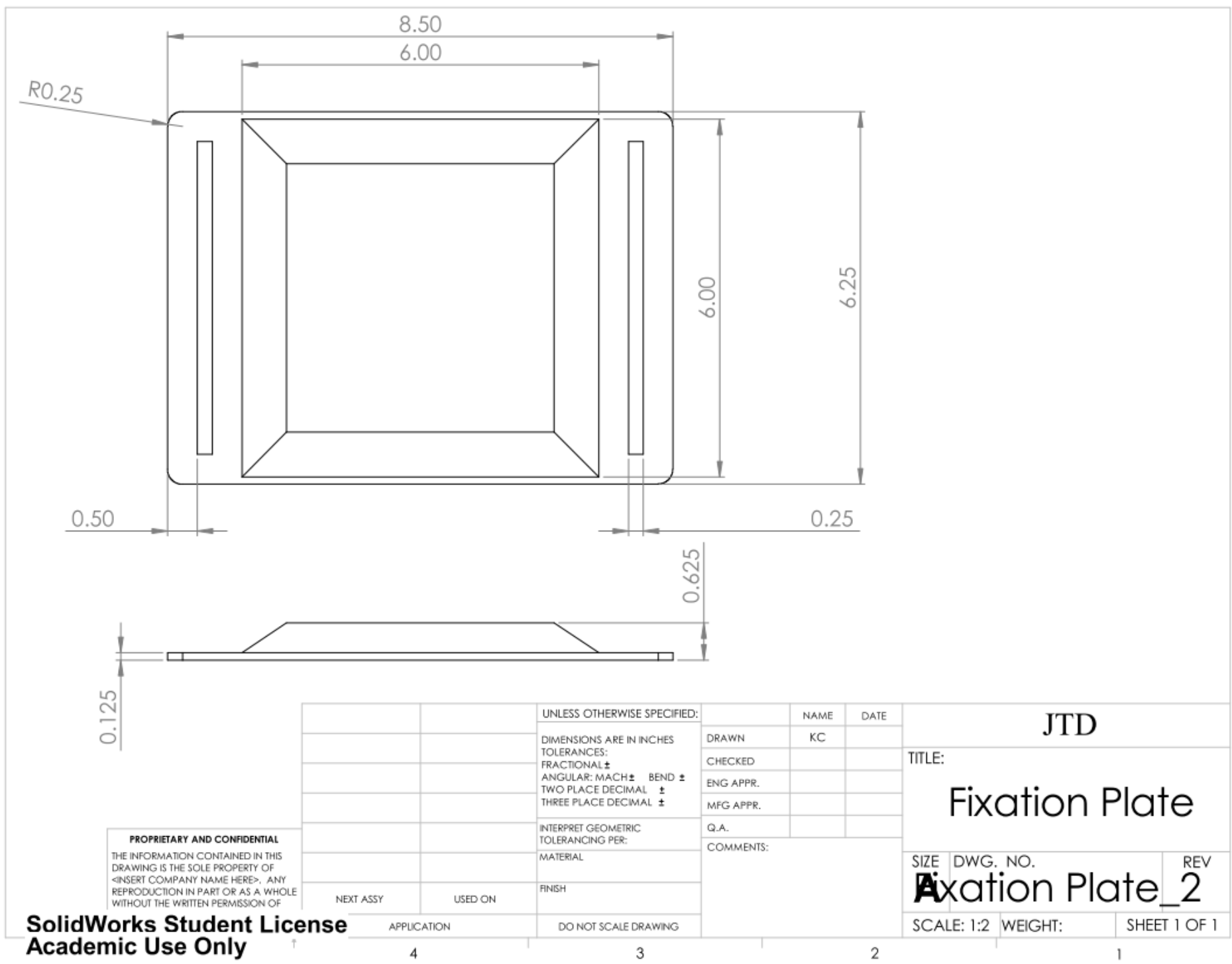


Figure B. 4

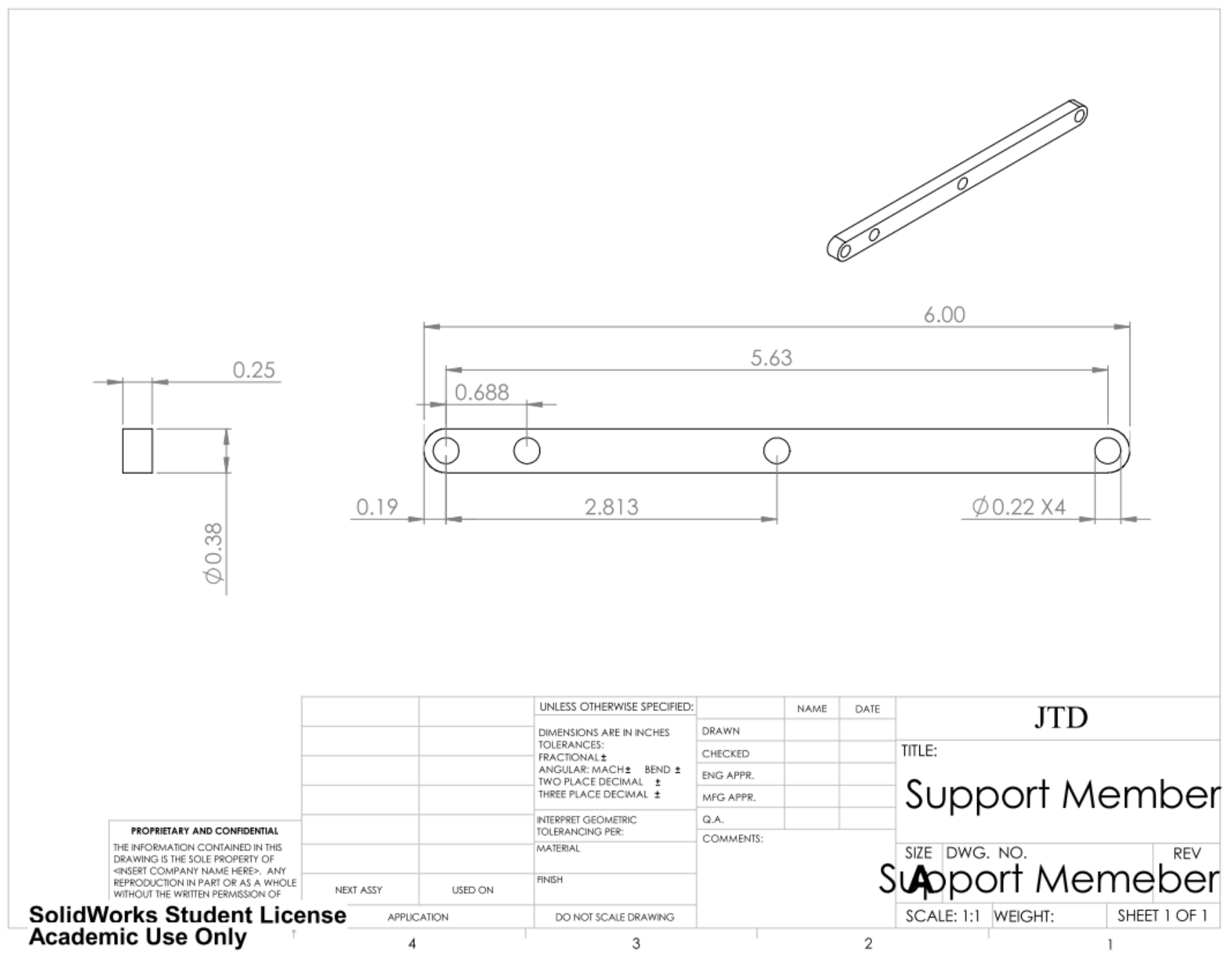


Figure B. 5

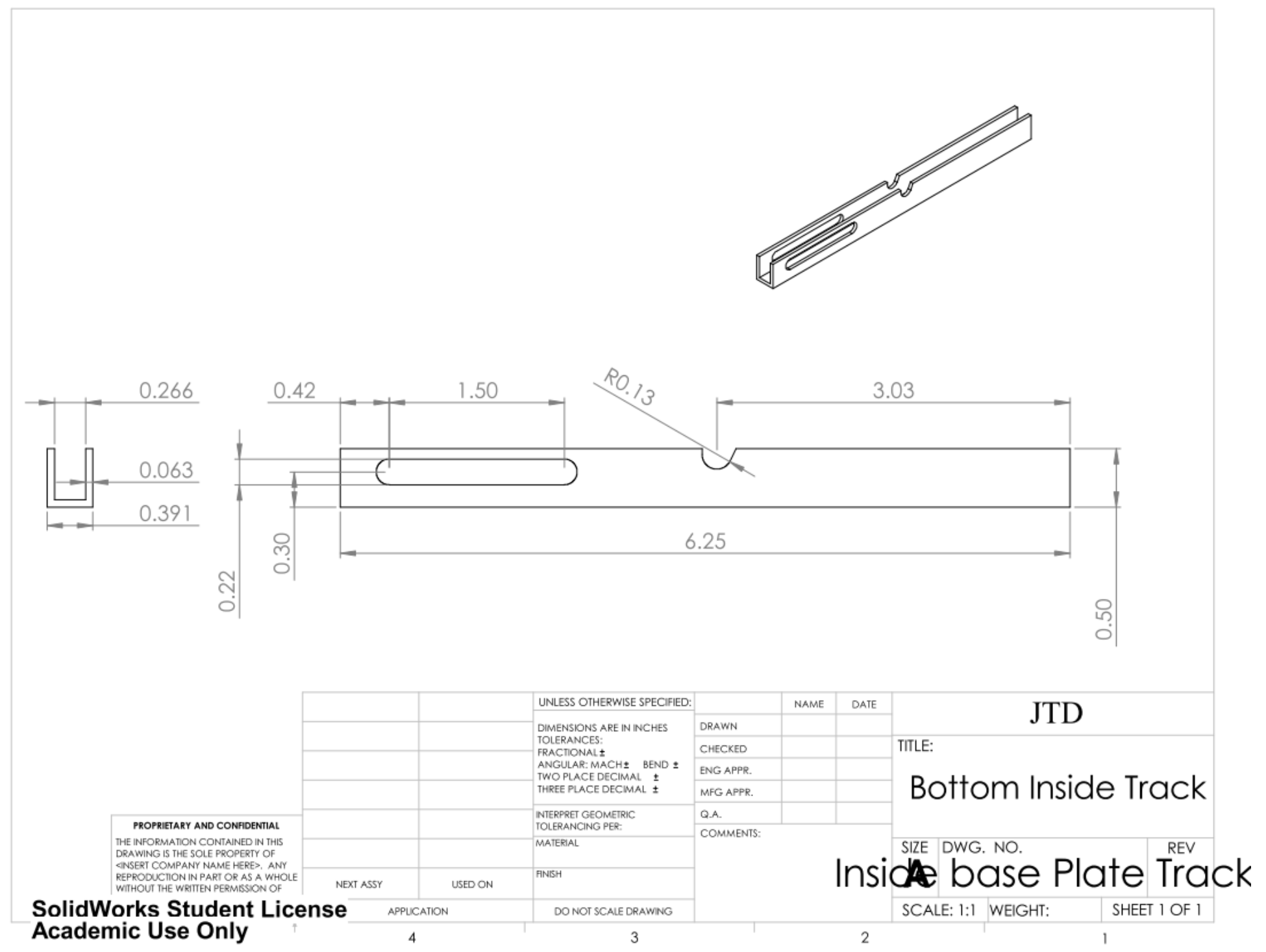


Figure B. 6

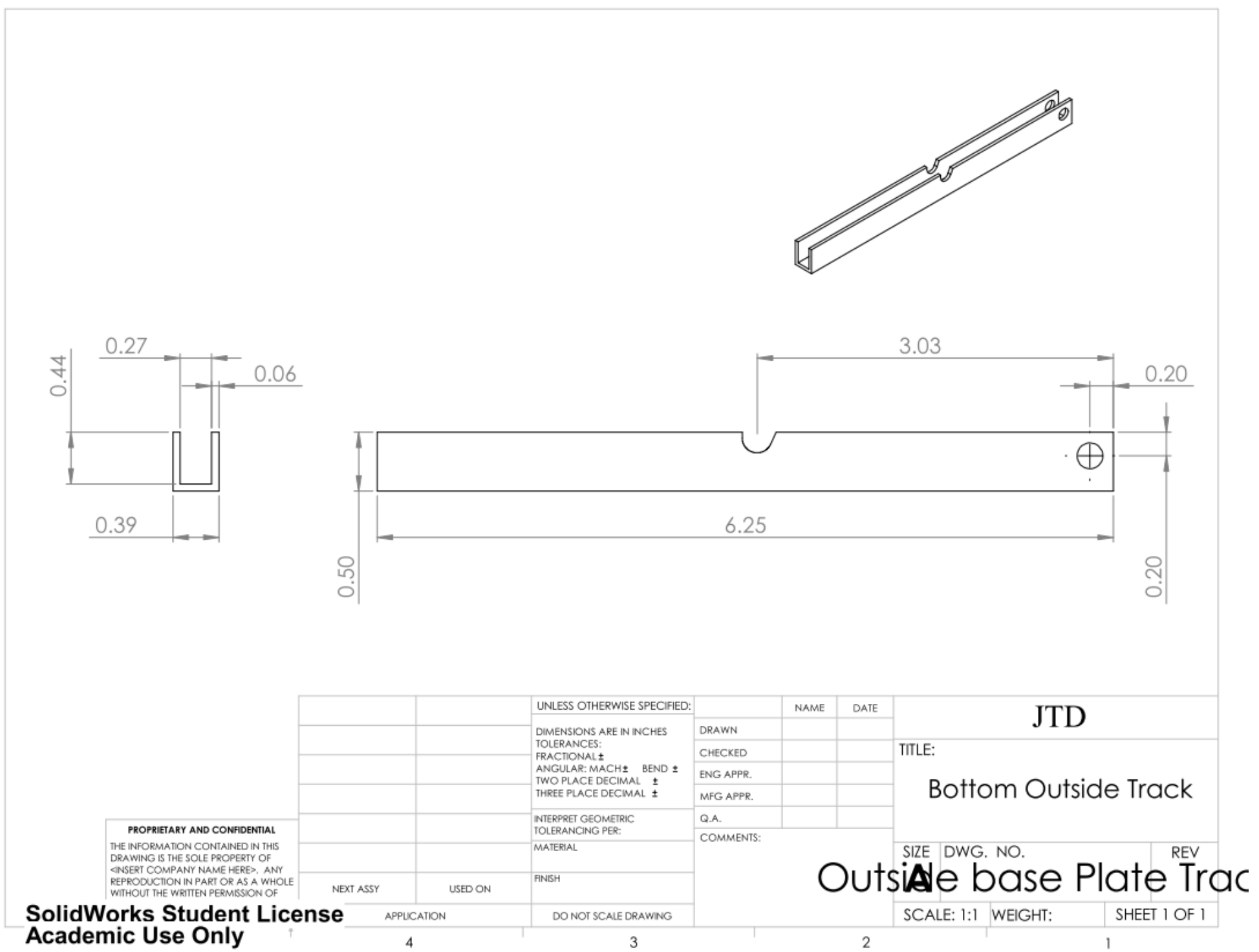


Figure B. 7

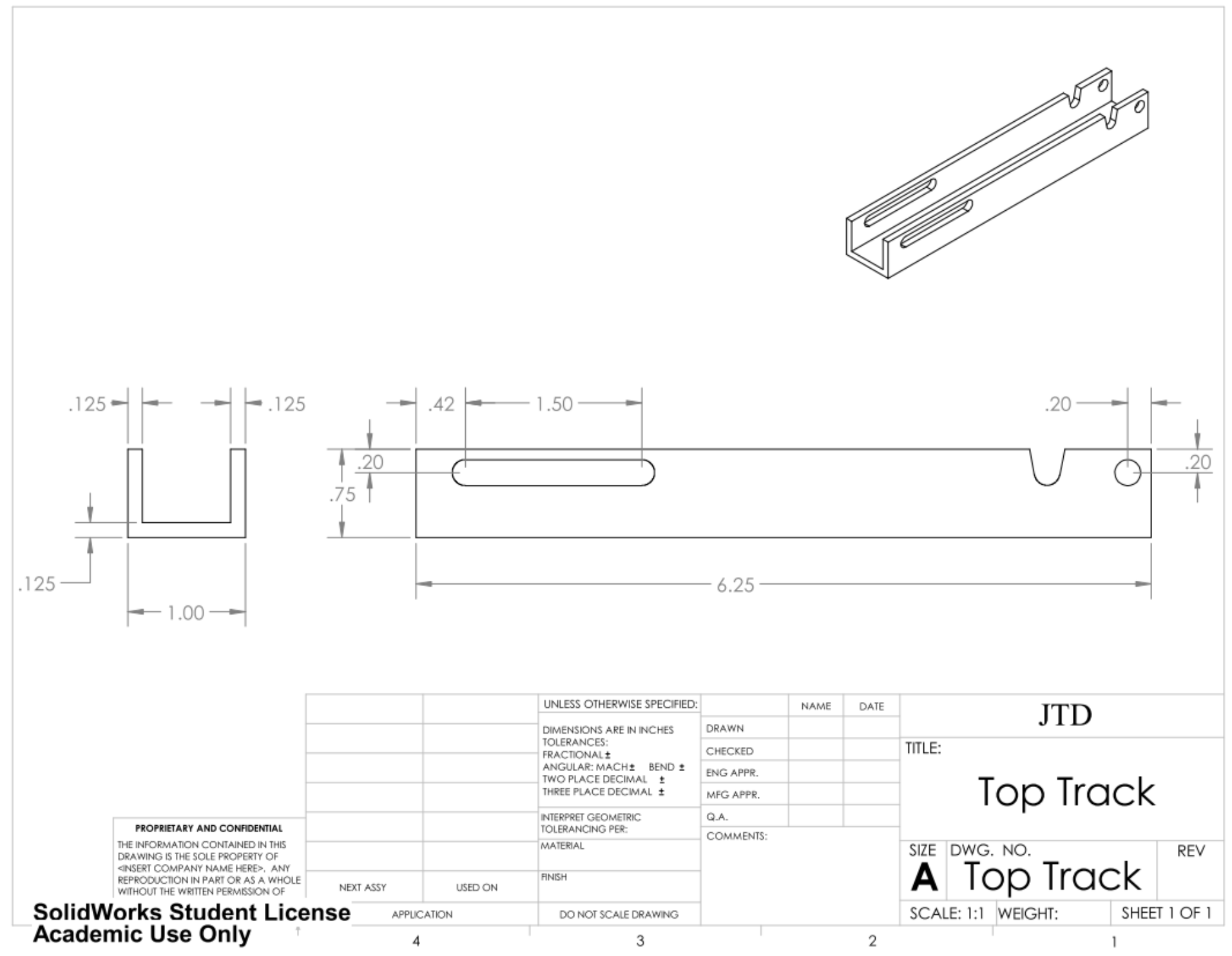


Figure B. 8

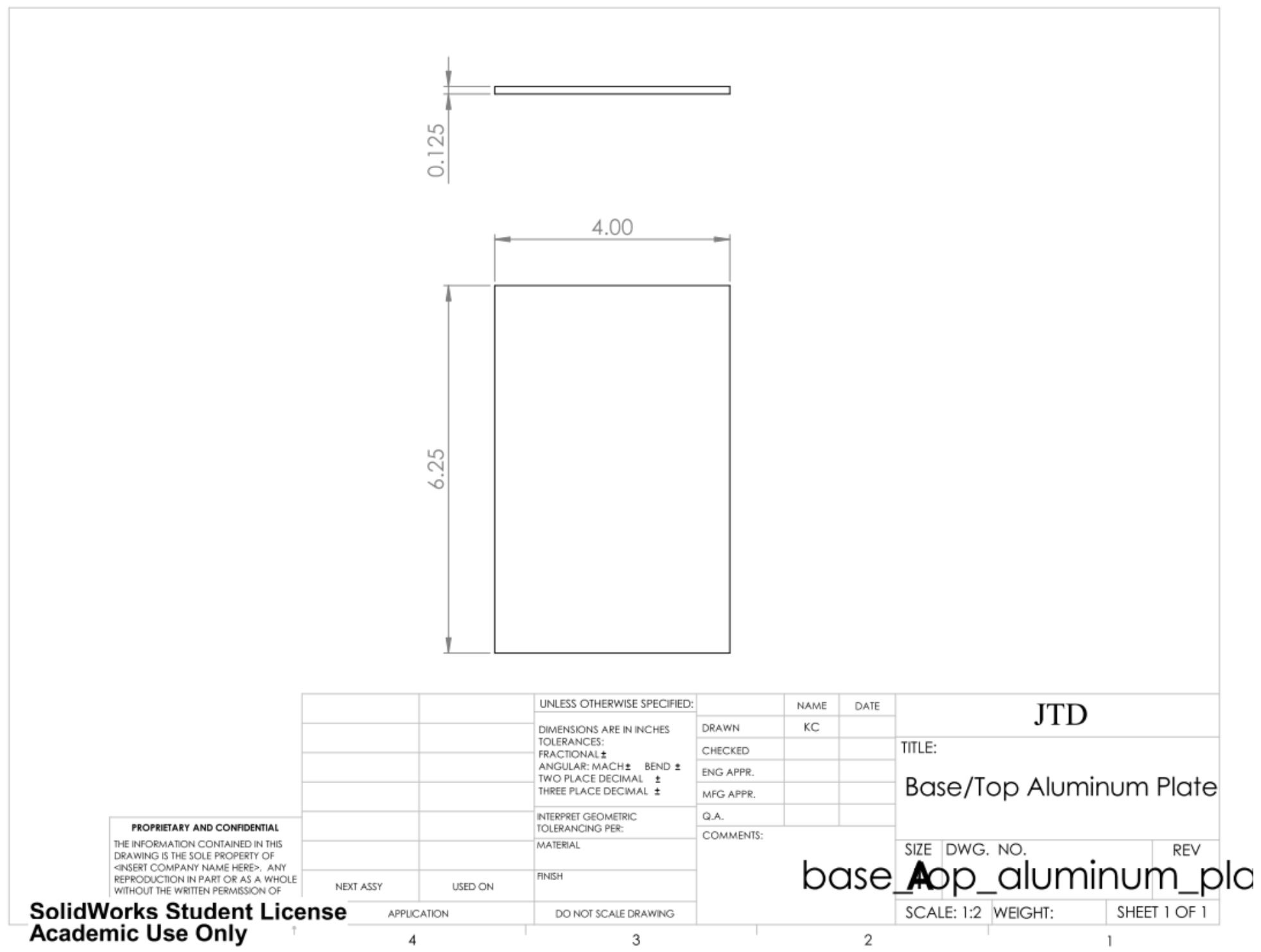




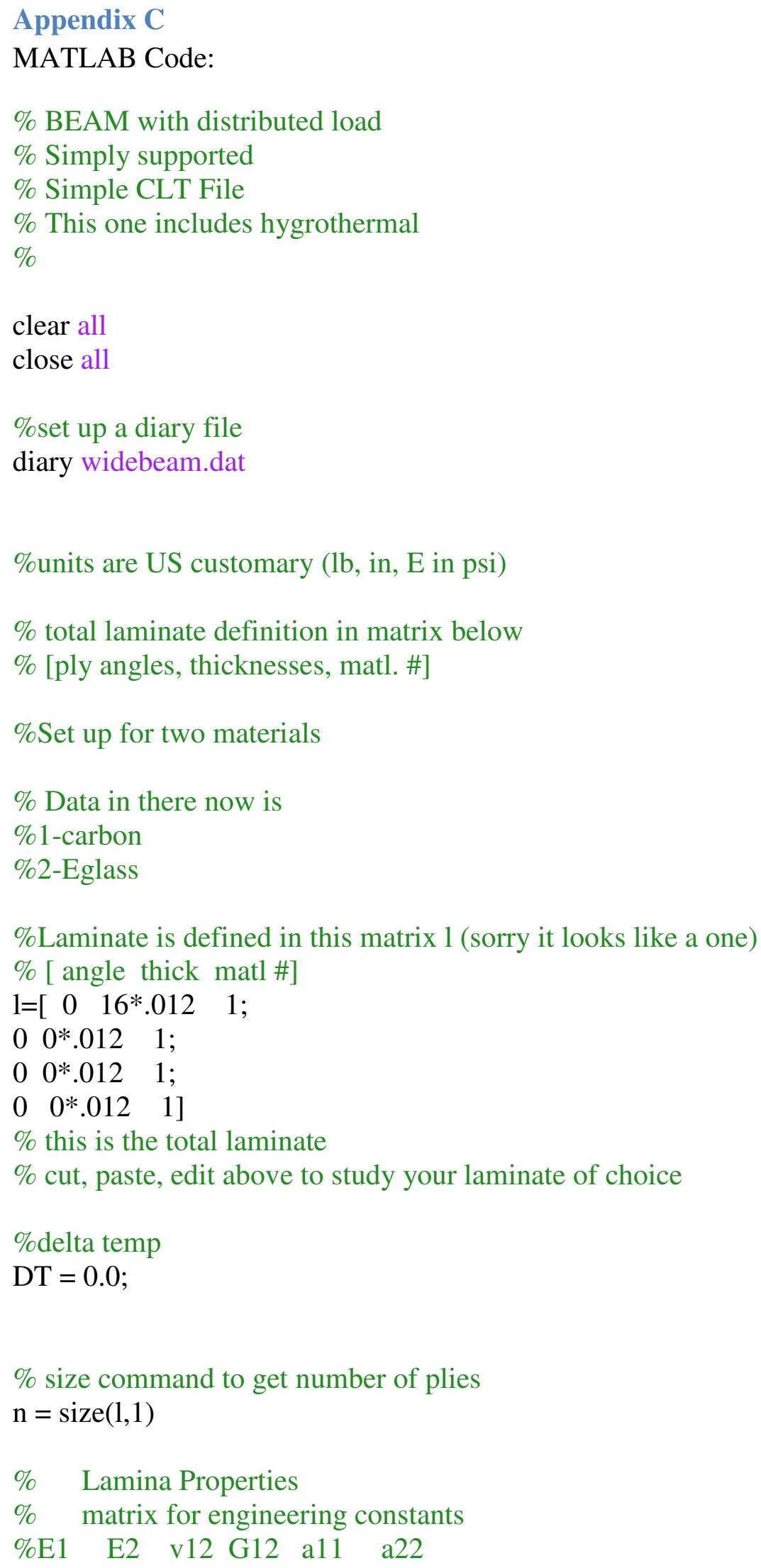




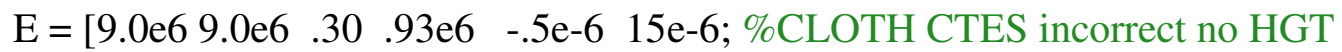
$5.4 \mathrm{e} 3 \quad 4.8 \mathrm{e} 3.32 .9 \mathrm{e} 3 \quad 0.0 \mathrm{e}-6 \quad 0.0 \mathrm{e}-6]$ \% E-Glass/Epoxy

$\%$ a's are CTE's

\%intiialize the ply distance and ABD matrices

$\mathrm{NT}=\operatorname{zeros}(3,1)$;

$\mathrm{MT}=\operatorname{zeros}(3,1)$;

$\mathrm{h}=\operatorname{zeros}(\mathrm{n}+1,1)$;

$\mathrm{A}=\mathrm{zeros}(3)$;

$\mathrm{B}=\operatorname{zeros}(3)$

$\mathrm{D}=\operatorname{zeros}(3)$;

$\%$ Form R matrix which relates engineering to tensor strain

$\mathrm{R}=\left[\begin{array}{lll}1 & 0 & 0\end{array}\right.$

$\begin{array}{lll}0 & 1 & 0\end{array}$

$\left.\begin{array}{lll}0 & 0 & 2\end{array}\right]$

$\%$ find the total thickness

total $=\operatorname{sum}(1,1)$

thick $=\operatorname{total}(1,2)$;

$\%$ locate the bottom of the first ply

$\mathrm{h}(1)=-$ thick $/ 2$;

$\operatorname{imax}=\mathrm{n}+1$;

$\%$ loop for rest of the ply distances from midsurf

for $\mathrm{i}=2$ : $\operatorname{imax}$

$\mathrm{h}(\mathrm{i})=\mathrm{h}(\mathrm{i}-1)+\mathrm{l}(\mathrm{i}-1,2)$;

end

\%loop over each ply to integrate the ABD matrices

for $\mathrm{i}=1: \mathrm{n}$

$\%$ ply material ID

$\mathrm{mi}=\mathrm{l}(\mathrm{i}, 3)$;

$\mathrm{v} 21=\mathrm{E}(\mathrm{mi}, 2) * \mathrm{E}(\mathrm{mi}, 3) / \mathrm{E}(\mathrm{mi}, 1)$;

$\mathrm{d}=1-\mathrm{E}(\mathrm{mi}, 3) * \mathrm{v} 21$;

$\%$ Q12 matrix

$\mathrm{Q}=[\mathrm{E}(\mathrm{mi}, 1) / \mathrm{d} \quad \mathrm{v} 21 * \mathrm{E}(\mathrm{mi}, 1) / \mathrm{d} \quad 0 ;$

$\mathrm{E}(\mathrm{mi}, 3) * \mathrm{E}(\mathrm{mi}, 2) / \mathrm{d} \quad \mathrm{E}(\mathrm{mi}, 2) / \mathrm{d} \quad 0$;

$\begin{array}{lll}0 & 0 & \mathrm{E}(\mathrm{mi}, 4)]\end{array}$ 
$\%$ ply angle in radians

a1=l(i,1)*pi/180;

$\%$ Form transformation matrices T1 for ply

$\mathrm{T} 1=\left[(\cos (\mathrm{a} 1))^{\wedge} 2 \quad(\sin (\mathrm{a} 1))^{\wedge} 2 \quad 2 * \sin (\mathrm{a} 1)^{*} \cos (\mathrm{a} 1)\right.$;

$(\sin (\mathrm{a} 1))^{\wedge} 2 \quad(\cos (\mathrm{a} 1))^{\wedge} 2 \quad-2 * \sin (\mathrm{a} 1) * \cos (\mathrm{a} 1)$;

$-\sin (\mathrm{a} 1)^{*} \cos (\mathrm{a} 1) \quad \sin (\mathrm{a} 1)^{*} \cos (\mathrm{a} 1) \quad(\cos (\mathrm{a} 1))^{\wedge} 2-(\sin (\mathrm{a} 1))^{\wedge} 2 \mathrm{]}$;

\%Form Qxy

$\mathrm{Qxy}=\operatorname{inv}(\mathrm{T} 1) * \mathrm{Q} * \mathrm{R} * \mathrm{~T} 1 * \operatorname{inv}(\mathrm{R})$;

$\%$ build up the laminate stiffness matrices

$\mathrm{A}=\mathrm{A}+\mathrm{Qxy} *(\mathrm{~h}(\mathrm{i}+1)-\mathrm{h}(\mathrm{i}))$;

$\mathrm{B}=\mathrm{B}+\mathrm{Qxy} *\left(\mathrm{~h}(\mathrm{i}+1)^{\wedge} 2-\mathrm{h}(\mathrm{i})^{\wedge} 2\right)$;

$\mathrm{D}=\mathrm{D}+\mathrm{Qxy} *\left(\mathrm{~h}(\mathrm{i}+1)^{\wedge} 3-\mathrm{h}(\mathrm{i})^{\wedge} 3\right)$;

\%load alphs into and array

$\mathrm{a}=[\mathrm{E}(\mathrm{mi}, 5) ; \mathrm{E}(\mathrm{mi}, 6) ; 0.0]$;

\%transform cte's mult by DT to get thermal strain exy

$\operatorname{exy}=(\mathrm{R} * \operatorname{inv}(\mathrm{T} 1) * \operatorname{inv}(\mathrm{R}) * \mathrm{a}) * \mathrm{DT}$;

\%build up thermal load as well now

$\mathrm{NT}=\mathrm{NT}+\mathrm{Qxy} \mathrm{exy}^{*}(\mathrm{~h}(\mathrm{i}+1)-\mathrm{h}(\mathrm{i}))$;

$\mathrm{MT}=\mathrm{MT}+.5^{*}\left(\mathrm{Qxy} \mathrm{exy}^{*}\left(\mathrm{~h}(\mathrm{i}+1)^{\wedge} 2-\mathrm{h}(\mathrm{i})^{\wedge} 2\right)\right)$;

\%end of stiffness loop

end

$\%$ change the display format for compliance matrix

format short e

$$
\begin{aligned}
& \mathrm{A}=1.0 * \mathrm{~A} \\
& \mathrm{~B}=.5 * \mathrm{~B} \\
& \mathrm{D}=(1 / 3) * \mathrm{D} \\
& \% \\
& \% \text { Quasi Checks pg230 ABC } \\
& \text { ck1=A(1,1)-A(2,2) } \\
& \text { ck2=A(1,1)-A(1,2)-2*A(3,3) } \\
& \% \text { also is Ai6=0 } \\
& \% \\
& \%
\end{aligned}
$$


$\mathrm{K}=[\mathrm{A}, \mathrm{B}$;

$\mathrm{B}, \mathrm{D}]$

$\%$ put in mechanical loads here

$\%$ mech loads

\%beam data

$\mathrm{L}=8 \%$ length (in)

$\mathrm{b}=6.25 \%$ width (in)

\% what is a reasonalbe effective pressure on side of railcar

pres $=20 \%$ psf

prespsi $=$ pres $/ 144$

$\mathrm{q}=$ prespsi*b \% $\%$ si

$\% \max$ line load

$\% \mathrm{Mx}=\mathrm{q}^{*} \mathrm{~L}^{\wedge} 2 /(8 * \mathrm{~b})$

$\%$ incude incduec moment to suppress kappy and Kappxy

$\mathrm{Nx}=22.0$

$\mathrm{Ny}=0.0$

$\mathrm{Ns}=0.0$

$\mathrm{Mx}=-60$

$\mathrm{My}=\mathrm{D}(1,2) * \mathrm{Mx} / \mathrm{D}(1,1)$

$\mathrm{Ms}=\mathrm{D}(1,3) * \mathrm{Mx} / \mathrm{D}(1,1)$

$\%$

$\%$ superimpose mech and thermal loads

$\operatorname{load}=[\mathrm{NT}(1)+\mathrm{Nx}$;

$\mathrm{NT}(2)+\mathrm{Ny}$;

$\mathrm{NT}(3)+\mathrm{Ns}$;

$\mathrm{MT}(1)+\mathrm{Mx}$;

MT(2) + My;

$\mathrm{MT}(3)+\mathrm{Ms}$ ]

$\mathrm{C}=\operatorname{inv}(\mathrm{K})$

$\%$

$\%$ wide and narrow effective stiffness

$\% \mathrm{EIn}=\mathrm{b} / \mathrm{C}(4,4)$

$\mathrm{EIw}=\mathrm{b} * \mathrm{~K}(4,4)$

$\%$

$\%$ deflection for SS

$\%$ wn $=-5 * \mathrm{q}^{*} \mathrm{~L}^{\wedge} 4 /(384 * \mathrm{EIn})$

$\mathrm{ww}=-5 * \mathrm{q}^{*} \mathrm{~L}^{\wedge} 4 /(384 * \mathrm{EIw})$

$\%$ 
$\%$ compute the strains $=$ compliance times load

$\mathrm{e}=\mathrm{C} *$ load

$\%$

$\%$

$\%$ reduction factor for ultimate (pseudo A-basis use .80

$\mathrm{RF}=.80$

$\%$

$\%$

$\%$ allowable strains reduced to account for ultimate strength after impact

$\%$ row1 is carbon

$\%$ row 2 is E-glass

$\%$ transverse prperties assumed same

$\%$ load allowable strains into array

$\%$ ELU ELUP ETU ETUP ELTU

ea $=\left[\mathrm{RF}^{*} .010 \mathrm{RF} * .010 \quad \mathrm{RF}^{*} .010 \mathrm{RF}^{*} .010 \mathrm{RF} * .025 ; \%\right.$ cloth guess

$\mathrm{RF}^{*} .02 \mathrm{RF} * .018$ RF*.0067 $\left.\mathrm{RF}^{*} .031 \mathrm{RF}^{*} .0296\right]$

$\%$

$\%$

$\%$ zero out results array

ERES $=\operatorname{zeros}(2 * n, 6)$

$\operatorname{SRES}=\operatorname{zeros}(2 * n, 6)$;

$\%$ loop over each ply and calculate strain

for $\mathrm{i}=1: \mathrm{n}$;

\%loop over top and bottom of each ply

for $\mathrm{j}=1: 2$;

$\%$ one is bottom two is top for loc

ply $=\mathrm{i}$;

loc $=\mathrm{j}$;

$\mathrm{z}=\mathrm{h}(\mathrm{i}-1+\mathrm{j})$;

$\%$ ply strain from midplane strain

$\mathrm{el}=\left[\mathrm{e}(1)+\mathrm{z}^{*} \mathrm{e}(4) ; \mathrm{e}(2)+\mathrm{z}^{*} \mathrm{e}(5) ; \mathrm{e}(3)+\mathrm{z}^{*} \mathrm{e}(6)\right] ;$

$\%$ ply material ID

$\mathrm{mi}=\mathrm{l}(\mathrm{i}, 3)$;

v21 = $\mathrm{E}(\mathrm{mi}, 2) * \mathrm{E}(\mathrm{mi}, 3) / \mathrm{E}(\mathrm{mi}, 1)$;

$\mathrm{d}=1-\mathrm{E}(\mathrm{mi}, 3) * \mathrm{v} 21$;

$\%$ Q12 matrix

$\mathrm{Q}=[\mathrm{E}(\mathrm{mi}, 1) / \mathrm{d} \quad \mathrm{v} 21 * \mathrm{E}(\mathrm{mi}, 1) / \mathrm{d} \quad 0 ;$

$\mathrm{E}(\mathrm{mi}, 3) * \mathrm{E}(\mathrm{mi}, 2) / \mathrm{d} \quad \mathrm{E}(\mathrm{mi}, 2) / \mathrm{d} \quad 0$;

$\begin{array}{lll}0 & 0 & \mathrm{E}(\mathrm{mi}, 4)]\end{array}$

$\%$ 


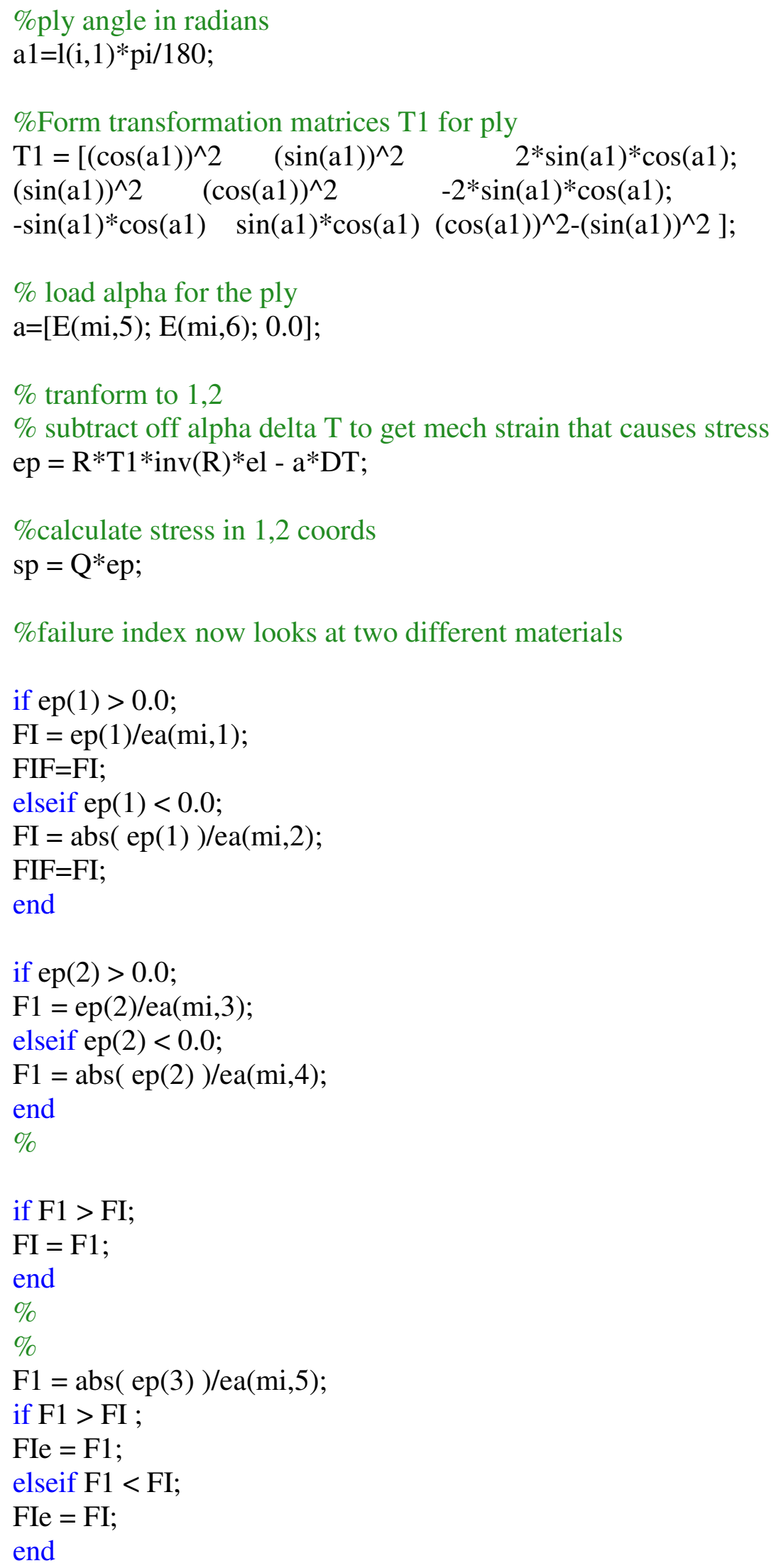


$\%$ load the results array

$\%$ note top and botom of every ply!

\%strain results, FI based on Max Strain

\%angle,eps1,eps2,gamma12,FI, FIfiber

$\operatorname{ERES}(2 * \mathrm{i}+\mathrm{j}-2,1)=\mathrm{l}(\mathrm{i})$;

$\operatorname{ERES}(2 * \mathrm{i}+\mathrm{j}-2,2)=\operatorname{ep}(1)$;

$\operatorname{ERES}(2 * i+j-2,3)=e p(2)$;

$\operatorname{ERES}(2 * \mathrm{i}+\mathrm{j}-2,4)=\mathrm{ep}(3)$;

$\operatorname{ERES}(2 * \mathrm{i}+\mathrm{j}-2,5)=\mathrm{FIe}$;

$\operatorname{ERES}(2 * \mathrm{i}+\mathrm{j}-2,6)=\mathrm{FIF}$;

$\%$ stress results, FI based on max strain

\%angle,Sigma1,Sigma2,Tau12, FI, FIfiber

$\operatorname{SRES}(2 * \mathrm{i}+\mathrm{j}-2,1)=\mathrm{l}(\mathrm{i})$;

$\operatorname{SRES}(2 * \mathrm{i}+\mathrm{j}-2,2)=\mathrm{sp}(1)$;

$\operatorname{SRES}(2 * \mathrm{i}+\mathrm{j}-2,3)=\mathrm{sp}(2)$;

$\operatorname{SRES}(2 * \mathrm{i}+\mathrm{j}-2,4)=\mathrm{sp}(3)$;

$\operatorname{SRES}(2 * \mathrm{i}+\mathrm{j}-2,5)=\mathrm{FIe}$;

$\operatorname{SRES}(2 * \mathrm{i}+\mathrm{j}-2,6)=\mathrm{FIF}$;

end
$\%$
end
ERES=ERES $* 1$
SRES=SRES $* 1$

diary off

$\%$

$\%$ 


\section{Appendix D}

Laboratory Procedure 2, Appendix A extracted from Dr. Mello's lab materials, Spring Quarter 2011

\section{Appendix A - Fabrication of a 16-Ply Carbon/Epoxy Interlaminar Shear Test Panel}

\section{Part I - Preparation of Carbon Prepreg}

1. Remove the carbon prepreg from the freezer. Allow bagged prepreg to reach room temperature before opening. Avoid contaminating the prepreg with dirt, fiberglass threads, oil, etc. during handling.

2. Cut sixteen 3"x4" rectangles out the carbon epoxy prepreg, using the caul plate as a template. Make sure that the fiber direction is oriented along the four-inch direction of the caul plate. If the gap between the fibers exceeds .040 inch, replace the ply. The prepreg is best cut with an OLFA cutter. See figures 1 and 2 below.

3. Bag unused carbon prepreg. Seal bag and return to freezer.

\section{Part II - Debulking Procedure}

1. Place the Debulking tool on the table.

2. Peel the bagging material back just far enough to lay down carbon plies. There is no need to completely remove the bagging material. Note: tear the bagging material back with a quick and firm tugging motion.

3. Remove the prepreg backing and place \#1 ply at the far left end of the release cloth on the Debulking tool. Squeegee this ply flat and ripple-free with a wooden roller.

4. Remove the backing material from ply \#2 and carefully place on ply \#1. Be careful as once these plies are together there is no separating them.

5. Again squeegee the plies with the wooden roller.

6. Repeat steps 4 and 5 with plies \#3 and \#4.

7. Begin a new pile of four plies adjacent to the first pile.

8. Lay-up four plies, made of 4 plies each.

9. Now the carbon epoxy is ready for debulking. Cover the plies with release cloth.

10. Place a layer of N-10 breather over the release cloth.

11. Cover the assembly with the bagging material and edge seal the bag with your fingers or the sealing tool. 
12. Connect the vacuum hose to the debulking tool.

13. Turn on the vacuum pump using the instructions on the card on the pump. Draw vacuum.

14. Draw vacuum at $25-30 \mathrm{~mm} \mathrm{Hg}$ and debulk for a minimum of five minutes.

15. After debulking, turn the pump off, pull back the bagging material and breather pack.

16. Combine the four piles carefully into two, squeegee, and repeat steps 10-14.

17. Repeat step 15. Combine the two piles into one, squeegee, and repeat steps 10-14.

18. Repeat step 15.

Debulking completed.

\section{Part III - Preparation of the Lay-up Tool}

Modify as needed the size of the non-porous release, breather and bag in the below instructions. 1. Cut a 10"x10" sheet of non-porous release cloth and place it at the center of the tool. Tape the corners down with single-sided tape. See the photo in figure 3.

2. Place a caul plate in the middle of the release cloth; form a dam around the caul plate with the damming material. Remove the caul plate.

3. Cut out $3 \frac{1 / 2}{2}$ "x $4 \frac{1 / 2}{2}$ " pieces of A-4000 release film.

\section{Part IV - Lay-up Assembly}

Refer to the section view of Figure 13 for the lay-up assembly.

1. Place the carbon/epoxy lay-up in the middle of the cavity formed by the dams. Some additional trimming maybe required to fit the laminate in the dams. Use the caul plate as a template. And cut with a Stanley knife. Wear safety glasses. See figure 4 which shows the laminate in the dams.

2. Place the A 4000 release on top of the laminate, ensure that the release completely overlays the part, see figure 5 .

(Do not use the porous release as this is net resin system)

3. Secure and seal the caul plate in place with single-sided tape, straddling the dam and the caul plate, see figure 8.

\section{Part V-Bagging Procedure}

1. Cut vacuum bag sealant tape and size it to surround the perimeter of the non-porous release on the tool, see figure 8 .

2. Place the thermocouple sandwiches along side the dam. Press the TC wires into the vacuum bag sealant tape. Cut a small piece of sealant tape and lay it over the wires to ensure a good seal. 
3. Lay one layer of $\mathrm{N}-10$ breather cloth over the lay-up as shown in figure 9 .

4. Cut a piece of bagging material with scissors to cover the tool as shown in figure 10. Install a vacuum valve by cutting a $1 / 2$ " diameter hole in the bag material. Put this hole in the corner if the plan is to cure two panels in the autoclave at once.

5. Edge seal the bag with your fingers or a wooden roller.

6. Connect the vacuum line to the pump and close the valve leading to the debulking hose.

7. Start the vacuum pump. Draw the vacuum down to $28-30 \mathrm{~mm} \mathrm{Hg}$ and close the main vacuum valve. This measures the integrity of the bag.

8. The maximum allowable leak rate is .5in $\mathrm{Hg} / \mathrm{min}$. Note: sealing the bag requires some experience and technique. Most leaks occur at the corners, around the vacuum inlet or through creases in the bag. The bag may need to be pulled up and laid down a few times to get a good seal.

9. After the leak check is passed, trim the excess bagging material from the lay-up.

10. Disconnect the vacuum line from the pump. The lay-up is now ready for curing.

Part VI - Autoclave Cure Procedure for T700/LC-930

See separate instructions for curing composites using the ASC Econclave.

The following overall procedures are based on manual control.

Part VII - Specimen Sawing

See separate instructions and briefing on cutting the laminate into test specimens.

Part VIII - Specimen Testing

Refer to previous handouts and the appropriate ASTM specifications for the two tests to be performed. 


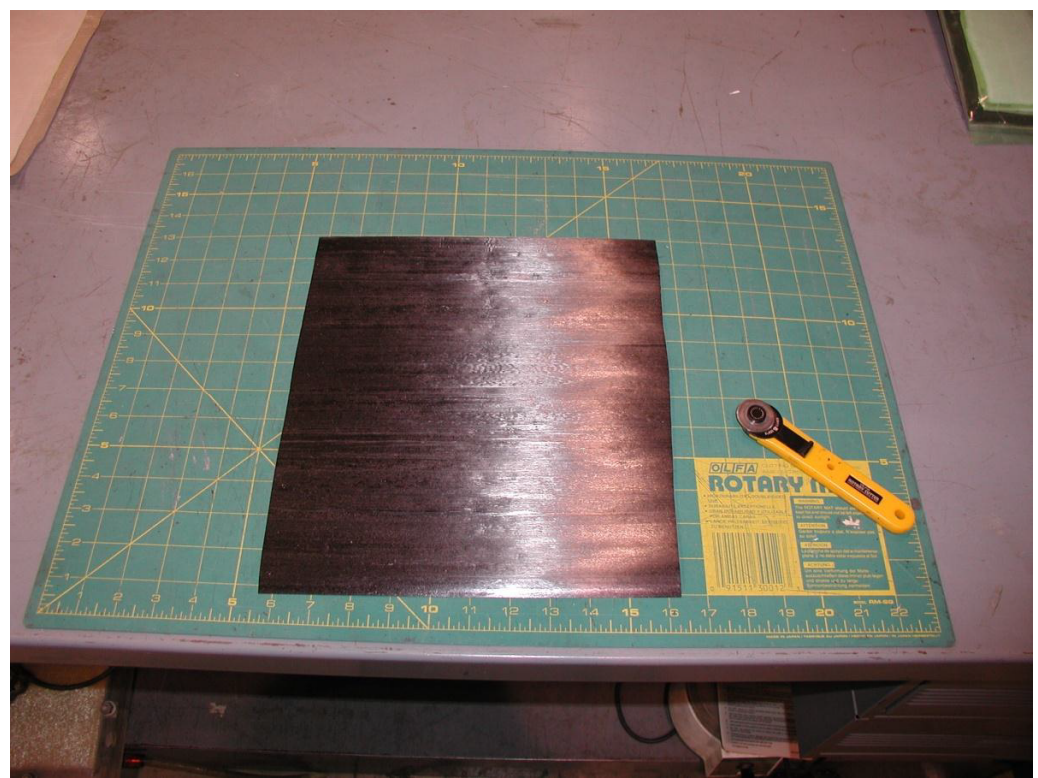

Figure 1 - Cut an appropriate amount of pre-preg to complete your lay-up

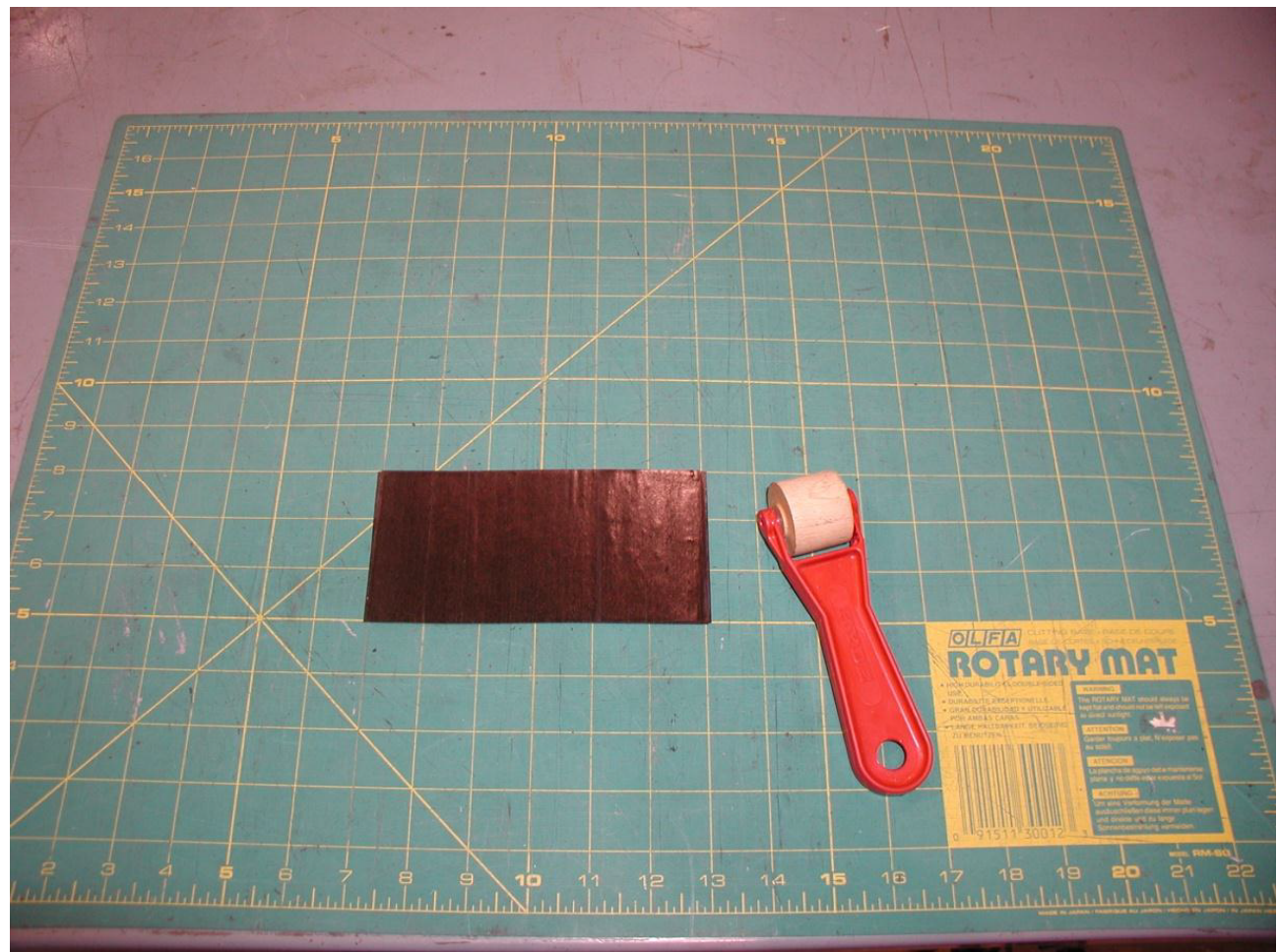

Figure 2 - Cut the prepreg into desired size by using a caul plate as a template and de-bulk 


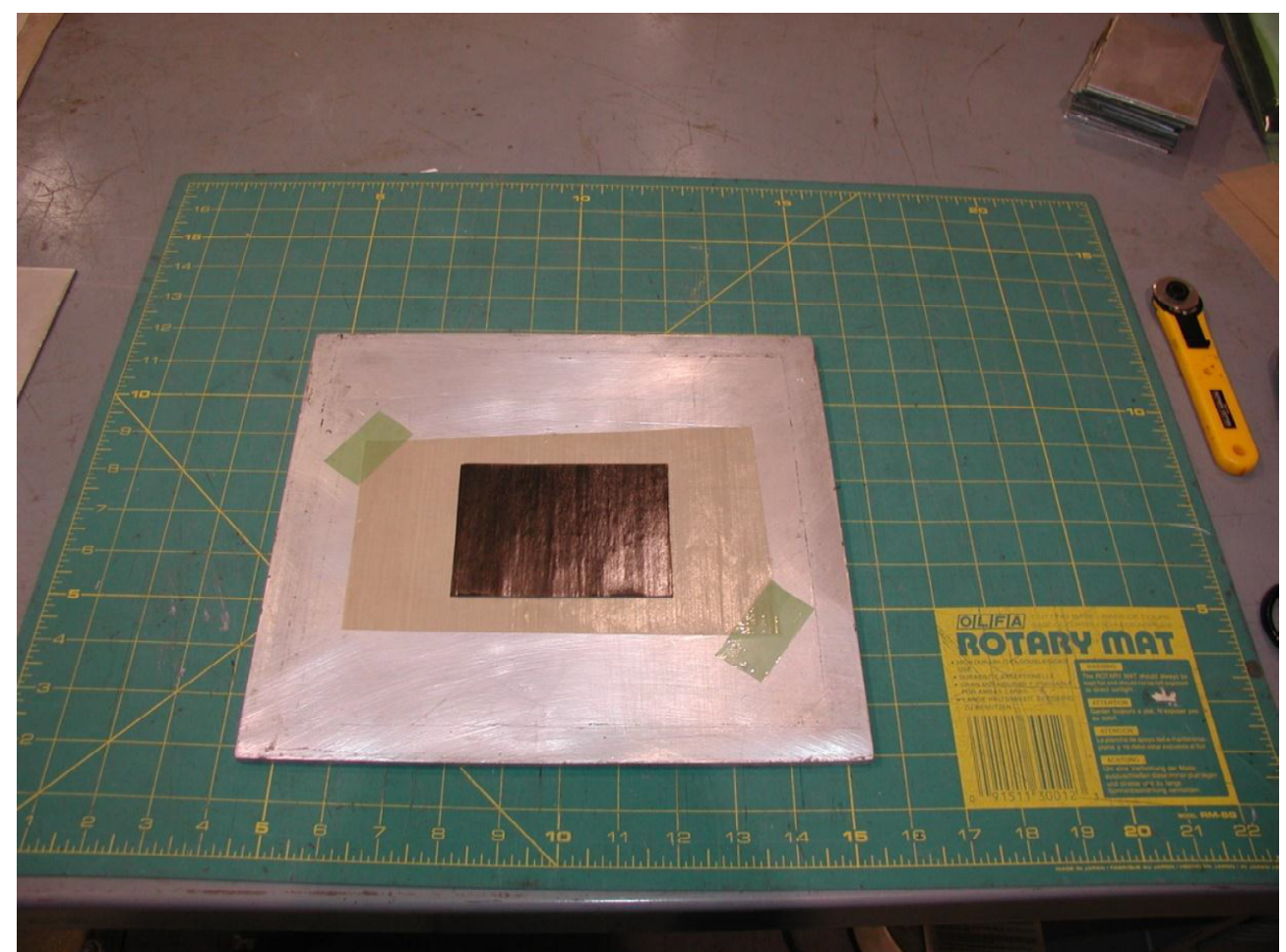

Figure 3 - Place a piece of non-porous release film that is slightly larger than the laminate onto a base plate and center the laminate on the release film.

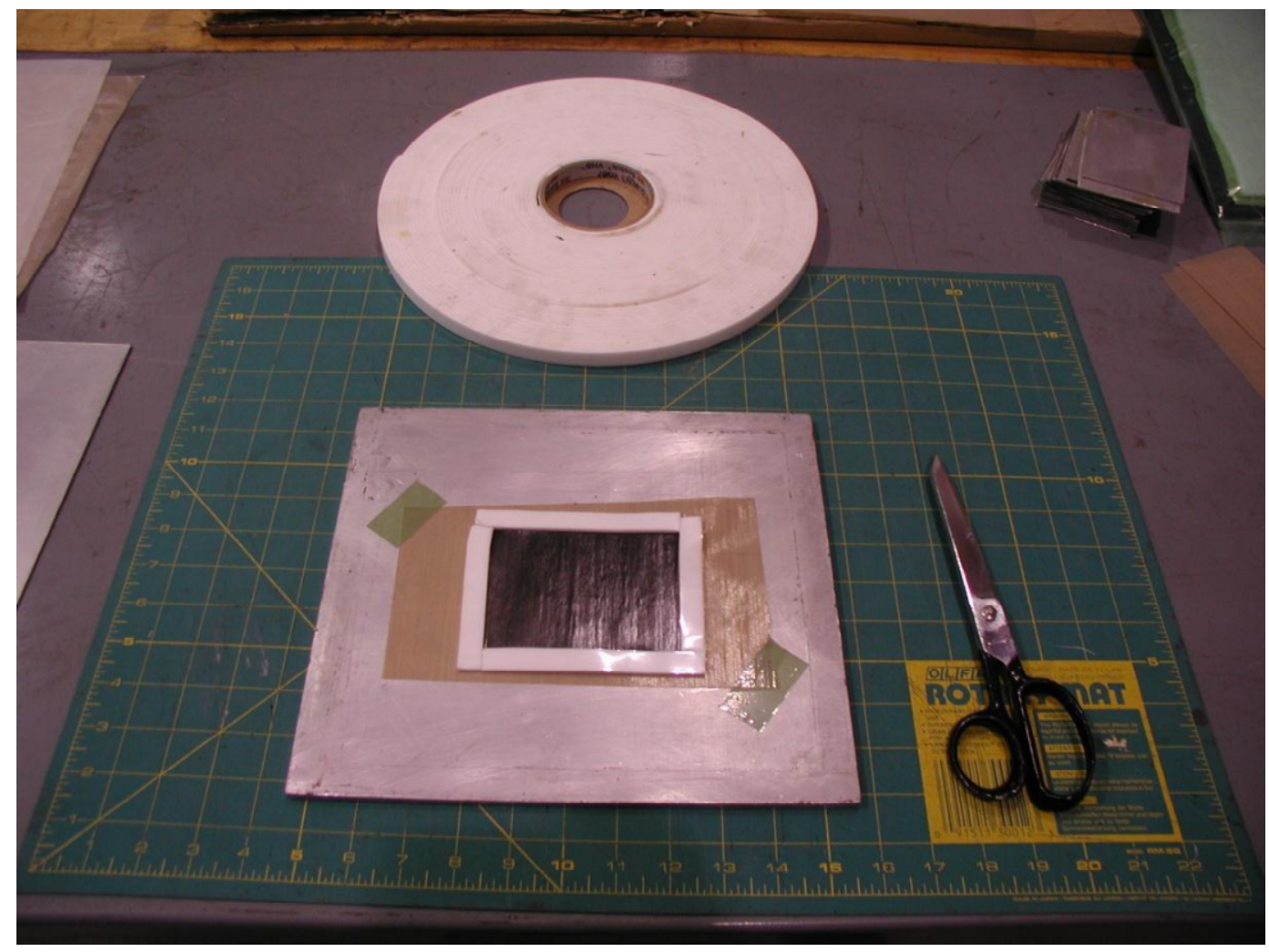

Figure 4 - Cut lengths of dam material to surround and butt up to the laminate 


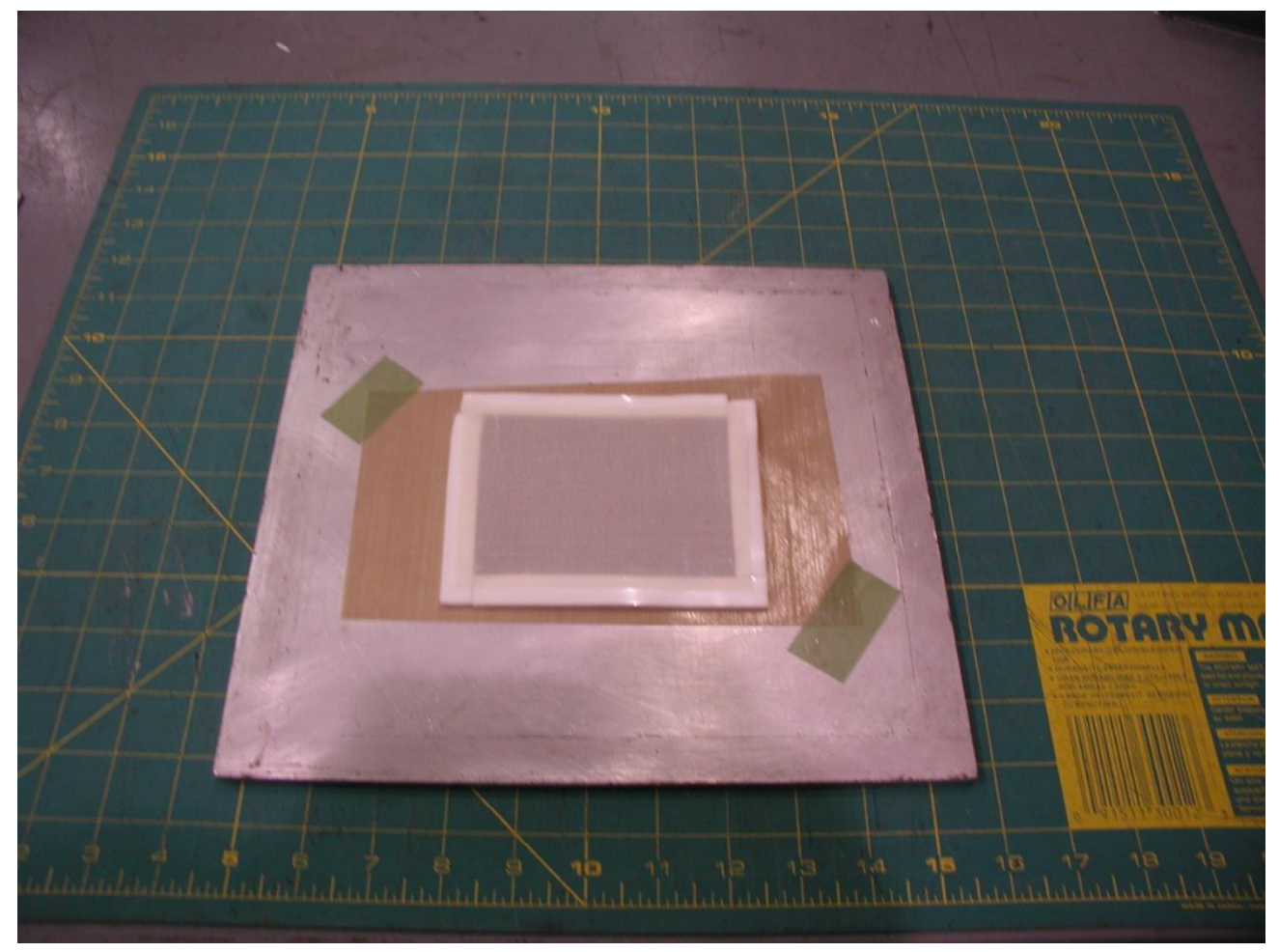

Figure 5 - Cut and lay down pieces of porous release cloth (not needed for net resin system) and A-4000 release film respectively. Cover approximately $1 / 2$ the dam material on all sides

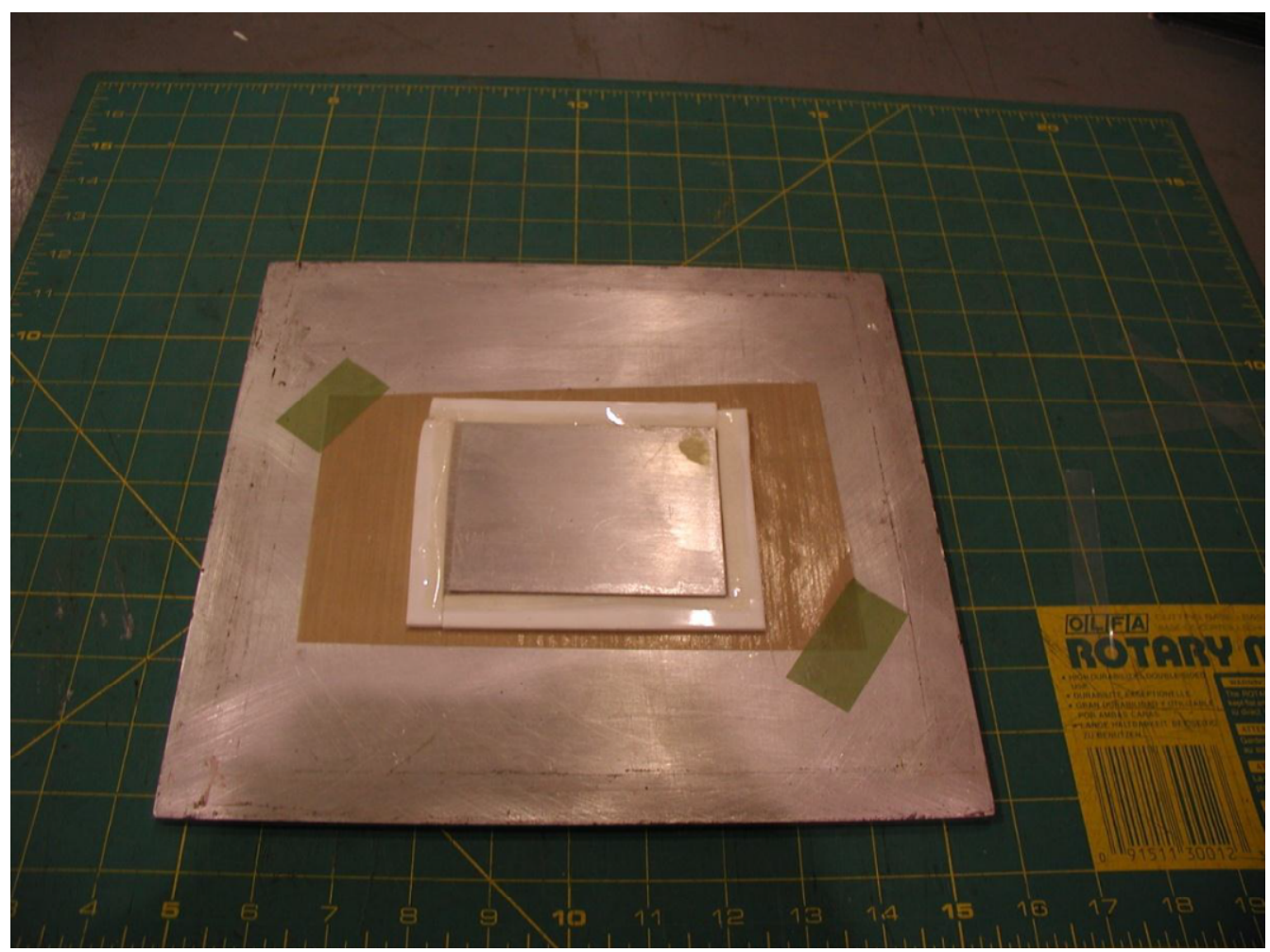

Figure 6 - Place a caul plate on top of the A-4000 release film 


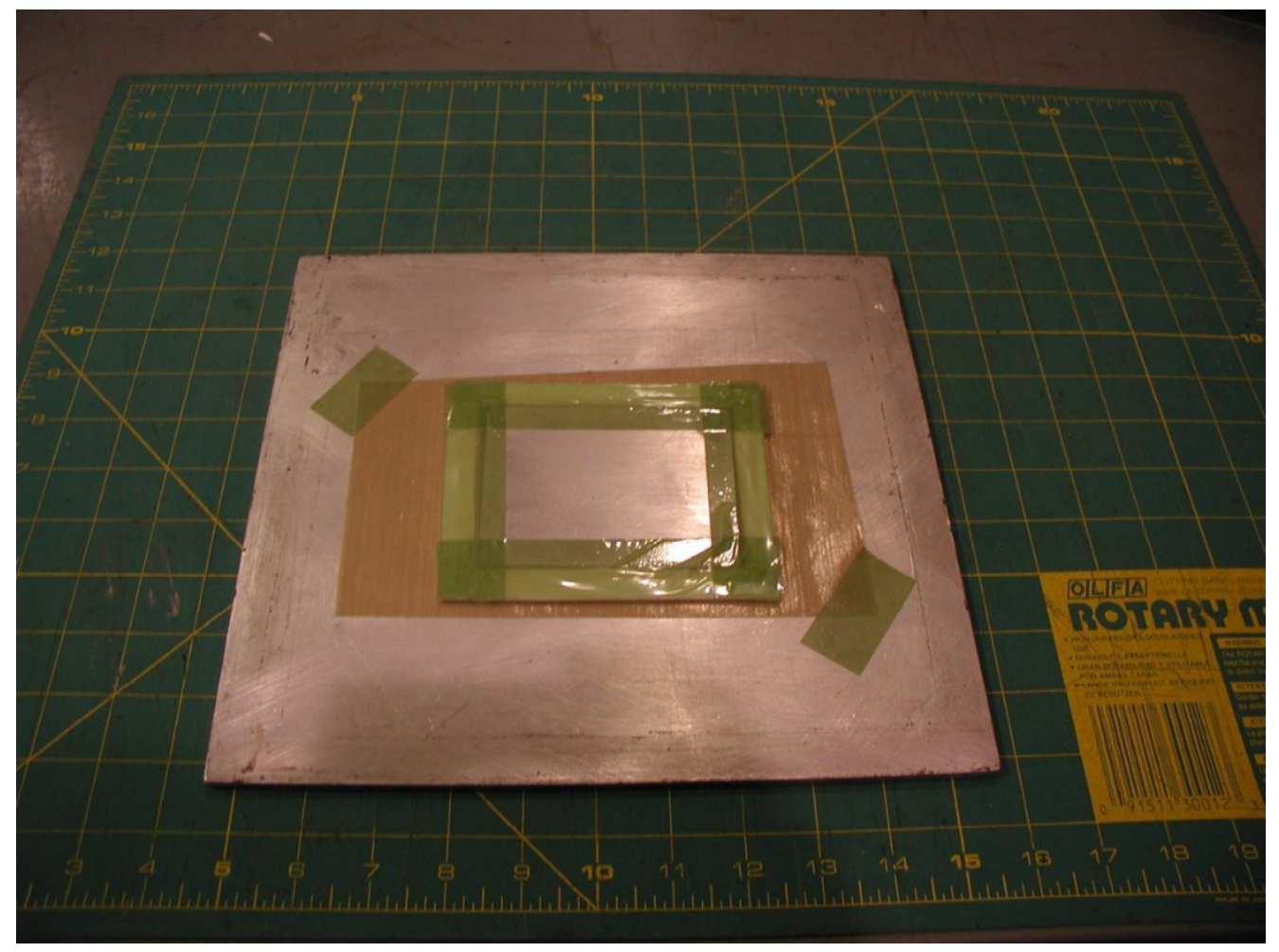

Figure 7 - Using single sided cellophane tape, tape the caul plate to the dam material (1/2 of the dam material should still be exposed and sticky)

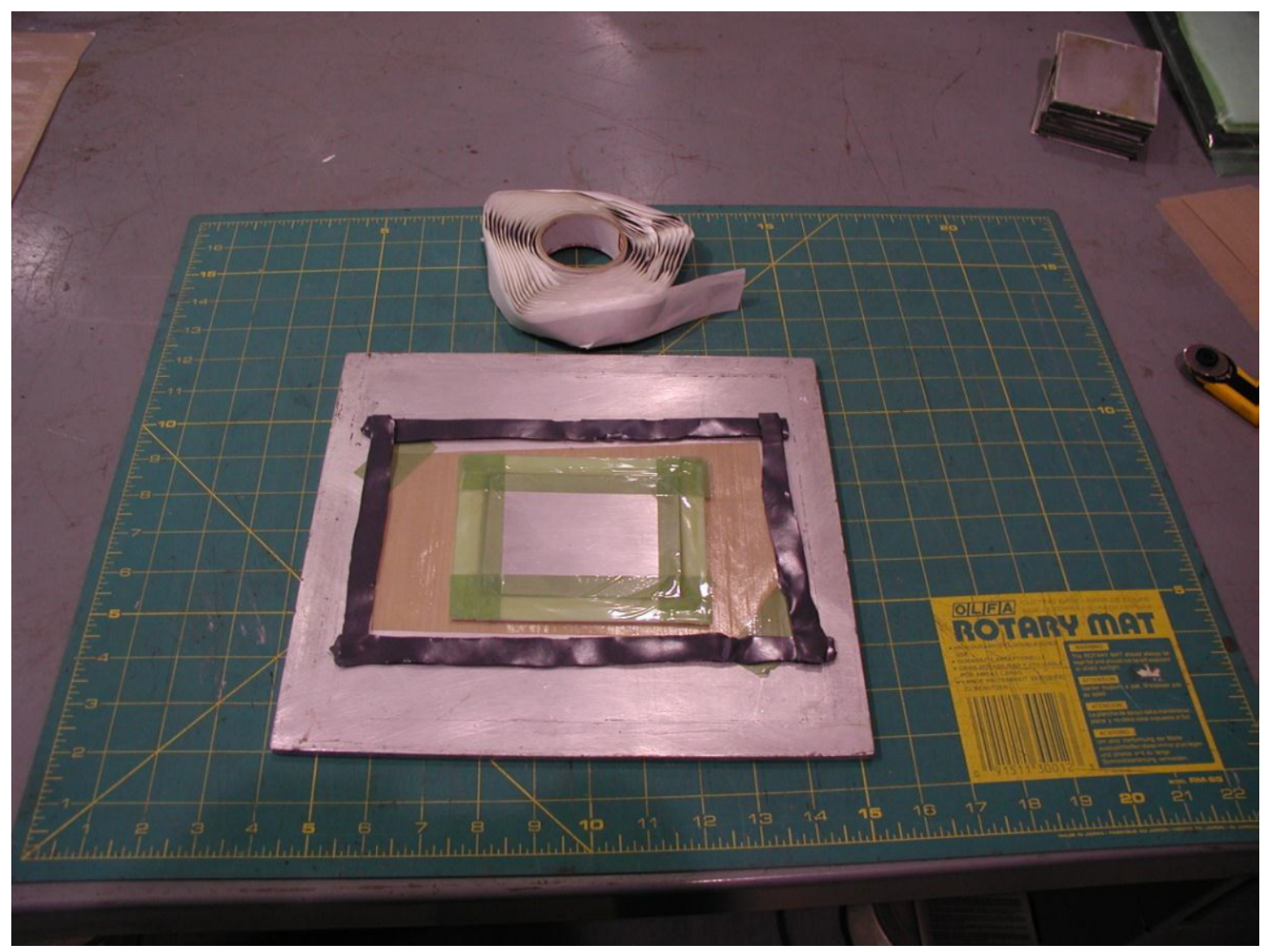


Figure 8 - Surround the layup with vacuum bag tape ensuring there are no gaps

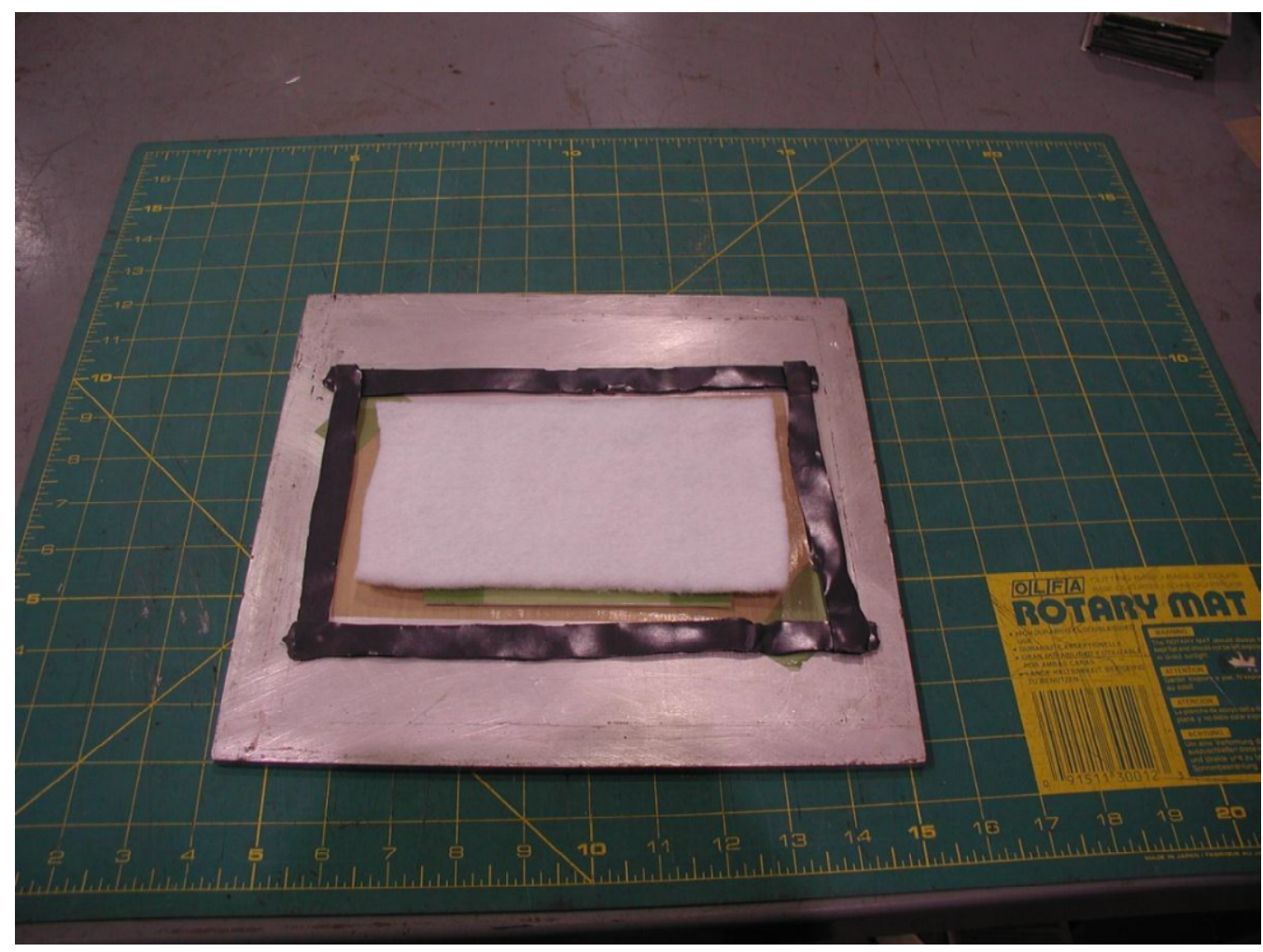

Figure 9 - Cut a piece of Airtech N - 10 Breather material and place over the caul plate

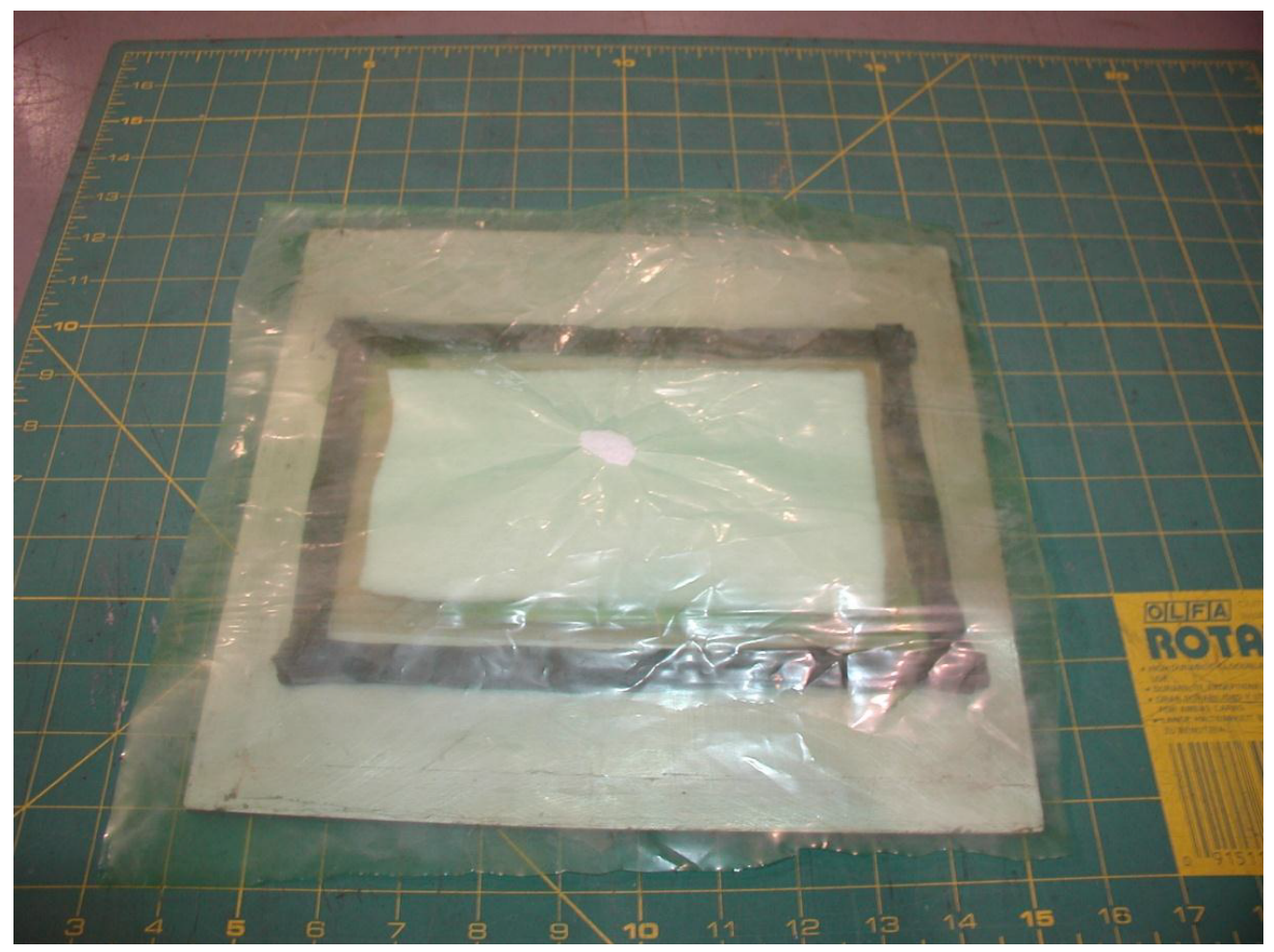


Figure 10 - Cut a piece of vacuum bag to size and make a small 1/2" diameter hole in an area that will be placed in the CORNER of vacuum bag tape (Not in center like shown) This is done so that two plates can be placed in the autoclave at one time

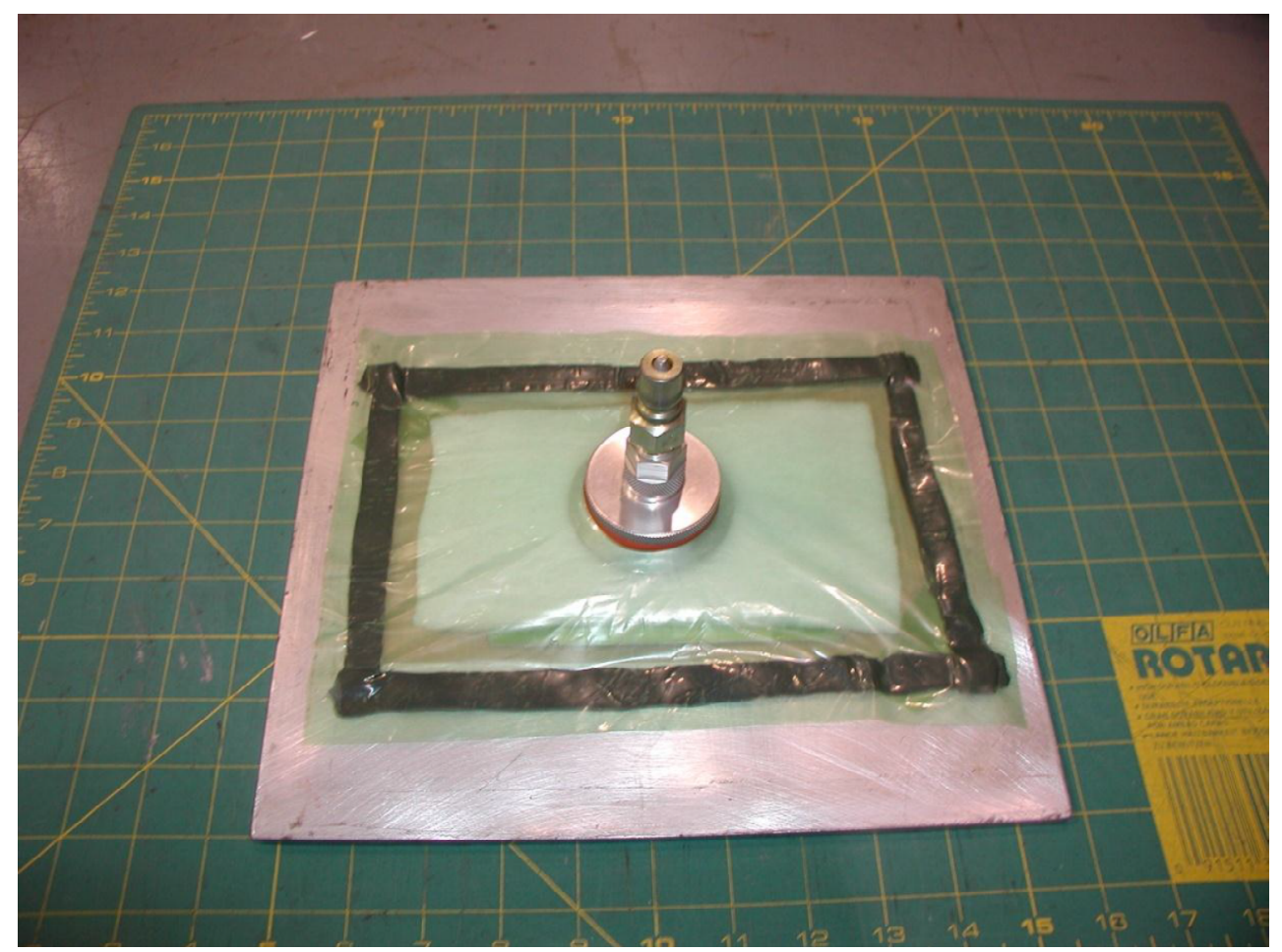

Figure 11 - Insert a vacuum valve in the $1 / 2$ " hole cut in the vacuum bag, again the valve should be towards one corner of the sealed area unlike shown 


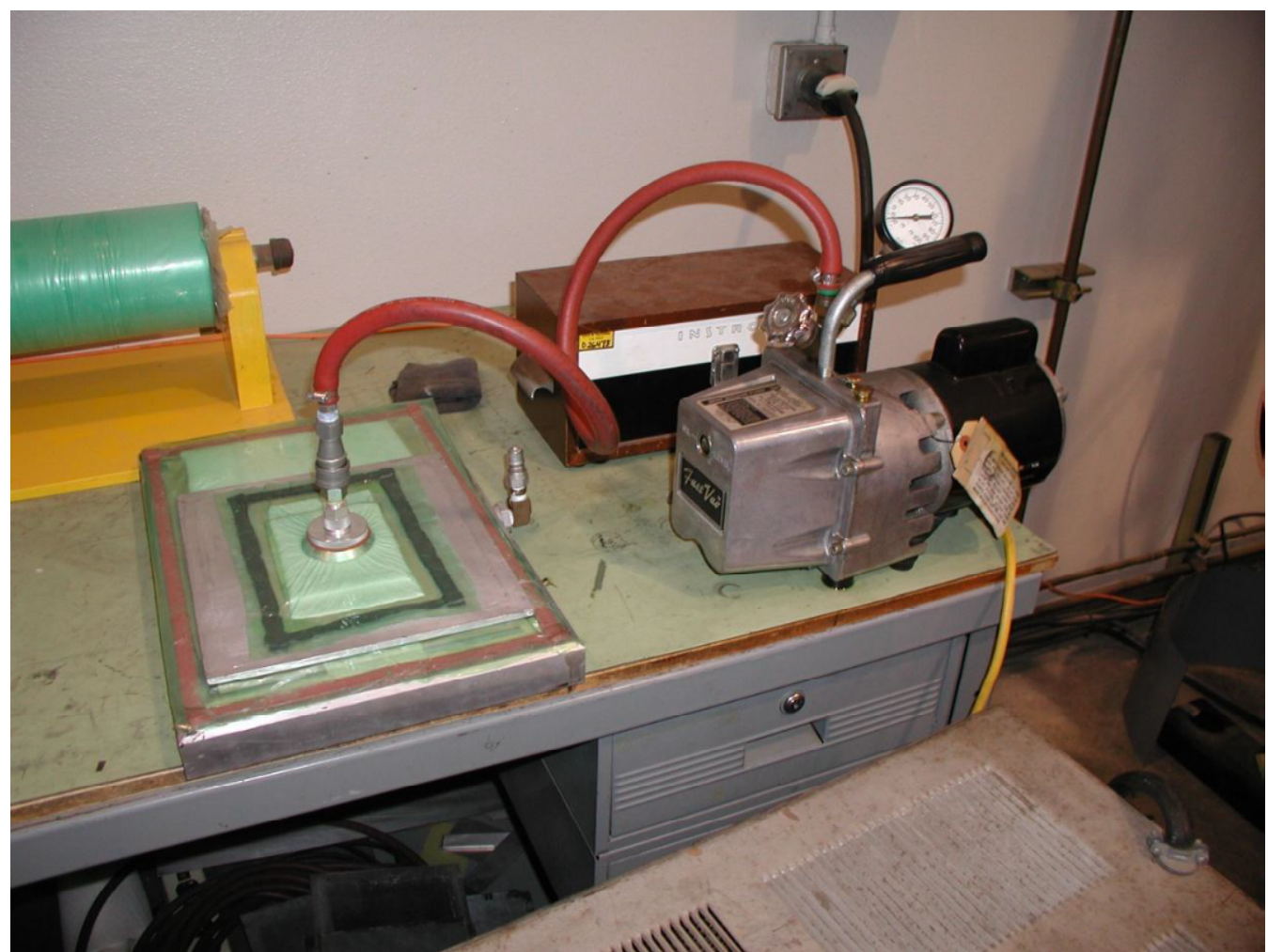

Figure 12 - Use the small vacuum pump to de-bulk the layup as well as to check for leaks, run the pump for about 3 to 5 minutes. 

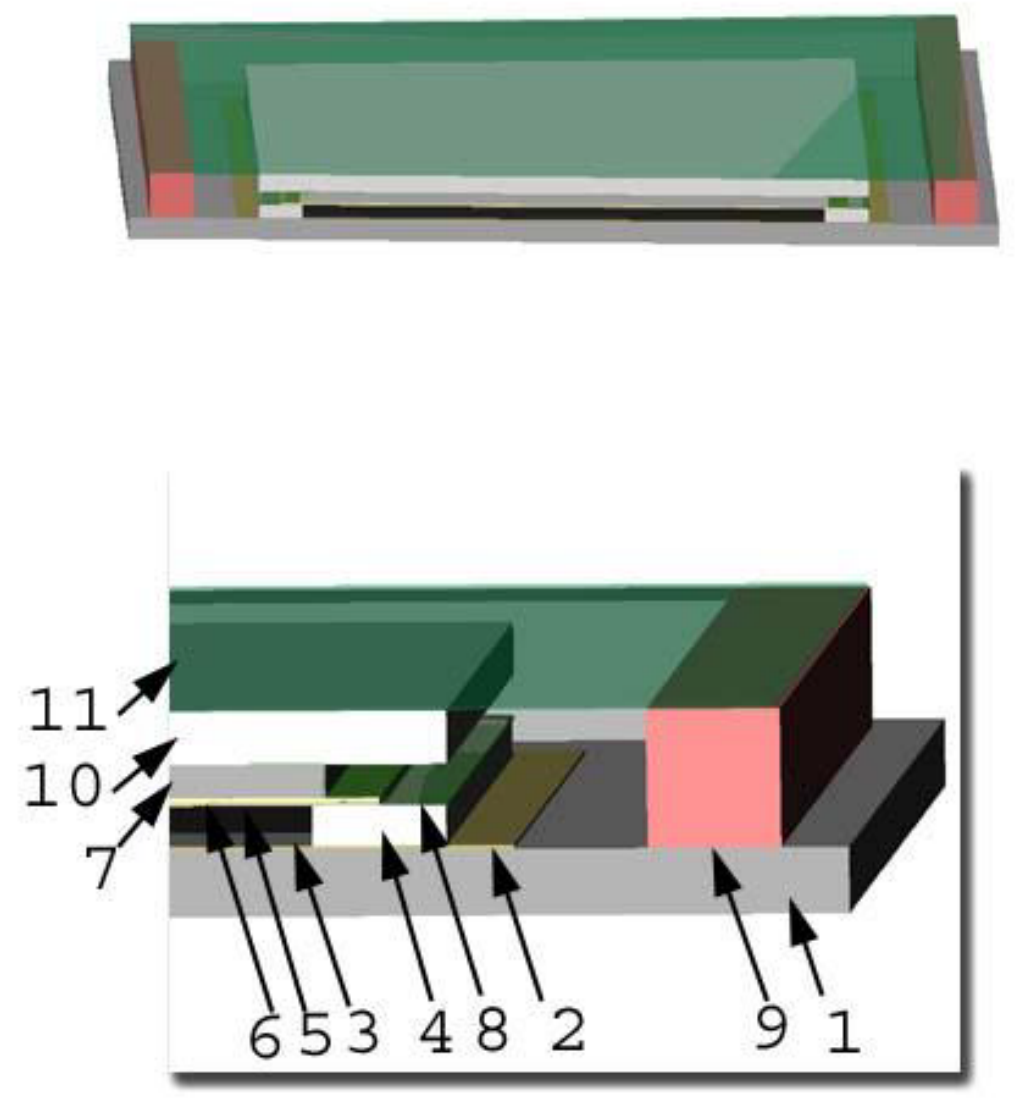

\begin{tabular}{|l|l|}
\hline Item No. & Description \\
\hline 1 & Tool Plate \\
\hline 2 & Non-Porous Release Cloth \\
\hline 3 & Composite Laminate \\
\hline 4 & Dams - white foam tape \\
\hline 5 & Porous Release (do not use for net resin system) \\
\hline 6 & A - 4000 Release \\
\hline 7 & Caul Plate \\
\hline 8 & Single-sided tape \\
\hline 9 & Vacuum bag sealing tape \\
\hline 10 & Air Tech N-10 Breather \\
\hline 11 & Vacuum Bag \\
\hline
\end{tabular}


Appendix E

\begin{tabular}{|l|l|l|l|l|l|l|l|}
\hline Size* & Shape** & Def_i & Force_i & Def_f & Force_f & Deflection & Force \\
\hline 4 & F & 1.944 & 3.3 & -1.45 & -93 & 3.394 & 96.3 \\
\hline 4 & F & 1.944 & 4.63 & -1.45 & -88.4 & 3.394 & 93.03 \\
\hline 4 & H & 1.955 & 2.93 & -1.917 & -130.6 & 3.872 & 133.53 \\
\hline 3 & H & 2.023 & 2.8 & -1.181 & -132 & 3.204 & 134.8 \\
\hline 3 & H & 2.09 & 4.95 & -1.157 & -120.8 & 3.247 & 125.75 \\
\hline 4 & H & 2.1 & 2.86 & -0.9811 & -146.9 & 3.0811 & 149.76 \\
\hline 3 & F & 1.398 & 5.7 & -1.5 & -43.5 & 2.898 & 49.2 \\
\hline 3 & H & 2.023 & 4.8 & -1.132 & -96 & 3.155 & 100.8 \\
\hline 3 & F & 1.394 & 6.42 & -1.589 & -44.5 & 2.983 & 50.92 \\
\hline 4 & H & 2.101 & 4.55 & -0.93 & -127 & 3.031 & 131.55 \\
\hline 3 & F & 1.397 & 6.58 & -1.681 & -51.9 & 3.078 & 58.48 \\
\hline 3 & F & 1.249 & 6.56 & -1.691 & -53 & 2.94 & 59.56 \\
\hline 4 & F & 1.577 & 6.71 & -1.223 & -41.8 & 2.8 & 48.51 \\
\hline 3 & F & 1.533 & 8.44 & -1.375 & -34.7 & 2.908 & 43.14 \\
\hline 4 & F & 1.77 & 8.63 & -0.9561 & -35.9 & 2.7261 & 44.53 \\
\hline 4 & H & 2.1 & 6.4 & -0.8781 & -107.8 & 2.9781 & 114.2 \\
\hline 3 & H & 2.1 & 9.05 & -1.17 & -94.6 & 3.27 & 103.65 \\
\hline 4 & F & 1.843 & 8.83 & -0.924 & -41.6 & 2.767 & 50.43 \\
\hline 4 & H & 2.1 & 6.34 & -0.9954 & -138.2 & 3.0954 & 144.54 \\
\hline 3 & H & 1.726 & 5.97 & -1.217 & -117 & 2.943 & 122.97 \\
\hline & $*$ & $3=3$ & inch diameter head; $4=4$ inch diameter head & \\
& F = Flat head; H = Hemispherical head & & \\
\hline
\end{tabular}




\section{Appendix F}

Figure F. 1: Hand Calculations of Force in Junction Tourniquet Device

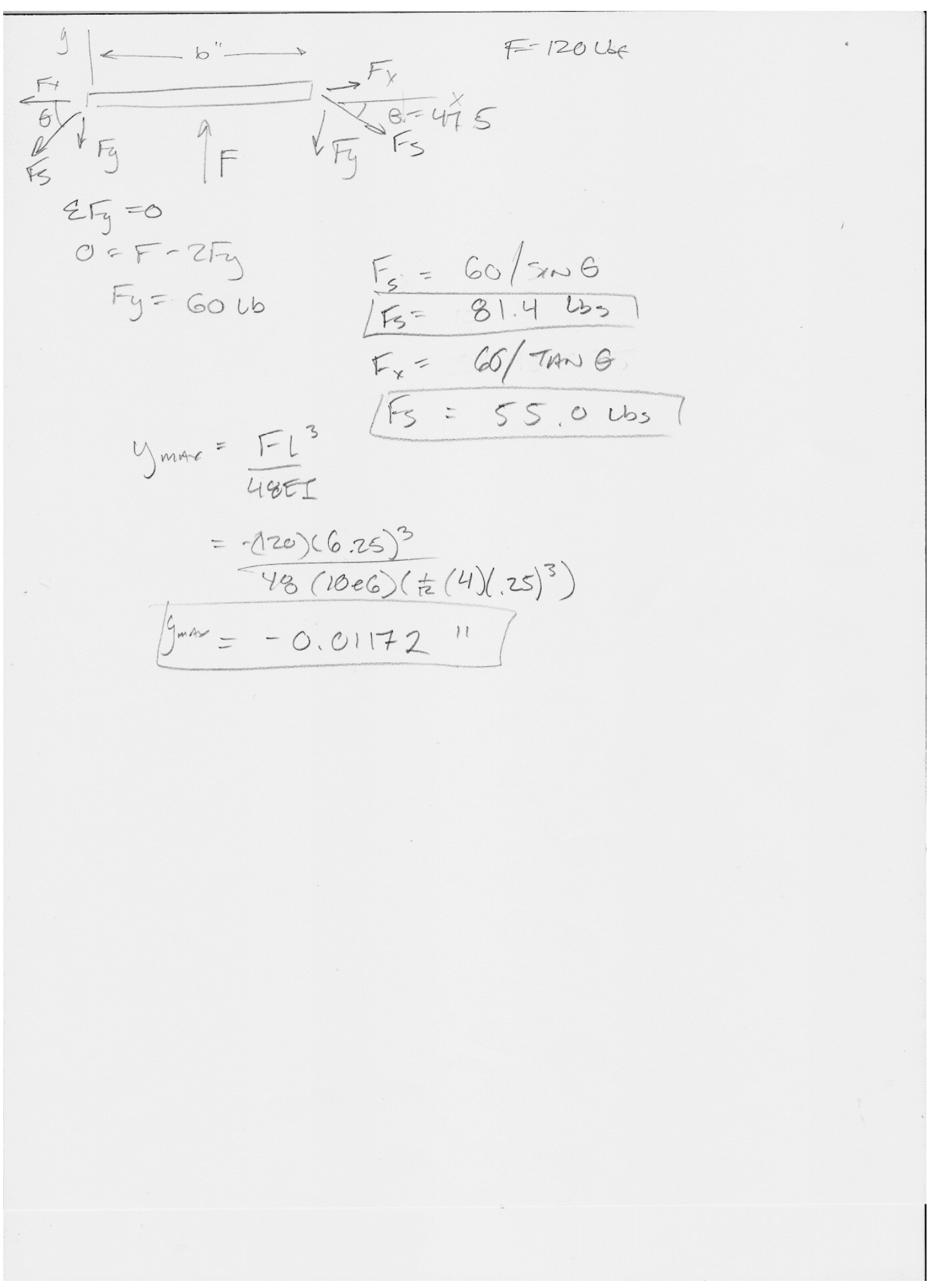


Figure F. 2: Stress Concentration Calculation

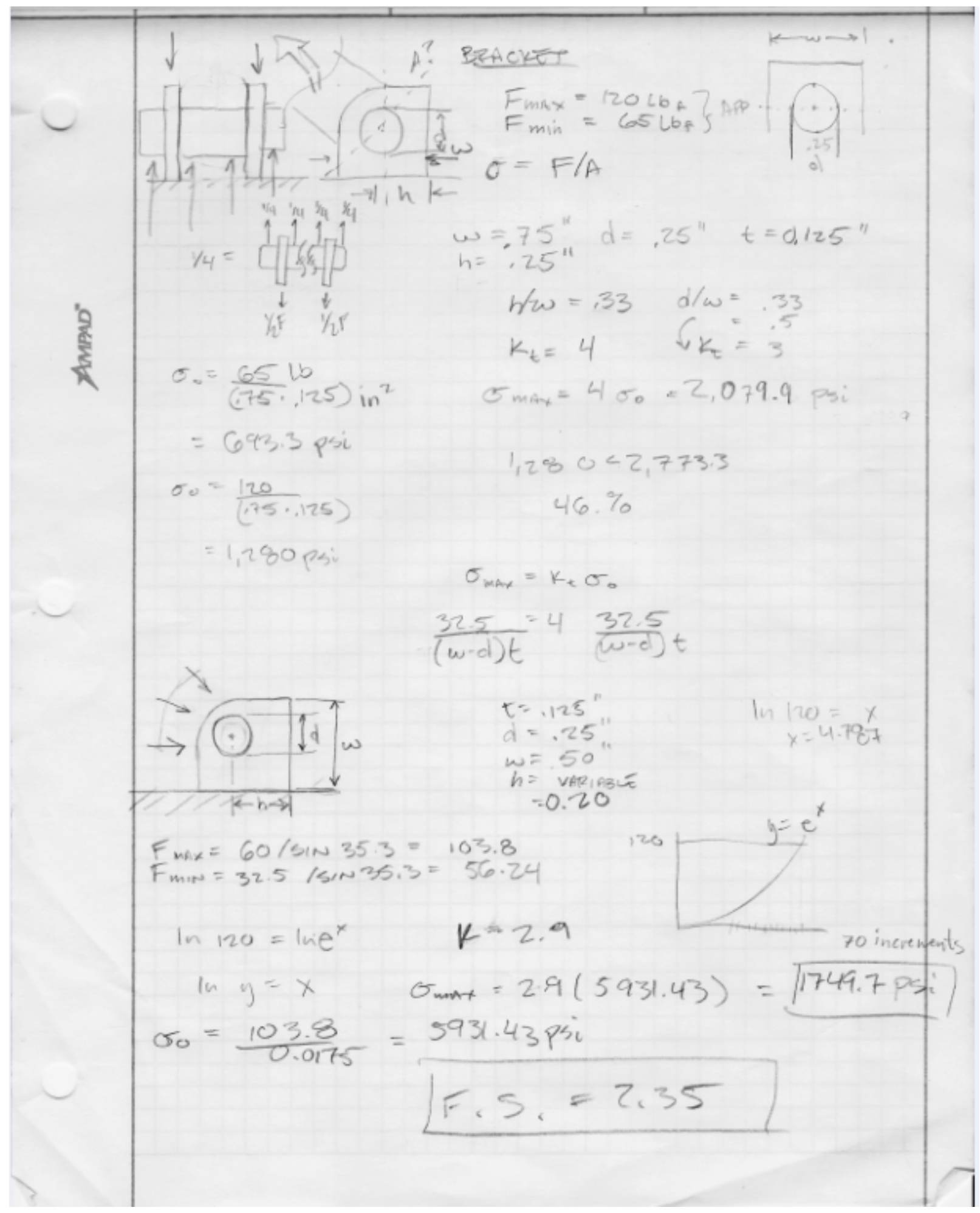


Figure F. 3: Static Analysis of MPL

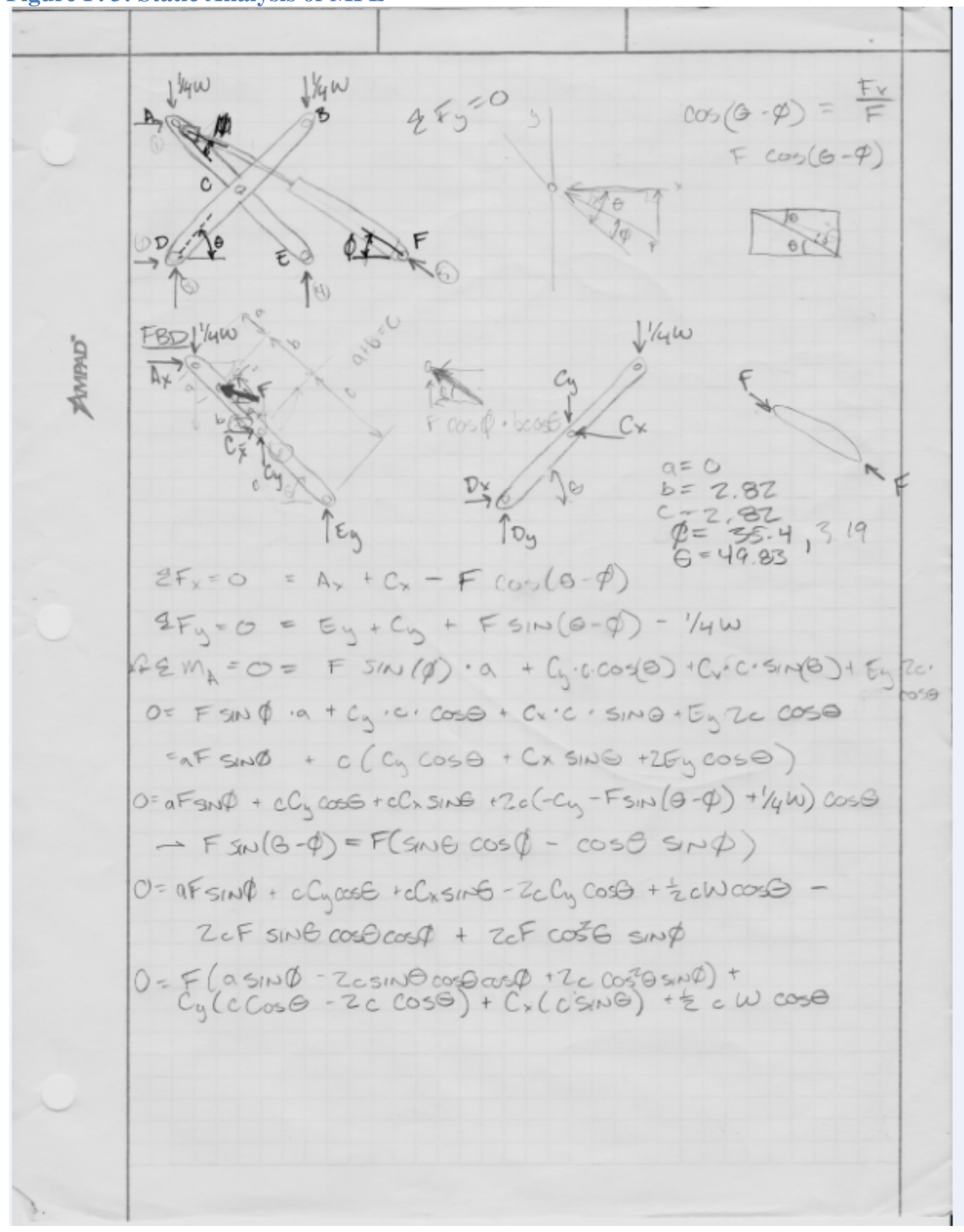




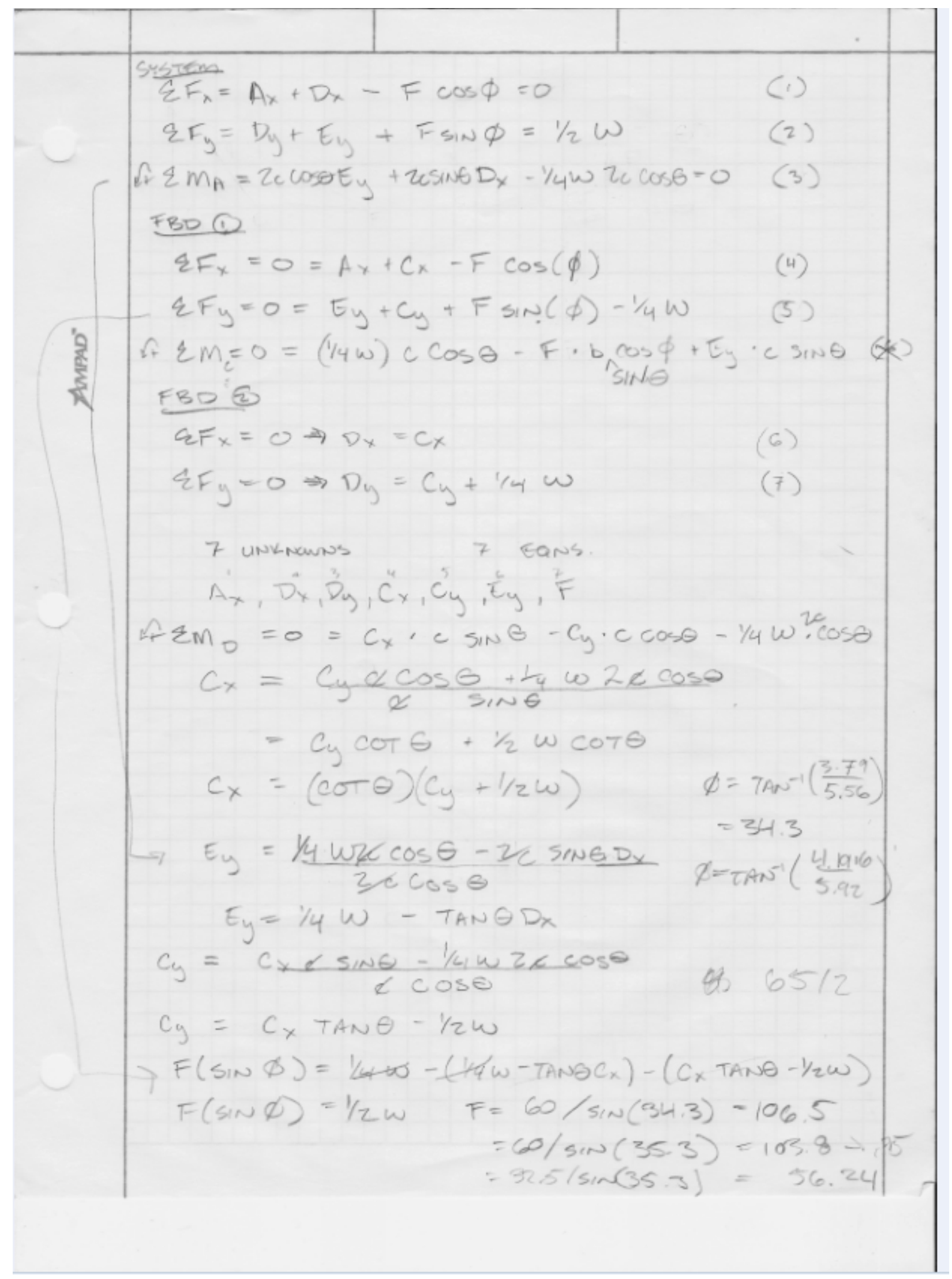




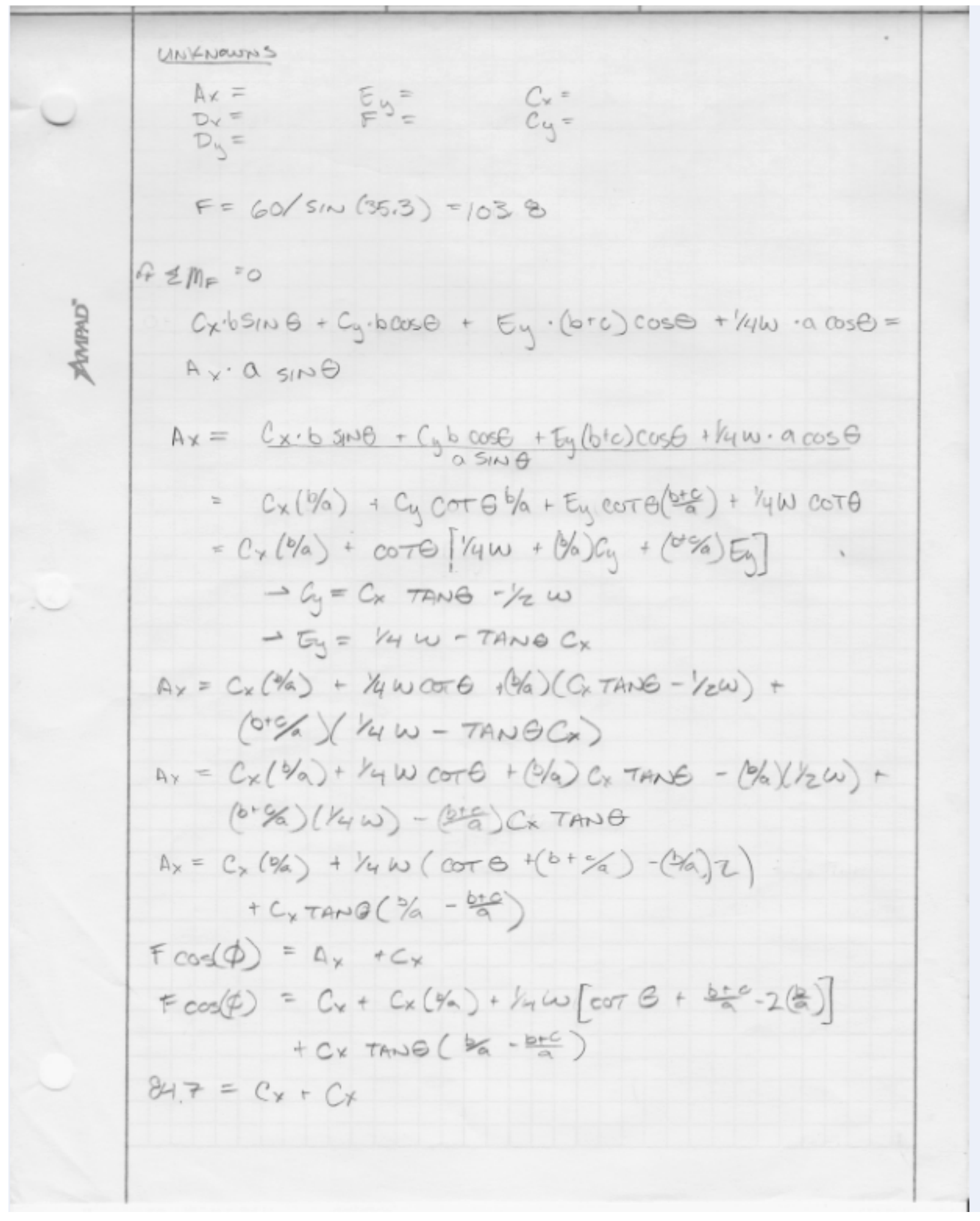




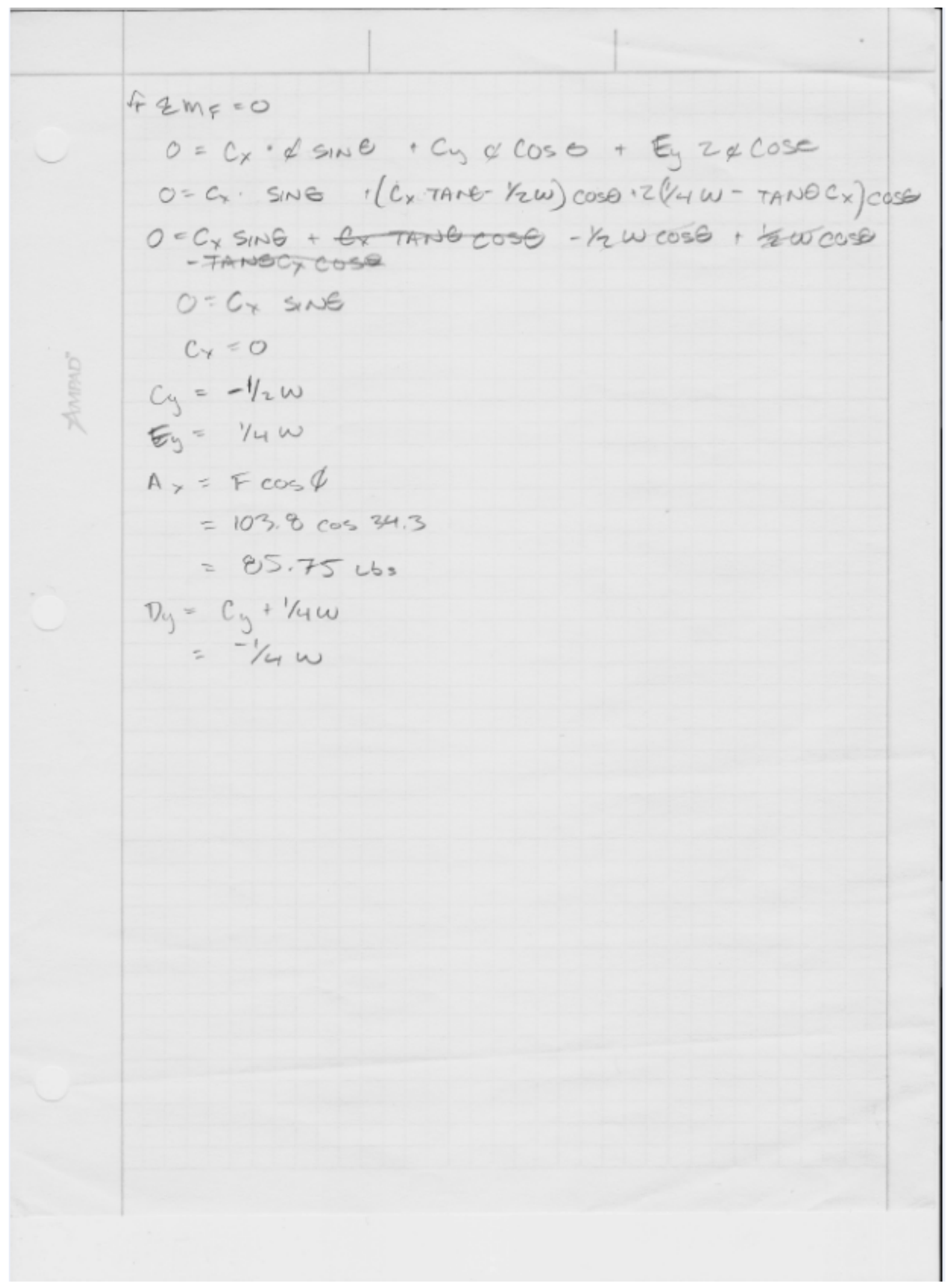


Figure F. 4: Plate Theory of Composite Structure for Fixation Plate

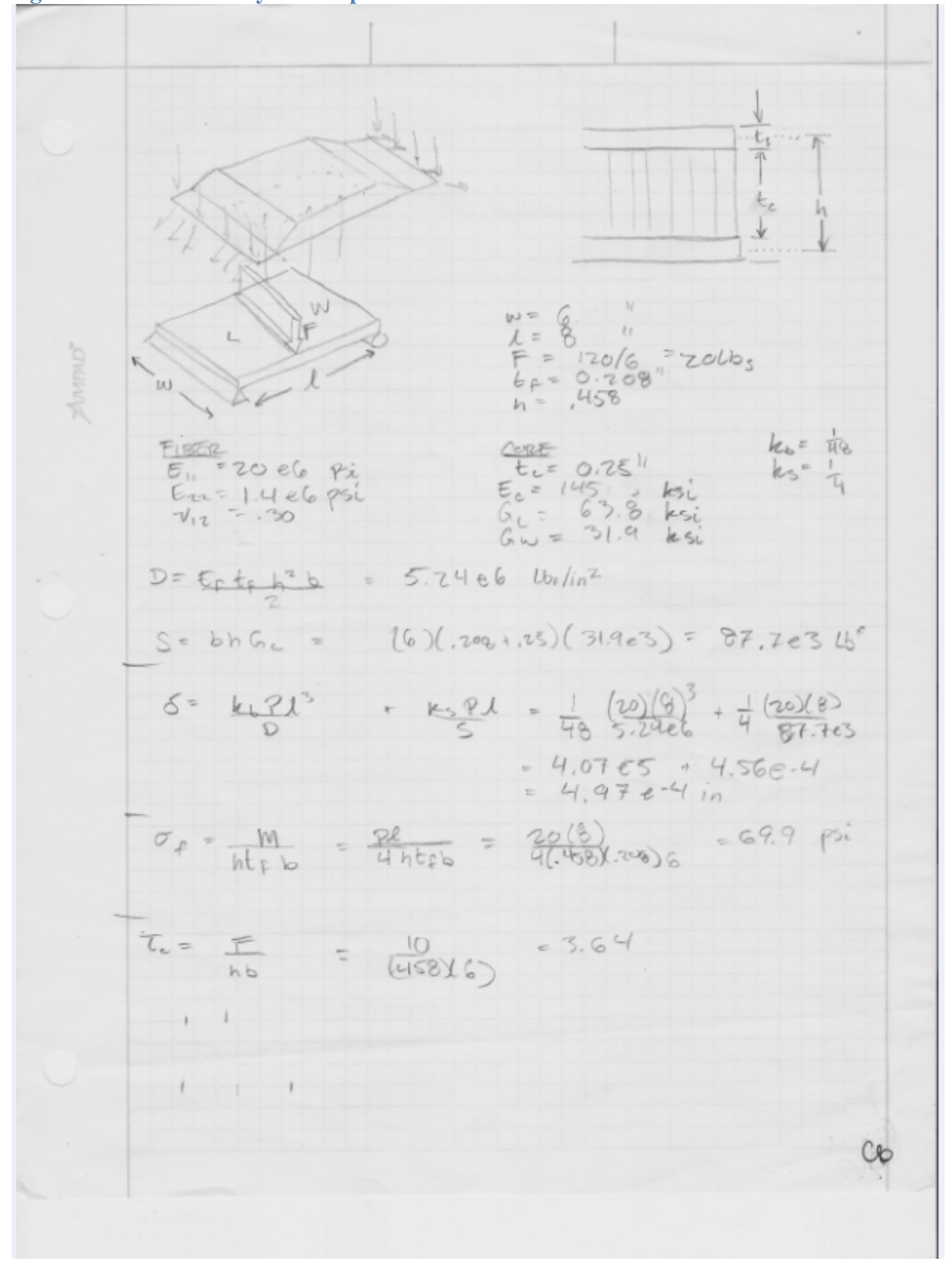




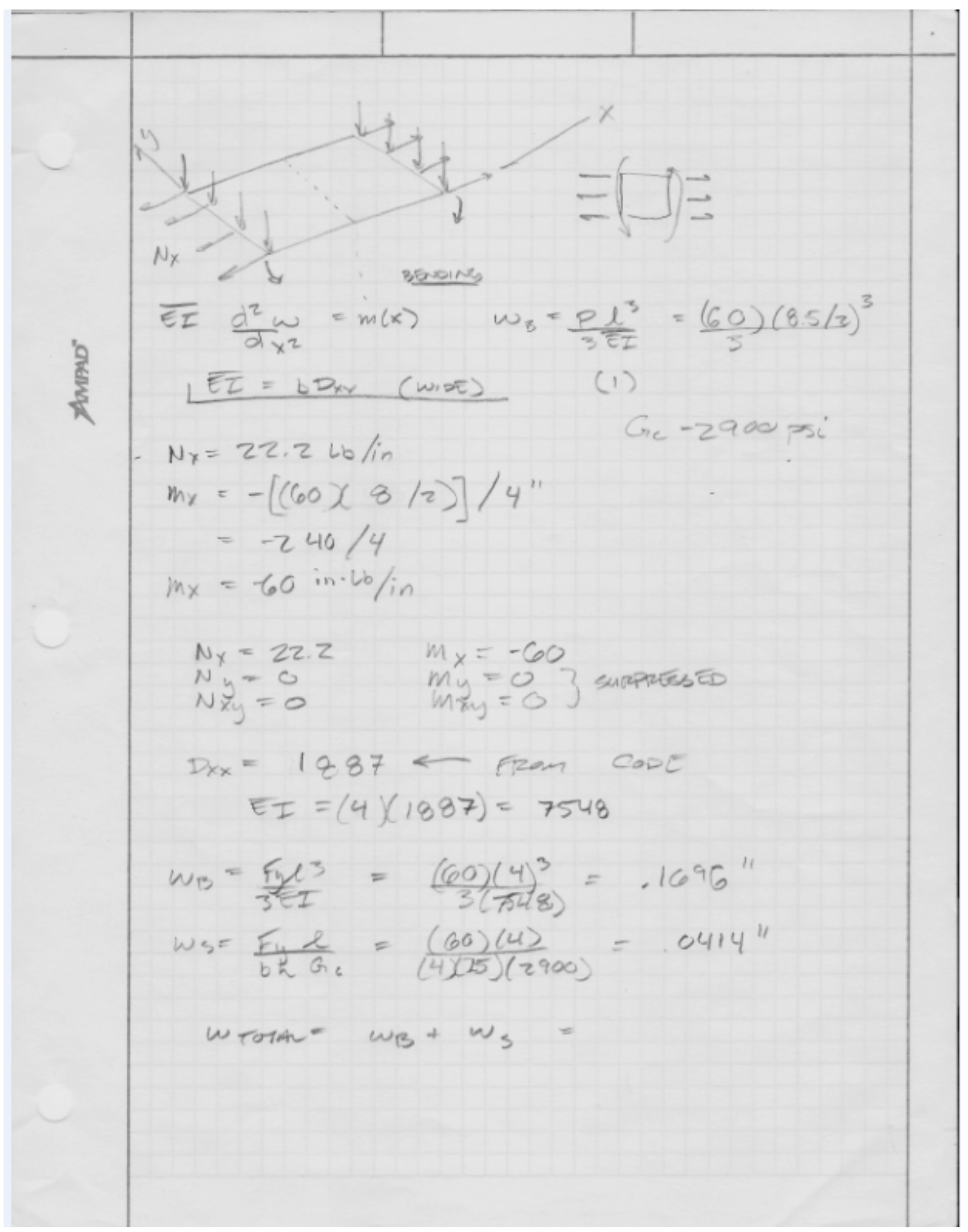


Figure F. 5: Collapsible Tube Theory Calculations

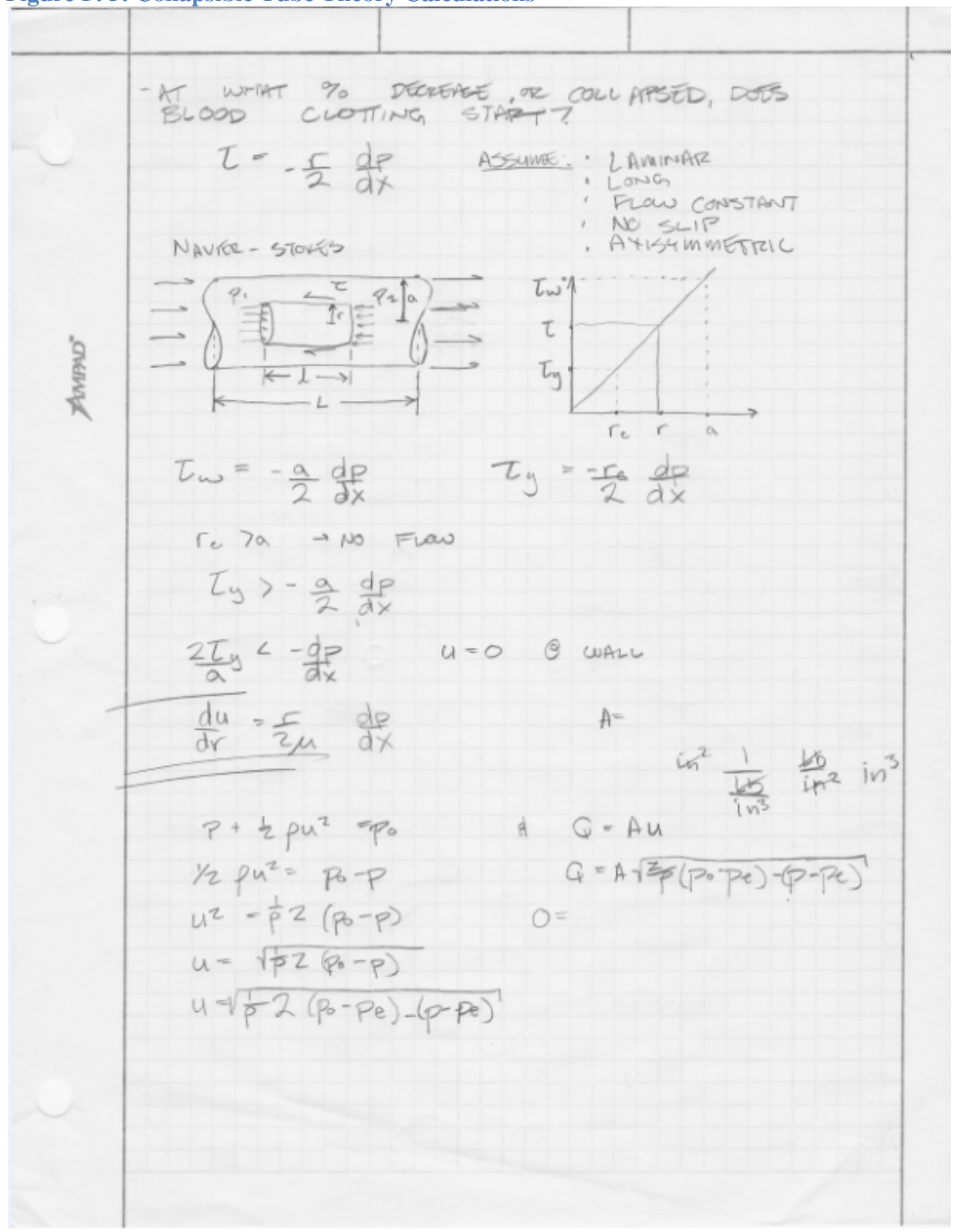




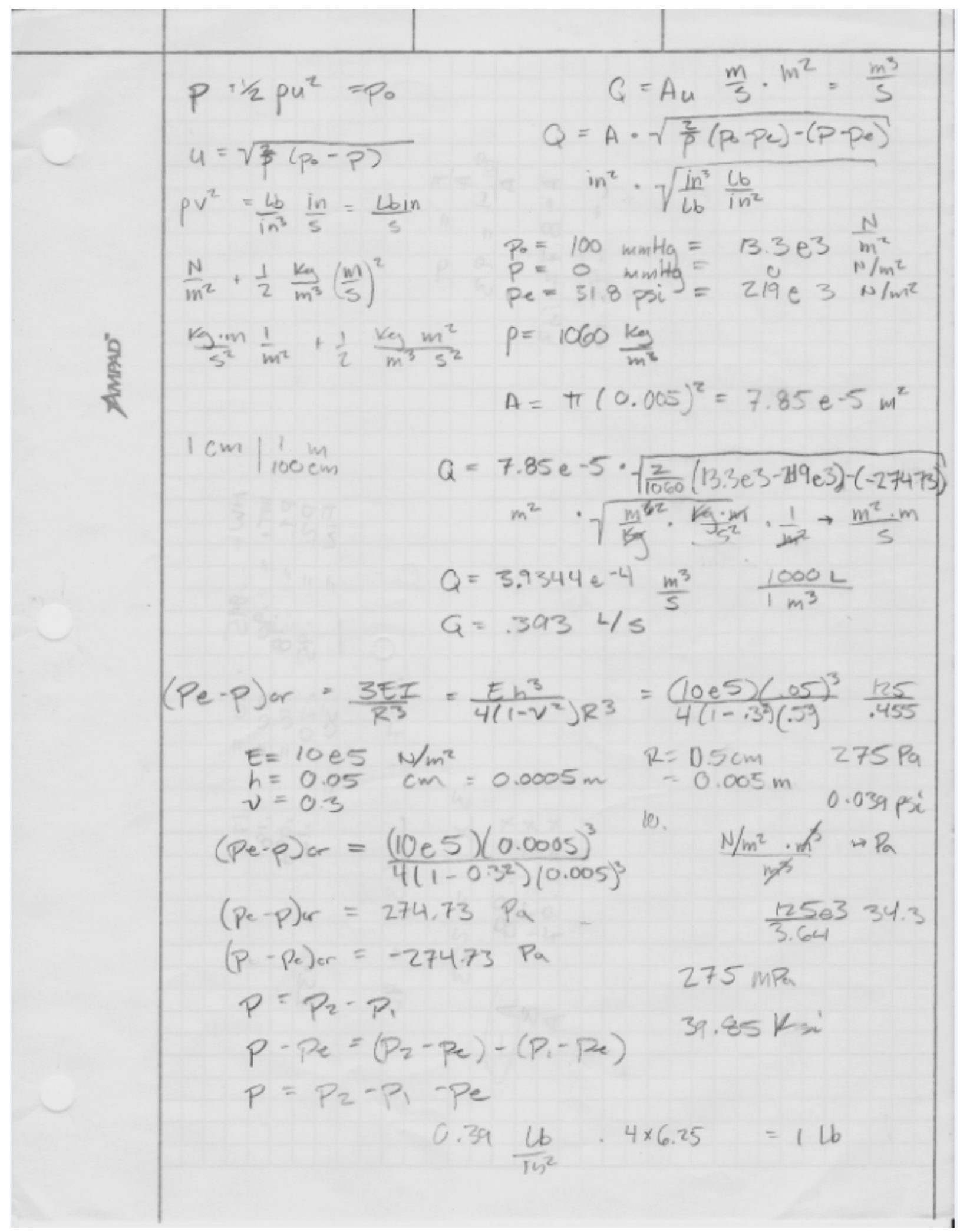




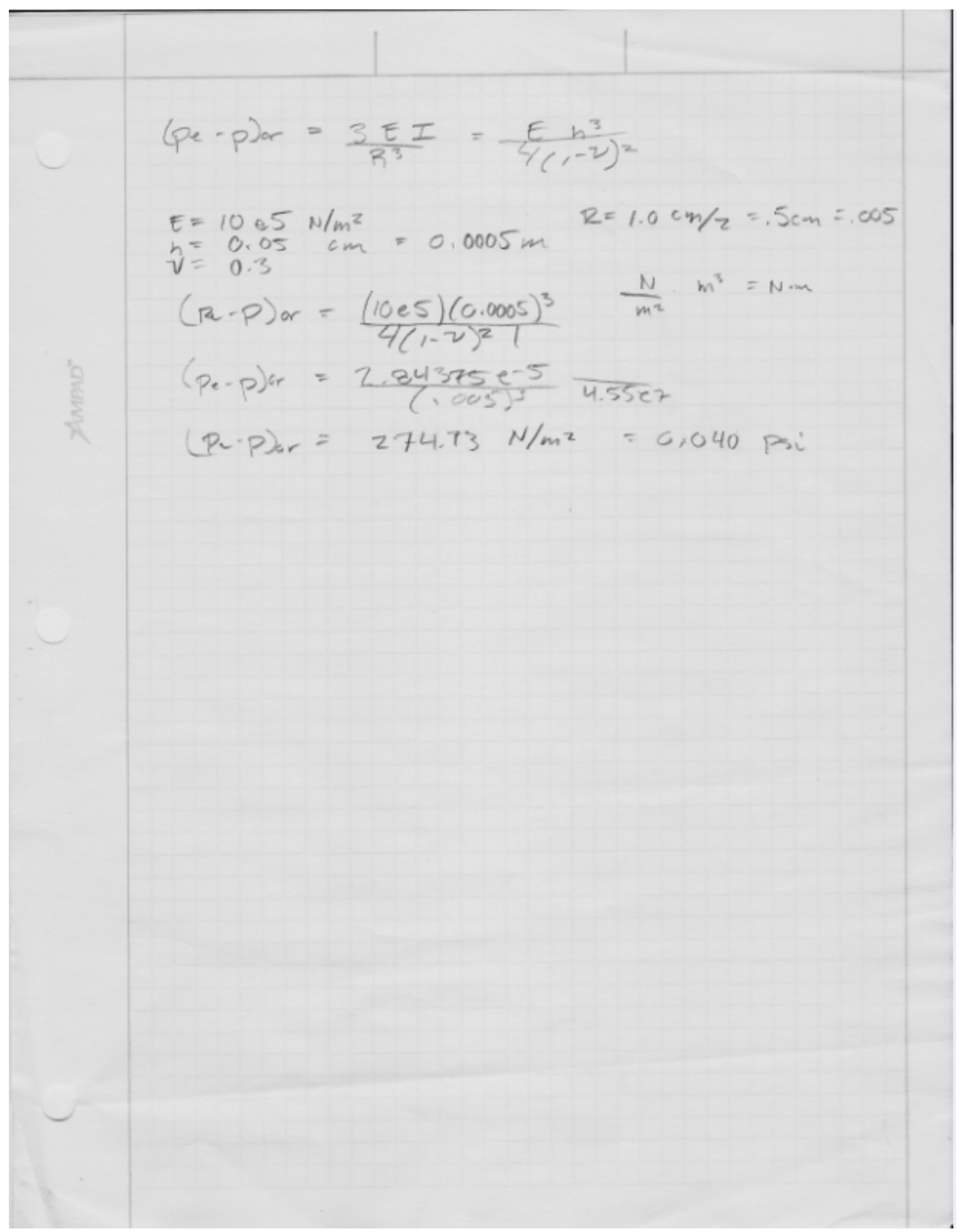




\section{Appendix G}

Table G. 1: Mesh Convergence Study for 2D model

\begin{tabular}{|c|c|c|c|c|c|}
\hline $2 \mathrm{D}$ & $\begin{array}{l}\text { Element } \\
\text { Size }\end{array}$ & DF & Deflection & Deflection & Stress \\
\hline Aluminum & 1.5 & 46 & 0.076 & & 23969.6 \\
\hline 0.25" Thick & 1 & 66 & 0.07883 & & 26602.7 \\
\hline & 0.5 & 146 & 0.0801833 & & 28933.4 \\
\hline & 0.25 & 266 & 0.08026 & & 29208.2 \\
\hline & 0.125 & 842 & 0.08033 & & 28886.6 \\
\hline
\end{tabular}

Table G. 2: Mesh Convergence Study for 3D model

\begin{tabular}{|lll|}
$\begin{array}{l}\text { Element } \\
\text { Size }\end{array}$ & DF & Deflection \\
\hline $\mathbf{1 . 5}$ & 762 & 0.014002 \\
\hline $\mathbf{1}$ & 1098 & $1.53 \mathrm{E}-02$ \\
\hline $\mathbf{0 . 7 5}$ & 1278 & 0.01641 \\
\hline $\mathbf{0 . 5}$ & 2148 & $1.85 \mathrm{E}-02$ \\
\hline $\mathbf{0 . 3 7 5}$ & & \\
\hline $\mathbf{0 . 2 5}$ & 14820 & 0.0171708 \\
\hline $\mathbf{0 . 1 8 7 5}$ & 25236 & 0.0187509 \\
\hline
\end{tabular}

